\title{
CONSERVATION OF ENDEMIC LIZARDS IN NEW ZEALAND CITIES
}

\section{Christopher K. Woolley}

A thesis submitted to Victoria University of Wellington

in fulfilment of the requirements for the degree of Doctor of Philosophy in Conservation Biology

Te Herenga Waka

Victoria University of Wellington

2020 



\section{Abstract}

Globally, biodiversity is in crisis. One contributing factor is the rapid urbanisation of the world's population. Land cover change associated with urbanisation radically alters ecosystems, making them uninhabitable for many species. Additionally, people who live in cities often have reduced contact with nature and there are fears that a lack of nature experience may diminish concern for the environment and biodiversity among urbanites. For these reasons, people in cities are increasingly being encouraged and empowered to reduce environmental impacts and connect with nature through urban restoration and backyard conservation. Internationally, lizards are a common feature of urban biodiversity but in New Zealand, where many species are threatened, little is known about populations of endemic skinks and geckos in cities. In order to effectively manage urban lizard populations, greater knowledge is needed about where and how lizards are surviving in cities, and what potential exists for their restoration. I investigated species diversity and abundance of lizards in New Zealand cities, making comparisons with historical species distributions to inform urban restoration and investigating the potential role that participatory conservation might play in their protection.

To collate current knowledge about past and present distributions of urbandwelling lizards, I reviewed records for six New Zealand cities from published and unpublished literature and databases. Little research was identified from cities and the 
majority of lizard records were of one-off sightings, or surveys related to salvage or biosecurity operations. Comparing current species records with historical species distributions, it found that the diversity of lizards in all of the cities has declined dramatically since human colonisation.

To begin to fill the identified knowledge gap and to provide baselines for future monitoring, I carried out skink surveys in four cities and trialled a citizen science project that collected public sighting records from residential backyards. Surveys undertaken in urban habitats captured four species of endemic skink: Oligosoma aeneum in Hamilton, O. polychroma, O. aeneum and O. ornatum in Wellington, O. polychroma in Nelson, and $O$. aff. polychroma Clade 5 in Dunedin. Site occupancy and number of captures were highly variable among the species and cities, with a very high proportion of sites occupied by skinks in Nelson and Wellington compared with Hamilton and Dunedin. Modelling showed $O$. polychroma catch per unit effort was positively related to rat tracking rates when grass cover was low but showed a negative relationship when grass cover was high. Higher proportions of urban land cover within $500 \mathrm{~m}$ were negatively associated with body condition.

The public sightings website gathered more than 100 records from around the Wellington region over one summer, suggesting citizen science may be a cost-effective solution for building knowledge about lizards in residential gardens that are otherwise difficult to survey. While skink sightings were reported from all over the city, gecko sightings appeared in clusters. Compared with a random sample of street addresses, both skink and gecko sightings were more common closer to forest land cover, but only skink sightings were more common in backyards that were north facing.

Finally, I administered a questionnaire survey to understand how sociodemographic characteristics relate to willingness to engage in three different proconservation activities that might benefit lizards: pest mammal trapping, biodiversity monitoring and pest mammal monitoring. Public willingness to engage in all three activities was positively related to respondents' nature relatedness and nature dosage, while only the two monitoring activities were positively related to education. The relationship between willingness and nature relatedness was weaker for pest trapping than it was for the two monitoring activities, suggesting that willingness to trap may be determined by factors other than environmental concern. 
Native lizards are an important component of New Zealand's urban biodiversity. Despite cities having lost significant proportions of their original lizard fauna, a wide variety of habitats in cities still support numerous species. Some of these species seem well adapted to cope with the challenges of urban living, while further research is required to understand whether populations of other species are stable or in decline. To ensure the persistence of lizards in cities, further surveys using a variety of methods should be undertaken to assess lizard diversity and abundance in urban habitats and understand population trends of rare and sparsely distributed species. Public sightings may provide a useful starting point for assessing distribution patterns and allowing the targeting of surveys. In the future, through urban restoration, cities may offer opportunities to conserve a larger proportion of endemic species by reintroducing species that have become regionally extinct. 


\section{Acknowledgements}

The length of this acknowledgements section illustrates the huge amount of intellectual, emotional, and physical support I have had throughout my PhD journey. First and foremost, I wish to thank my academic supervisors: Nicky Nelson, Stephen Hartley and Danielle Shanahan. I could not have asked for a better team of mentors and advisors, and I greatly value the contributions you have made to this project and to my development as a researcher. I also wish to thank other members of the People, Cities and Nature research programme, in particular the 'Lizard' team: Deb Wilson, John Innes, Hayley Ricardo and Neil Fitzgerald from Manaaki Whenua-Landcare Research, and Yolanda van Heezik from Otago University. All of you contributed to my project in very diverse ways, from survey design to helping with the grunt work of digging holes - some of you even let me search for lizards in your backyards! I really enjoyed working as part of the team and appreciate the advice and time you gave me.

I wish to acknowledge and thank mana whenua of the areas in which I worked. I greatly appreciated your interest in my research and your support. In particular, I want to thank Tania Williams of Araiteuru Marae in Dunedin, who allowed me to use the marae land as a study site.

I also wish to thank the councils of the four cities in which I worked for their support of the project and for facilitating access to land. A number of people in these organisations also provided specialist knowledge about urban ecology, lizards and/or 
study sites, and I am very grateful for their time. These people included: Myfanwy Emeny, Daniela Biaggio, Heidy Kikillus, Elizabeth Reddington, Rewi Elliot, Finn Michalak, David Bidgood and Bernard Smith from Wellington City Council; Richard Romijn from Greater Wellington Regional Council; Leigh Marshall, Andrew Nevin and Haidi Spence from Nelson City Council; Aalbert Rebergen from Dunedin City Council; and Moniqua Nelson-Tunley from Waikato Regional Council.

I also appreciated advice from a number of herpetological experts and researchers who provided their knowledge and access to unpublished reports and databases. Thank you to Lynn Adams, Jo Monks, Rod Hitchmough and Benno Kappers from the Department of Conservation; Trent Bell and Asha Fernandez from EcoGecko; Carey Knox and Jacqui Wairepo from Wildlands Consultants; Sabine Melzer from Auckland Council; Marieke Lettink from Fauna Finders; and Jon Sullivan and Colin Meurk from iNaturalist NZ.

This project required a huge amount of field work and gear preparation, and I am hugely grateful for the work of the many people who helped me. Sometimes it was enjoyable (I have fond memories of the 'Drinks $n$ Drills' working bee), sometimes it was hot, hard work, but whatever it was, there was always a willing helper to pass me a Pesola balance and remind me to eat. Thank you to: Ellen Webb, Joseph Burgoyne-Smith, Natasha Stanton, Thomas Peters, Jonás C. Agulló Brotons, Ellen Irwin, CJ Macfarlane, Rachael Shaw, Regan MacKinlay, Neville Higgens, John Kim, Liz Gaiduch, Brittany Florence-Bennett, Jessica Aguilar, Casey Bannon, Brennan Panzarella, Grace Tocker, Shadley van Wyk, Benjamin Woolley, Jen Vaughan, Finbar Grealish, Frances Perez, Max Harvey, Kim Miller, Ludovic Dutoit, Vanitha Elangovan, and Xuhong Chai.

While away from home for extended periods doing fieldwork, I was very fortunate to stay with wonderful people. Thank you to Marina Hanger, Catherine Kirby and Elizabeth Elliot-Hogg (and flatmates). I greatly appreciated the company and conversation.

I want to thank all the people who allowed me access to their properties, permitted me to (and sometimes helped me to) dig bucket-sized holes in their garden, and indulged me in lizard-related chats. Likewise, thank you to all the people who contributed sightings via the Lizard Locator citizen science project and iNaturalist NZ, or who just found me online and shared a gecko pic.

I am grateful of the advice and support I received from staff and colleagues at Victoria University: Julie Whitburn for providing me advice early on regarding the nature 
relatedness construct; Sue Keall and Mel Dohner for sorting out my field equipment requirements (even when I requested gear at the last minute) and for advising me on RiskTeq to ensure that my field assistants and I stayed safe; and Lisa Woods and Murray Efford for their assistance with statistics and their reassuring words.

To members of the lab groups Fixit and Bug Club, and to everyone who worked alongside me at Vic or at Rātā Café, thank you. I appreciated the camaraderie, the stats chats, the assistance with R, Excel and Word, and the willingness to be distracted by a cup of tea and a chat: Ox Lennon, Sarah Herbert, Linlin Liu, Sarah Lamar, Liam McAuliffe, Brittany Florence-Bennett, Florence Kelly, Doug Rands, Sydney Dean, Michelle Goh, Olivia Vergara, Nyree Fea, Annemieke Hendriks, Cherie Balls, Regan MacKinlay, Daniel Donohuge, Tom Dawes, Victor Anton, Johannes Fischer, Rachael Shaw, Ellen Irwin and CJ Macfarlane.

My final and most heart-felt thanks, however, is reserved for my family, which has grown substantially since I began this thesis (and is about to grow again). To Mum, Dad, Andrew and Ben (and their associated people in Auckland and Melbourne), thank you for your support during this project, and all of the projects that went before. To the Vaughan whānau, thank you for welcoming me into your family and for the great times we've shared - I look forward to many more in the thesis-free future. Lastly, Jen. Thank you for allowing yourself to be dragged into the world of field ecology, for all your support during the project, and for your belief in me that I could get it done. Most of all, thank you for ensuring that life went on around this thesis (despite my best protestations) and that it was not the only thing achieved in the last three years. 


\section{TABLE OF CONTENTS}

$\begin{array}{lll}\text { Abstract } & \text { I }\end{array}$

Acknowledgements $\quad$ V

Chapter 1: Cities and nature: challenges and opportunities 1

1.1. Introduction 1

1.1.1. Urbanisation and biodiversity conservation 1

1.1.2. Social dimensions of urban biodiversity 3

1.1.3. Management of urban nature 4

1.1.4. New Zealand conservation and urban ecology 6

1.1.5. Reptile conservation in New Zealand 9

1.2. Thesis aims and organisation $\quad 10$

$\begin{array}{ll}\text { 1.2.1. Main questions } & 10\end{array}$

$\begin{array}{ll}\text { 1.2.2. Thesis outline and style } & 10\end{array}$

1.2.3. Contributions to research 11

1.2.4. Permits and Ethics 12

Chapter 2: Reviewing the past, present and potential lizard faunas of New Zealand cities

2.1. Introduction $r$

2.1.1. Urban restoration and conservation $\quad 13$

2.1.2. Conservation of native lizards in New Zealand cities $\quad 14$

$\begin{array}{ll}\text { 2.1.3. Opportunities } & 14\end{array}$

2.1.4. Challenges $\quad 15$

2.1.5. Aims 16

2.2. Methods $\quad 16$

2.2.1. Defining and characterising the six urban cores 16

$\begin{array}{ll}2.2 .2 \text {. Identifying a city's historical lizard fauna } & 20\end{array}$

$\begin{array}{ll}2.2 .3 \text {. Identifying a city's current lizard fauna } & 20\end{array}$

$\begin{array}{lr}\text { 2.2.4. Characteristics of urban-dwelling lizards } & 21\end{array}$

2.3. Results $r$

\begin{tabular}{ll} 
2.3.1. & Description of urban cores \\
\hline
\end{tabular}

$\begin{array}{ll}\text { 2.3.2. Review of databases and literature } & 23\end{array}$

$\begin{array}{lr}\text { 2.3.3. Historical urban lizard faunas } & 24\end{array}$

$\begin{array}{ll}\text { 2.3.4. Current urban lizard faunas } & 25\end{array}$

$\begin{array}{ll}\text { 2.3.5. Characteristics of urban lizards } & 28\end{array}$

2.4. Discussion $\quad 29$

2.4.1. Historical lizard faunas $\quad 29$

2.4.2. Current lizard faunas $\quad 30$

2.4.3. Potential lizard faunas $\quad 32$

2.4.4. Future research and challenges $\quad 35$

$\begin{array}{ll}\text { 2.4.5. Conclusions } & 36\end{array}$ 
$\begin{array}{lr}\text { 3.1. Introduction } & 39\end{array}$

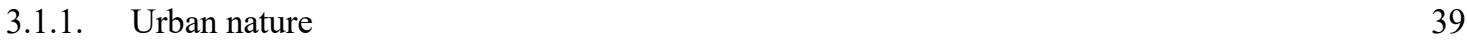

3.1.2. Lizards in New Zealand cities $\quad 40$

3.1.3. Aims $\quad 42$

3.2. Methods $r$

3.2.1. Study sites $r$

3.2.2. Skink surveys $\quad 46$

3.2.3. Habitat- and landscape-scale covariates 46

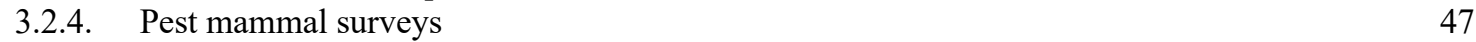

$\begin{array}{llr}\text { 3.2.5. } & \text { Statistical analyses } & 48\end{array}$

$\begin{array}{lr}\text { 3.3. Results } & 51\end{array}$

3.3.1. Site variation $\quad 51$

3.3.2. Skink species diversity and abundance in the four cities $\quad 53$

$\begin{array}{ll}\text { 3.3.3. Phenotypic characteristics of urban populations } & 58\end{array}$

3.3.4. Effect of environmental factors on Oligosoma polychroma 62

3.4. Discussion $\quad 64$

3.4.1. Diversity and abundance of skinks in New Zealand cities $\quad 64$

3.4.2. Impact of urban environments on skink populations $\quad 68$

$\begin{array}{lr}\text { 3.4.3. Limitations and future research } & 70\end{array}$

$\begin{array}{ll}\text { 3.4.4. Conclusions } & 71\end{array}$

Chapter 4: Using citizen science to understand human wildlife interactions in urban environments $\quad 73$

$\begin{array}{ll}\text { 4.1. Introduction } & \mathbf{7 3}\end{array}$

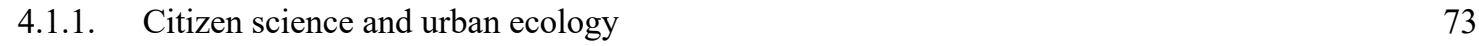

4.1.2. Lizards in New Zealand cities $r$

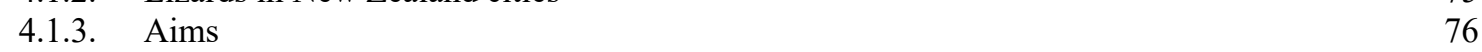

4.2. Methods $\quad \mathbf{7 6}$

$\begin{array}{lll}\text { 4.2.1. } & \text { Public sightings website } & 76\end{array}$

$\begin{array}{ll}\text { 4.2.2. Factors influencing lizard sightings } & 78\end{array}$

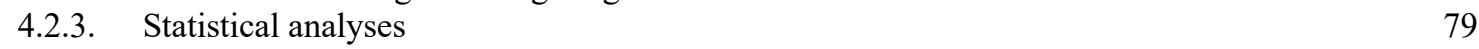

\begin{tabular}{lr} 
4.3. & Results \\
\hline
\end{tabular}

4.3.1. Characteristics of public lizard sightings $\quad 80$

4.3.2. Comparison of skink and gecko sightings $\quad 83$

4.3.3. Spatial relationships of reported sighting $\quad 84$

$\begin{array}{lr}\text { 4.4. Discussion } & 85\end{array}$

4.4.1. Characteristics of human-lizard interactions $\quad 85$

4.4.2. Spatial distribution of human-lizard interactions $\quad 86$

4.4.3. Citizen science as a tool for urban lizard conservation $\quad 87$

4.4.4. Conclusions $\quad 88$

Chapter 5: Understanding motivation and interest for participatory conservation 91

$\begin{array}{lr}\text { 5.1. Introduction } & 91\end{array}$

5.1.1. Urban conservation: issues and solutions $\quad 91$

5.1.2. Citizen participation in ecology and conservation $\quad 92$

5.1.3. Nature engagement and conservation in New Zealand backyards 93

5.1.4. Aims 94 
\begin{tabular}{lr} 
5.2. & 95 \\
\hline
\end{tabular}

$\begin{array}{ll}\text { 5.2.1. Survey design and recruitment } & 95\end{array}$

$\begin{array}{ll}\text { 5.2.2. Statistical analysis } & 95\end{array}$

5.3. Results $r$

5.3.1. Respondent demography $\quad 99$

5.3.2. Willingness to participate in backyard nature-based activities 99

$\begin{array}{lr}\text { 5.3.3. } & 102\end{array}$

$\begin{array}{lr}\text { 5.3.4. Motivations } & 103\end{array}$

$\begin{array}{lr}\text { 5.4. Discussion } & 105\end{array}$

5.4.1. Willingness to participate in backyard conservation activities 105

5.4.2. Differences between the activity types 106

$\begin{array}{lr}\text { 5.4.3. Barriers to participation in backyard conservation } & 107\end{array}$

5.4.4. Motivating participation in backyard conservation 108

$\begin{array}{ll}\text { 5.4.5. Implications for conservation and future research } & 108\end{array}$

$\begin{array}{lr}\text { 5.4.6. Conclusions } & 109\end{array}$

Chapter 6: Conservation of lizards in cities 111

$\begin{array}{lr}\text { 6.1. Introduction } & 111\end{array}$

6.2. Chapter overviews $r 12$

6.2.1. Chapter 2: Reviewing the past, present and potential lizard faunas of New Zealand cities 112

6.2.2. Chapter 3: Establishing population baselines of skinks in New Zealand cities 113

6.2.3. Chapter 4: Using citizen science to understand human-wildlife interactions in urban environments

6.2.4. Chapter 5: Understanding motivation and interest for participatory conservation 114

$\begin{array}{lr}\text { 6.3. Discussion and future research } & 114\end{array}$

$\begin{array}{ll}\text { 6.3.1. Overview } & 114\end{array}$

6.3.2. How can we improve knowledge of urban lizard populations? 115

6.3.3. What can be done to support lizards in cities? 119

$\begin{array}{ll}\text { 6.3.4. Urban conservation and nature engagement } & 120\end{array}$

$\begin{array}{ll}\text { References } & 123\end{array}$

$\begin{array}{ll}\text { Appendix } & 147\end{array}$

$\begin{array}{lr}\text { Chapter } 3 \text { Supplementary materials } & 157\end{array}$

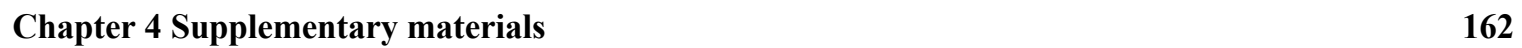

$\begin{array}{lr}\text { Chapter } 5 \text { Supplementary materials } & 163\end{array}$ 


\section{Chapter 1}

\section{Cities and nature: challenges and opportunities}

\subsection{Introduction}

\subsubsection{Urbanisation and biodiversity conservation}

The impact of human activities on the environment through destruction of indigenous land covers, climate change, over-harvest and spread of invasive species is causing unprecedented biodiversity loss, species endangerment and damage to ecosystems (Lande 1998; Czech et al. 2000; Fahrig 2003; Brashares et al. 2004; Doherty et al. 2016). While human behaviours responsible for environmental degradation have existed for many hundreds of years, technological advances and commensurate increases in the size of the human population in the last century have dramatically increased their impact and reach (Vitousek 1994; Alberti et al. 2008). With 68\% of the world's population predicted to live in urban centres by 2050 (United Nations 2019), cities are increasingly being viewed as important battlegrounds for biodiversity conservation (Miller \& Hobbs 2002; Dunn et al. 2006). While urban processes have significant negative impacts on biodiversity (McKinney 2002), because cities are home to the majority of the world's human population, they also offer the potential to reduce these impacts through human behaviour change (Dunn et al. 2006; St. John et al. 2010). 
Urban development involves landscape-scale changes that replace indigenous land covers with ones suited to human purposes. The resulting landscape, with reduced proportions of vegetation and increased proportions of impervious surfaces (e.g., asphalt, pavement, buildings), has implications for both its biotic and abiotic environment (Pickett et al. 2001). Cities, in general, are warmer and receive higher rainfall than their surrounding landscapes (Oke 1973; Botkin \& Beveridge 1997). They also experience altered hydrology (increased surface runoff and reduced evapotranspiration; Dow \& DeWalle 2000; Paul \& Meyer 2001) and soil chemistry (higher acidity and concentrations of organic matter and heavy metals; Pouyat \& McDonnell 1991; McDonnell et al. 1997). These changes cause a reduction and fragmentation of suitable habitat for indigenous species (Swenson \& Franklin 2000; He et al. 2014) often resulting in the loss of species from cities (McKinney 2006). One review identified urbanisation as the second largest cause of species endangerment in the United States (Czech et al. 1997).

In spite of their highly modified nature, biodiversity does exist in cities, although the amount varies greatly among cities in response to a number of anthropogenic drivers (Aronson et al. 2014). A recent study of bird and plant species densities in more than 100 cities around the world found that diversity was explained best by a city's urban land cover, age of urban area, as well as the amount of intact urban vegetation cover (Aronson et al. 2014).

Biodiversity also varies greatly within cities. A common approach to studying intra-urban variation in biodiversity is to use rural-urban gradients (e.g., Germaine \& Wakeling 2001; McKinney 2008; van Heezik et al. 2008). Using this method, reviews of different taxa (birds, Marzluff 2001a; plants, invertebrates and non-avian vertebrates, McKinney 2008) find a general trend of decreasing species richness with increasing urbanisation, especially where it is most intense (e.g., a central business district). However, there are exceptions, notably plants, which a majority of studies show increasing in richness with moderate urbanisation (e.g., residential suburbs) (McKinney 2008). Such increases in diversity have been explained by spatial heterogeneity (Porter et al. 2001), intermediate disturbance (Germaine \& Wakeling 2001) and the importation of exotic species (e.g., invasive species or ornamental species in residential gardens) (McKinney 2008). In studies that aim to relate variation in intra-urban biodiversity to individual habitat variables, patch size and connectivity have been found to be important factors (Shanahan et al. 2011; Beninde et al. 2015). 
While the intense human influence in cities radically alters the original ecosystem, biological components of the new urban ecosystem remain important for the functioning of the city and the wellbeing of its human inhabitants. Trees and forests filter particles from the air, reduce unwanted noise, sequester carbon and regulate the microclimate. Wetlands and vegetation around bodies of water are important for stormwater drainage and sewage treatment, and can mitigate flooding and coastal erosion (Bolund \& Hunhammar 1999). These services are increasingly being recognised as cost-effective solutions to the infrastructure requirements of cities and their monetary value has been estimated at between US\$3212 and US\$17772 per hectare (Elmqvist et al. 2015).

\subsubsection{Social dimensions of urban biodiversity}

In addition to the utility services that ecosystems provide a city, urban nature provides important cultural and recreational resources for urban residents. Urban green spaces are frequently used by residents and valued as places to escape from the city, exercise and watch or interact with wildlife (Rupprecht et al. 2015a; Woolley \& Hartley 2019). Animal and plant species in cities are sometimes harvested for food or cultural purposes (Clark \& Nicholas 2013; Meurk et al. 2013; Parry et al. 2014). There is also a growing body of evidence linking nature to human health and wellbeing (Keniger et al. 2013; Hough 2014). A recent review identified air quality, physical exercise, social cohesion and stress reduction as pathways through which nature can affect physical, psychological and social wellbeing (Hartig et al. 2014). A wide range of aspects of nature-human interactions have been studied. One study found that neighbourhood vegetation cover and bird abundance were positively associated with lower rates of depression, anxiety, and stress (Cox et al. 2017). Another found that participants who were shown videos of natural scenes with higher species richness reported improved mental wellbeing relative to those who watched scenes of lower species richness (Wolf et al. 2017). The amount of nature interaction (nature dosage) is also important, determining the strength of the health benefits gained (Shanahan et al. 2016).

Another important social outcome of urban nature is that by facilitating humannature interactions it helps to foster concern for biodiversity conservation and the global environment. A number of studies show that people who participate in outdoor activities as children are more inclined towards pro-environmental attitudes and behaviours later in life (Ewert et al. 2005; Wells \& Lekies 2006). A study conducted in Hong Kong found 
that willingness to pay for urban green space was positively related to people's use of such spaces (Lo \& Jim 2010). This link between experience and attitude has led some to suggest that global biodiversity conservation may depend upon human interaction with nature in cities (the so called 'pigeon paradox'; Dunn et al. 2006).

Concerningly however, there is a growing body of research suggesting that people living in cities (especially children) are becoming increasingly disconnected from nature. This declining relationship with nature has been attributed to an 'extinction of experience' (Miller 2005; Soga \& Gaston 2016). Recent generations of children spend less time outdoors in natural areas, engage in outdoor activities less frequently and are less knowledgeable about nature compared with previous generations (Soga \& Gaston 2016). Urbanisation is thought to be an important factor in these declines. In cities, ecosystem processes and services are divorced from human needs and hidden from view (Miller 2005). Additionally, people's access to nature in cities can be limited. Although areas of cities can be biodiverse, human residents tend to be concentrated in areas of impoverished biodiversity (Turner et al. 2004). Other factors thought to contribute to the extinction of experience are the emergence of sedentary past times (e.g. television, electronic gaming, the internet, etc.) that compete with outdoor pursuits and the overscheduling of children's lives (Soga \& Gaston 2016). As a result of the declining human-nature relationship, new generations may experience reduced health and wellbeing benefits derived from nature experience and be less inclined to protect the environment (Soga \& Gaston 2016).

\subsubsection{Management of urban nature}

Reflecting the growing awareness of the myriad effects that humans have on the environment and recent research into the benefits of urban nature to people, perceptions of biodiversity in cities are changing (Cranz \& Boland 2003; Standish et al. 2013). Increasingly, city administrators such as councils and governments are considering biodiversity in their decision-making and are seeking to make urban environments more nature-rich (ODPM 2005; Wellington City Council 2015).

For the last two decades, ecological restoration has been a common approach to ecosystem conservation (Martínez \& López-Barrera 2008). Ecological restoration is the assisted recovery of a degraded ecosystem that aims to set it on a trajectory towards a state resembling its historic structure, species composition, and function (SER 2004). 
Recently it has been employed in cities to restore remnant patches of indigenous cover, with much success (Gobster 2010; Clarkson \& Kirby 2016). Urban restoration projects vary greatly in their scale and objectives but often include removal or control of exotic plants and animals, planting, and occasionally the reintroduction of animals (Clarkson \& Kirby 2016; van Heezik \& Seddon 2018). In some cases, ecological restoration can have pronounced effects on a city's biodiversity. In Wellington, New Zealand, the fenced Zealandia ecosanctuary adjacent to residential suburbs has contributed to changes in the diversity of the city's avifauna (Brockie \& Duncan 2012). The 'spill-over' of reintroduced birds to neighbouring reserves and backyards, and the improved breeding success of existing native birds inside the sanctuary has led to a proliferation of native species and the reestablishment of some species previously extirpated from the city (Brockie \& Duncan 2012).

However, the definition of ecological restoration has sometimes been criticised as being too rigid to be appropriate for cities where environments face altered biophysical conditions, non-historical species assemblages, and on-going anthropogenic disturbance (Standish et al. 2013). Additionally, because the green spaces where restoration takes place are often public land, changes to them must reflect the diverse values of a range of stakeholders (Gobster 2001; Eden \& Tunstall 2006; Farinha-Marques et al. 2011). For example, regarding an urban river restoration project in London, local people were more concerned about managing crime and mitigating flood and drowning risks than the site's ecological value (Eden \& Tunstall 2006). In some cases, the restoration of a site in a city may have wide-reaching effects for residents in other areas of the city. This was the case when kākā (Nestor meridionalis), a previously regionally extinct parrot species, were reintroduced to Wellington with a translocation to Zealandia in 2002. The local population quickly grew substantially and kākā are now present across much of Wellington City where they have been responsible for causing damage to backyard trees and the roofs and windows of some houses (Linklater et al. 2018). As a result of the issues marrying restoration and urban ecology, some commentators have called for the broadening of its traditional goals to include the social values of the system along with the ecological (Ingram 2008; Kowarik 2011; Standish et al. 2013).

Another approach that supplements ecological restoration has been proposed in reconciliation (Rosenzweig 2001). Proponents argue that so much of Earth's habitable land has been given over to human use that there is not enough space left to sustain the current diversity using reservation and restoration (Rosenzweig 2003a, 2003b). 
Reconciliation ecology therefore aims to modify and diversify anthropogenic environments so that they can harbour a wider variety of species. Unlike restoration, the novelty of the ecosystem is acknowledged, and anthropogenic and ecological influences encouraged to coexist. Examples of reconciliation ecology in urban environments include green roofs and walls (Francis \& Lorimer 2011), plantings along the margins of transport infrastructure (Rupprecht et al. 2015b), swales for stormwater runoff (Ignatieva et al. 2008) and gardening for wildlife in residential backyards (Rosenzweig 2003b; Goddard et al. 2013). Although often undervalued, these more informal green spaces contribute important habitat for wildlife in cities (Rupprecht et al. 2015b). Residential backyards, for example, are a major component of the total green space in many cities with estimates of their proportion of city areas ranging from 16\% in Stockholm, Sweden to $36 \%$ in Dunedin, New Zealand (Mathieu et al. 2007; Goddard et al. 2010). Though their quality as habitat is variable, they can contribute important nesting and food resources, and are also one of the primary venues for human-wildlife interactions (Soulsbury \& White 2015).

\subsubsection{New Zealand conservation and urban ecology}

New Zealand is a cluster of oceanic islands situated in the South Pacific Ocean. Its geographical location (in particular its isolation) has had a pronounced impact on its unique ecology. After separating from the southern supercontinent Gondwana around 82 million years ago, the fragments that would become the current archipelago remained isolated from other land masses (Wallis \& Trewick 2009). As a result, its fauna reflects a long history of colonisation by over-water dispersal and niche specialisation (Worthy \& Holdaway 2002). Birds and lizards, which over time dispersed to the islands, complementing the existing Gondwanan fauna, filled niches left vacant by the lack of terrestrial mammals and in many cases lost their coevolved defences against terrestrial predators.

Due to this same geographic isolation, New Zealand was one of the last land masses on Earth to be colonised by humans. The arrival of the first people from the Pacific in the thirteenth century AD applied the first anthropogenic stressors to its ecosystems through hunting, clearance of forest and the introduction of the first mammals, dogs (Canis familiaris) and rats (Rattus exulans) (Wilmshurst et al. 2008). These activities resulted in the extinction of a number of bird species (notably all species 
of moa, Dinornis spp.) as well as the decline of many others (Diamond 1990; Allentoft et al. 2014). European discovery and subsequent colonisation in the nineteenth century continued the unravelling of New Zealand's ecosystems. Clearance of land for agriculture, harvest of species and the introduction of a wide variety of new species caused extinctions and continued the decline of many vertebrates. Today, threats to wildlife continue due to loss of habitat for agriculture, urban development and mineral extraction, and the ongoing impacts of invasive species (especially mammals). Currently, $82 \%$ of all extant terrestrial vertebrates have a threat status of 'At Risk' or 'Threatened', including $75 \%$ of amphibian species, $84 \%$ of reptiles, $82 \%$ of birds and $67 \%$ of bats (Fig. 1; Hitchmough et al. 2016a; Robertson et al. 2017; Burns et al. 2018; O’Donnell et al. 2018).
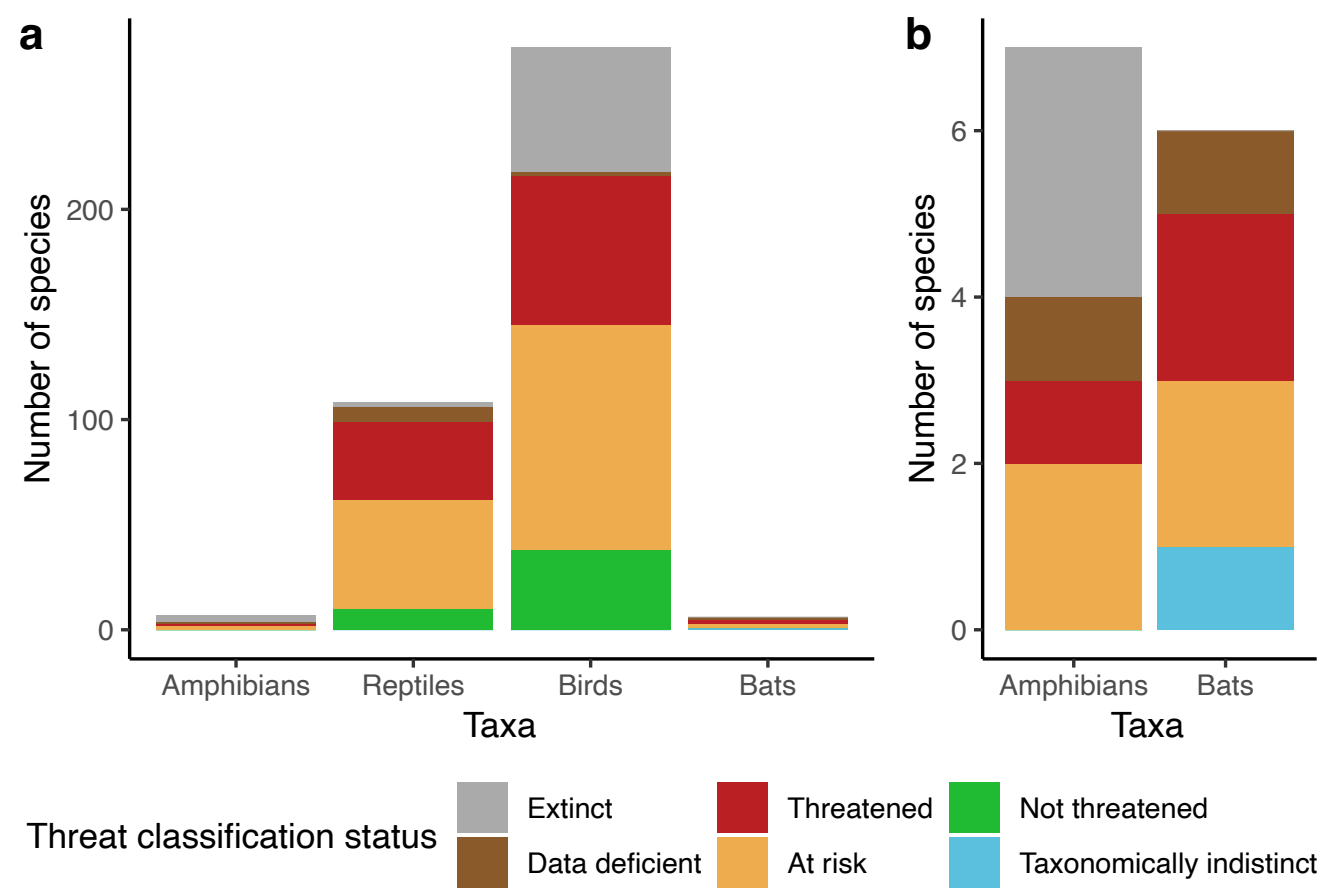

Figure 1 a. New Zealand Threat Classification statuses for native terrestrial vertebrates (New Zealand resident species only). Data from Burns et al. 2018, Hitchmough et al. 2016, Robertson et al. 2017 and O'Donnell et al. 2018. b. Threat Classification statuses of amphibians and bats enlarged for clarity (N.B. the different scales of y axes)

Due to the vulnerability of many native species to mammalian predators, islands have a long history in New Zealand conservation (Daugherty et al. 1990). Islands that remained free of mammalian predators served as refuges for species such as tuatara (Sphenodon punctatus) and tieke (Philesturnus rufusater) that otherwise likely would have gone extinct (Daugherty et al. 1990). In recent years, many more islands have been made free 
of mammals following advances in eradication techniques and technologies (Towns \& Broome 2003).

However, preservation of species on offshore islands has a number of limitations. Firstly, islands do not meet the habitat requirements of all species. This is an issue where species have large home ranges, geographic distributions that do not coincide with islands, or specific feeding or breeding habitat requirements that are not satisfied by islands (Saunders \& Norton 2001). Secondly, keeping iconic species locked away on island strongholds means that very few New Zealanders are able to engage with conservation in situ. For these reasons, conservation on the mainland (either of New Zealand's two main islands) has been important. In the mid 1990s a number of 'mainland islands' were established by the New Zealand Department of Conservation (DOC) with the goals of rehabilitating habitats and enhancing populations of particular animal and plant species (Saunders \& Norton 2001). At these sites a wide range of animal pests are controlled using trapping and poisoning. Around the same time, the development and implementation of pest-exclusion fences, which reduce the need for ongoing pest animal control (Innes et al. 2012), allowed the establishment of wildlife sanctuaries close to cities (Miskelly \& Powlesland 2013).

New Zealand's cities are highly variable in the opportunities they offer for native species (Clarkson et al. 2007). Area and connectivity of remnant indigenous vegetation is dependent upon a city's topography and history of settlement. The first urban settlements in New Zealand grew in the second half of the $19^{\text {th }}$ Century along the lines of British town planning (Schrader 2016). Many used components of the 'Picturesque' and 'Garden City' movements popular in Britain which provided space for nature (albeit often exotic species) within the city (Ignatieva et al. 2011). As a result, many cities include extensive town belts and bush reserves that provide important habitat for wildlife. City and regional councils have responsibility for managing these green spaces and many have biodiversity or urban ecology strategies for managing wildlife and controlling pest species (Auckland Council 2012; Wellington City Council 2015). As in other parts of the world, many New Zealand cities are seeking to make themselves more habitable for native biodiversity (Clarkson \& Kirby 2016). One extreme example of this is in Wellington City, where a current initiative aims to eradicate rats, possums and mustelids from the city (Predator Free Wellington 2018). Ambitious projects such as this may one day allow cities to make substantial contributions to species conservation. 


\subsubsection{Reptile conservation in New Zealand}

New Zealand has an internationally renowned reptile fauna including tuatara, the only extant representative of the Rhynchocephalian order, and two highly diverse families of lizard: skinks (Scincidae) and geckos (Diplodactylidae) (Chapple 2016). Both skinks and geckos colonised New Zealand via over-water dispersal before undergoing rapid speciation to occupy a wide range of habitats and niches (Chapple et al. 2009; Nielsen et al. 2011). Due to the ecology of New Zealand (the absence of mammals, and its temperate climate), the fauna evolved unusual life history characteristics including high rates of K-selected, nocturnal and viviparous species (Chapple 2016). While there are fewer records of reptile extinctions compared with birds, many species have suffered dramatic range contractions. Tuatara and some $37 \%$ of lizard species are currently restricted to offshore or mainland islands where mammal predators either never arrived or have been eradicated (Towns et al. 2001).

Key threats to New Zealand's lizards are ongoing habitat loss and introduced predators, especially rats (Rattus rattus, $R$. novegicus, $R$. exulans) and mustelids (Mustela furo, M. erminea, M. nivalis). Some evidence also indicates that house mice (Mus musculus), hedgehogs (Erinaceus europaeus), and owned and unowned house cats (Felis catus) may also pose a significant threat to populations (van Heezik et al. 2010; Jones et al. 2013; Norbury et al. 2014). Impacts of introduced predators, especially rats, have been well documented in studies of population recovery following rodent eradication on offshore islands. For example, on Korapuki Island, the eradication of kiore (R. exulans) led to an almost 10-fold increase in lizard captures over three years (Towns 1991). Less is known, however, about the impacts of predators in medium and low densities as might be maintained through control or suppression on the mainland. While some evidence suggests pest control may be adequate in some cases (e.g., Reardon et al. 2012), in others, control has not been sufficient to prevent further population declines (Hoare et al. 2007).

Little is known about urban lizard populations in New Zealand despite them being a key component of the native terrestrial fauna. Anecdotal and limited published research suggests that lizards are present in many cities, but how populations are faring is largely unknown. Given the relatively small home ranges of many species and the current interest in urban conservation and restoration, it is possible that urban environments, such as bush reserves and backyards, may provide opportunities for lizard conservation. It is also possible that, with the current lack of monitoring, populations of some species could be in unnoticed decline. 


\subsection{Thesis aims and organisation}

\subsubsection{Main questions}

In order to effectively manage urban lizard populations, greater knowledge is needed of where and how lizards are surviving in cities, and what potential exists for urban lizard restoration. To build this knowledge, this thesis uses a socio-ecological approach that considers the ecology of New Zealand lizards, as well as the human dimensions of cities. Its central aim is to provide knowledge that will inform lizard restoration and conservation in cities by identifying what lizard species are present where in NZ cities and how people might play a role in their protection. To address this aim, I sought to answer four key questions:

- What lizards historically would have lived in the regions of New Zealand cities? (Chapter 2)

- What lizards are currently found in cities? (Chapters 2, 3 and 4)

- What factors in the urban environments impact lizard populations? (Chapter 3)

- What can be done to support lizards in cities? (Chapters 2, 3 and 5)

\subsubsection{Thesis outline and style}

This thesis includes four data chapters formatted for journal submission. In order to make each chapter coherent in its own right, some repetition of information has been necessary, particularly in the introductory sections. This thesis is the first work examining conservation of lizards in New Zealand cities. By reviewing current knowledge of lizard diversity in cities and contributing baseline data on the current state of urban-dwelling skink populations it provides a roadmap for how lizards may be restored and conserved in cities. Additionally, by studying citizen science and participatory conservation, it builds knowledge about how these tools may contribute to conservation and foster human-nature relationships.

In Chapter two, I review existing knowledge about lizards in New Zealand cities and quantify 1) what lizard species currently live in these cities and 2) what species could be candidates for restoration in cities based on knowledge of historical distributions and opportunities for lizards in New Zealand cities. This chapter has been published in 
Landscape and Urban Planning (Woolley et al. 2019). Chapter three builds upon the very limited knowledge of lizard populations in cities by describing urban populations of skinks in four New Zealand cities. Chapters four and five examine some of the social opportunities for lizard conservation offered in cities. Chapter four uses public-reported lizard sightings to evaluate the use of citizen science for gathering information about lizard distributions in cities, while Chapter five investigates socio-demographic correlates of public willingness to engage in a range of backyard conservation activities including biodiversity monitoring. Chapter six is a general discussion and synthesis of the thesis findings including recommendations for management and future research.

\subsubsection{Contributions to research}

All study design, data collection and data analyses were undertaken by the author with advice from supervisors. In addition, the below collaborations contributed to the completion of this thesis.

- Study design: the lizard survey methods in Chapter 3 were designed in collaboration with the People, Cities and Nature (PCaN) Lizards team, consisting of: Nicola Nelson and Stephen Hartley of Victoria University, Yolanda van Heezik of University of Otago and, John Innes and Deb Wilson of Manaaki Whenua - Landcare Research.

- Data collection: a large number of field assistants aided in the preparation of field equipment and sites, as well as the collection of data for Chapters 3 and 5. Pest mammal indices for sites in Hamilton, Wellington and Dunedin used in Chapter 3 were provided by the PCaN Mammal team.

- Lizard biogeography: expert advice on lizard biogeography in relation to cities was sought from Rod Hitchmough of the Department of Conservation for Chapter 2.

- Manuscript review: prior to publication of Chapter 2, the manuscript benefited from revisions and comments from the PCaN Lizards team, Rod Hitchmough and three anonymous reviewers. These have been incorporated into Chapter 2. 


\subsubsection{Permits and Ethics}

This research was carried out with approval from the Victoria University of Wellington Animal Ethics (permits AEC22347 and AEC27041) and Human Ethics Committees (permits HEC25153 and HEC24735), and the Department of Conservation (50568-FAU). 


\section{Chapter 2}

\section{Reviewing the past, present and potential lizard faunas of New Zealand cities}

\subsection{Introduction}

\subsubsection{Urban restoration and conservation}

Although urbanisation is associated with massive modification and degradation of habitat, and results in species loss (Czech et al. 2000; McKinney 2002; Shea \& Chesson 2002; McKinney 2006), cities also offer opportunities for the conservation of some species. A growing awareness of the myriad effects of human behaviours on the environment and biodiversity, and the acknowledgement of diminishing relationships between people and nature, are changing the way people view biodiversity in cities (Miller \& Hobbs 2002; Dunn et al. 2006). In many cities, administrators are increasingly considering biodiversity in their decision making (Beatley 2011; Blaustein 2013; Wellington City Council 2015), commercial enterprises are offering ecotourism experiences (Rosenzweig 2003a), and community-led restoration projects are flourishing (Peters et al. 2015; Clarkson \& Kirby 2016). Individual citizens too have the opportunity to make significant contributions to 
biodiversity conservation, both by mitigating the negative environmental effects of urban processes and enhancing green spaces in cities to make them habitable for wildlife.

This is the case in New Zealand where, over the last two decades, a number of new initiatives have seen dramatic changes in the fauna of some cities (Brockie \& Duncan 2012). These include, predator-free sanctuaries, community restoration groups and backyard pest trapping. Additionally, several city councils have adopted biodiversity strategies supporting these initiatives and encouraging public involvement (Auckland Council 2012; Wellington City Council 2015). With this developing interest in urban biodiversity it is an opportune time to evaluate the potential for faunal restorations in cities.

\subsubsection{Conservation of native lizards in New Zealand cities}

One group that might be a suitable candidate for urban conservation, either through ecological restoration (sensu Clewell \& Aronson 2013) or reconciliation (sensu Rosenzweig 2003), is the native lizards. New Zealand's lizard fauna, which consists of two families: skinks (Scincidae) and geckos (Diplodactylidae), is notable for its exceptionally high diversity (more than 100 species in total), high rates of viviparity (only one oviparous species) and K-selected reproductive strategies (Chapple 2016). While many of New Zealand's lizard species are threatened, range-restricted or highly managed to ensure survival (Hitchmough et al. 2016a, 2016b), others remain widespread and occur at varying densities in many cities (Melzer \& Bell 2014; Department of Conservation 2017). However, little is known about these urban populations, and anecdotal reports and studies at mainland sites suggest that many may be in slow decline (e.g., Hoare et al. 2007). Threats to lizards in cities are numerous, including predation by introduced mammals such as rats (Rattus rattus and $R$. norvegicus), house mice (Mus musculus), European hedgehogs (Erinaceus europaeus occidentalis) and domestic cats (Felis catus), as well as habitat loss (Towns \& Daugherty 1994), and population fragmentation resulting from urban development (Noël \& Lapointe 2010; Krawiec et al. 2015).

\subsubsection{Opportunities}

Many of New Zealand's skink and gecko species have small home ranges (often less than $20 \mathrm{~m}^{2}$; Eifler \& Eifler 1999; Wilson et al. 2017), which allow them to exploit small patches of adequate habitat among the mosaic of environments found in cities, while 
being largely unaffected by nearby disturbance. Strong site fidelity can aid survival of urban-dwelling skinks (Koenig et al. 2001). In cities, strategies to manage lizard populations in the presence of introduced predators (Reardon et al. 2012; Norbury et al. 2014) could be applied in natural areas such as bush reserves and wetlands, as well as modified environments like parks, backyards and informal greenspaces (Rupprecht et al. 2015a, 2015b). Although untested, intensive, localised predator control and enhancement of habitat might be able to safeguard existing lizard populations in cities and potentially provide safe areas for future translocations.

Urban restoration of lizards may also serve to enhance the nature experience of urbanites and indirectly influence their perception of biodiversity in cities. Lizards are the only native non-avian vertebrate likely to occur in backyards and the fact that the home ranges of some animals may make use of habitat in just a single backyard makes some species excellent candidates for wildlife gardening. New Zealand has a number of charismatic lizard species including one of the world's largest geckos, Duvaucel's gecko (Hoplodactylus duvaucelii). Brightly coloured 'green' geckos of the genus Naultinus are commonly used as advocacy animals and still occur in and around some New Zealand cities. It is therefore conceivable that urban citizens might be motivated to undertake proconservation behaviours, such as incorporating native plant species into their gardens or maintaining predator control on their property, by the prospect of increasing the viability of their local gecko or skink population.

\subsubsection{Challenges}

Research into lizard population ecology has tended to focus on vulnerable populations (Hoare et al. 2007; Reardon et al. 2012), effects of predator control (e.g., Towns 1991; Norbury et al. 2014; Wilson et al. 2017) or translocation outcomes (e.g., Bogisch et al. 2016; Romijn \& Hartley 2016; Towns et al. 2016b) and there are few published studies that specifically focus on urban populations. As a result, there is a lack of knowledge about current distributions and abundances of lizard species in New Zealand cities.

In addition, despite recent advancements, the taxonomy of New Zealand lizards remains incompletely resolved (Hitchmough et al. 2016b), making it challenging to know which species might have historically been present in regions now occupied by cities. Species' distributions have been dramatically altered by invasive species and land cover 
change, in some cases resulting in the extinction of once widespread species from the mainland (Towns \& Daugherty 1994; Towns et al. 2016a).

There is also a lack of knowledge about the ecology of the urban environment and how lizards might fit into this. Highly modified habitats and invasive predators are ubiquitous in most cities and their interaction with other environmental factors, such as temperature in particular, likely influences the degree to which they affect the fauna of a given city (Gaby et al., 2011). For example, certain types of land cover and their position in a city may modify effects of introduced predators on populations. There is some evidence that complex cover, such as dense vegetation or rock piles, may reduce the detectability of prey or the hunting efficiency of predators (Towns 1996).

\subsubsection{Aims}

This review aims to compile current knowledge about the past and present distributions of endemic lizards in New Zealand cities, and to discuss what opportunities exist in urban areas that might facilitate the restoration of lizard species. This information will provide a foundation for future research into urban conservation of lizards and identify what potential exists for restoration. Specifically, the review will address the following questions: 1. What lizard species were present in the regions of six New Zealand cities prior to human colonisation? 2. What is the current lizard fauna of each of these cities? 3. How do the six cities differ in their land cover composition and other opportunities available to their lizard faunas, and 4 . What potential exists for restoration of lizards in New Zealand cities?

\subsection{Methods}

\subsubsection{Defining and characterising the six urban cores}

The three largest cities in each of New Zealand's two main islands (North Island: Auckland, Hamilton, Wellington; South Island: Nelson, Christchurch, Dunedin) were selected for this study (Fig. 1). This selection provided representatives that varied in latitude, human population size and density, disturbance history and included both coastal and inland cities. For each city, an urban core was defined using ArcMap (v10.5.1; ESRI 2017) by first identifying all "Built-up area (settlement)", "Surface mine or dump", "Transport infrastructure" and "Urban parkland/open space" polygons (henceforth "Urban" see S1) from the New Zealand Land Cover Database (LCDB v.4.1, 
https://lris.scinfo.org.nz/layer/48423-lcdb-v41-land-cover-database-version-41-mainlandnew-zealand/, accessed: 12/3/19) that were within $600 \mathrm{~m}$ of each other. All land area that fell within the extent of these polygons, plus a $150 \mathrm{~m}$ buffer to account for the infiltrating effects of urban development, was considered urban.

The six urban cores were then described in terms of their total area, location, and types and proportions of land cover they encompass. The 26 land cover types from the land cover database were reclassified into eight more general classes: exotic grassland, exotic forest, exotic scrub, horticulture, indigenous forest, indigenous scrub, wetland and gravel (see S1). Water was excluded from the analysis (Fig. 1). 


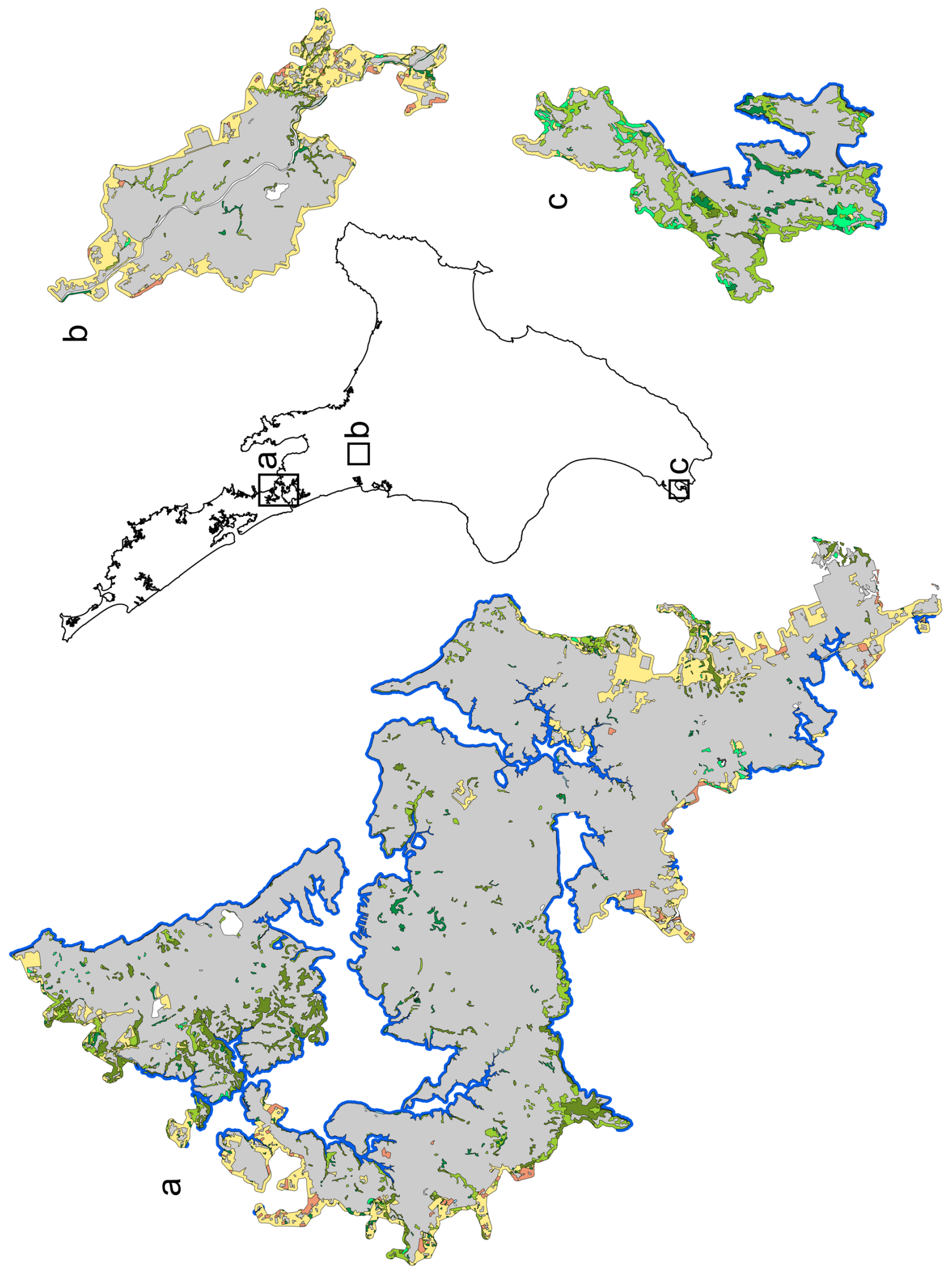

18 - Chapter 2: Past present and potential urban lizard faunas 


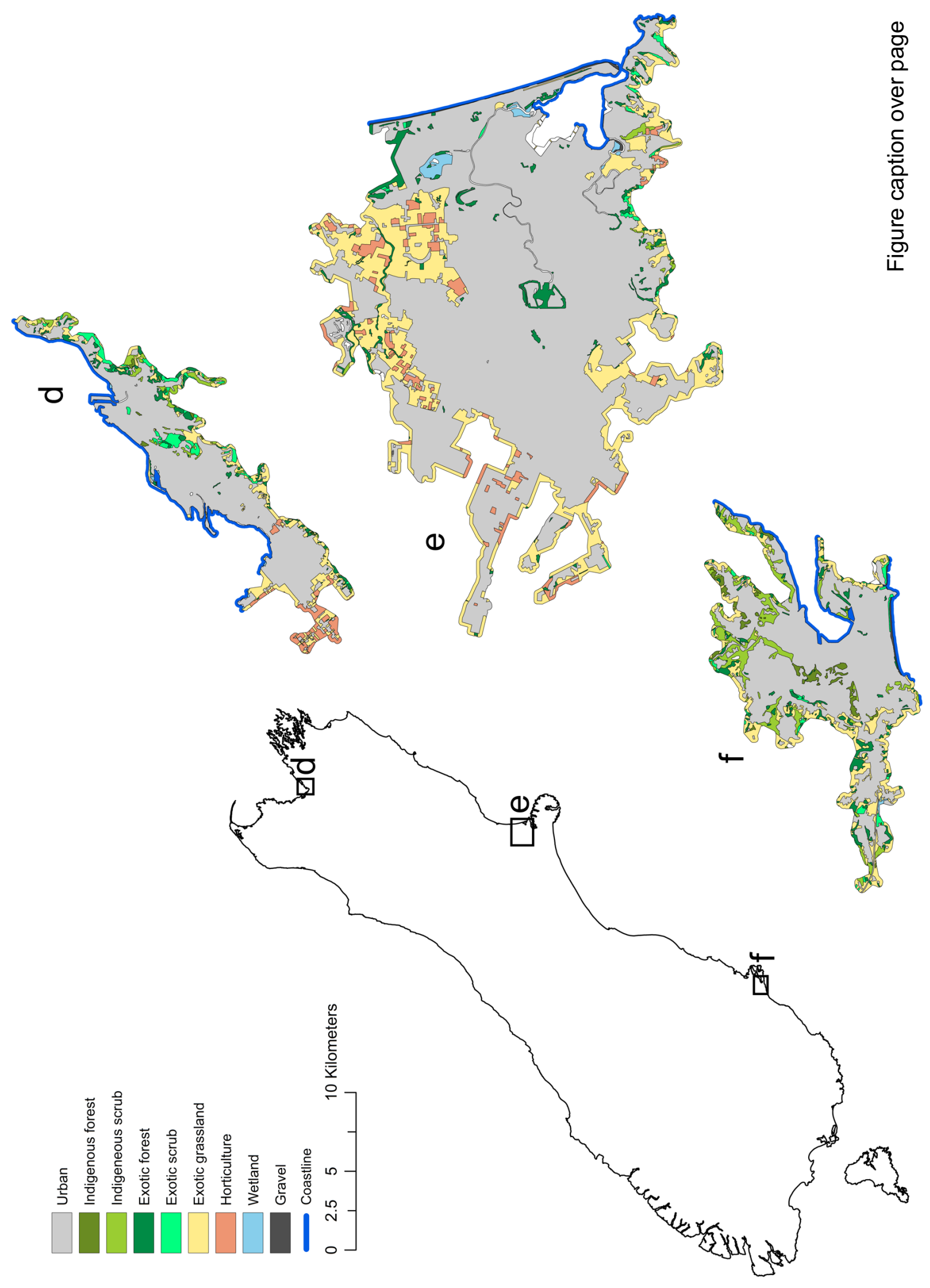


Figure 1 Maps of the land cover of the defined urban cores for a. Auckland, b. Hamilton, c. Wellington, d. Nelson, e. Christchurch, f. Dunedin. City locations are indicated on outline map of their respective islands

\subsubsection{Identifying a city's historical lizard fauna}

Inferences about which species were likely to be present historically within the urban core were made using the most recent classification of species to biogeographical categories based on the BioWeb Herpetofauna Database (Chapple \& Hitchmough 2016). Of the 22 biogeographic categories used by the authors, 14 coincided with the cities used in this study (see S2) and were used to create a preliminary list of species that are likely to occur in each city. This list was then refined by removing and adding species on a case by case basis. Removals were made by considering three criteria: 1 . the known presence of a closely related species in a city's location (e.g., Mokopirirakau 'Cupola' where $M$. granulatus is present), 2. a species' known range being too far from a city or excluded from a city by a known boundary (e.g., species not found north of Wairau River), and 3. the absence of a species' known habitat in a city's location (e.g., montane or alpine). Additions were made where the use of the biogeographical categories excluded species whose occurrence in regions of cities could not be ruled out. The full candidate list of 'urban' species along with rationale for removals is available in supplementary material $\mathrm{S} 2$.

\subsubsection{Identifying a city's current lizard fauna}

There is no regular survey or monitoring effort for lizards, either in New Zealand cities or nationally. Therefore, to identify which species are currently present within these urban cores, records were pooled from a range of sources. These included two national databases: the Bioweb herpetofauna database and iNaturalist (https://inaturalist.nz/, accessed: 12/3/19, contributor usernames acknowledged in S3), published literature that identified populations in cities, and statements, reports and records from the councils of the six focus cities.

The BioWeb Herpetofauna database is administered by the New Zealand Department of Conservation (DOC) to collate information reported via the amphibian and reptile distribution scheme. This system records detailed, expert-verified information about national species distributions (including sub-fossils). Due to the quality standard required, the majority of records are added by professional herpetologists working in non- 
urban locations. iNaturalist NZ (formerly NatureWatch NZ) is a website and mobile application that allows members of the public to record observations of organisms by completing a form and/or uploading a georeferenced photograph. This record is then reviewed by other users who verify the identity of the species.

In selecting records from the BioWeb database, two temporal categories were used: (1) species present within the urban core in the last 20 years, and (2) additional species present within the urban core in the last 50 years. The latter was used to reduce the risk of excluding species that are present but were not detected during the 20 -year period due to a presumed low number of surveys. I included data from all temporal periods from the iNaturalist NZ database as the website has only been in operation since 2012. Species records from these databases were selected based on their location within any of the urban cores.

The systematic review of literature was carried out using Web of Science with the search terms: (skink* OR gecko* OR lizard*) AND (urban* OR suburb* OR city OR Auckland OR Hamilton OR Wellington OR Nelson OR Christchurch OR Dunedin) AND "New Zealand". Results were deemed relevant if they provided any evidence of a lizard species distributed in any New Zealand urban environment. Reference lists of these articles were also checked and papers with promising titles included based on the same criteria.

All six city councils were contacted and asked to provide any relevant grey literature in the form of reports or datasets. Often, they suggested contacting a contract herpetologist or DOC regional office. All material gathered was reviewed where it described work carried out within the prescribed urban cores or provided useful contextual information. Where GIS databases existed (i.e., Auckland Council), these were analysed by methods equivalent to those used for the other databases.

\subsubsection{Characteristics of urban-dwelling lizards}

Using data from Tingley et al. (2013), I assessed the effect of five characteristics on the likelihood that a species that was once present in a city's region has become extirpated. A logistic regression model was run in $\mathrm{R}$ ( $\mathrm{R}$ Core Team 2018) using presence of species in a city (within the last 20 years) as a binomial response $(1=$ present within core, $0=$ extirpated) and family (skink or gecko), activity phase (nocturnal or diurnal), body size (snout-vent length; SVL), maximum reproductive output (number of young per female 
per year) and habitat specialisation (a measure of the number of land cover categories where species records occurred) as predictors. These predictors were chosen because of their hypothesised importance to survival in the presence of disturbance and introduced predators (Towns 1991, 1996; Tingley et al. 2013). Interactions between family and body size, and activity phase and body size were also tested but found to be non-significant and subsequently dropped from the model. All means are reported with standard errors.

\subsection{Results}

\subsubsection{Description of urban cores}

The standardised method used to define urban cores created polygons that ranged in area from 52,186 ha (Auckland) to 5063 ha (Nelson) (S4). The percentage of this area occupied by urban land cover also varied widely among cities, with Auckland having the greatest percentage urban cover (87.3\%) and Dunedin having the least (66.3\%) (S4, Fig. 2). The remaining land cover (non-urban land cover) was dominated by exotic grassland in all cities except Wellington where the largest non-urban cover type was indigenous scrub (61.2\% of non-urban) (S4, Fig. 2). The six cities fall between the latitudes of $36.84^{\circ} \mathrm{S}$ and $45.88^{\circ} \mathrm{S}$ and all are coastal except for Hamilton, the edge of which is approximately $40 \mathrm{~km}$ from the nearest coast.
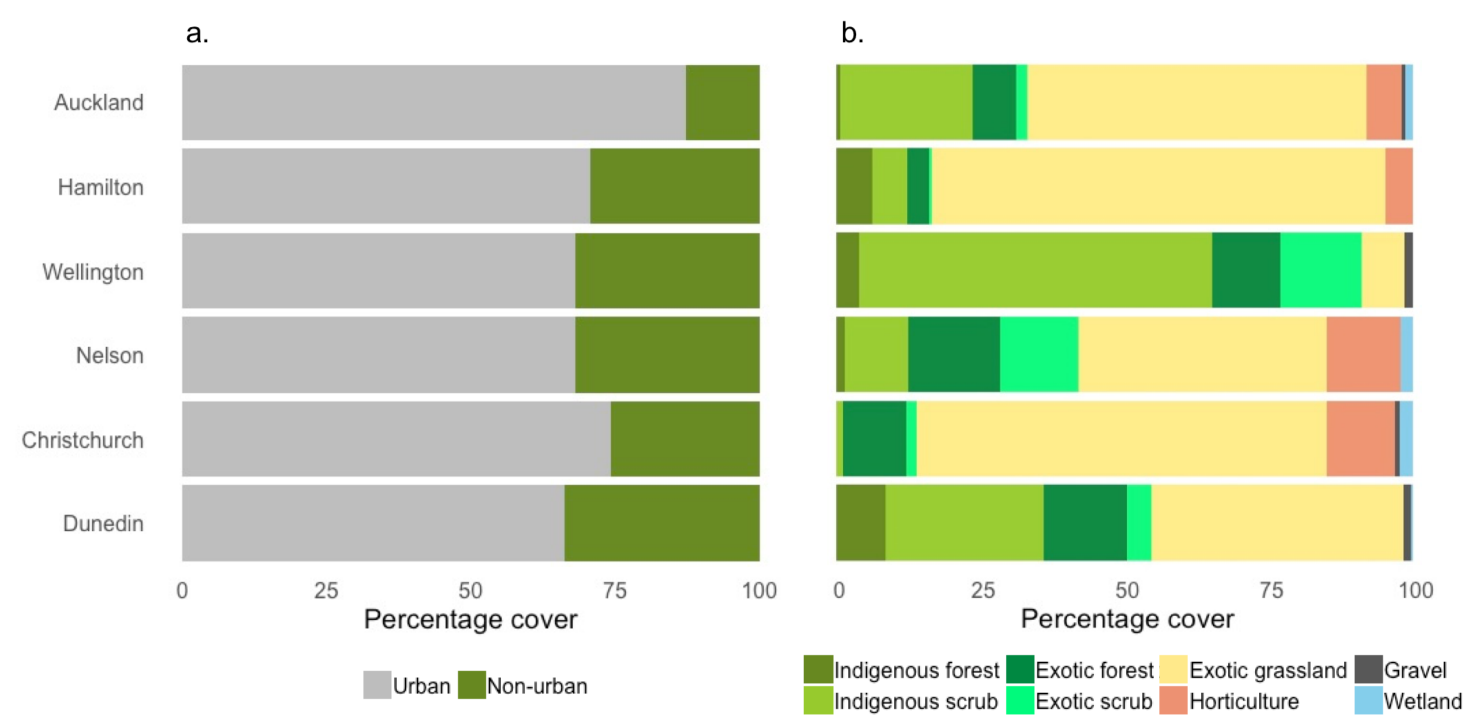

Figure 2 Area of land cover types within the defined urban cores. a. urban and non-urban land cover as a percentage of total area, and $\mathbf{b}$. adjacent non-urban land cover types as a percentage of total non-urban area. Cities ordered from north to south (Auckland to Dunedin) 


\subsubsection{Review of databases and literature}

The BioWeb Herpetofauna database contains 15,996 records of lizards in total across the country dating back to 1837 . Of these, only 743 (4.6\%) occurred in any of the urban cores. By comparison, records in the iNaturalist NZ database show a marked difference in bias with $32.9 \%$ of the 1137 reptile records coming from the six cores. The DOC BioWeb Herpetofauna database was the most comprehensive source of records of species presence. No other sources identified species records within the urban cores that were not present in this database.

The literature review identified only four published articles that contributed relevant information about lizard distributions in the six focal cities (S5). Two recent additional papers were also identified that reported on studies conducted in other urban centres. Of the resulting six papers, only two studies were carried out within the last 35 years and only one (van Heezik \& Ludwig 2012) discussed the effect of the urban environment on populations.

Four further urban studies identified by the search were notable for including lizards as prey items of cats. Morgan et al. (2009) reported 172 Oligosoma polychroma being brought home by 88 cats living around a wetland in suburban Christchurch over a period of 12 months. Over the same length of time in Auckland, Gillies and Clout (2003) reported 46 cats bringing in 45 skinks in the Browns Bay area, and 34 cats bringing in 10 geckos and 72 skinks in Oratia. Species were not recorded. Also over the course of a year, van Heezik et al. (2010) reported that O. polychroma made up $8.1 \%(\mathrm{~N}=149)$ of the prey brought back by 151 cats in Dunedin and that $17 \%$ of the cats brought back skinks. Finally, nine $O$. aeneum were caught in a suburban garden in Lower Hutt by a single house cat over its 17 year life (Flux 2007).

Enquiry at the relevant city and regional councils yielded biodiversity survey work from Wellington, contract survey work from Hamilton and Christchurch and a database from Auckland City Council (S6).

Of the 18 unpublished reports, five were undertaken for the purposes of research or biodiversity assessment. Four were student projects, two in Wellington (Jamieson 2010 and Oliver-Smith 2015), one in Christchurch (McClure 2010) and another in Auckland (Nichols 2014). All of the projects took place in reserve areas, a wetland in Christchurch, dune systems in Wellington, and forest reserves in Auckland and Wellington, and sought to assess which species were present and relate this to habitat characteristics. Similarly, a report prepared for Wellington City Council (Melzer \& Bell 2014) assessed which 
species were present in 40 urban reserves and parks (some outside this review's definition of the urban core).

One report was a biodiversity survey assessing the potential introduction of the invasive Australian skink, Lampropholis delicata at a commercial freight company in Christchurch (Lettink 2006). The remaining reports relate to ecological assessments and salvage operations prior to roading or development work required by New Zealand law under the Resource Management (1991) and Wildlife Management Acts (1953).

The Auckland Council database contains records dating from 2002 and provides georeferenced information about which species were observed when, what monitoring tools were used and details of the observation including: number found, what sort of habitat it took place in and other available information (e.g., life stage, sex etc.). Additionally, some locations are recorded where surveys have been undertaken but nothing found.

Within the defined urban boundary of Auckland, 110 records exist, including: 53 O. aeneum, 18 O. ornatum, 8 Naultinus elegans, 15 M. granulatus, 2 Dactylocnemis pacificus and 12 L. delicata. Additionally, one gecko of the species Lepidodactylus lugubris, a species not known to be resident in the country, was recorded along with one unidentified skink.

\subsubsection{Historical urban lizard faunas}

The 14 biogeographic categories identified 15 lizard species in the Auckland region, 18 in and around Hamilton, 16 in Wellington, 23 in Nelson, 11 in Christchurch and 16 in Dunedin (S2). These long lists contained numerous species that were unlikely to have ever been present in the vicinity of the cities, and species were removed according to the reasons outlined in supplementary materials (S2). Likewise, the use of the selected biogeographical categories excluded some widespread (e.g., W. chrysosiretica and $M$. granulatus) and island relict (e.g., O. alani) species whose occurrence in cities was likely or could not be ruled out based on current knowledge of their distribution. These species were added. This refinement resulted in 19 species (5 geckos, 14 skinks) in Auckland, 17 (6 geckos and 11 skinks) in Hamilton, 16 (7 geckos and 9 skinks) in Wellington, 9 (5 geckos and 4 skinks) in Nelson, 6 (3 geckos and 3 skinks) in Christchurch and 7 (3 geckos and 4 skinks) in Dunedin (Table 1, Fig. 3). 
Sixteen out of the 43 (37.2\%) currently recognised New Zealand gecko species and 24 out of the 61 (39.3\%) skink species were determined to have a range that likely historically included one or more of the six cities. These include all but one of the seven gecko genera (the genus Tukutuku occurs only on Rakiura/Stewart Island; all New Zealand skinks belong to the genus Oligosoma).

\subsubsection{Current urban lizard faunas}

In all, eleven species of gecko and ten species of skink have been recorded within at least one of the six urban cores in the last 50 years (Table 1, Fig. 3).

In the North Island, six species of geckos were recorded as living in one of the defined urban centres in the last 20 years. Of these, three were present in Auckland: $N$. elegans, D. pacificus, M. granulatus and three were present in Wellington: Woodworthia maculata, M. 'southern North Island' and N. punctatus. An additional species, $W$. 'Marlborough mini', was recorded in Wellington in the last 50 years. No geckos were reported in the defined area of Hamilton City in the last 50 years (Table 1, Fig. 3). In the South Island, only one species of gecko has been recorded as living in one of the urban areas in the 20-year period. This was $W$. cf. brunnea which was recorded in Christchurch. Within the 50-year period however, N. stellatus and W. maculata were found in Nelson while $N$. gemmeus was recorded in Christchurch and Dunedin and $W$. 'Otago/Southland large' in Dunedin only.

Excluding the invasive rainbow skink, L. delicata, which is established in Auckland and Hamilton, six skink species were found to be present across the three North Island cities: three in Auckland (O. aeneum, O. moco and O. ornatum), one in Hamilton (O. aeneum) and five in Wellington (O. ornatum, O. aeneum, O. polychroma, $O$. zelandicum, and O. kokowai (previously O. aff. lineoocellatum (Melzer et al. 2017); released in the fenced Zealandia wildlife sanctuary in 2016). An additional species, $O$. smithi was recorded in Auckland in the 50-year period.

In the South Island, five species of skinks have been recorded in the three cities within the 20-year period. In Nelson, these were O. kokowai and O. polychroma, and in Christchurch, O. maccanni, O. lineoocellatum and $O$. aff. polychroma clade 5. $O$. aff. polychroma clade 5 was also recorded in Dunedin during this period. 
Table 1 Records of lizard species present and inferred to have been present historically in defined urban cores during the three temporal periods. Genera: Dactylocnemis, Hoplodactylus, Lampropholis (introduced), Mokopirirakau, Naultinus, Oligosoma, Toropuku, Woodworthia.

Caption continues over page

\begin{tabular}{|c|c|c|c|c|}
\hline City & Family & $\begin{array}{l}\text { Species recorded in } \\
\text { urban core in last } 20 \\
\text { years }\end{array}$ & $\begin{array}{l}\text { Additional } \\
\text { species recorded } \\
\text { in urban core in } \\
\text { last } 50 \text { years }\end{array}$ & $\begin{array}{l}\text { Additional species } \\
\text { inferred to be historically } \\
\text { present in core }\end{array}$ \\
\hline \multirow[t]{2}{*}{ Auckland } & Geckos & $\begin{array}{l}\text { D. pacificus }(\mathrm{Rel}) \\
\text { M. granulatus }(\mathrm{D}) \\
\text { N. elegans }(\mathrm{D})\end{array}$ & Nil & $\begin{array}{l}\text { H. duvaucelii }(\mathrm{Rel}) \\
\text { W. maculata }(\mathrm{NT})\end{array}$ \\
\hline & Skinks & $\begin{array}{l}\text { O. aeneum }(\mathrm{NT}) \\
\text { O. moco }(\mathrm{Rel}) \\
\text { O. ornatum }(\mathrm{D}) \\
\text { L. delicata* }\end{array}$ & O. smithi (NU) & $\begin{array}{l}\text { O. suteri }(\mathrm{Rel}) \\
\text { O. striatum }(\mathrm{D}) \\
\text { O. macgregori }(\mathrm{Rec}) \\
\text { O. whitakeri }(\mathrm{NE}) \\
\text { O. alani }(\mathrm{Rec}) \\
\text { O. oliveri }(\mathrm{Rel}) \\
\text { O. townsi }(\mathrm{Rec}) \\
\text { O. homalonotum }(\mathrm{NV}) \\
\text { O. aff. infrapunctatum } \\
\text { 'crenulate' (Rel) } \\
\text { O. 'Whirinaki' (NC) }\end{array}$ \\
\hline \multirow[t]{2}{*}{ Hamilton } & Geckos & Nil & Nil & $\begin{array}{l}\text { D. pacificus }(\mathrm{Rel}) \\
\text { N. elegans }(\mathrm{D}) \\
\text { T. 'Coromandel'1 (NV) } \\
\text { H. duvaucelii }(\mathrm{Rel}) \\
\text { M. granulatus }(\mathrm{D}) \\
\text { W. maculata }(\mathrm{NT})\end{array}$ \\
\hline & Skinks & $\begin{array}{l}\text { O. aeneum }(\mathrm{NT}) \\
\text { L. delicata* }\end{array}$ & Nil & $\begin{array}{l}\text { O. ornatum (D) } \\
\text { O. whitakeri }(\mathrm{NE}) \\
\text { O. alani }(\mathrm{Rec}) \\
\text { O. homalonotum (NV) } \\
\text { O. macgregori }(\mathrm{Rec}) \\
\text { O. oliveri }(\mathrm{Re}) \\
\text { O. townsi }(\mathrm{Rec}) \\
\text { O. aff. infrapunctatum } \\
\text { 'crenulate' (Rel) } \\
\text { O. striatum (D) } \\
\text { O. 'Whirinaki' (NC) }\end{array}$ \\
\hline
\end{tabular}


Table 1 (caption continued) Codes in parentheses indicated conservation status (Hitchmough et al. 2016a): nationally critical (NC), nationally endangered (NE), nationally vulnerable (NV), declining (D), recovering (Rec), relict (Rel), naturally uncommon (NU) and not threatened (NT). * Introduced species; ** Reintroduced species. ${ }^{1}$ Only known from the Coromandel Peninsula;

${ }^{2}$ Specimens a long way from any natural populations, possible that these may represent accidental or deliberate undocumented translocations, ${ }^{3}$ Specimen might have been $W$. 'Marlborough mini' which was at the time not distinguished from W. maculata

\begin{tabular}{|c|c|c|c|c|}
\hline \multirow[t]{2}{*}{ Wellington } & Geckos & $\begin{array}{l}\text { W. maculata }(\mathrm{NT}) \\
\text { M. 'southern North Island' } \\
\text { (D) } \\
\text { N. punctatus }(\mathrm{D})\end{array}$ & $\begin{array}{l}W . \text { 'Marlborough } \\
\text { mini' (NT) }\end{array}$ & $\begin{array}{l}\text { H. duvaucelii }(\mathrm{Rel}) \\
\text { W. chrysosiretica } \\
(\mathrm{Rel}) \\
\text { D. pacificus }{ }^{2}(\mathrm{Rel})\end{array}$ \\
\hline & Skinks & $\begin{array}{l}\text { O. aeneum }(\mathrm{NT}) \\
\text { O. ornatum }(\mathrm{D}) \\
\text { O. polychroma }(\mathrm{NT}) \\
\text { O. zelandicum }(\mathrm{D}) \\
\text { O. } \text { kokowai }^{* *}(\mathrm{Rel})\end{array}$ & Nil & $\begin{array}{l}\text { O. whitakeri (NE) } \\
\text { O. aff. } \\
\text { infrapunctatum } \\
\text { 'southern North } \\
\text { Island' (NV) } \\
\text { O. macgregori (Rec) } \\
\text { O. alani (Rec) }\end{array}$ \\
\hline \multirow[t]{2}{*}{ Nelson } & Geckos & Nil & $\begin{array}{l}\text { N. stellatus }(\mathrm{NV}) \\
\text { W. } \text { maculata }^{3}(\mathrm{NT})\end{array}$ & $\begin{array}{l}\text { M. granulatus }(\mathrm{D}) \\
W . \text { 'Marlborough } \\
\text { mini' }(\mathrm{NT}) \\
\text { T. stephensi }(\mathrm{NV})\end{array}$ \\
\hline & Skinks & $\begin{array}{l}\text { O. kokowai }(\mathrm{Rel}) \\
\text { O. polychroma }(\mathrm{NT})\end{array}$ & Nil & $\begin{array}{l}\text { O. infrapunctatum } \\
\text { (D) } \\
\text { O. zelandicum (D) }\end{array}$ \\
\hline \multirow[t]{2}{*}{ Christchurch } & Geckos & W. cf. brunnea (D) & N. gemmeus (D) & M. granulatus (D) \\
\hline & Skinks & $\begin{array}{l}\text { O. maccanni }(\mathrm{NT}) \\
\text { O. aff. polychroma clade } 5 \\
\text { (D) } \\
\text { O. lineoocellatum (Rel) }\end{array}$ & Nil & Nil \\
\hline \multirow[t]{2}{*}{ Dunedin } & Geckos & Nil & $\begin{array}{l}W . \text { 'Otago/Southland } \\
\text { large' (D) } \\
\text { N. gemmeus }(\mathrm{D})\end{array}$ & $\begin{array}{l}M \text {. 'southern forest' } \\
\text { (NE) }\end{array}$ \\
\hline & Skinks & $\begin{array}{l}\text { O. aff. polychroma clade } 5 \\
\text { (D) } \\
\text { O. maccanni }(\mathrm{NT})^{2}\end{array}$ & Nil & $\begin{array}{l}\text { O. chloronoton (D) } \\
\text { O. inconspicuum (D) }\end{array}$ \\
\hline
\end{tabular}



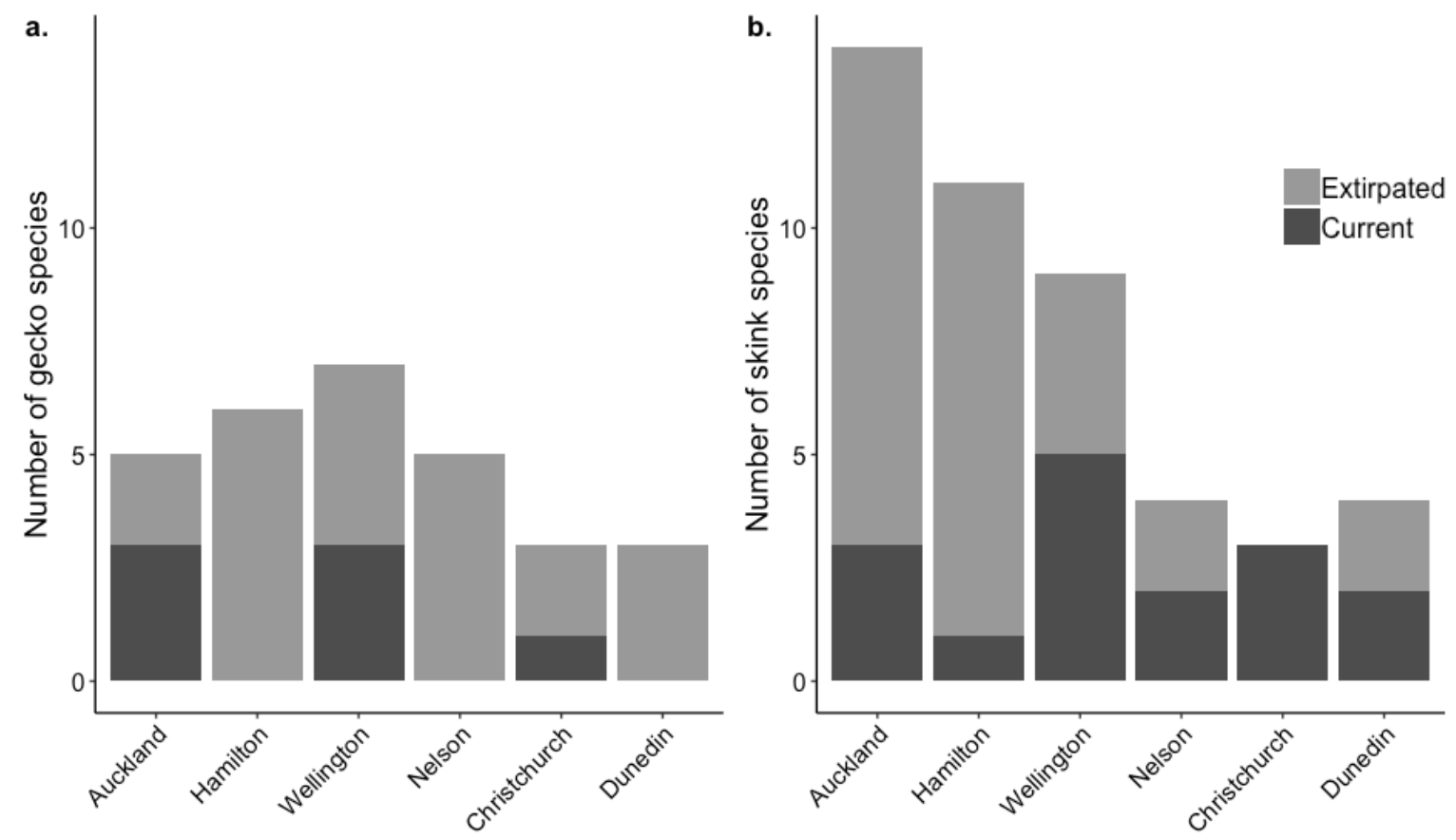

Figure 3 Variation in the number of species historically and currently present among the six urban centres for a. geckos and b. skinks. Total height of bar shows estimated number of historical species, dark grey the number currently present (within last 20 years) and light grey the number extirpated

\subsubsection{Characteristics of urban lizards}

Although none of the factors in the model showed a statistically significant effect on the likelihood of extirpation, I did find weak evidence that the average snout-vent lengths of urban-dwelling lizard species were smaller than those extirpated $(82.1 \pm 3.0 \mathrm{~mm}$ cf. 98.6 $\pm 5.2 \mathrm{~mm} \mathrm{SE} ; \mathrm{z}=-1.77, \mathrm{p}=0.076$, Fig. $4, \mathrm{~S} 7)$. 


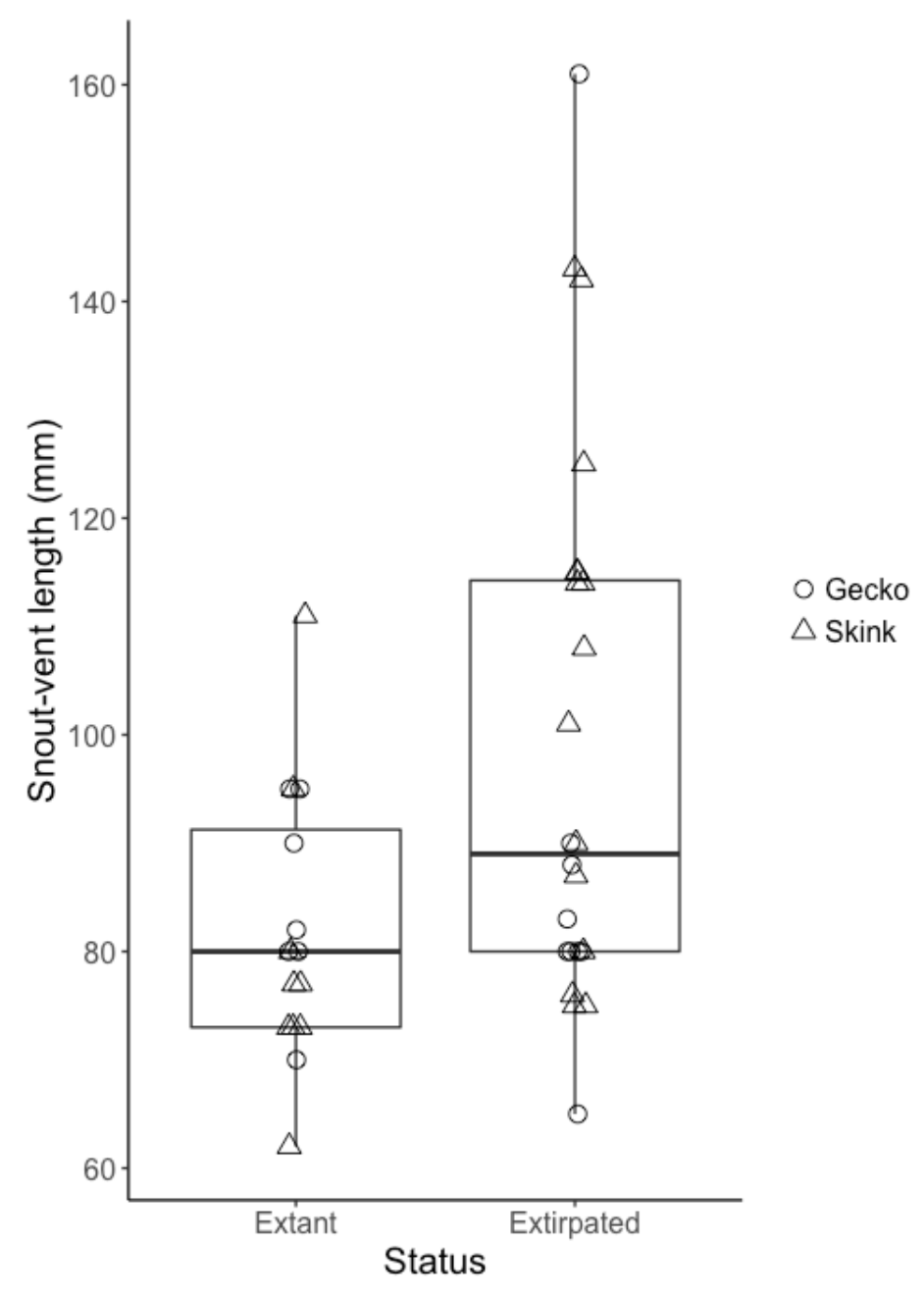

Figure 4 Snout-vent lengths of gecko and skink species that are extant and extirpated in the six urban cores. Points have been jittered horizontally for clarity. Sample sizes: geckos, extant $=7$, extirpated $=9$; skinks, extant $=9$, extirpated $=15$

\subsection{Discussion}

\subsubsection{Historical lizard faunas}

New Zealand has one of the most diverse and unique lizard faunas of any temperate region on earth (Chapple 2016). The 38.5\% $(\mathrm{n}=40)$ of New Zealand's endemic gecko and skink species that are likely to have occurred in the areas of the urban cores prior to human settlement represent some of this diversity (S8). While a few of New Zealand's lizard species have, or had, widespread distributions (e.g., O. ornatum and H. duvaucelii), others have regional distributions and are replaced by closely related species in other regions (e.g., species of the $O$. aff. polychroma and $O$. aff. infrapunctatum complexes) (Chapple \& Hitchmough 2016). Eighteen of the 40 species (43.2\%) were present in only 
one of the six city regions, illustrating the importance of spatial turnover (beta diversity) in New Zealand's lizard communities.

The species identified as historically present in the regions of cities generally reflect a cross-section of New Zealand's lizard fauna. Seven of New Zealand's eight lizard genera are identified, and a broad diversity of size, activity pattern, habitat use and reproductive mode are represented for both skinks and geckos. The group also represents a wide variety of threat statuses, with 27 species currently classified as 'at risk' and eight classified as 'threatened' (Hitchmough et al. 2016a). Restoration of the lizard faunas of cities could therefore not only offer excellent representation of national lizard diversity, but also have benefits for current lizard conservation at a species level.

\subsubsection{Current lizard faunas}

More than half $(60 \%)$ of the species that historically occurred in the locations of the present cities have not been recorded in the last 20 years and have likely been lost from these areas. These species were, in many cases, the same as those that more generally suffered range contractions or extirpation on New Zealand's mainland (two largest islands; e.g., H. duvaucelii, O. alani, O. macgregori). Other species have remained on the mainland and still exist in populations just outside the urban fringe (e.g., W. maculata in Nelson or $N$. gemmeus in Dunedin). The majority of species lost from cores (58\%) were local endemics (those that historically existed in a single city).

Tingley et al. (2013) found that, across all of New Zealand's lizard species, a high degree of habitat specialisation, large body size and small geographic range size were the strongest predictors of extinction risk. Our evidence that the body sizes of currently urban-dwelling species tend to be smaller than those of extirpated species is consistent with these findings, although weak. It is thought that small body size enables lizards to exploit crevices that exclude rodents and other mammalian predators, providing protection (Towns 1996).

Given the importance of temperature to ectothermic animals it is possible that it has played a role in the loss of some species in interaction with novel predators. Research into the temperature-dependence of the sprint speeds of two cold-adapted lizards $(O$. maccanni and $W$. "Otago/Southland large") found that the optimal temperature required to achieve maximum sprint speed was warmer than that commonly attainable in the wild (Gaby et al. 2011). This suggests that lizards living in cooler environments may be less 
adept at escaping predators than those in warmer environments. The two cities that have retained the highest proportion of their gecko fauna (Wellington and Auckland) also have the warmest winter temperatures (MetService 2018).

It seems likely that patterns of extirpation in urban environments are driven by the same factors acting across the country - predation by introduced mammals and changes in land cover, which may be intensified or augmented in cities. Urban environments possess unique challenges: traffic and related infrastructure, high densities of domestic cats (van Heezik 2010), and high levels of maintenance of public and private green spaces (e.g., landscaping, lawn mowing, use of pesticides) all of which could pose a significant threat to urban lizard populations. A wide variety of urban factors are known to affect reptiles, including landscape change and fragmentation, predation and human presence, as well as abiotic factors such as temperature, light and noise (French et al. 2018). While most research documents decreases in population size and species richness with urbanisation (but see Moreno-Rueda \& Pizarro 2007), responses to factors can be speciesand location-specific and therefore should only be generalised with caution (French et al. 2018).

All of the urban cores reviewed are dominated by urban land cover. However, the proportion of the different non-urban covers nearby and intermingled varies considerably between cities. Combined indigenous scrub and forest cover, for example, varies between $0.32 \%$ in Christchurch to $20.86 \%$ in Wellington. While differences in current land cover likely reflect topographic constraints on the degree of historical disturbance and habitat loss in a city, how they relate to its lizard fauna is unclear. It is probable that survival of some species (especially arboreal geckos) in an urban landscape is dependent upon remnant fragments of suitable habitat. However, many of the remaining species are relatively unspecialised and capable of surviving in a wide range of habitats, including some that are highly modified. Summarising habitat use from our search of literature and data, lizards were found in long grass in cemeteries (Barwick 1959), scrubland around transport infrastructure (Feickert 2018), agricultural land (Charteris \& Lettink 2015), residential gardens (Melgren 2012; van Heezik \& Ludwig 2012; Bell et al. 2018), industrial sites (Lettink 2006) and exotic plantings in botanical gardens (Chapter 3), as well as natural areas such as urban reserves (Melzer \& Bell 2014; Nichols 2014), wetlands (McClure 2010) and native grasses around coastal dunes (Chapter 3).

Another consideration is that, while some species have undoubtedly been negatively affected since human settlement, other species may have actually benefited. 
Oligosoma polychroma, the most widespread and abundant skink in both Wellington and Nelson (Chapter 3), is diurnal and an avid basker that inhabits native and exotic grassland habitats that have expanded in coverage since human settlement (Melzer \& Bell 2014; Chapter 3). This species also possibly benefits from highly modified open habitats in the urban environment as it is often seen basking on artificial surfaces such as wooden decking or asphalt. Likewise, changes in the structure of lizard communities, as larger species declined or were extirpated, may have allowed smaller species occupying similar niches to benefit from competitive release (e.g., O. polychroma after declines in $O$. infrapunctatum).

\subsubsection{Potential lizard faunas}

Although urban environments are designed and maintained primarily for the purpose of supporting human activities, they can also offer significant habitat for indigenous biodiversity. For example, Ives et al. (2016) found that 30\% of Australia's threatened species occur in cities that make up just $0.23 \%$ of the total land area. This study shows that $15 \%$ of New Zealand's lizard species are currently found in six cities whose area represents around $0.4 \%$ of New Zealand's land area, and that $38 \%$ of lizard species might have been found in these areas historically. Through restoration of these species in urban habitats, huge potential exists for lizard conservation.

Several ecological restoration projects involving eradication of mammalian predators (e.g., Towns 1991; Newman 1994; Towns \& Ferreira 2001) have allowed recovery of lizard populations that were previously in low numbers, and enabled successful translocations. Additionally, there is some experimental and theoretical evidence that predator and herbivore control at appropriate scales may benefit populations (e.g., Norbury 2001; Reardon et al. 2012). There are some sites in cities where this type of restoration is possible. In all of the cities reviewed here, areas of 'indigenousdominated' green space are managed by a combination of city or regional councils, community groups and commercial ventures. In these locations, control or eradication of exotic plants and animals, regulation of human activities, restoration planting and occasionally reintroduction of animals are enabling ecological restoration within the bounds of cities (Clarkson \& Kirby 2016). There are several successful models for this type of urban restoration. 
Zealandia, a fenced reserve nestled in the suburbs of Wellington, is an ecosanctuary that works closely with city council, community groups and volunteers to provide safe habitat for a wide variety of species. Given their infrastructure and commitment to long-term conservation goals, mammal-exclusion fenced sanctuaries not only allow the growth of existing populations but can also act as sites for the reintroduction of extirpated species where the agent of decline has been removed (IUCN/SSC 2013). Two fenced reserves in New Zealand cities have already received lizard translocations: Zealandia received a conservation translocation of $O$. kokowai in 2016 and Riccarton Bush, another fenced sanctuary in Christchurch, received $W$. cf. brunnea salvaged from a roading project in 2015 (Lettink 2015; Cairns 2015).

Not all restoration sites have the resources for mammal-exclosure fences, however, and many other reserves in New Zealand cities are committed to providing habitat for wildlife. Polhill Gully is a bush reserve adjacent to Zealandia that receives native birds that naturally disperse over the fence. Restoration of this reserve is a community-driven initiative supported by Wellington City Council, with high levels of predator control maintained by a network of volunteers (Prebble 2015). This reserve is highly valued by the community as a green space for walking, mountain biking and exercising dogs, as well as for the habitat it provides for wildlife (Woolley \& Hartley 2019). Building knowledge about lizard populations in reserves such as these would add to their value and allow management to consider them in decision making. Reserves lacking lizard populations, but with appropriate habitat and a demonstrated commitment to ongoing predator control, could potentially receive translocations from local source populations or salvage operations. Greater Wellington Regional Council and DOC are currently looking at the possibility of supporting salvage of lizards into Wellington's regional parks when they are undertaken to a high standard and with appropriate monitoring to ensure that there are tangible learnings to inform whether lizard translocations are an effective mitigation tool (pers. comm. Lynn Adams, DOC; Richard Romijn, Greater Wellington Regional Council 2019).

Translocation into such environments is largely unprecedented and the idea should be approached cautiously. However, in addition to the conservation benefits of establishing new populations, translocation into public reserves could be a significant motivator for both volunteers and the wider community. van Heezik and Seddon (2018) present a decision tree for selecting suitable candidate species for urban reintroduction and emphasise that although some factors are limiting, for species that are unable to 
disperse naturally, reintroduction may be necessary to facilitate restoration. Knowledge built around a reserve's current or potential biodiversity might also promote discussion within the community about how different values are prioritised. For example, the free roaming of cats from the suburbs surrounding Polhill Gully is likely to be a significant barrier to the successful breeding and establishment of dispersing birds from Zealandia (Woolley \& Hartley 2019). Changing people's knowledge and values regarding their local reserve may have an impact on behaviours such as pet ownership or control.

Formal green spaces such as those discussed above, make up only a fraction of a city's total area, however, with the remaining portion set aside as places where humans live and work (Fig. 2). These spaces too offer habitat for native lizards, and provide opportunities to protect and reinforce existing populations using a more reconciliatory approach. Lizard gardening, the planting or construction of habitat to provide resources for lizards, is increasingly being encouraged in backyards (Department of Conservation 2018). Nectar- and fruit-producing plants offering food resources, or dense shrubs and grasses that provide cover from predators are often used. A number of weedy, exotic species (e.g., Tradescantia fluminensis) are also thought to provide habitat for lizards, and one study found that garden untidiness correlates with skink occurrence, indicating that lizard gardening does not require intensive management (van Heezik \& Ludwig 2012).

Another burgeoning backyard initiative in New Zealand is community pest trapping where community groups in residential suburbs receive funding to buy or build traps for pest mammals, which are distributed by group members around their properties (Predator Free New Zealand Trust 2018). In Wellington, 27 suburbs have their own group, with up to 5526 traps deployed across the city (Predator Free Wellington 2018). Due to the large contribution of domestic gardens to the urban green space, such initiatives in backyards could have significant benefits for wildlife populations (González-García \& Sal 2008; Goddard et al. 2010). One limitation of privately-owned gardens, however, is that unlike public spaces the maintenance of habitat is at the discretion of the current owner and there is always a risk of garden destruction when ownership changes. One way to ensure greater longevity might be to encourage the use of covenants, currently used on natural areas on privately-owned land (Cocklin \& Doorman 1994), on small residential sites.

Other informal green spaces such as planted strips alongside roads and around the perimeter of playing fields currently provide habitat for lizards in cities (Melzer \& Bell 2014; Chapter 3) and modifying these to make them more lizard-friendly might increase 
the available habitable space in cities. Modifications could involve predator control, increasing cover using rocks or plantings, altering maintenance regimes, and halting the use of glyphosate sprays (Carpenter et al. 2016; Weir et al. 2016). Additionally, novel structures such as green roofs have been found to support invertebrate communities and may also provide habitat for skinks (Davies 2004; Francis \& Lorimer 2011). Green walls too, planted with epiphytes, might provide much needed vertical green space for arboreal lizards (Francis 2011). As well as providing habitat, these small patches of green space may serve to connect isolated populations that have become fragmented as a result of urban infrastructure.

\subsubsection{Future research and challenges}

One of the biggest challenges for managing native lizards in cities is the lack of knowledge about the current state of populations. This review highlights the dearth of information about lizards living in urban environments in New Zealand. Future research is needed to create a baseline to assess lizard population trends in cities, and assess the value of different kinds of urban habitats for supporting lizard populations. In the highly heterogeneous environments of cities, where populations are likely fragmented and suitable habitat is patchy, citizen science might be a useful tool for gathering distribution data. Citizen science projects, such as the Great Kererū Count and BioBlitzes, have been very successful in raising awareness and growing knowledge for biodiversity among the urban populace (Peters 2016). While not a substitute for more rigorous ecological surveys, citizen science could provide an efficient way to identify locations for more intensive lizard research, and offers the additional benefit of encouraging public engagement.

Greater knowledge about urban lizard populations would also enable greater protection. Under the New Zealand Wildlife Act (1953) and Resource Management Act (RMA, 1991) all urban development projects must consider effects on native wildlife and the environment. However, consideration of the impacts on lizards prior to development is highly variable and with limited knowledge about where populations exist and the difficulties of predicting the presence of lizard populations based on habitat, development often commences under the assumption that lizards are not present (pers. comm. Lynn Adams, DOC, 2019). 
Research that builds knowledge about where populations exist, the effects of development on populations (including implications for population genetics), and the effectiveness of the current application of the Wildlife Act and RMA, is needed to inform best-practice management of wildlife during urban development.

Predator control and eradication strategies currently proposed may have unintended consequences for the conservation of some native species, particularly if some introduced species are targeted and not others (Zavaleta et al. 2001; Ruscoe et al. 2011; Norbury 2017). For lizards, the threats of prey switching (e.g., by domestic cats), competitive release (e.g., hedgehogs) and meso-predator release of mammals not targeted by control (e.g., mice) loom large. More research is needed into the relative effects of different exotic and native predators of lizards in New Zealand ecosystems to provide knowledge about how changes in their abundance or behaviour may affect lizard populations. Where members of the public are involved in predator control, their values for and perceptions of different types of wildlife are very important. People's reluctance to confine cats or trap hedgehogs, for instance, mean that even when the effect of these predators is understood, management of such animals will still face challenges. To this end, research into the values that urban citizens have for different aspects of urban wildlife could also be beneficial.

Human dimensions such as these are always important to consider in biodiversity conservation, and for New Zealand's reptiles these dimensions provide unique challenges. New Zealand lizards are of high value to overseas collectors and are therefore at risk of poaching for illegal wildlife trade. Species of the Naultinus genus in particular are common targets and have been seen advertised for sale on the websites of northern hemisphere collectors (Hitchmough et al. 2016b). For this reason, it is critical to balance the needs of advocacy for the group against the security of targeted populations.

\subsubsection{Conclusions}

Native lizards are an important component of New Zealand's urban biodiversity. Despite the six major cities in this review having lost significant proportions of their original lizard fauna, a wide variety of habitats in cities still support numerous species. The current climate of urban restoration and promotion of biophilic cities in New Zealand promises to improve the prospects of wildlife in cities. Building knowledge about lizards in urban habitats and the challenges they face will ensure that this group benefits from 
such changes. In future, cities may offer opportunities to conserve a larger proportion of endemic species by reintroducing species that have become regionally extinct. Additional to direct conservation benefits to species, supporting urban lizards provides an opportunity to engage the public, especially through some of the large, charismatic species that are native to many of the cities' regions. 
38 - Chapter 2: Past present and potential urban lizard faunas 


\section{Chapter 3}

\section{Establishing population baselines for skinks in New Zealand cities}

\subsection{Introduction}

\subsubsection{Urban nature}

The effects of human activities on ecosystems are wide-reaching, long-lasting and seldom more intense than in cities where the majority of the world's population now lives (United Nations 2014). Landscape-scale changes inherent to urbanisation dramatically decrease the proportion and connectivity of vegetated land cover, substantially reducing the availability of resources for wildlife (Valiela \& Martinetto 2007; Grimm et al. 2008; Dupras \& Alam 2015). Additionally, wildlife face challenges of ongoing anthropogenic disturbance (e.g., traffic, development etc.), and exotic competitors and predators (McKinney 2006). These urban processes tend to have strong negative effects on native biodiversity (McKinney 2006), and in the United States, urbanisation has been identified as one of the leading causes of species extinction (Czech et al. 2000).

However, while there is consensus that urbanisation generally has a pronounced effect on wildlife, how patterns vary among taxa and the mechanisms of responses are 
less well understood (McKinney 2008; French et al. 2018). Possible responses to the challenges of urban living include altered population size or range, behavioural change, altered fitness, and extirpation (McDonnell \& Hahs 2013; French et al. 2018). Knowledge of how urbanisation impacts populations could be crucial for identifying and mitigating threats to species and maintaining biodiversity in urban environments (French et al. 2018).

Globally, reptile populations are in decline and one contributing factor is land cover change resulting from urbanisation (Todd et al. 2010). However, to date there has been little research into reptile responses to urbanisation compared with that of birds and mammals (Magle et al. 2012). What little research has been undertaken shows that the size and direction of effects can vary widely, from neutral or even positive, to negative (French et al. 2018). This variation in responses may be due to the highly variable nature of cities, with differing levels of disturbance and high rates of heterogeneity particularly at moderate levels of urbanisation. In Tucson, Arizona, while reptile abundance and diversity was found to generally decrease across a rural to urban gradient, it peaked with a moderate level of residential housing density (Germaine \& Wakeling 2001). Similar patterns have been observed in a number of other taxa where it has been suggested they result from the wide range of land uses that take place in the transition zone between a city's centre and outskirts (McKinney 2006, 2008). However, it is also inevitable that some species may be better adapted to cope with the challenges of urban life than others so called urban adapters (McKinney 2002; Kark et al. 2007). The eastern blue-tongued skink (Tiliqua scincoides) is an example of one such species, commonly found in suburban Sydney, Australia. This species has likely been successful in these habitats because it exhibits strong site fidelity, readily makes use of artificial refuges and has relatively $r$-selected reproductive traits (i.e., early maturation and large litters; Koenig et al. 2001).

\subsubsection{Lizards in New Zealand cities}

In New Zealand, where ecosystems evolved in the absence of nearly all terrestrial mammals, threats to native reptiles in cities may differ from those internationally. Like other modified landscapes on the mainland (either of New Zealand's two largest islands), New Zealand's cities retain only a fraction of the species diversity likely found in their regions before human colonisation (Chapter 2; Woolley et al. 2019). Although the 
declines of now extirpated species were not documented, patterns of species loss in cities appear similar to those across much of the New Zealand mainland and likely resulted from similar threats: anthropogenic habitat loss and the introduction of mammalian predators (Tingley et al. 2013; Woolley et al. 2019). While some of the most vulnerable species are likely to have already been lost, around two thirds of the species currently found in cities are classified as 'Declining' or 'Relict' according to the New Zealand Threat Classification System (Hitchmough et al. 2016a) and cities present several unique challenges that may pose threats to species' ongoing persistence (Chapter 2; Woolley et al. 2019). Free-roaming domestic cats (Felis catus), often present in high densities (>200 individuals $\mathrm{km}^{-2}$; van Heezik et al. 2010), are difficult to manage in cities and are known to consume large numbers of lizards (Daugherty \& Towns 1991; van Heezik et al. 2010). Other predators, such as rodents and mustelids have altered behaviour and ecology in cities relative to rural environments (Feng \& Himsworth 2014; Balls 2019). Processes of urban development and sprawl are ongoing in cities, disturbing and at least temporarily reducing valuable habitat. Although endemic lizards are protected by New Zealand law (Wildlife Act 1953, Resource Management Act 1991), development does not always consider them and when it does, the outcomes from mitigation tools, such as translocations, are uncertain (Germano et al. 2015; Romijn \& Hartley 2016; Lennon 2019) Additionally, the highly heterogeneous nature of urban landscapes means that suitable habitat for lizards is often small and discontinuous, with populations fragmented by roads, buildings or unsuitable habitat (McKinney 2002; Krawiec et al. 2015).

In spite of these challenges, cities do offer opportunities for lizards. Green spaces such as parks and urban bush reserves are a mainstay for biodiversity in cities. Recent surveys have identified a number of lizard populations in parks and reserves across Wellington City (Melzer \& Bell 2014; Bell 2019). In addition to reserves, cities also offer valuable habitat in the form of backyards and 'informal green spaces', such as the edges of transport infrastructure or urban parks. Although the value of these areas for biodiversity has not been well studied (Rupprecht et al. 2015b), some of the only published research about lizards in New Zealand cities comes from these habitats. Southern grass skinks (Oligosoma aff. polychroma Clade 5) in Dunedin were found to be present in suburban residential gardens, especially on the edges of the city (van Heezik \& Ludwig 2012) and in Wellington, published studies investigated urban populations of Oligosoma polychroma in a cemetery in Kelburn (Barwick 1959) and Oligosoma aeneum in a suburban backyard in Lower Hutt (Bell et al. 2018). 
However, in general, little effort has been invested into understanding what lizard species are present in cities, where they occur and how populations are faring (Chapter 2; Woolley et al. 2019). Very few biodiversity surveys for lizards have taken place in cities (but see Melzer \& Bell 2014; Bell 2019), and the majority of information on species occurrence is anecdotal, often coming from salvage and biosecurity operations. With little information about the current state of lizard populations in cities, there is currently no way to assess population trends that would enable the identification of declines.

\subsubsection{Aims}

In order to conserve existing populations of lizards in New Zealand cities, robust baseline data of their distribution and abundance are needed. Understanding how population characteristics relate to different urban environments may serve to inform biodiversity management and facilitate the restoration of populations. In this chapter, I aim to build on the currently sparse data on the status of skink populations in four New Zealand cities, characterising populations and assessing their relationship with environmental covariates. Specifically, I will address the following questions: 1) what species diversity and abundance do urban habitats support?,2) what are the phenotypic characteristics of urban-dwelling skink populations?, and 3) how do skink population characteristics relate to pest mammal abundance, habitat types and degree of urbanisation?

\subsection{Methods}

\subsubsection{Study sites}

Twelve study sites were selected within the urban core (defined in Chapter 2) of each of four New Zealand cities: Hamilton, Wellington, Nelson and Dunedin ( $\mathrm{n}=47$ in total, as one Dunedin backyard was withdrawn from the study; Fig. 1). To ensure sites were representative of the diversity of habitats available in urban environments, in each city the sites were evenly divided among three strata: bush reserve, amenity and backyard. Within strata, site characteristics differed widely, however, strata did have certain internal similarities and defining features. Reserves comprised areas of remnant or replanted native vegetation that were often actively managed and valued as 'green spaces' (Fig. 2a). Amenity areas were less densely vegetated and usually comprised more grassland or scrubland. These areas were often found at the margins of sports fields or transport infrastructure (Fig. 2b). Backyards consisted of privately-owned suburban gardens and 
were recruited by door-knocking. Environments presented by backyards were highly variable: lawns and cultivated exotic species were common components, though many had native plantings. The degree of management ranged from untidy (Fig. 2c) to highly maintained (Fig. 2d). 


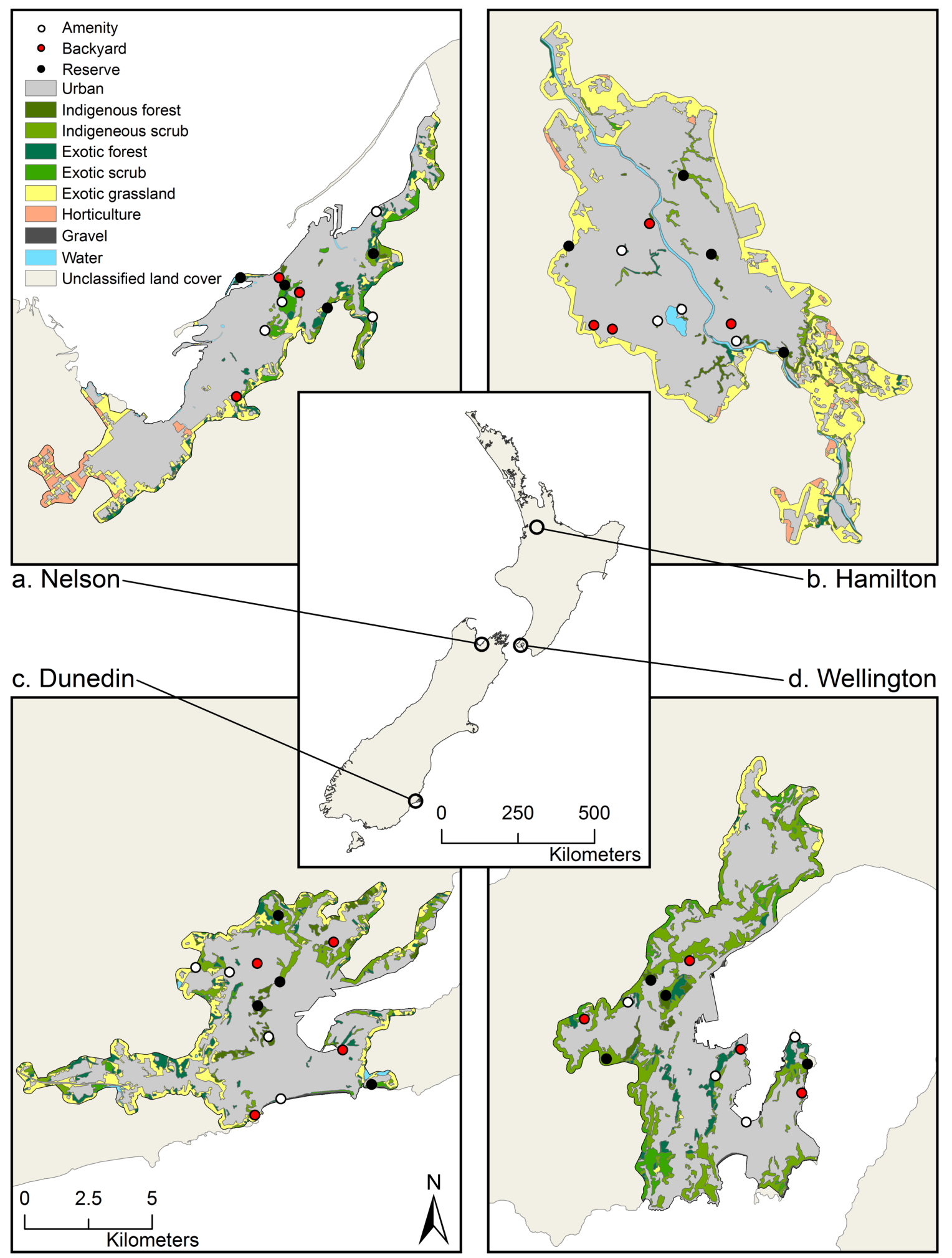

Figure 1 Map of study sites. a. Nelson $(n=12)$, b. Hamilton $(n=12)$, c. Dunedin $(n=11)$, d. Wellington $(n=12)$. Land cover types and urban core defined using the methods described in Chapter 2 (Woolley et al. 2019) using data from LCDB v4.1 (LINZ 2015) 


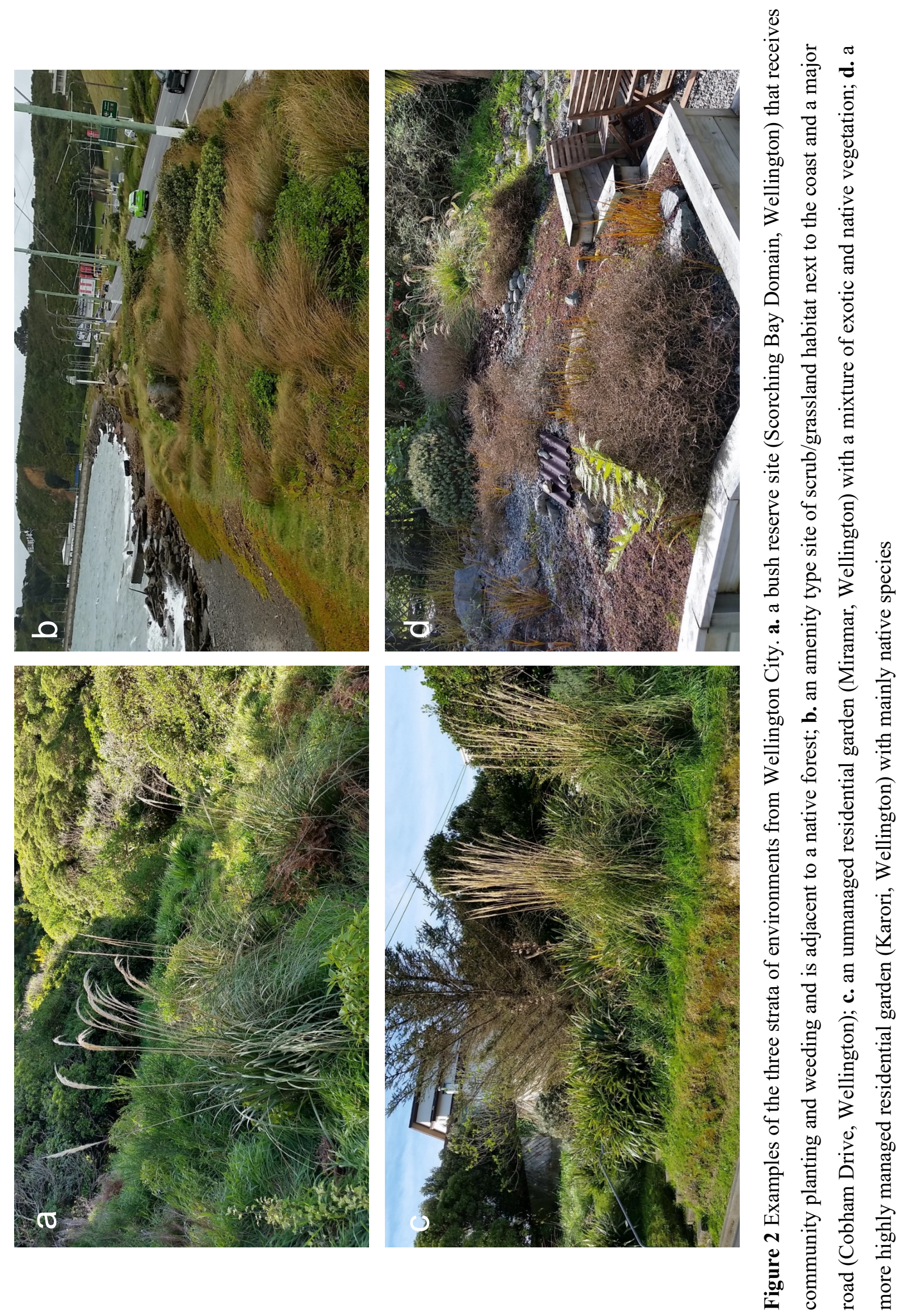




\subsubsection{Skink surveys}

Pitfall trapping was used to sample skinks at each site as all skink species known to be present in cities are terrestrial and thus are able to be captured in ground-based traps. This technique is less effective for geckos which are able to climb out of traps. In reserves and amenity areas, trapping grids consisted of 25 traps in a five by five arrangement with $2 \mathrm{~m}$ spacing as recommended by other studies (Lettink et al. 2011; Wilson et al. 2017). In backyards, either 6- or 10-trap grids were used depending on the availability of space. These were installed either in two by three or two by five arrangements comparable with the other grids or, where space did not allow, were distributed around the garden at distances greater than $2 \mathrm{~m}$. Traps were $4 \mathrm{~L}$ plastic buckets dug into the ground so that their openings were flush with the substrate with a lid pegged $10-20 \mathrm{~mm}$ above to provide shade. Traps had $6-8$ holes (approx. $4 \mathrm{~mm}$ in diameter) drilled in their underside to allow water drainage, and contained a layer of soil and foliage (approx. 30 $\mathrm{mm}$ deep) to provide cover, a moistened sponge (40 $\mathrm{mm} \times 60 \mathrm{~mm} \times 10 \mathrm{~mm})$ to prevent dehydration and a square of wire mesh $\left(100 \mathrm{~mm}^{2}\right.$ with $\sim 10 \mathrm{~mm}$ mesh) curved over the floor of the trap to help prevent predation by rodents (Hare 2012a). Traps were baited with canned pear (approx. $2 \mathrm{~cm}^{3}$ ) and checked daily while open for periods of between seven and ten days. Two trapping sessions (early summer, November - December and late summer, February - March) took place in 2017/18 and 2018/19 (four sessions in total). In Wellington, trapping took place during all four sessions, while in Hamilton, Nelson and Dunedin only three were used (see S1 for details of trapping effort). Captured animals were identified to species level, weighed and measured (snout-vent length, total length, length of tail regeneration). In Wellington and Nelson, skinks were made individually identifiable by clipping one toe on each foot (natural toe loss was incorporated into combinations). Tail loss and natural toe loss were recorded, and pregnant females were determined visually by the shape of their abdomen. These methods were carried out in accordance with approval from the Department of Conservation (DOC) (50568-FAU) and the Victoria University of Wellington Animal Ethics Committee (AEC 27041).

\subsubsection{Habitat- and landscape-scale covariates}

A number of covariates were collected to characterise the study sites, both at the scale of the local habitat and the wider landscape. I used a convex densiometer (Model A, Forest 
Suppliers) to measure summer canopy cover at each site by recording the proportion of mirrored squares where the sky was obscured by foliage. Measurements were taken at heights of $1.2 \mathrm{~m}$ at the four cardinal compass points at each corner of the 25-trap grids or either end of the smaller backyard grids. Measurements from the cardinal points were averaged to calculate a mean canopy cover for the site. Proportion of grass cover within pitfall grids was estimated visually on a $1-5$ scale $(1=0-19 \%, 2=20-39 \%, 3=40-$ $59 \%, 4=60-79 \%, 5=80-100 \%)$.

Hourly temperature at the substrate level was recorded at each site using iButton data loggers (DS1921G-F5\#, Maxim Integrated) covered in $400 \mathrm{~mm}^{2}$ squares of parafilm (one square was enough to cover an iButton in two layers of parafilm) to increase weather resistance. Two data loggers were deployed at each site $(n=94)$ between November and December 2018 and were collected between January and February 2019. This provided a period of 34 days when all loggers were in the field at the same time (19/12/18 - 21/1/19). Data loggers were tethered to traps at opposite corners of the grid using nylon monofilament at distances of $200 \mathrm{~mm}$ and oriented north. They were nestled into substrate (i.e. amongst soil, vegetation or leaf litter) to simulate realistic locations of skinks and to avoid them being in direct sunlight.

I used a GIS to calculate the proportion of urban land cover within a $500 \mathrm{~m}$ radius of each site. I clipped the Land cover Database (LCDB v.4.1, https://lris. scinfo.org.nz/ layer/48423-lcdb-v41-land-cover-database-version-41- mainland-new-zealand/, accessed: 12/3/19) within $500 \mathrm{~m}$ radii of each of the site locations using the buffer and clip tools in Arcmap v.10.5.1 (ESRI 2017). The resulting polygons were exported into their own layer and the dissolve tool was used to calculate single values for the proportional area of each land cover type. Urban cover consisted of 'Built-up Area (settlement)', 'Urban Parkland/Open Space' and 'Transport Infrastructure'.

\subsubsection{Pest mammal surveys}

Concurrent with lizard surveys, pest mammal surveys took place in each of the cities. In Hamilton, Wellington and Dunedin this was carried out as part of an aligned research project investigating pest mammal densities in New Zealand cities during spring (late October - early December) 2017 and 2018, and autumn (late May - June) 2018 and 2019. I used a subset of these data focussing on three key predators of lizards: rats (Rattus rattus, $R$. norvegicus), mice (Mus musculus), and European hedgehogs (Erinaceus 
europaeus) during spring. I matched this project's methods, installing monitoring gear at the eight public sites in Nelson in early December 2018. At each site, a line of ten stations of monitoring equipment at approximately $50 \mathrm{~m}$ spacings was deployed similar to the standard mammal monitoring protocol for forests (Gillies \& Williams 2013). Each station consisted of a plastic chew card pre-baited with an aniseed-based possum dough (traps.co.nz) and a plastic tracking tunnel (Black Trakka, NZ) with pre-inked card (Gotchatraps, NZ). Chew cards were folded and nailed to a tree or other suitable object approximately $300 \mathrm{~mm}$ from the ground. Tracking tunnels were pegged into the ground 2 $-5 \mathrm{~m}$ from the chew card and baited at either end of the card with rabbit paste (Erayz). Both tracking tunnels and chew cards were deployed for six nights. To make the mammal indices more relevant to the immediate area of the trapping grid, only the 5 closest stations were used in analyses. The maximum distance between any grid of pitfall traps and its furthest mammal station was around $200 \mathrm{~m}$. As tracking tunnel and chew card indices were correlated for the three mammal types (rats, $r=0.63, p<0.001$; mice, $r=$ $0.35, \mathrm{p}<0.044$; and hedgehogs, $\mathrm{r}=0.37 \mathrm{p}=0.032$ ), only the tracking tunnel indices were used in analyses as these were most sensitive to the targeted species (especially hedgehogs, Balls 2019).

\subsubsection{Statistical analyses}

Site characteristics (Table 1) were compared using one-way anova and where significant effects were found, pairwise comparisons were made using Tukey's HSD post-hoc tests.

For each site, an index of abundance for each skink species was made by calculating catch per unit effort (CPUE; number of skinks captured per 100 trap days). At sites where $O$. polychroma occurred, I estimated population density of this species during three trapping sessions using spatially explicit capture-recapture (SECR) models (Efford \& Fewster 2013). Populations were assumed to be closed for the duration of each session. Using the 'secr' package v. 3.2.0 (Efford 2019) in R v. 3.5.1 (R Core Team 2018), I fitted spatial detection models to the capture data using half-normal functions by maximising full likelihood. SECR uses mark-recapture data to estimate density along with two spatial detection parameters: $g_{0}$, the probability of capture at a trap located at the centre of an animal's home range, and $\sigma$, the width of the half-normal detection function. Skink home range centres were assumed to be distributed according to a Poisson point process, whose density parameter was estimated from the capture data. For each trapping session, model 
selection was used to compare models with different covariates for the capture probability $\left(g_{0}\right)$ term. $g_{0}$ was either constant (i.e., the null model) or a function of time (sampling day) and/or one of four behavioural responses: $b, b k, B, B k$; where $b$ is a permanent behavioural response to capture (either trap-happiness or trap-shyness), $b k$ is a permanent behavioural response to capture in relation to a particular trap (i.e., trap-specific), $B$ is a transient response of trap-happiness or -shyness only if it had been captured on the previous capture occasion, and $B k$ is transient, trap-specific response (Efford 2019). This provided 10 candidate models for each trapping session. For all models, density was modelled as a function of site and $\sigma$ was fitted as a constant. Models were compared using Akaike's Information Criterion adjusted for small sample sizes $\left(\mathrm{AIC}_{\mathrm{c}}\right)$ and took density estimates either from the best supported model (where the second best model had a $\Delta \mathrm{AIC}_{\mathrm{c}}>2$ ) or those of the average model found using model averaging of all models where $\Delta \mathrm{AIC}_{\mathrm{c}} \leq 2$.

Phenotypic characteristics including mass, snout-vent length (SVL), vent-tail length (VTL; total length - SVL), length of tail regeneration and body condition were collated and mean values compared between cities using t-tests (no species was found in more than two cities). A body condition index (BCI) was calculated using the ratio of $\log _{10}$-transformed mass to $\log _{10}$-transformed SVL for all non-pregnant individuals of a species (as used in other studies, e.g., Grayson et al. 2014; Batson et al. 2015).

Linear mixed effects models (LMM) were used to assess the effect of different environmental factors on abundance and body condition of $O$. polychroma in Nelson and Wellington. Before running models, predictors were tested for multicollinearity using Spearman's rank correlation analyses and were dropped where correlations were strong. Separate models were run with catch per unit effort and BCI index as dependent variables. Catch per unit effort was $\log _{10}$-transformed to meet the assumptions of the model (normally distributed residuals, homogeneity of variance). Canopy cover, grass cover, mammal tracking indices (rat, hedgehog and mouse), substrate temperature and proportion of urban cover within $500 \mathrm{~m}$ of the sites were fixed effects, and site nested within city and session were random effects (Table 1). Interactions between grass cover and the three mammal tracking indices were tested but were removed from the model if non-significant. 
Table 1 Summary of the variables used in linear mixed effects models

\begin{tabular}{|c|c|}
\hline Variable & Description \\
\hline \multicolumn{2}{|l|}{ Dependent } \\
\hline Skink abundance & Catch per unit effort (CPUE) of $O$. polychroma \\
\hline Average body condition & $\begin{array}{l}\text { Mean BCI }\left[\log _{10}(\text { mass }) / \log _{10}(\mathrm{SVL})\right] \text { of non-pregnant } \\
\text { adult individuals }\end{array}$ \\
\hline \multicolumn{2}{|l|}{ Independent } \\
\hline Canopy cover & $\begin{array}{l}\text { Average proportion canopy cover recorded at four } \\
\text { locations per grid using a convex densiometer }\end{array}$ \\
\hline Grass cover & $\begin{array}{l}\text { Estimated proportion of grass cover on grid recorded on } \\
\text { 5-point scale. } 1=0-19 \%, 2=20-39 \%, 3=40-59 \% \text {, } \\
4=60-79 \%, 5=80-100 \%\end{array}$ \\
\hline Urban cover & $\begin{array}{l}\text { Proportion of 'built up area' and 'transport } \\
\text { infrastructure' within a } 500 \mathrm{~m} \text { radius of site (data from } \\
\text { LCDB v. } 4.1 \text { (LINZ 2015)) }\end{array}$ \\
\hline Substrate temperature & $\begin{array}{l}\text { Mean hourly temperature averaged between two iButton } \\
\text { data loggers deployed at substrate level }\end{array}$ \\
\hline Mammal tracking indices & Rat, hedgehog and mouse tracking rates \\
\hline City & $\begin{array}{l}\text { The city in which sampling took place }(n=2 \text {, random } \\
\text { effect) }\end{array}$ \\
\hline Site & $\begin{array}{l}\text { The site at which sampling took place }(n=47 \text {, random } \\
\text { effect) }\end{array}$ \\
\hline Session & $\begin{array}{l}\text { The session during which sampling took place }(n=24 \text {, } \\
\text { random effect) }\end{array}$ \\
\hline
\end{tabular}




\subsection{Results}

\subsubsection{Site variation}

The study sites varied substantially in their environmental characteristics within and among the cities and habitat types. The average substrate temperature during the 34-day period ranged from $24.6^{\circ} \mathrm{C}$ at the backyard in Stoke, Nelson to $12.9^{\circ} \mathrm{C}$ at Frasers Gully in Dunedin. Temperature was significantly lower at sites in Dunedin compared with all other cities $\left(\mathrm{F}_{3,43}=43.35, \mathrm{p}<0.001\right)$ and sites in Nelson were warmer than those in Wellington ( $\mathrm{p}<0.001$; Fig. 3a). Proportion canopy cover also differed between cities $\left(F_{3,43}=9.833, p<0.001\right)$, with sites in Dunedin having more canopy cover than Nelson and Wellington $(\mathrm{p}<0.001$; Fig. $3 \mathrm{~b})$. Higher rat tracking indices were recorded at sites in Hamilton than all other cities $\left(F_{3,37}=7.514\right.$; Dunedin and Nelson $p<0.001$, Wellington $p$ $<0.05$; Fig. 3e). Hedgehog tracking rates also varied significantly between cities with higher rates detected in Dunedin compared with Hamilton and Wellington $(\mathrm{p}<0.001)$, and Nelson compared with Hamilton and Wellington ( $p<0.05$; Fig. 3f). No differences were detected between cities in terms of proportion grass cover, proportion urban land cover or mouse tracking rates (Fig. 3c, $\mathrm{d}$ and g).

The proportion of urban land cover did differ among the three site types $\left(\mathrm{F}_{2,40}=\right.$ $6.18, \mathrm{p}<0.01)$. Sites in residential backyards on average had $76 \%$ more urban cover within a $500 \mathrm{~m}$ radius compared with bush reserve sites. No other variables differed significantly among site types. 

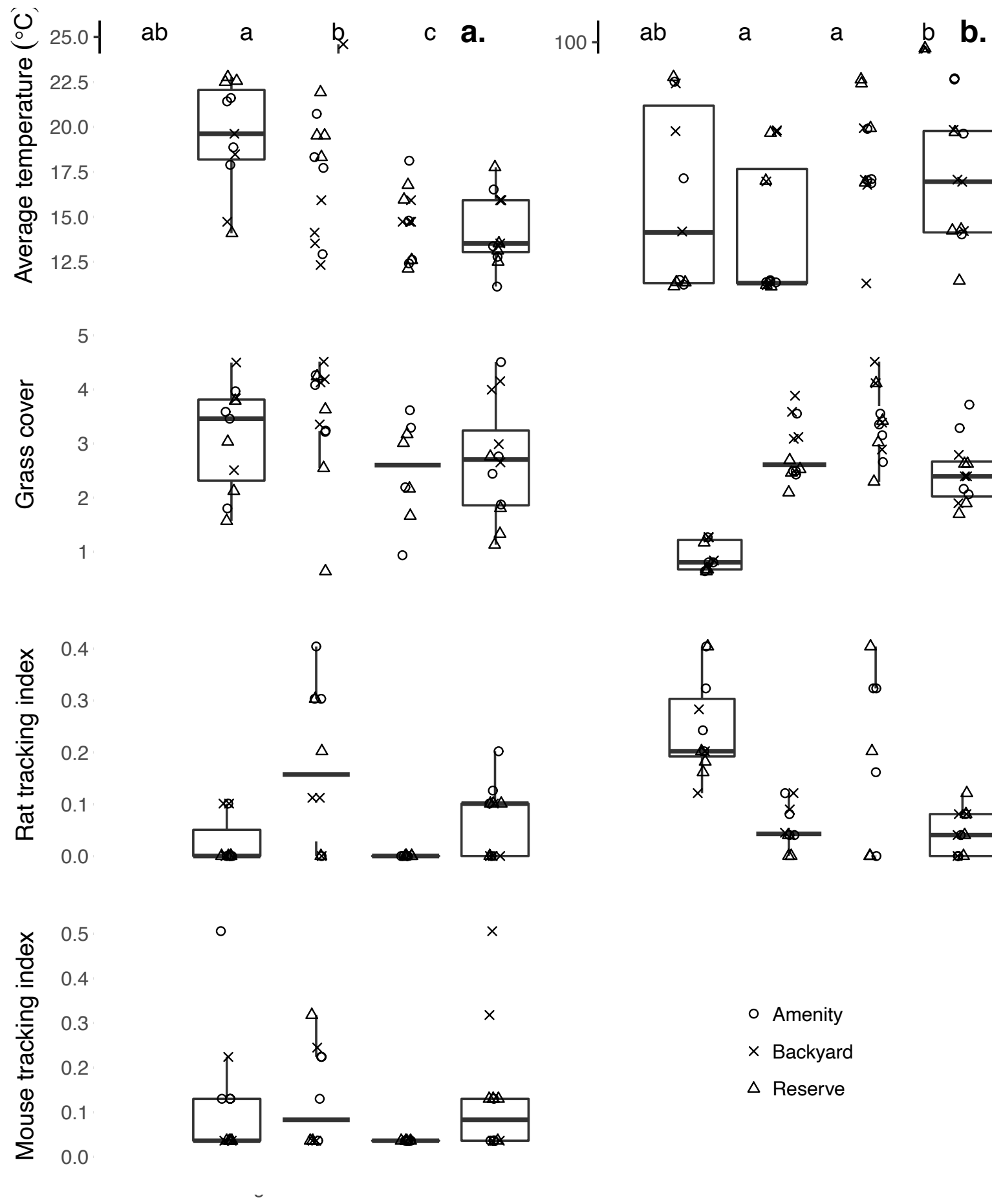
○ Amenity
$\times$ Backyard
$\Delta$ Reserve

Figure 3 Environmental covariates: a. average substrate temperature; b. percentage canopy cover; c. grass cover; d. percentage urban cover; e. rat tracking rate; f. hedgehog tracking rat; g. mouse tracking rates; at study sites in the four cities. Shapes indicate site habitat type: circles = amenity, crosses $=$ backyard, triangles $=$ bush reserve. Points are jittered horizontally to improve clarity. Non-identitical letters above boxplots indicate significant differences $(\mathrm{p}<0.05)$ 


\subsubsection{Skink species diversity and abundance in the four cities}

Inability to access some sites during some seasons and anthropogenic disturbance of traps caused variation in the trapping effort, both among sites within cities and among seasons (S1).

Across the four cities, five species of skinks were captured (four endemic and one introduced), though species diversity in each city varied considerably (Table 2). Only one endemic species, Oligosoma aeneum, was detected in Hamilton over the course of the three survey periods. This was found at four of the twelve sites (33.3\%). Additionally, the introduced skink species, Lampropholis delicata, was caught at two of the sites (16.7\%). Three endemic species were captured across the twelve Wellington sites: O. polychroma at ten sites $(83.3 \%), O$. aeneum at three sites $(25 \%)$ and $O$. ornatum at one site $(8.3 \%)$. In Nelson, the only species captured was $O$. polychroma, but animals were captured at all of the twelve sites. In Dunedin, the only species captured was $O$. aff. polychroma Clade 5. This species was captured at two sites (18.2\%).

Catch per unit effort of the four endemic species varied considerably both by city and by site. The largest CPUE of any species was of $O$. polychroma in Nelson and Wellington. In Nelson, mean CPUE ( \pm standard error of mean; SEM) was $6.47 \pm 2.19$ captures per 100 trap days, ranging from 0.17 to 28.00 (Fig. 4a). In Wellington, similarly high CPUEs were recorded at some sites $(3.56 \pm 1.2$, range $=0.00-15.25)$. In Dunedin, CPUE of $O$. aff. polychroma Clade 5 at the coastal site at Ocean Grove (4.32 captures per 100 trap days) was comparable with those of $O$. polychroma in Wellington and Nelson (Fig. 4a). However, only one other individual was captured at another site (Ellis Park). In Wellington, mean CPUE of O. aeneum was $0.92 \pm 0.74$ captures per 100 trap days ranging from 0.00 to 9.03 and in Hamilton mean CPUE of $O$. aeneum was $0.12 \pm 0.08$ $($ range $=0.00-1.04)($ Fig. $4 b)$. 


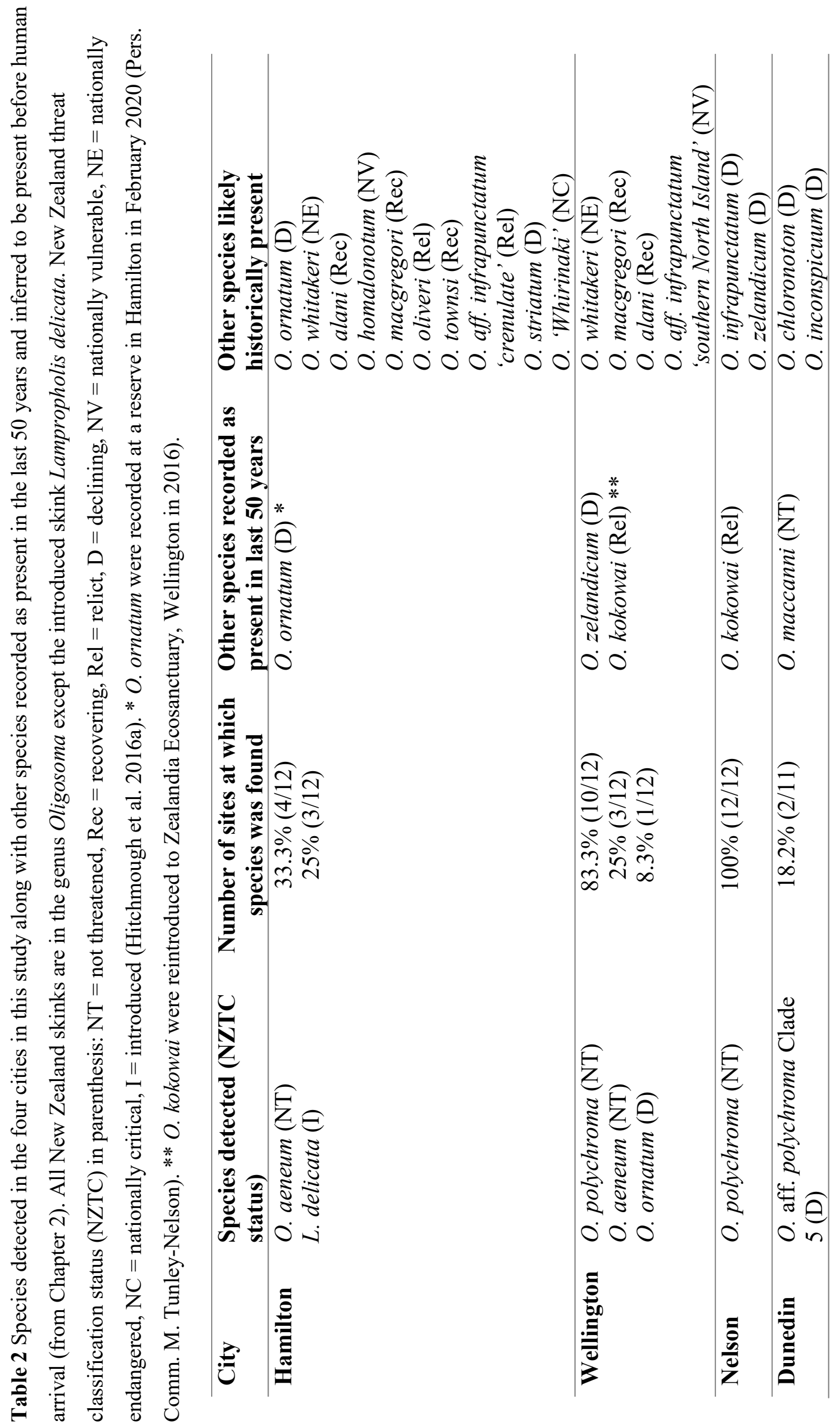

54 - Chapter 3: Population baselines of urban lizards 

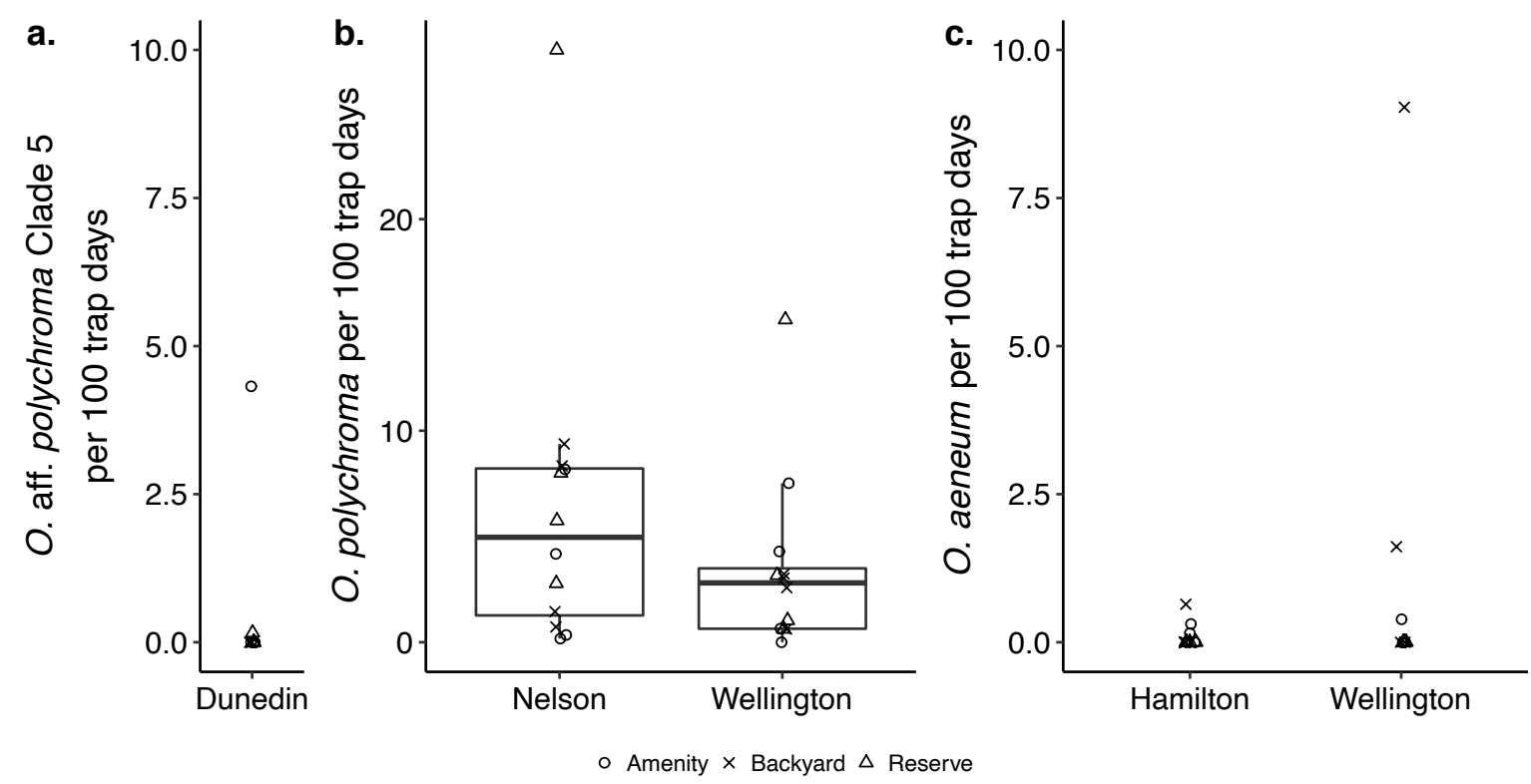

Figure 4 Captures per 100 trap days for a. $O$. aff. polychroma Clade 5 in Dunedin, b. $O$. polychroma in Wellington and Nelson, and c. O. aeneum in Hamilton and Wellington. Points are jittered horizontally for clarity. Box plots only shown where medians and quartiles are not zero. Note different scales of y-axes

Population density in the immediate vicinity of the trapping grid was estimated at sites where more than one O. polychoma was captured within a trapping session. I caught 148 individual $O$. polychroma (180 total captures) across all sites in February 2018, 68 (80 total captures) in November 2018, and 190 (247 total captures) in February 2019. Parameters included in the best supported model varied by trapping session (Table 3 ). Density estimates $( \pm$ SEM) from the best supported SECR models ranged from $71 \pm 97$ per hectare to $2610 \pm 704$ skinks per hectare (Fig. 5). 


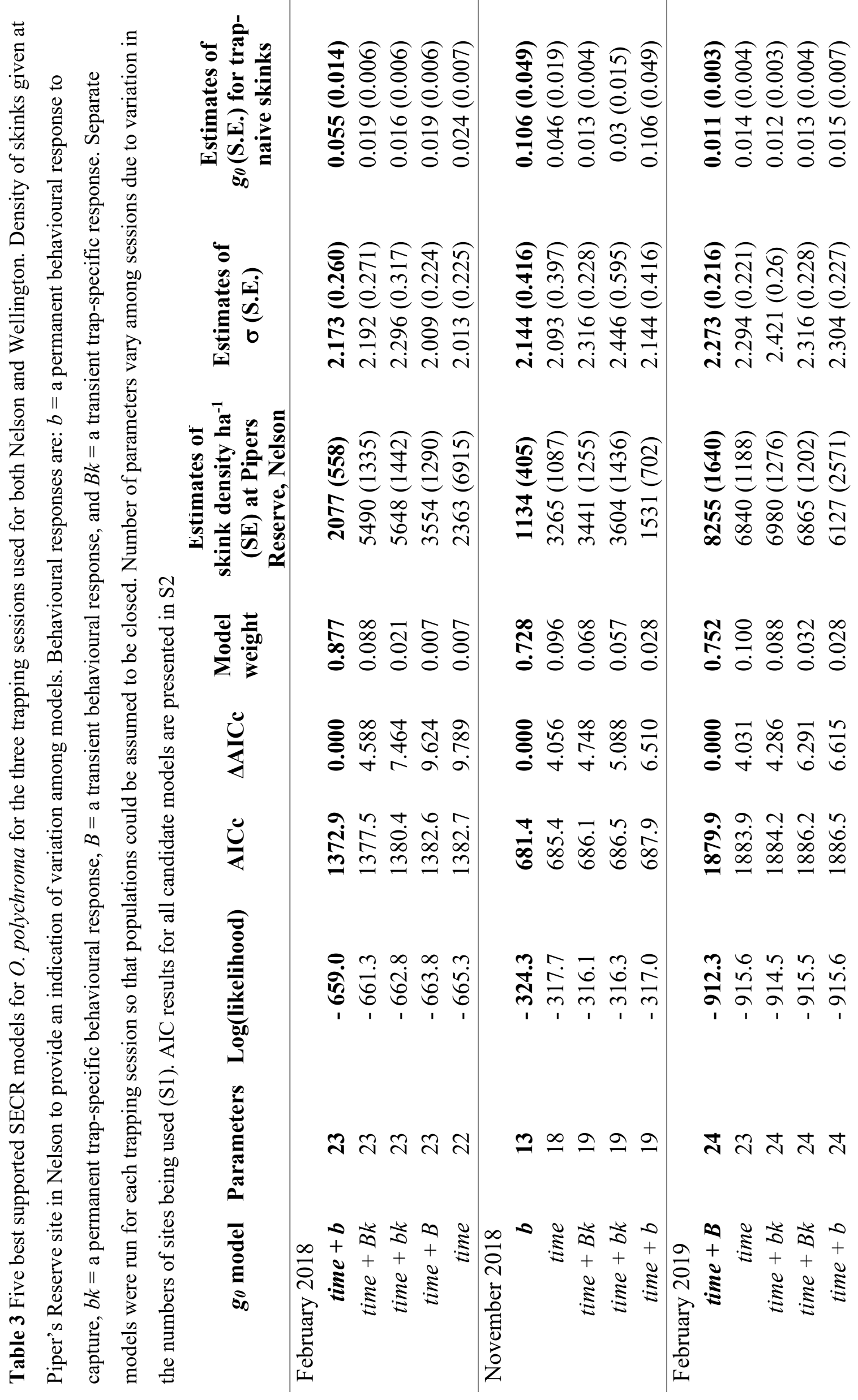

56 - Chapter 3: Population baselines of urban lizards 


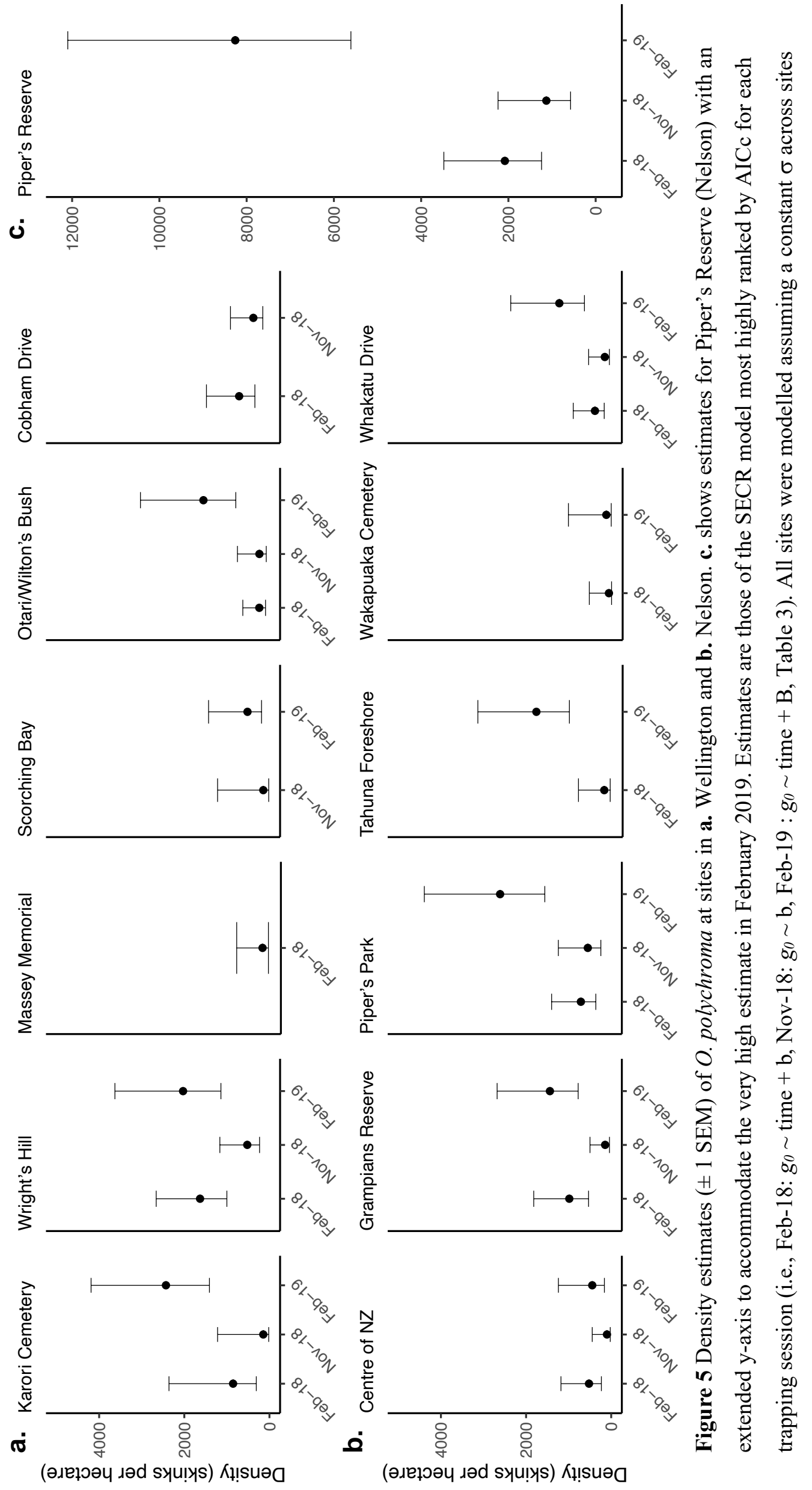




\subsubsection{Phenotypic characteristics of urban populations}

Numbers of captures varied greatly among the different species. Only two O. ornatum were captured, both at the same backyard site in Wellington. The first was caught in February of 2018 and weighed $15 \mathrm{~g}$ with a SVL of $86 \mathrm{~mm}(\mathrm{VTL}=61 \mathrm{~mm}$, tail regeneration $=41 \mathrm{~mm}$ ). The second was caught during the next session in November 2018 and was smaller, weighing $7.5 \mathrm{~g}$ with an SVL of $68 \mathrm{~mm}$ (VTL $=47 \mathrm{~mm}$, tail regeneration $=27 \mathrm{~mm}$ ).

Four O. aeneum were captured in Hamilton compared with twenty-eight in Wellington. Although skinks were not marked in Hamilton, differences in morphometrics and the sites at which they were captured allowed me to be confident that they were different individuals. Mean SVL ( \pm SEM) for adults of this species was $53.67 \pm 3.71 \mathrm{~mm}$ in Hamilton and $54.27 \pm 0.8$ in Wellington. Mean adult body condition was $0.30 \pm 0.04$ in Hamilton and $0.28 \pm 0.01$ in Wellington (Table 4). Morphometrics of $O$. aeneum caught in Hamilton were all within the range of those caught in Wellington and t-tests found no statistical differences in morphometrics between the two cities.

In total, 28 O. aff. polychroma Clade 5 were captured in Dunedin. As skinks were not marked in Dunedin, I was unable to determine if these animals were unique individuals. Mean SVL for $O$. aff. polychroma Clade 5 was $62.25 \pm 1.66$ and mean adult body condition was $0.39 \pm 0.02$ (Table 5).

Catch numbers for $O$. polychroma were much higher, with 200 individuals captured in Wellington and 274 in Nelson. Mean adult SVL for this species was $57.40 \pm$ 0.428 in Nelson and $56.75 \pm 0.31$ in Wellington. Mean adult body condition was $0.33 \pm$ 0.01 in Nelson and $0.33 \pm 0.003$ in Wellington (Table 6). Results from t-tests found no statistical differences in morphometrics between the two cities.

Across all cities in which they were caught, O. aeneum had experienced greater proportions of tail loss than $O$. polychroma $\left(96.8 \% \mathrm{cf} .69 .0 \% ; x^{2}{ }_{1}=9.52, p<0.005\right)$ and O. aff. polychroma Clade 5 (cf. 40.7\% $x^{2}=19.3, p<0.001$ ) (Table 7). Differences in proportions of tail loss for O. polychroma between Wellington and Nelson were nonsignificant $\left(72.2 \%\right.$ cf. $\left.66.7 \%, x^{2}{ }_{1}=1.40, p=0.237\right)$. Tail loss was evident in higher proportions among adults than juveniles in $O$. polychroma $\left(82.1 \%\right.$ cf. $42.3 \% ; x^{2}{ }_{1}=70.38$, $p<0.001$ ) but not in $O$. aeneum or $O$. aff. polychroma Clade 5. For O. polychroma, tail loss was significantly related to SVL $(b=0.107 \pm 0.011, z=10.07, p<0.001)$. A similar 
pattern was observed for $O$. aff. polychroma Clade 5, though this was not significant $(b=$ $0.063 \pm 0.037, z=1.73, p=0.084)$. 


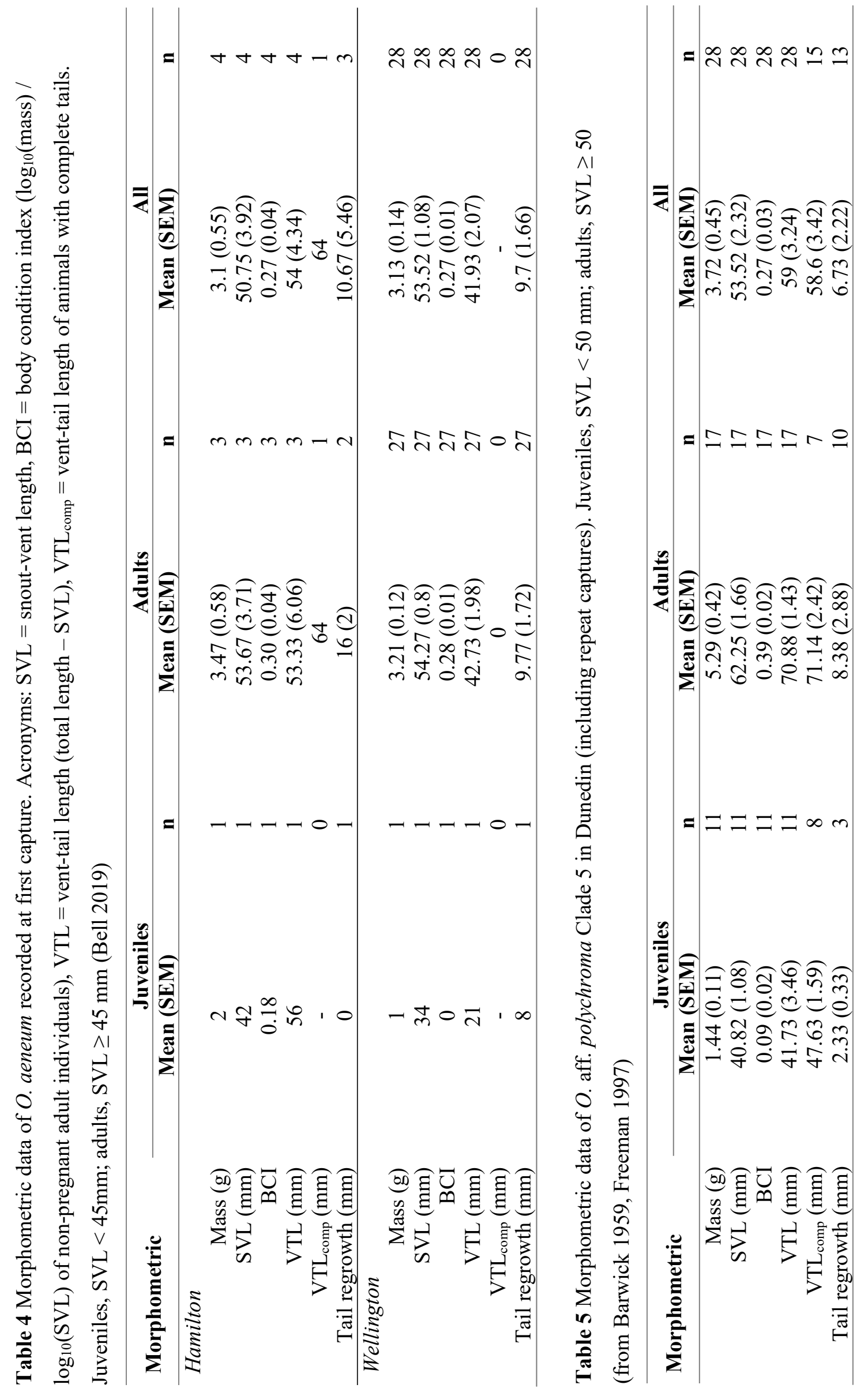




\subsubsection{Effect of environmental factors on Oligosoma polychroma}

Due to the low catch rates for other species, relationships with environmental factors were assessed only for O. polychroma. Spearman's rank correlation analysis found that mouse tracking index was correlated with grass cover $(\mathrm{r}=-0.75, \mathrm{p}<0.001)$, substrate temperature $(\mathrm{r}=-0.47, \mathrm{p}<0.001)$ and rat tracking index $(\mathrm{r}=0.34, \mathrm{p}=0.004 ; \mathrm{S} 3)$. As these relationships were moderate to strong, mouse tracking rate was dropped from the models to prevent multicollinearity. All other correlations were either non-significant or had a correlation coefficient smaller than $|0.3|$ (S3). Linear mixed effects modelling found that rat tracking rate and proportion grass cover were both positively related to $O$. polychroma CPUE, but that these main effects were interactive (positive relationship at low proportions of grass cover, and negative at high; Table 8, Fig. 6a). Proportion of urban cover had a negative relationship with BCI (Table 9, Fig. 6b). No other factors were significant in either model. A summary of CPUE and BCI is available in S4.

Table 8 Results of linear mixed effects models showing relationships between model's fixed effects and catch per unit effort of $O$. polychroma. Catch per unit effort was log transformed $\left(\log _{10}\right)$ to meet the assumptions of normality. Effects with $\mathrm{p}<0.05$ are highlighted in bold

\begin{tabular}{rrrrrr}
\hline & Estimate & S.E. & df & t value & p value \\
\hline Canopy cover & $-8.07 \mathrm{E}-03$ & 0.005 & 12.22 & -1.573 & 0.141 \\
Grass cover & $\mathbf{0 . 2 7 8}$ & $\mathbf{0 . 0 9 5}$ & $\mathbf{1 2 . 0 1}$ & $\mathbf{2 . 9 3 5}$ & $\mathbf{0 . 0 1 2}$ \\
Proportion urban land cover & -0.063 & 0.286 & 12.11 & -0.221 & 0.829 \\
Mean substrate temperature & $5.74 \mathrm{E}-03$ & 0.047 & 12.24 & 0.123 & 0.904 \\
Rat tracking index & $\mathbf{1 3 . 8 0 9}$ & $\mathbf{3 . 7 4 3}$ & $\mathbf{1 1 . 9 3}$ & $\mathbf{3 . 6 8 9}$ & $\mathbf{0 . 0 0 3}$ \\
Hedgehog tracking index & -0.087 & 0.322 & 12.39 & -0.271 & 0.791 \\
Grass cover x rat tracking & $\mathbf{- 4 . 4 3 2}$ & $\mathbf{1 . 1 3 2}$ & $\mathbf{1 1 . 8 7}$ & $\mathbf{- 3 . 9 1 7}$ & $\mathbf{0 . 0 0 2}$ \\
\hline
\end{tabular}

Table 9 Results of linear mixed effects models showing relationships between model's fixed effects and body condition index of $O$. polychroma. Effects with $\mathrm{p}<0.05$ are highlighted in bold

\begin{tabular}{rrrrrr}
\hline & Estimate & S.E. & df & t value & p value \\
\hline Canopy cover & $1.12 \mathrm{E}-04$ & 0.001 & 10.76 & 0.213 & 0.835 \\
Grass cover & $-2.91 \mathrm{E}-03$ & 0.009 & 13.18 & -0.315 & 0.758 \\
Proportion urban land cover & $\mathbf{- 0 . 0 6 3}$ & $\mathbf{0 . 0 2 8}$ & $\mathbf{1 2 . 5 9}$ & $\mathbf{- 2 . 2 8 6}$ & $\mathbf{0 . 0 4 0}$ \\
Mean substrate temperature & $-5.08 \mathrm{E}-03$ & 0.005 & 10.65 & -1.047 & 0.318 \\
Rat tracking index & 0.097 & 0.148 & 13.87 & 0.652 & 0.525 \\
Hedgehog tracking index & -0.253 & 0.127 & 12.18 & -1.989 & 0.070 \\
Grass cover x hedgehog tracking & 0.073 & 0.036 & 12.68 & 2.016 & 0.065 \\
\hline
\end{tabular}




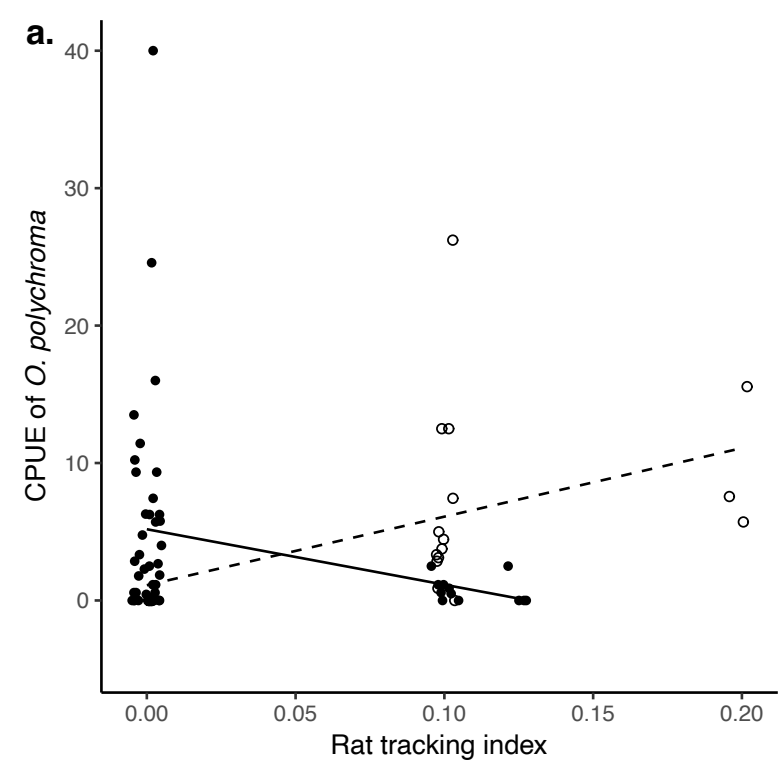

$-\circ<60 \%$ grass cover $\rightarrow \geq 60 \%$ grass cover

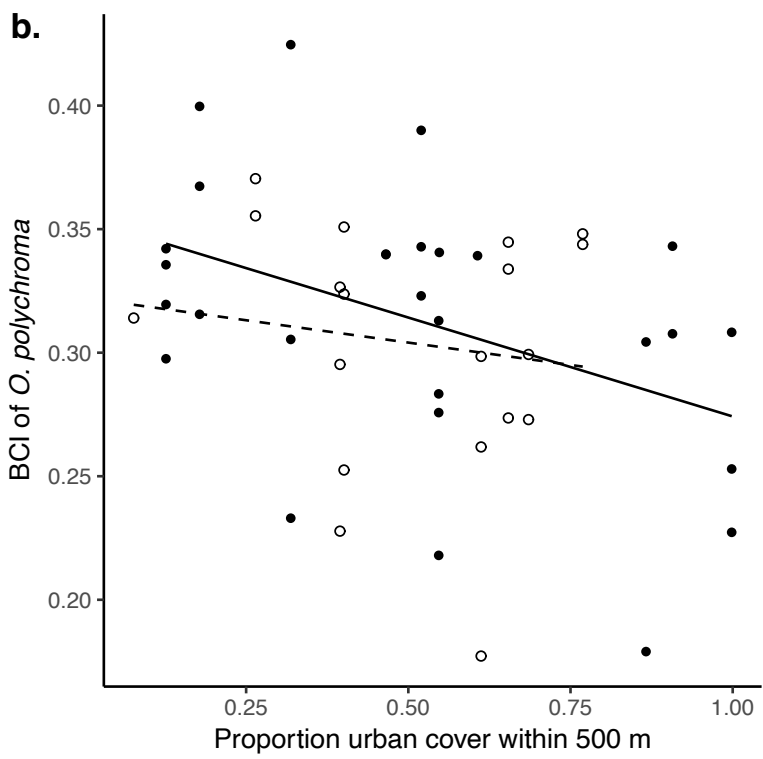

-o- Nelson $\rightarrow$ Wellington

Figure 6 a. Relationship between rat tracking index and catch per unit effort of $O$. polychroma at sites of high and low proportion grass cover b. Body condition of $O$. polychroma declined with increasing proportion of urban cover in both Nelson and Wellington. Points are jittered horizontally for clarity. Trend lines are fitted to raw data points 


\subsection{Discussion}

\subsubsection{Diversity and abundance of skinks in New Zealand cities}

This is the first research to investigate the state of New Zealand's urban lizards in multiple cities. Four species of endemic skink were detected across the study cities: Oligosoma aeneum, O. ornatum, $O$. polychroma and $O$. aff. polychroma Clade 5. Although at least one species was captured in each city, in general, species diversity in the four cities was low relative to the size of the historical fauna and consistent with current knowledge about urban lizard faunas (Chapter 2; Woolley et al. 2019).

Despite the highly altered distributions and loss of many lizard species from New Zealand cities, biogeography still plays an important role in determining patterns of species diversity and abundance among the cities (Chapter 2; Chapple \& Hitchmough 2016). Differences in the characteristics of skink species that make up the historical (prehuman) lizard faunas of regions, mean that regions differ in the number of skinks that are able to survive in urban areas. For example, O. aeneum and $O$. ornatum have distributions that are restricted to the North Island and were therefore not expected to be found in Nelson or Dunedin. Likewise, $O$. polychroma and $O$. aff. polychroma Clade 5 are part of the grass skink complex consisting of five presently undescribed species that have allopatric distributions ranging from the lower North Island through the majority of the South Island (Liggins et al. 2007). The distribution of $O$. polychroma includes only Wellington and Nelson of the four study cities, while the distribution of $O$. aff. polychroma Clade 5 only includes Dunedin.

These four urban-dwelling species share a number of characteristics that may make them more adept at surviving in the altered habitats that cities present. Compared with other New Zealand lizards they have relatively high reproductive outputs (around five offspring per year) and fast maturation (less than 2 years to sexual maturity; Cree \& Hare 2016; summarised in Table 10). They are also all habitat generalists and are known to exist in a wide variety of environments (van Winkel et al. 2018). Behavioural and life history traits such as these have been identified in other urban-dwelling reptiles and it is possible that these traits allow these species to survive in urban environments where others cannot (Koenig et al. 2001). 
Table 10 Characteristics of urban-dwelling skink species. Information from: * BioWeb Herpetofauna Database (accessed May 2017), ${ }^{\dagger}$ van Winkle et al. (2018), ${ }^{\ddagger}$ Lettink \& Cree (2016). ${ }^{\S}$ Nelson et al (2016)

\begin{tabular}{|c|c|c|c|c|}
\hline Species & Distribution* $^{*}$ & Habitat use ${ }^{\dagger}$ & $\begin{array}{l}\text { Age at } \\
\text { sexual } \\
\text { maturity } \ddagger \S\end{array}$ & $\begin{array}{l}\text { Annual } \\
\text { reproductive } \\
\text { output } \dagger \S\end{array}$ \\
\hline O. aeneum & $\begin{array}{l}\text { Widespread } \\
\text { across North } \\
\text { Island }\end{array}$ & $\begin{array}{l}\text { Sandy beaches, coastal } \\
\text { vegetation, grassland, dry } \\
\text { scrubland, closed forest, } \\
\text { managed agricultural land }\end{array}$ & $\begin{array}{l}\text { Not } \\
\text { available }\end{array}$ & $\begin{array}{l}\text { Usually } 1- \\
4, \text { up to } 7\end{array}$ \\
\hline O. ornatum & $\begin{array}{l}\text { Widespread } \\
\text { across North } \\
\text { Island }\end{array}$ & Forests, scrubland, grassland & $<2$ years & 5 \\
\hline $\begin{array}{l}\text { O. } \\
\text { polychroma }\end{array}$ & $\begin{array}{l}\text { Lower North } \\
\text { Island and } \\
\text { upper South } \\
\text { Island }\end{array}$ & $\begin{array}{l}\text { Littoral zone, duneland, } \\
\text { wetlands, grassland, } \\
\text { shrubland, forest edges, screes } \\
\text { and talus slopes }\end{array}$ & 1.75 years & $\sim 5$ \\
\hline $\begin{array}{l}O . \text { aff. } \\
\text { polychroma } \\
\text { Clade } 5\end{array}$ & $\begin{array}{l}\text { Lower South } \\
\text { Island }\end{array}$ & $\begin{array}{l}\text { Littoral zone, duneland, } \\
\text { wetlands, grassland, } \\
\text { shrubland, forest edges, screes } \\
\text { and talus slopes }\end{array}$ & $2-3$ years & $3-6$ \\
\hline
\end{tabular}

Capture rates of the four species, however, differed substantially. Oligosoma aeneum was captured at only three sites in both Hamilton and Wellington, and generally only in low numbers. Mark-recapture studies of this species are rare, however, one study undertaken in the early 1970s in suburban Wellington found that populations can reach densities greater than 2000 skinks per hectare in suitable habitat (Bell et al. 2018). Although I was unable to estimate density for $O$. aeneum in this study, capture rates were very low at the majority of sites where they were captured (mean $=2.02$ captures per 100 trap days, range $=0.15-9.03$; Fig. 4). This may indicate that present populations in urban habitats are not as large as they were 50 years ago, however, further research is necessary to ascertain if populations are declining. Recent skink surveys for Wellington City Council recorded the species at fewer sites than expected across the city and described the paucity of site occupancy as a cause for concern (Melzer \& Bell 2014; Bell 2019).

Oligosoma ornatum was only captured in a single backyard in Wellington and was not observed in Hamilton (despite its presence being recorded subsequently in a reserve in Hamilton in February 2020, pers. com. Moniqua Nelson-Tunley, Waikato Regional Council, 2020). Although this may reflect its patchy distribution, this is concerning, as other recent skink surveys of parks and reserves in Wellington have 
identified very few individuals of this species, and only at a few sites (Melzer \& Bell 2014; Bell 2019). In contrast, the species is frequently captured in pitfall trapping surveys at the predator exclusion fenced Zealandia ecosanctuary (Nelson et al. 2016), suggesting predation by introduced mammals may be an important factor driving these patterns. It is likely that populations of O. ornatum in Hamilton and Wellington are sparse and in low numbers.

The highest capture rates in this study were those of $O$. polychroma in Wellington and Nelson, and $O$. aff. polychroma Clade 5 in Dunedin. Both of these species are small, diurnal skinks that are able to exploit artificial basking surfaces and a wide range of environments including rank grass (Chapter 4). The difference in site occupation by $O$. polychroma in Wellington and Nelson, and $O$. aff. polychroma Clade 5 in Dunedin was pronounced. Almost every site sampled in Wellington (83.3\%) and Nelson (100\%) was occupied whereas in Dunedin, individuals were captured at only two sites out of 11 $(18.2 \%)$. While this may be explained to an extent by differences in the habitats surveyed (sites in Dunedin had significantly greater canopy cover than those in Wellington and Nelson), an earlier study of $O$. aff. polychroma Clade 5 in suburban Dunedin found that the species was mainly distributed around the rural fringe of Dunedin and was seldom found in the inner suburbs (van Heezik \& Ludwig 2012). These differences are reflected in the Threat Status Classifications of these species, with O. polychroma classified as 'Least Concern' and $O$. aff. polychroma Clade 5 as 'Declining' (Hitchmough et al. 2016a).

The estimated densities of $O$. polychroma at sites in urban environments ranged widely from a few hundred per hectare (e.g., Scorching Bay Domain, Wellington) to several thousand per hectare (e.g., Pipers Reserve, Nelson; Table 11). In general, these were comparable with those of other studies of $O$. polychroma and $O$. aff. polychroma Clade 5 in a range of habitats with varying predator control regimes (Table 11). 


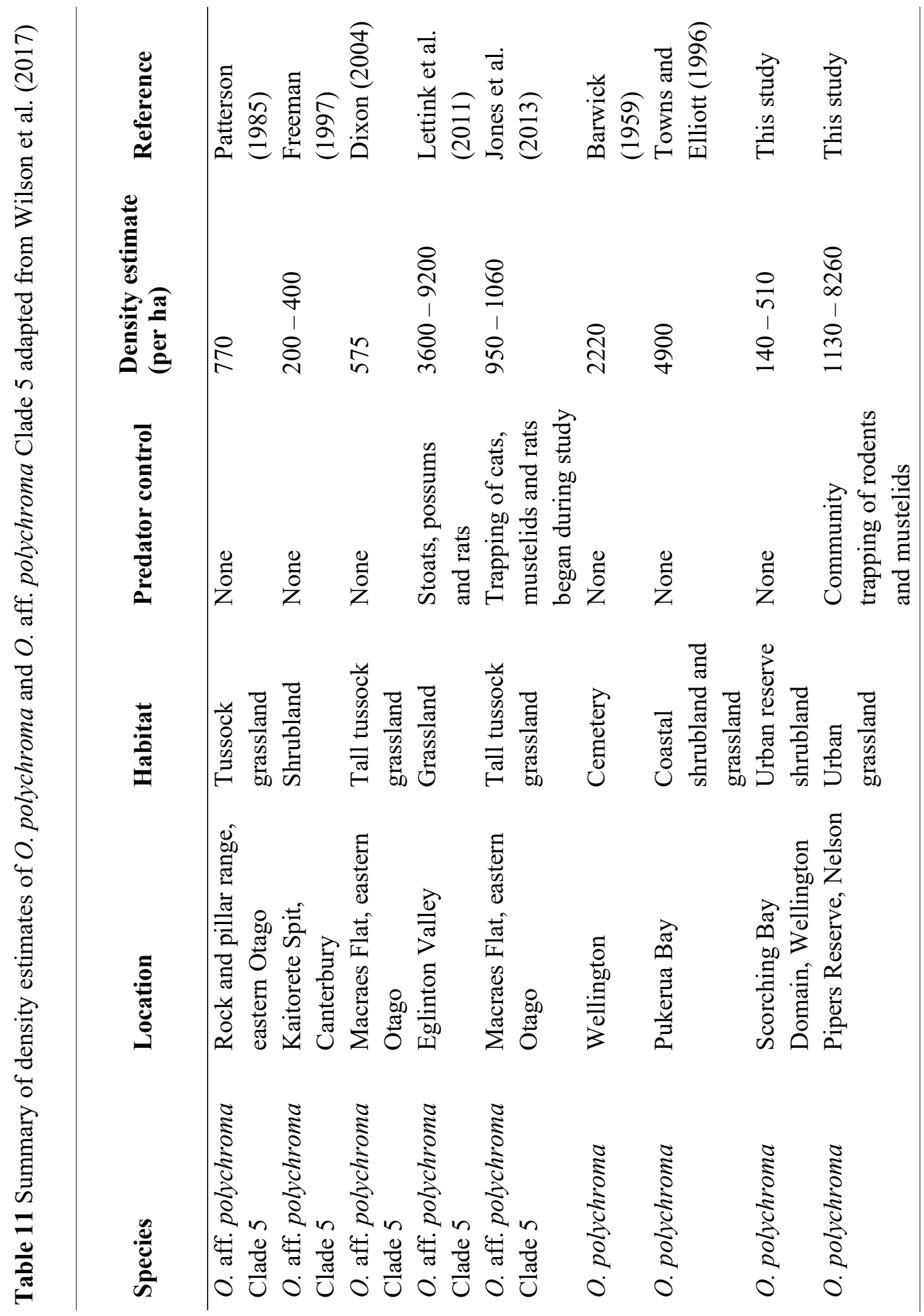


The introduced skink, Lampropholis delicata, was captured at two sites in Hamilton, both of which also had captures of $O$. aeneum. At these sites, capture rates of the introduced species greatly exceeded those of the endemic (12.6 per 100 trap days cf. 0.15 at Innes Common and 2.6 cf. 0.64 at the backyard in Beerescourt; C. Woolley, unpublished data). Introduced in Auckland in the 1960s, L. delicata has spread through much of the North Island and made incursions into the South Island (Chapple et al. 2016). Although there is currently no conclusive evidence of the negative impacts of this species, either in New Zealand or internationally, its diet and habitat use overlap with endemic species with which it is sympatric, and there are concerns that large populations may inflate the abundance of predators (Norbury 2001).

My surveys failed to detect a number of species thought to be present in cities (Table 2). In particular, O. zelandicum was not captured at any site in Wellington despite being regularly recorded in surveys at Zealandia (Romijn 2013; pers. com. Ellen Irwin, Zealandia, 2020). Concerningly, this species has also not been captured in other recent surveys of Wellington reserves (Melzer \& Bell 2014; Bell 2019). It has a Threat Status Classification of 'Declining' (Hitchmough et al. 2016a).

\subsubsection{Impact of urban environments on skink populations}

Proportion of grass cover at sites was found to be positively related to catch per unit effort of $O$. polychroma. Previous research has identified similar positive relationships between number of captures and grass cover for this species (Newman 1994; Thalia East et al. 1995), as well as for O. aff. polychroma Clade 5 (Patterson 1992; Walker et al. 2014). Grass cover likely provides cover and food resources for skinks, as well as maintaining a favourable thermal environment (Knox et al. 2012).

I found no clear evidence for a negative impact of rats or hedgehogs on CPUE of O. polychroma. While many mammalian predators are known to consume lizards (Newman 1994; Gillies \& Clout 2003; Jones et al. 2013) and the impact of rodents on some lizard populations has been inferred by patterns of loss on the mainland and population recovery on islands following pest mammals eradication (Towns 1991; Towns $\&$ Daugherty 1994), evidence for the negative impacts of pest mammals on $O$. polychroma populations is mixed. As discussed in Wilson et al. (2017; and adapted in Table 11), there is no clear pattern indicating that populations of this species respond numerically to predator control. While in the South Island, locations with predator control 
had some of the highest densities of $O$. aff. polychroma Clade 5, populations of $O$. polychroma in Wellington and at Pukerua Bay achieved high densities in the absence of predator control (Table 11). On Mana Island too, while numbers of the gecko Woodworthia maculata increased following the eradication of mice, O. polychroma did not (Newman 1994).

The effect of rat tracking rate on CPUE was, however, dependent upon the proportion of grass cover, with a positive relationship when grass cover was low and a negative relationship when high (Table 8 , Fig. 6a). This suggests that grass cover may benefit populations of $O$. polychroma when rat abundance is low but not when it is high. Interactions between vegetation, herbivores and predators can result in complex and sometimes unexpected impacts for lizard populations (Norbury 2001; Knox et al. 2012; Norbury et al. 2013). Densities of jewelled geckos (Naultinus gemmeus) in Coprosma spp. shrubland on the Otago Peninsula were four times higher in grazed sites than ungrazed, likely due to the higher activity of rodents at ungrazed sites (Knox et al. 2012). Additionally, at Pukerua Bay near Wellington, the removal of grazing stock and the subsequent seeding of introduced grasses are thought to have caused rodent irruptions that contributed to declines in skink populations (Hoare et al. 2007).

Body condition of $O$. polychroma was also negatively related to urban land cover (Table 9), in both Wellington and Nelson (Fig. 6b). This may be because as the proportion of urban land cover increases, patch size of suitable habitat decreases making habitat and food resources more limited. Several studies document a decline in invertebrate abundance and diversity with increasing urbanisation (Niemelä et al. 2002; Ishitani et al. 2003; McKinney 2008). Alternatively, increased levels of disturbance may cause changes in foraging behaviours. This could be in the form of human behaviours (e.g., green space maintenance) or increased predator activity in more urban environments (e.g., domestic cats; Woolley \& Hartley 2019). For example, a number of studies report differences in flight initiation distances and sprint speeds between lizards living in modified urban habitats and those in more natural environments (Prosser et al. 2006; Chejanovski et al. 2017).

Morphological traits of urban-dwelling skinks appear similar to those of other populations that co-occur with pest mammals. For $O$. polychroma, SVL of individuals in urban Wellington and Nelson were similar to those in non-urban environments (mean = $49.6 \mathrm{~mm}$ range $=22-76 \mathrm{~mm}$, Dumont 2015) as were those of $O$. aff. polychroma Clade 5 in Dunedin $(\mathrm{SVL}$; mean $=50.5 \pm 0.6 \mathrm{~mm}$, range $25-65 \mathrm{~mm}$, Lettink \& Seddon 2007; 
adult mean $=58 \pm 4.2 \mathrm{~mm}$, range $=50-66 \mathrm{~mm}$, Freeman 1997) and O. aeneum in Hamilton and Wellington (mean $=54.9 \pm 0.5 \mathrm{~mm}$, range $=45-66 \mathrm{~mm}$; Bell et al. 2019). Reptile responses to urbanisation likely depend on a wide range of factors and may be species specific. Differences in size and body condition have been associated with changes in diet (Luiselli et al. 2001; Wolfe et al. 2018), particularly increases for species that consume synanthropic prey (e.g., rodents; Savidge 2012). However, smaller-bodied species can be less susceptible to road mortality (Shine \& Koenig 2001; Gibbs \& Shriver 2002) and are able to find cover more readily (Bell 2010).

\subsubsection{Limitations and future research}

While the range of species captured in my surveys was generally consistent with existing knowledge of lizards in New Zealand cities, the failure to detect O. ornatum in Hamilton in a reserve where it has subsequently been found, illustrates a key limitation of this study: that detection of some species, particularly those that are secretive, at low densities, or have patchy distributions, requires sustained effort and a wide range of methods. Further surveys in cities are needed to identify the locations of populations of skink species for which records are scarce (in particular, O. ornatum, O. aeneum and $O$. zelandicum). Additionally, future surveys in cities should target the full range of species possibly present, including geckos and arboreal skinks not surveyed in this study, using a variety of lizard sampling tools (e.g., pitfall trapping, tracking tunnels, artificial cover objects and systematic searching; Hare 2012a, 2012b, 2012c; Lettink 2012). Due to the cryptic, secretive nature of many of New Zealand's lizards, it remains possible that species thought to have been lost from the mainland could yet be discovered in cities (such as was possibly the case for Hoplodactylus duvaucelii at Maungatautari Mountain Sanctuary; Morgan-Richards et al. 2016 ). For this reason, managers should be open minded in their use of survey techniques.

However, due to the heterogeneity of the urban landscape and costs associated with formal lizard surveys, sampling all potential habitats at the necessary intensity is likely not possible. Backyards, though highly variable in the habitat they offer, often constitute large proportions of urban green space in a city (e.g., 36\% in Dunedin; Mathieu et al. 2007). Furthermore, the backyards surveyed in this study were among the most important sites, supporting high diversity (three species were caught at a backyard in Wadestown), high abundance (highest CPUE for O. aeneum was in the backyard in 
Miramar, Wellington), and the only record of $O$. ornatum. While more formal surveys of backyards are recommended, these may be supplemented by the use of citizen science. Records of lizard observations by members of the public could provide valuable information about species' distributions in backyards and other habitats that may allow the targeting of more intensive surveys. Such a citizen science project could also serve to increase public awareness for lizards and threats to them in cities (Ives et al. 2018).

Identifying the presence and location of lizard populations in cities, however, is only the first step towards their management and protection. For some species, there remains the possibility that populations are in unnoticed decline. In order to identify population trends of urban-dwelling species, there is a need for ongoing monitoring at this study's sites as well as others. This may be critical for ensuring the persistence of some species in cities, particularly those that are cryptic and secretive.

Finally, it is possible that some of New Zealand's urban-dwelling lizards may be well adapted to survive in urban environments, in particular O. polychroma. Internationally, other studies have identified a number of apparently urban-adapted reptiles (Germaine \& Wakeling 2001; Koenig et al. 2001) and in New Zealand, endemic birds vary in their resilience to introduced predators depending on their body size and degree of endemicity (Fea et al. 2020). Future research should identify what life history or behavioural traits facilitate the survival of these species in New Zealand cities. Understanding the mechanisms by which some species are able to survive in these highly modified environments will allow these species to be managed through further environmental change (Shine \& Fitzgerald 1996; Koenig et al. 2001). This is increasingly important as urban restoration intensifies in many New Zealand cities, especially with regard to landscape-scale predator control (such as that which is underway in Wellington; Predator-free Wellington, 2019) and the opportunities it may offer for lizard conservation in the future (Chapter 2; Woolley et al. 2019).

\subsubsection{Conclusions}

Despite lizards being an important component of New Zealand's terrestrial ecosystems, they have, until recently, rarely been considered in urban ecology and restoration. Across four cities, I detected four skink species living in a range of urban environments. While some species have widespread and sometimes large populations (e.g., O. polychroma), others appear to be sparse and in low numbers (e.g., O. ornatum). Impact of introduced 
mammalian predators on CPUE depended on proportion of grass cover, and increasing urban cover was related to reduced body condition. Data characterising these urban populations should serve as baselines against which future surveys can be compared. Understanding population trends in urban habitats is essential to ensuring the persistence of lizards in New Zealand cities. 


\section{Chapter 4}

\section{Using citizen science to understand human-wildlife interactions in urban environments}

\subsection{Introduction}

\subsubsection{Citizen science and urban ecology}

Urban green spaces such as reserves and residential gardens contribute valuable habitat for wildlife living in cities (Mathieu et al. 2007; González-García \& Sal 2008). However, understanding species' distributions and ecological trends of wildlife in these habitats can be challenging due to the heterogeneity of the urban landscape (Scott et al. 2014). Not only is the physical environment a mosaic of privately and publicly owned land making it difficult to survey, but the quality of this land as habitat for wildlife is influenced by human values and behaviours which vary discontinuously (Dixon 2017). One approach that is increasingly being used to understand landscape-scale species' distributions is citizen science. Citizen science is a methodology that engages members of the public in research through project design, data collection or analyses, and has been employed effectively in a wide range of scientific fields (Dickinson et al. 2010). It has frequently been used in ecology to provide data about spatial and temporal changes in species distributions (Hurlbert \& Liang 2012; Soroye et al. 2018). Citizen-reported species 
occurrences could be a cost-effective solution for gathering information about species distributions in residential areas that would otherwise be very difficult to survey.

Unfortunately, the utility of citizen science as a tool for this purpose can be restricted by confounding social and environmental factors. Because the geographic distribution of both the focal species and a project's participants can both be influenced by environmental factors. While species distributions are directly associated with suitable habitat (e.g., vegetation types; van Heezik \& Ludwig 2012), the distribution of willing project participants can also be influenced indirectly through the positive relationship between nature engagement and social advantage (e.g., education and income; Chapter 5; Evans et al. 2005; Franzen \& Meyer 2010) and how this affects where people live in a city. This means that occurrence data contributed by the public are likely to be spatially biased, and therefore difficult to interpret unless information about species absence is also provided.

In addition to building ecological knowledge, however, citizen science can also be used to facilitate public engagement with nature (Ives et al. 2018) and provide information about the location and nature of human-wildlife interactions (Wine et al. 2015; Walter et al. 2018). This is especially important in cities, where people often live in nature-poor environments and lack experience with native species (Turner et al. 2004; Soga \& Gaston 2016). While the cultural and recreational benefits of urban green space are well known (Bolund \& Hunhammar 1999), less research has investigated the social and cultural value of urban wildlife (Soulsbury \& White 2015). In general, people enjoy seeing and interacting with wildlife in cities (Dandy et al. 2011), though this does vary by species (Bjerke \& Østdahl 2004), and research indicates that contact with wildlife can have positive effects on human wellbeing and nature relatedness (Fuller et al. 2007; Luck et al. 2011). Given the heterogeneity of the urban landscape (McKinney 2006), it is inevitable that wildlife interactions will not be evenly distributed across a city and, as a result, it is possible that some people may not have the opportunity to experience them. There are numerous examples of socio-economic inequalities in access to nature in cities. Tree cover, overall vegetation cover and in some cases species richness have all been found to be positively related to socio-economic advantage (Hope et al. 2003; van Heezik et al. 2013; Shanahan et al. 2014). As conservationists and NGOs increasingly seek to engage and mobilise the public, understanding the nature of human interactions with urban wildlife will be important (Dunn et al. 2006). 


\subsubsection{Lizards in New Zealand cities}

Citizen science may be a particularly useful tool for building knowledge about lizards in urban environments, both regarding their ecology and the nature of people's interaction with them. Many of New Zealand's cities support lizard populations in a variety of habitats including residential gardens (Chapter 3; van Heezik \& Ludwig 2012). However, due to their cryptic nature and their relatively small home ranges (Eifler \& Eifler 1999; Wilson et al. 2017), these populations can be challenging to survey.

New Zealand has a highly speciose lizard fauna (comprised of skinks and geckos) with many species that are threatened and conservation dependent (Hitchmough et al. 2016c). Threats to the group include predation by invasive mammalian predators, anthropogenic disturbance, and habitat loss (Hitchmough et al. 2016c). These threats are ubiquitous in the urban environment and the ranges of some urban-dwelling lizard species are thought to be declining (Towns et al. 2016a). At the same time, there is a paucity of information about lizard species distributions and population trends in New Zealand cities (Chapter 2; Woolley et al. 2019). While ecological surveys are possible in large public reserves, this is more challenging in suburban areas where parcels of land are smaller and land is privately owned. Yet suburbs offer significant habitat for wildlife. In many New Zealand cities residential backyards contribute a large proportion of the total urban green space (e.g., 36\% in Dunedin; Mathieu et al. 2007).

Knowledge of where lizards are present in residential areas could offer benefits to lizard conservation at a national level. One of the biggest threats to urban lizard populations is land development for roading or construction (Hitchmough et al. 2016c). Although lizards are protected under the Wildlife Act (1953) and Resource Management Act (RMA, 1991), a lack of knowledge about where populations occur and the highly variable application of these acts means that often development goes ahead without their consideration.

Although not a panacea for understanding lizard ecology in cities, citizen science may provide a starting point for more rigorous survey work by identifying locations of populations of species with patchy distributions. Additionally, from the point of view of nature engagement, an urban lizard citizen science project might provide an opportunity to improve public education and advocacy for lizards, and be used to capture information about where and how people are encountering them. 


\subsubsection{Aims}

Here I piloted a citizen science project that collated opportunistic public sightings of lizards in a suburban environment. The aim of this pilot was to gather information that builds on the sparse knowledge of lizard distributions in cities and to explore the environmental and social factors associated with skink and gecko sightings in cities. Specifically, I sought to address the following research questions: 1) how frequently and in what types of environments are lizards being observed? 2) how do reported sightings relate to landscape-scale social and environmental variables? 3) what opportunities and challenges exist for the use of citizen science in the conservation of New Zealand lizards?

\subsection{Methods}

\subsubsection{Public sightings website}

Commonly, ecological citizen science projects use methods that encourage participants to make observations over timed periods and record the absence of the target species (e.g., the Great Kererū Count; Brumby et al. 2015). However, as all of New Zealand's endemic lizards are protected under the Wildlife Act (1953), I did not want to direct participants to 'search' for lizards as this might risk encouraging the disturbance of lizards or their habitat (which is prohibited under the act). Instead, I asked people to report sightings opportunistically as they occurred or to recall previous sightings.

A public sightings website was designed using GoogleForms (Victoria University of Wellington Human Ethics Approval: 24735). Its purpose was to record information about where people were encountering skinks and geckos in cities and in what types of habitats. It included questions about how frequently lizards were observed, how many were seen at one time and in what sorts of environments observations took place (Table 1). As it is difficult to identify New Zealand lizards to species (or even genus) level without handling them, the form only asked for lizards to be classified to family level using the categories 'skink', 'gecko' or 'not sure'. The form also provided space for respondents to include additional information (which could include species-level identification) (Table 1). The website was established on 21 July 2017. It was publicised via social media on the Facebook pages of five conservation-related community groups (26/8/17), through the Wellington City Council (WCC) 'Branch out' e-newsletter (1/9/17) and in an article on Radio New Zealand (30/11/17), and remained active until 15 April 
2018. On 4 November 2017 the option was added to submit a photograph via email.

These were used to assess the accuracy of lizard identification at family level.

Table 1 Questions asked and types of responses for the public sightings website

\begin{tabular}{lc}
\hline Question & Response type \\
\hline Where were you when you saw the lizard? & $\begin{array}{c}\text { Select one of: residential address, urban } \\
\text { reserve, other; and specify street } \\
\text { address or name. }\end{array}$ \\
$\begin{array}{l}\text { What sort of lizard did you see? } \\
\begin{array}{c}\text { How frequently have you seen lizards in this } \\
\text { location? }\end{array}\end{array}$ & $\begin{array}{c}\text { Select one of: every day in summer, } \\
\text { most days in summer, a few times } \\
\text { each summer, just once or twice }\end{array}$ \\
$\begin{array}{l}\text { When did you last see the lizard/s in this } \\
\text { location? Write the date if you can } \\
\text { (dd/mm/yy) or give the approximate } \\
\text { month and year (e.g. approx. Feb 2014) }\end{array}$ & $\begin{array}{c}\text { Short answer } \\
\text { What is the maximum number you have seen } \\
\text { there at one time? }\end{array}$ \\
$\begin{array}{c}\text { What sort of habitat (environment) was it in? } \\
\text { Short answer }\end{array}$ \\
$\begin{array}{c}\text { Select one of: bare ground, leaf litter, } \\
\text { stones or rocks, grass, ground } \\
\text { covering vegetation, tree, other } \\
\text { (please describe [long answer]) }\end{array}$ \\
$\begin{array}{c}\text { like to provide about your sighting? } \\
\text { Do you have a photo you would like to share? }\end{array}$ & $\begin{array}{c}\text { Participants were directed to send a } \\
\text { photo to an email address }\end{array}$ \\
\hline
\end{tabular}

The addresses provided by respondents where lizard sightings occurred were geocoded using the 'Geocode by Awesome' add-on in GoogleSheets. For analysis, records were limited to those described as occurring in backyards at locations within the Wellington urban core (defined by aggregating urban land cover from the Land Information New Zealand (LINZ) Land Cover Database (LCDB) v.4.1 (LINZ 2015) using the methods described in Chapter 2; Woolley et al. 2019).

To enable statistical analysis, pseudo-absence points were generated by taking a random sample of 100 residential street addresses (LINZ 2017) from within the Wellington urban core. A number of studies have investigated sampling designs for species distribution models using pseudo-absences, including the effects of sample size (Stokland et al. 2011; Barbet-Massin et al. 2012). I used a relatively small number to match the number of reported sightings. 


\subsubsection{Factors influencing lizard sightings}

Environmental and socioeconomic data for the location of each record were gathered using a geographic information system in the software ArcMap (v10.5.1; ESRI 2017) (Table 2). Environmental predictors were chosen based on their hypothesised importance to lizard occurrence. It was hypothesised that lizards would be more commonly observed close to land covers that may provide habitat and, being ectothermic, on north-facing sites that may be warmer than other aspects. Using a $5 \mathrm{~m}$ digital elevation model of the Wellington area (Wellington City Council (WCC), 2002), I created polygons representing land with aspects 45 degrees either side of north with the 'Aspect' tool in ArcMap. I created polygon layers representing two different land cover types: grass/scrubland and forest by reclassifying different forest, grassland and scrubland land cover classes from the LCDB into more general categories (S1).

Given the importance of socio-economic factors (e.g., affluence and education) on recruitment into the project and likelihood of encountering a lizard should one be present, three social variables were assessed: household income, educational attainment and means of travel to work (as a proxy for time spent outside). These data were obtained for polygons representing mesh block units populated with data from the New Zealand census (Statistics New Zealand, 2013).

Both lizard sightings and pseudo-absence points were ascribed these environmental and socioeconomic attributes using either the 'spatial join' function, when the variable required the point fall within a polygon (e.g., North aspect), or the 'Near' tool (Arcmap, ESRI 2017) when the distance between a point and a polygon was needed (e.g., Distance to forest land cover; Table 2). 
Table 2 Predictor variables of urban lizard sightings

\begin{tabular}{|c|c|c|}
\hline Variable & Data source & Description \\
\hline $\begin{array}{r}\text { Environmental } \\
\text { North aspect }\end{array}$ & $\begin{array}{l}5 \text { m digital elevation } \\
\text { model (WCC, 2002) }\end{array}$ & $\begin{array}{l}\text { Binary: Whether or not the sighting } \\
\text { occurred in an area with aspect } \pm \\
45^{\circ} \text { of north }\end{array}$ \\
\hline $\begin{array}{r}\text { Distance to forest } \\
\text { land cover }\end{array}$ & $\begin{array}{l}\text { LCDB v4.1 (LINZ } \\
2015)\end{array}$ & $\begin{array}{l}\text { Distance to nearest indigenous or } \\
\text { exotic forest land cover }\end{array}$ \\
\hline $\begin{array}{r}\text { Distance grass/scrub } \\
\text { land cover }\end{array}$ & $\begin{array}{l}\text { LCDB v4.1 (LINZ } \\
\text { 2015) }\end{array}$ & $\begin{array}{l}\text { Distance to nearest grassland or } \\
\text { scrubland land cover }\end{array}$ \\
\hline \multicolumn{3}{|l|}{ Socioeconomic } \\
\hline Income & $\begin{array}{l}\text { NZ census } 2013 \\
\text { (mesh block) }\end{array}$ & $\begin{array}{l}\text { Median household income in a } \\
\text { mesh block }\end{array}$ \\
\hline $\begin{array}{r}\text { Educational } \\
\text { attainment }\end{array}$ & $\begin{array}{l}\text { NZ census } 2013 \\
\text { (mesh block) }\end{array}$ & $\begin{array}{l}\text { Percentage of people with a } \\
\text { bachelor degree or higher in mesh } \\
\text { block }\end{array}$ \\
\hline $\begin{array}{r}\text { Means of travel to } \\
\text { work }\end{array}$ & $\begin{array}{l}\text { NZ census } 2013 \\
\text { (mesh block) }\end{array}$ & $\begin{array}{l}\text { Percentage of people who walked } \\
\text { or cycled to work in mesh block }\end{array}$ \\
\hline
\end{tabular}

\subsubsection{Statistical analyses}

Responses to the questions about sighting frequency, maximum number seen at one time and the types of environments where observations took place were summarised as proportions for skink and gecko reports. Differences between the groups were tested using a two-proportion z-test in R (R core team 2018). Spatial autocorrelation among gecko and skink sightings was tested for using Moran's I in the Spatial Statistics toolset in ArcMap. To do this, sightings were aggregated by counting their number within squares of a $50 \times 50 \mathrm{~m}$ grid drawn across the urban core.

Two approaches were used to assess the spatial relationships between the predictor variables and the lizard sightings. First, Wilcoxon signed-rank tests were used to compare the means of the predictor variables of the skink and gecko sightings with those of an equivalent number of randomly chosen residential street addresses $(n=100$, LINZ, 2017) from within the Wellington urban core. The second approach compared the distribution of skink and gecko sightings using a logistic regression model with taxonomic family (skink coded as 0 and gecko coded as 1 ) as the response. North aspect, forest land cover, grass/scrub land cover, income, educational attainment and means of travel to work were predictors and a binomial distribution of errors was assumed. 
Correlations were tested for among predictor variables prior to modelling using Spearman's correlation analyses. All analyses were performed in R (R core team 2018).

\subsection{Results}

\subsubsection{Characteristics of public lizard sightings}

In all, 231 sightings were reported from across the country, 103 of which were from the Wellington region. This number was further reduced by removing historical sightings (sightings prior to 2015) and those that did not occur in backyards to give 93. Of these, 32 (34.4\%) were gecko sightings, 59 (63.4\%) were skink and $2(2.2 \%)$ were not identified to family level (Fig. 1). Seventeen photos were received in relation to sightings. All records submitted with a photo were correctly identified to family level by the reporter. Some participants also described the subject of their sighting to species level: five geckos, three as "raukawa" (W. maculata), one as "Pacific" (D. pacificus) and one as "goldstripe" $(W$. chrysosiretica); and four skinks (6.7\%), three as "northern grass" or "common" $(O$. polychroma) and one as "glossy brown" (O. zelandicum). However, as none of these were submitted with photos they could not be verified. 


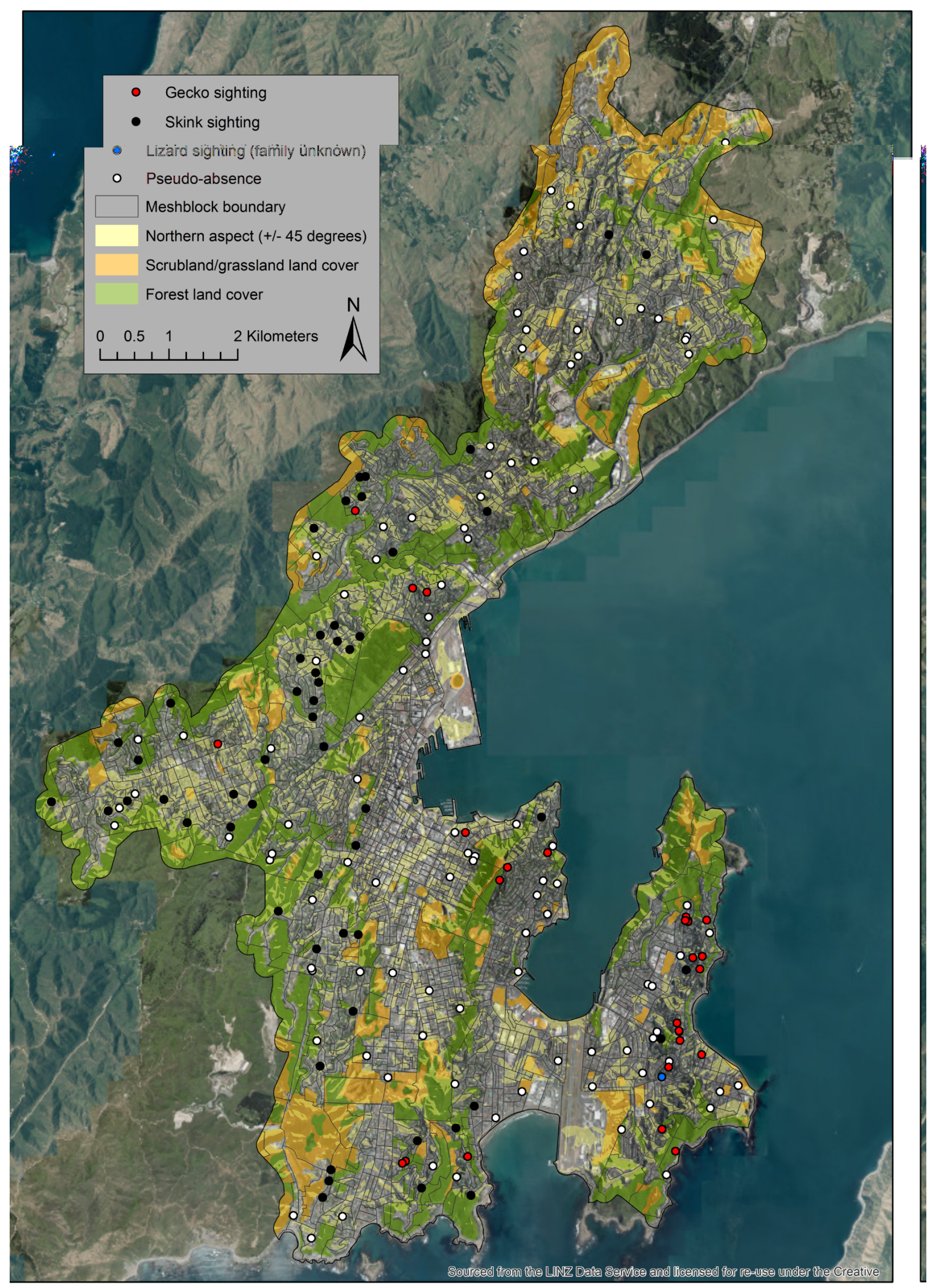

Figure 1 Map of Wellington City showing locations of skink and gecko sightings, pseudoabsences, mesh block boundaries and land cover types (Basemap: LINZ 2015) 
Skink and gecko sightings showed similar trends in the frequency with which they were seen. The greatest proportion of sightings reported for both families was "A few times a summer" (42.4\% for skink sightings and $40.6 \%$ for geckos) followed by "Just once or twice" (30.5\% for skinks and 37.5\% for geckos) (Fig. 2a). The majority (around 60\%) of skink and gecko sightings were of single animals, though sightings of multiple animals were reported for both families (Fig. 2b). The majority of skinks were observed amongst ground-covering vegetation (34.5\% compared with $6.3 \%$ of gecko sightings, $\mathrm{z}=7.44, \mathrm{p}<$ $0.001)$ followed by stones or rocks $(13.8 \%$; Fig $2 \mathrm{c})$. Geckos, by contrast, were more frequently reported as being seen on man-made structures such as garden sheds, wood piles, or under a deck $(50.0 \%$ compared with $12.1 \%$ of skink sightings, $\mathrm{z}=13.67, \mathrm{p}<$ 0.001; Fig. 2c). Observations of skinks and geckos were frequently made inside houses (13.8\% and $21.9 \%$ respectively). Four out of the 32 (12.5\%) gecko sightings involved comments describing a cat interacting with the lizard compared with ten of the 59 skink sightings $(16.9 \%)$. 

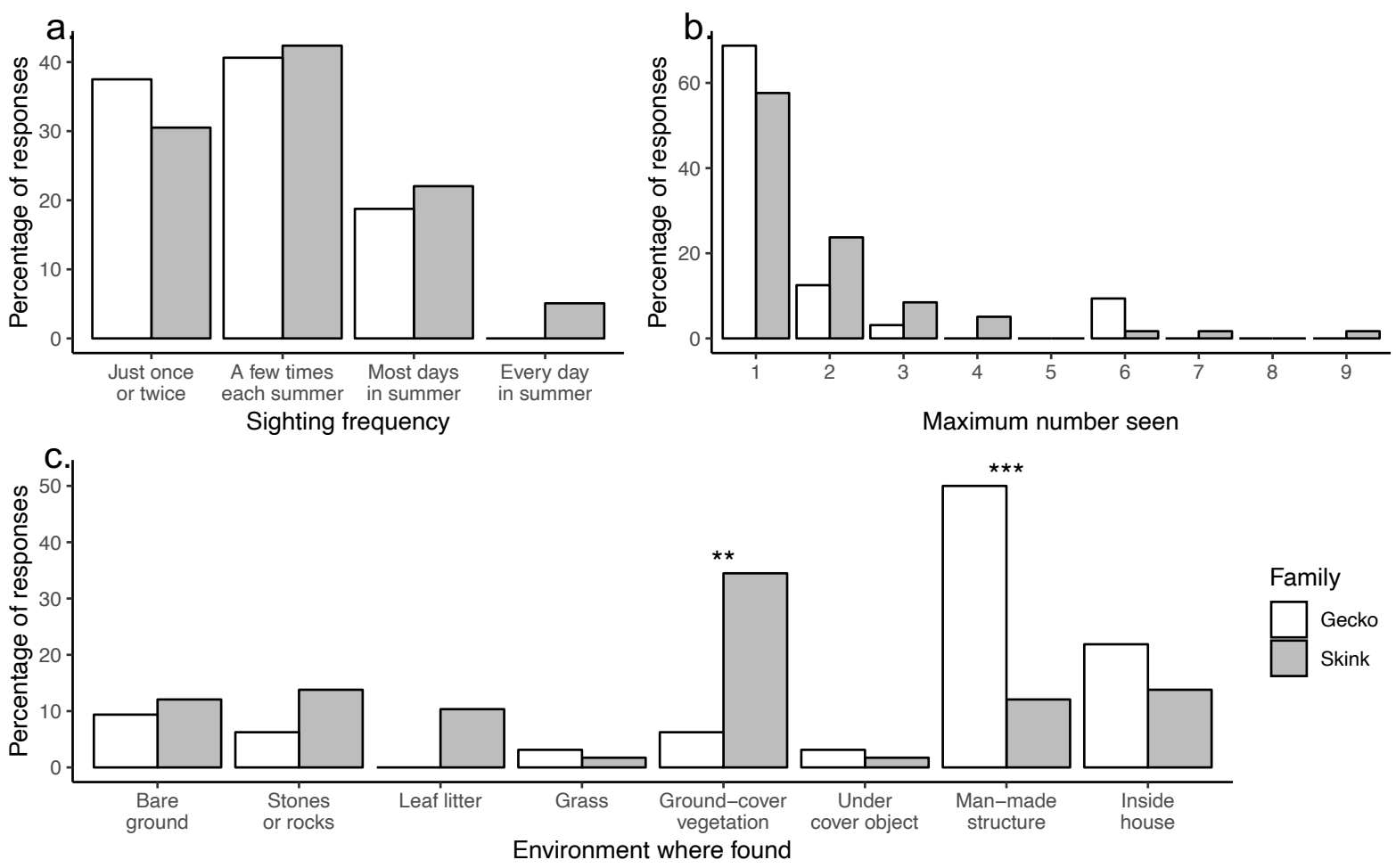

Figure 2 Percentages of reports of geckos (white bars) and skinks (grey bars) describing a. the frequency with which sightings were made, $\mathbf{b}$. the maximum number seen at one time, and $\mathbf{c}$. the environment the lizard was observed in. Statistically significant differences are indicated by asterisks $*<0.05, * *<0.01, * * *<0.001$

\subsubsection{Comparison of skink and gecko sightings}

Testing for spatial autocorrelation found that reported gecko sightings were significantly clustered (Moran's I $=0.117, \mathrm{p}<0.001$ ), however, no such pattern was evident for skink sightings (Moran's $\mathrm{I}=0.008, \mathrm{p}=0.297$ ). The logistic regression comparing gecko and skink sightings found that gecko sightings were more likely to occur in areas of high income than skink sightings (Table 3). No other factors in the model were significant. 
Table 3 Model estimates for the logistic regression comparing gecko and skink sightings. Gecko sightings were coded as 1 and skink sightings as 0

\begin{tabular}{rcccc}
\hline Factor & Estimate & SE & Z value & p value \\
\hline Distance to nearest grass/scrub land cover & -0.001 & 0.001 & -1.036 & 0.300 \\
Distance to forest land cover & 0.003 & 0.003 & 1.144 & 0.253 \\
North-facing aspect & -0.106 & 0.678 & -0.156 & 0.876 \\
Income (\$1000) & $\mathbf{0 . 0 4 1}$ & $\mathbf{0 . 0 1 2}$ & $\mathbf{3 . 5 2 8}$ & $<\mathbf{0 . 0 0 1}$ \\
Transport & 0.065 & 2.350 & 0.028 & 0.978 \\
Education & -2.911 & 2.591 & -1.124 & 0.261 \\
\hline
\end{tabular}

\subsubsection{Spatial relationships of reported sighting}

Spearman's correlation analyses identified significant correlations between distance to grass/scrub land cover and education level, grass/scrub land cover and north-facing aspect, income and north-facing aspect, and transport and education (S2). However, as these were weak $($ all $<|0.35|)$ all factors were retained in the model. Both skink and gecko sightings were on average reported from locations closer to forest land cover (75.24 \pm $9.45 \mathrm{~m}$ and $97.03 \pm 14.77 \mathrm{~m}$ respectively) than the pseudo-absences (186.15 \pm 16.49 ; skink sightings: $\mathrm{W}=4244, \mathrm{p}<0.001$, gecko sightings: $\mathrm{W}=2055.5, \mathrm{p}=0.008$, Fig. 3b). A greater proportion of skink sightings were reported on properties with a north-facing aspect than were pseudo-absence points $(27.1 \% \mathrm{cf} .15 .3 \%, \mathrm{p}=0.018)$, however, this was not the case for geckos ( $15.6 \%$ cf. $15.3 \%, p=1.00$, Fig. $3 \mathrm{c})$.

Reports of gecko sightings came from areas with mean annual incomes $25 \%$ greater than that of the pseudo-absence group $(\$ 127,359 \pm 3,918$ cf. $\$ 101,368 \pm \$ 3,177$; $\mathrm{W}=808.5, \mathrm{p}<0.001$, Fig. 3d). Skinks, on the other hand, were disproportionately reported from areas of higher educational attainment (48.64 $\pm 1.49 \%$ for sightings cf. $41.92 \pm 1.42 \%$ for pseudo-absences; $\mathrm{W}=2128, \mathrm{p}=0.006$, Fig. $3 \mathrm{e}$ ). All other differences were non-significant. 

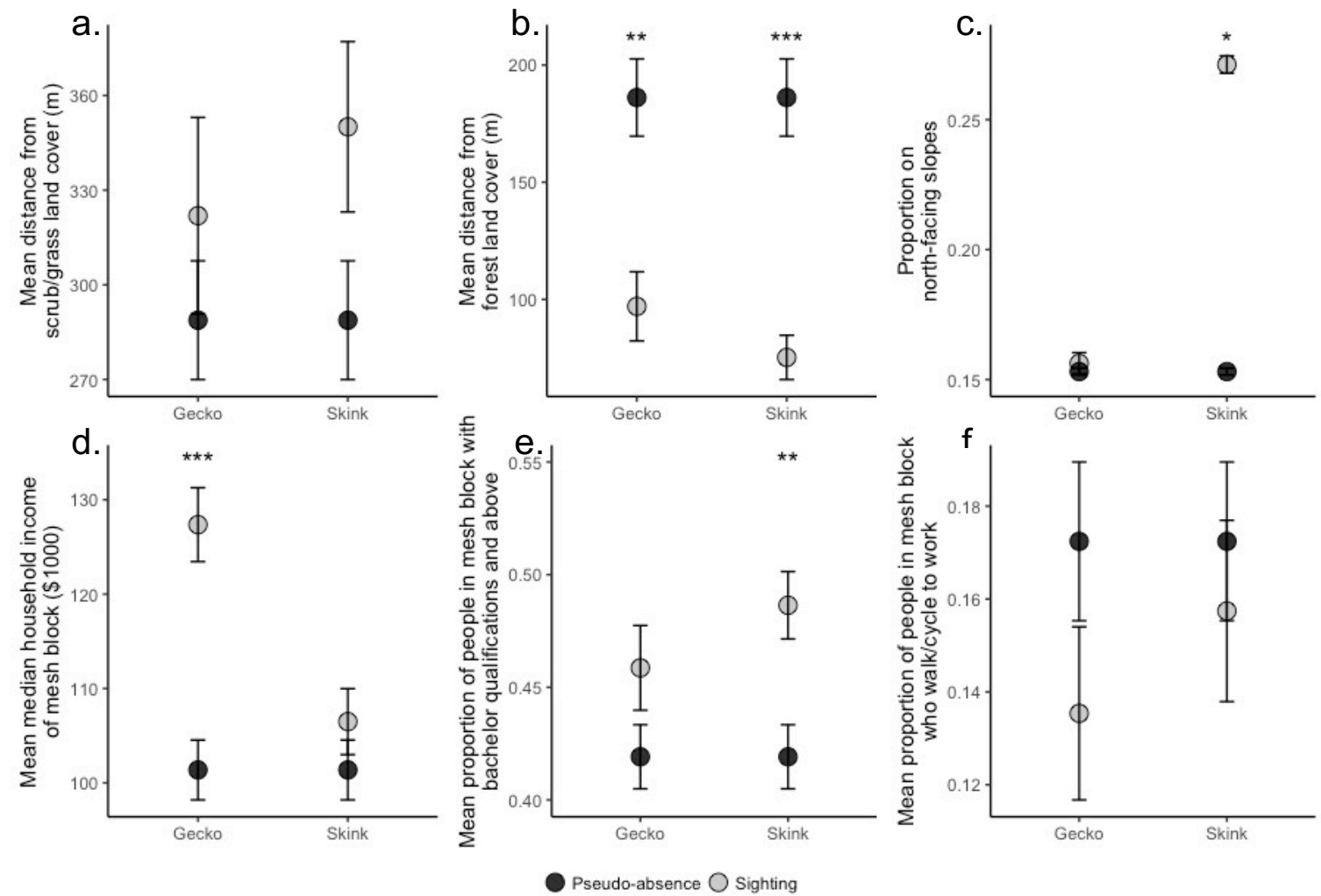

Figure 3 Differences between gecko and skink sightings and pseudo-absences for six factors: a. distance from scrub or grass land cover, $\mathbf{b}$. distance from forest land cover, $\mathbf{c}$. proportion of sightings on north-facing slopes, d. median household income, e. proportion of people with a bachelor's degree or above, and f. proportion of people who walk or cycle to work. Asterisks indicate statistical significance (c., binomial test; all others Wilcoxon signed rank test: ***, $\mathrm{p}<$ $0.001 ; * *, p<0.01 ; *, p<0.05)$. Errors bars are \pm 1 SEM

\subsection{Discussion}

\subsubsection{Characteristics of human-lizard interactions}

This study is the first research to document how people are encountering lizards in a New Zealand city. It finds that both geckos and skinks are commonly observed at residential properties in a range of locations across Wellington. From the number of people who responded, it seems that there is interest among the public for a citizen science project such as that piloted and that the method could be an effective tool for building knowledge about the locations of lizard populations in cities.

The majority of respondents indicated that they observed lizards around the property at least a few times each summer, suggesting that many of the respondents are 
aware of lizards in their environment from year to year. While the majority of skinks were encountered in relatively natural environments, such as among rocks or groundcovering vegetation, geckos were frequently found indoors or associated with humanmade structures such as decks, woodsheds or tree houses. This likely reflects differences in the habitat-use and activity of the skink and gecko species found in Wellington. One of the most abundant skink species in Wellington City, O. polychroma (Chapter 3), is diurnal and heliothermic and is therefore likely to be seen basking in the open on warm days. In contrast the two most common gecko species, W. maculata and M. "southern North Island", are arboreal, active at night, and are more likely to be encountered in a refuge (van Winkel et al. 2018). These differences in habits likely influence the chance of their detection, and it is probable that this contributed to differences in the number of sightings for the two families.

More than $15 \%$ of the reports involved a cat interacting with the observed lizard making this a common characteristic of human-lizard interactions. Given that the reporting form did not specifically ask about cats and some participants may not have mentioned them in their report, it is possible this figure may underrepresent the actual number. Cats are known to be significant predators of reptiles, both in New Zealand and internationally (Gillies \& Clout 2003; Woinarski et al. 2018). However, the populationlevel impact of this predation is hard to determine due to the lack of knowledge about the size of the lizard populations being depredated. Given that cats appear to be important facilitators of human-lizard interactions in Wellington, it is possible that greater public awareness and value for lizards may be able to alter public perceptions and norms around cat ownership behaviour.

\subsubsection{Spatial distribution of human-lizard interactions}

Assuming that the probability of reporting a sighting when it occurs is equal for skinks and geckos, it is possible to make comparisons about how human-lizard interactions differ between these groups.

Skinks are more frequently encountered at residential addresses than geckos. This could be due to them being more abundant in backyards, or to them being more readily detected due to their habitat use or behaviour. Some skink species (especially $O$. polychroma) can achieve high densities in urban environments, sometimes even in the presence of high pest numbers (Chapter 3). Gecko sightings were clustered, with groups 
occurring in four distinct areas: Miramar, Mount Victoria, Wadestown and Island Bay. Interestingly, these sightings were more likely to be associated with areas of high household income. This may be due to an association with some unmeasured habitat characteristic in these areas (e.g., sizes of properties or styles of garden). In Phoenix, Arizona, lizards were thought to be more abundant and diverse in higher income areas due to the effects of garden irrigation creating more hospitable environments (Ackley et al. 2015). Alternatively, it may be that geckos are more readily detected in these areas due to garden design that makes lizards more visible, structures on properties or the behaviours of people (e.g., more frequent gardeners or home renovators).

\subsubsection{Citizen science as a tool for urban lizard conservation}

Citizen-reported lizard sightings offer potential for understanding the location of lizard populations in cities. While people's abilities to correctly identify species is highly variable, because all but one of New Zealand's lizard species are protected (Wildlife Act, 1953), knowing that any lizard is present in an area could have important implications for management (e.g., consent requirements for development). Additionally, photographs submitted as part of the project may allow expert identification to genus or even species level. In this way it could be used to identify new populations of rare species with patchy distributions (e.g., Naultinus punctatus in Wellington).

Compared with standard lizard survey techniques, citizen science offers numerous benefits for identifying locations of lizard populations at a city-wide scale. Negotiating site access and carrying out herpetological surveys at nearly 100 sites would have taken many hours of effort at great expense. Additionally, citizen-science projects such as this may offer the opportunity to gather a richness of information not possible from a standard survey. For example, it may be possible to investigate population trends by asking questions about how participants' observations have changed in the time they have lived there.

The great limitation with this style of survey, however, is its lack of absence data and quantification of search effort (van Strien et al. 2013). As a result, it is difficult to make inferences about the processes underlying the distribution of sightings. While I found that spatial patterns of reported sightings differed from the random sample of street addresses in their associations with environmental and socio-demographic factors (Fig. 3 a-f), it is impossible to know whether these patterns are driven by actual lizard occurrence 
or by variation in detection or reporting. Figure 4 illustrates a conceptual model for understanding the relationships between factors influencing the three sources of probability that contribute to the distribution of reported wildlife sightings. Socioeconomic factors such as income, educational attainment and participant's environmental attitudes are likely to influence people's likelihood of discovering the project through social media or word-of-mouth, being willing to participate and ultimately, them reporting sightings when they occur. These socio-economic factors may also influence the likelihood of detection when lizards are present through the behaviours that people engage in on their properties (e.g., home maintenance, gardening, etc.). Environmental factors such as aspect of the land, composition of its vegetation, backyard design and maintenance regimes may also influence detection, especially through their interaction with socio-economic factors. Ultimately it is the environment that determines the probability of wildlife occurrence, though in a suburban context, this too is mediated by the socio-economic characteristics of those who manage the land.

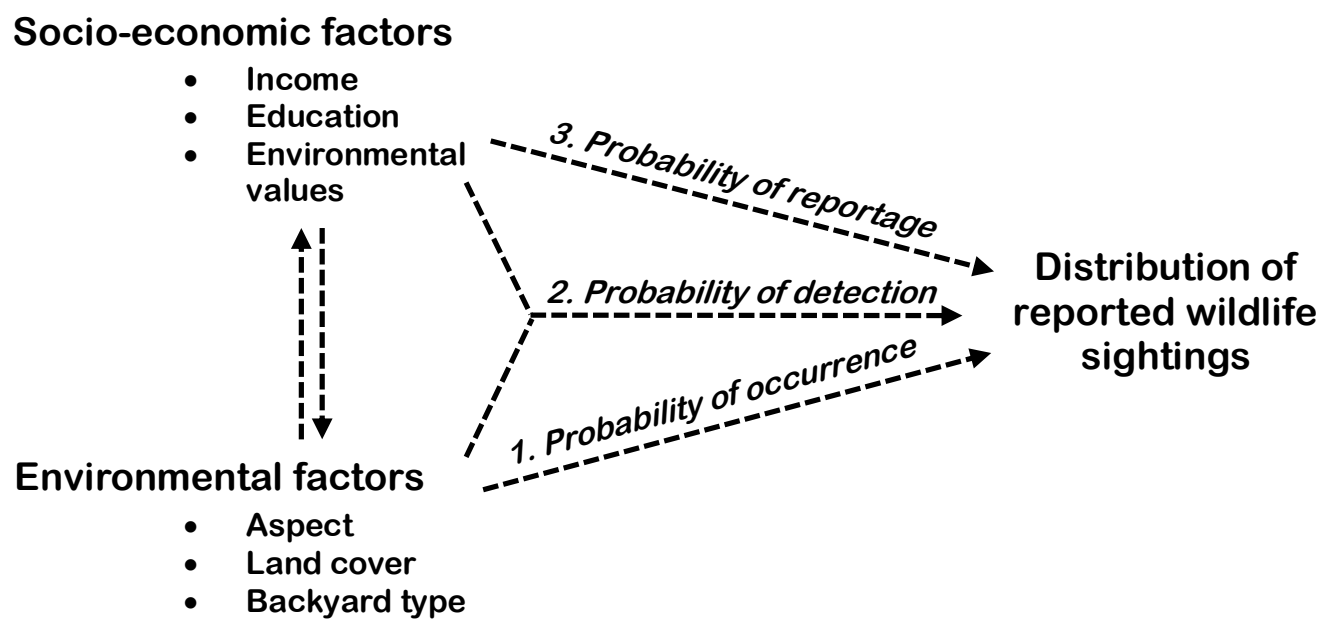

Figure 4 Diagram showing the hypothesised relationships between the factors (socio-economic and environmental) and the observed spatial pattern of reported sightings through their influence on the probabilities of occurrence, detection and reportage (numbered according to their conditionality, e.g. 3. conditional on 2., 2. conditional on 1.)

\subsubsection{Conclusions}

This study demonstrates that citizen science could be an effective tool for gathering landscape-scale information about lizards in cities, and for understanding how and where people are encountering lizards at residential properties. It found that while people encounter skinks across much of the city, gecko observations are rarer and more 
clustered. A citizen science project such as this could contribute to lizard conservation by enabling the identification of rarely observed lizard species that may be declining and informing the location of more intensive surveys. Future research should develop this tool and evaluate its potential for lizard advocacy and education. 
90 - Chapter 4: Public sightings citizen science 


\section{Chapter 5}

\section{Understanding motivation and interest for participatory conservation}

\subsection{Introduction}

\subsubsection{Urban conservation: issues and solutions}

As the human population continues to urbanise (United Nations 2014), concerns grow that city-dwellers, who have less opportunity to interact with wildlife, are becoming disconnected from nature and apathetic to environmental causes (Turner et al. 2004; Miller 2005; Soga \& Gaston 2016). At the same time, cities themselves usually have negative impacts on their endemic species and can result in the degradation or wholesale loss of native ecosystems (McKinney 2002). For these reasons, over the last two decades encouraging nature-friendly or "biophilic" cities has become an increasingly prominent goal for global biodiversity conservation (Dunn et al. 2006; Beatley 2011).

In cities, where the predominant land covers are impervious, green spaces not only serve people but also provide much needed habitat for wildlife (Standish et al. 2013). While natural areas with high biodiversity value have tended to be a focus for management (SER 2004), other informal green spaces (sensu Rupprecht et al. 2015b) and 
backyards also make important contributions (Rudd et al. 2002; Wellington City Council 2015). In many cities, residential backyards make up a significant proportion of the urban green space (e.g., 16\% in Stockholm, Sweden and 36\% in Dunedin, New Zealand; Mathieu et al. 2007; González-García \& Sal 2008), contributing valuable habitat for wildlife and providing an important setting for human-wildlife interactions (Goddard et al. 2010; Sushinsky et al. 2017).

\subsubsection{Citizen participation in ecology and conservation}

Initiatives seeking to conserve biodiversity or build ecological knowledge in cities increasingly aim to engage local residents in participatory projects related to conservation (Marzluff 2001b; Krasny \& Tidball 2012). Not only does this fulfil the goal of managing green spaces for biodiversity by making use of the resource of citizen volunteers, but also helps connect the public with nature through stewardship roles (Ives et al. 2018).

Public conservation actions include any activity undertaken by the public aimed at mitigating threats to biodiversity. Common examples range from community planting or weeding days to large-scale, long-term restoration projects (Krasny \& Tidball 2012; Clarkson \& Kirby 2016). Such projects can have significant environmental and conservation benefits and can even help facilitate the recovery of threatened species (e.g., Hamilton et al. 2011; Norris et al. 2019).

Conservation citizen science differs from public conservation action in that it does not necessarily directly benefit conservation, but rather focuses on gathering information about the environment or wildlife populations that may, or may not, be acted upon (McKinley et al. 2017; Brown \& Williams 2019). Examples of conservation citizen science projects include wildlife surveys or monitoring activities (Peters 2016; Brown \& Williams 2019). These activities can provide significant new knowledge, for example, international projects such as eBird and iNaturalist have revealed changes in species distribution and phenology resulting from climate change (e.g., Hurlbert \& Liang 2012; Soroye et al. 2018).

Any participatory project that encourages people to spend time outdoors interacting with nature may also offer social benefits for the individuals and communities taking part (Hobbs \& White 2015). These include stress relief and other health benefits (van den Berg et al. 2007; Shanahan et al. 2016), as well as community satisfaction and cohesion (Kaplan 2000; Shanahan et al. 2016). Experiences gained through participation 
in these activities can affect individuals' understanding of and relationships with nature (Nisbet et al. 2009; Toomey \& Domroese 2013). By doing so, it may encourage pathways to further environmentalism (Wells \& Lekies 2006) and help facilitate positive changes in social attitudes towards wildlife (Hobbs \& White 2015).

However, conservation using citizen participation can present additional difficulties compared with traditional approaches (Sakurai et al. 2015). A primary concern is acquiring and maintaining the support of the community and so it is essential that project design is based on the motivations and interests of those the project aims to recruit. The types of outcomes that motivate participation in environmental projects vary widely and while managers often focus on benefits to the environment, sociopsychological outcomes for participants can also be strong motivators (Asah \& Blahna 2012). These can include a sense of contributing to their community and opportunities for social interaction, learning new skills, spending time outdoors or getting exercise (Clary et al. 1992). Defending or enhancing one's ego can also be an important motivator of participation, for example, the need to feel important or alleviate guilt (Clary et al. 1992).

\subsubsection{Nature engagement and conservation in New Zealand backyards}

In New Zealand, the greatest causes of animal species endangerment are habitat loss and invasive mammalian predators (Diamond \& Veitch 1981; Towns \& Daugherty 1994). Participatory conservation projects in New Zealand cities have included, for example, restoration of remnant habitat fragments through planting, weeding and pest control (Clarkson \& Kirby 2016), and monitoring aspects of urban biodiversity (both pest and endemic species) on public land. Such projects are often led by community groups in conjunction with councils or other land managers (e.g., Clarkson \& Kirby 2016; Woolley \& Hartley 2019). Recently, however, there has been an upsurge in participatory conservation activities in residential gardens (Brumby et al. 2015; Predator Free New Zealand Trust 2018).

One notable activity is backyard trapping where residents use traps to kill small mammals on their property. Pest mammal trapping has seen a surge in popularity in New Zealand over the last five years. The concept grew in part out of the Wellington suburb of Crofton Downs which aimed to become the first suburb in New Zealand to eradicate rats and mustelids (Thomas 2016). Around 200 rodent and mustelid traps were distributed 
among recruited households (approximately one in five houses). Following the New Zealand Government's backing of a national project to make New Zealand free of predators by 2050 (Russell et al. 2015), Predator-free Wellington was established in 2016 through a partnership between Wellington City Council (WCC), Greater Wellington Regional Council (GWRC) and the Next Foundation. Predator-free Wellington's goal is to eradicate possums (Trichosurus vulpecula), mustelids (M. furo, Mustela erminea, $M$. nivalis ) and rats (Rattus rattus and $R$. norvegicus) from the entire city (Cardwell 2016). Since then, 28 suburbs have joined the 'Predator-free' initiative (Predator Free Wellington 2018).

Other conservation activities frequently carried out in backyards involve recording the numbers or types of different species. Citizen science activities such as the Great Kererū Count and the Garden Bird Survey provide ecological information (albeit with some well known limitations; Dickinson et al. 2010) and encourage people to engage with biodiversity and the natural environment in the places they live (Peters 2016).

Despite the benefits of these participatory conservation initiatives and their increasing use, in New Zealand there has been little research into sociodemographic characteristics associated with willingness to undertake them or the appeal of different motivators of participation. The dependence of New Zealand's threatened fauna on predator control and the resulting perceptions of strategies used in biodiversity conservation, may mean that motivations and willingness to undertake conservation differ from those of other countries (Sakurai et al. 2015).

\subsubsection{Aims}

I aimed to examine what demographic, experiential and philosophical perspectives of individuals are associated with willingness to undertake three different types of participatory conservation activities: 1) native biodiversity monitoring, 2) pest mammal monitoring and 3) pest mammal trapping. These three activities represent common ways in which urban-dwelling New Zealanders engage in backyard conservation but with some important differences. Pest mammal trapping is a conservation action undertaken to achieve a goal that will directly benefit native biodiversity. The monitoring activities on the other hand, are both conservation citizen science projects, one aiming to measure a positive conservation state (native biodiversity monitoring), the other a negative state 
(pest mammal monitoring). Given the differences among these activities, they are likely to appeal to different types of people.

Understanding how various personal characteristics relate to people's interest in participating in different nature-based activities is important for understanding what sort of uptake might be expected from recruitment and could inform design of participatory projects that appeal to a wider section of the community (Sakurai et al. 2015).

Specifically, I aimed to address three questions: 1) what are the sociodemographic characteristics of people who are willing to participate in the three activities?, 2) what barriers do people report that prevent them from participating? and 3) what motivations are people most likely to consider when choosing whether or not to participate and how do these different motivations relate to respondents' willingness to participate?

\subsection{Methods}

\subsubsection{Survey design and recruitment}

The questionnaire survey was designed to record information about respondents' willingness to undertake the three behaviour types, other conservation activities they engaged in, motivations for engaging, amount of time spent outdoors and relationship with nature, along with age, gender, education and income (Table 1). Methods were carried out with the approval of the Victoria University of Wellington Human Ethics Committee (Ethics approval 25153). The full questionnaire survey is available in the supplementary material (S1).

I recruited people over the age of 18 who lived in a New Zealand city using social media, direct targeting of environmental groups and tertiary biology students through email, and door knocking. As I expected the sampling to be biased towards people with pro-environmental tendencies, door knocking was used in three suburbs in Hamilton, Wellington and Dunedin to increase the chances of capturing people who were less inclined to this attitude.

\subsubsection{Statistical analysis}

Two questions were used to quantify willingness to undertake each of the behaviours (henceforth "willingness"). The first asked if the respondent was currently, or had ever undertaken the behaviour, and if they had not they were asked how interested on a $1-5$ scale ( 1 being not interested and 5 being very interested) they would be in undertaking it. 
This $1-5$ scale from the second question was retained and responses of "Yes" from the first question were categorised as a 5 (i.e., the fact that they had undertaken the behaviour was considered the highest level of willingness) to create a combined 'willingness' scale from 1 to 5 .

The amount of time spent outdoors or 'nature dosage' was measured using three questions: "How often do you usually spend more than 10 mins in your own backyard or on your deck?" (henceforth 'backyard 10 mins'), "Thinking about last week, about how much time did you spend in your own backyard or on your deck?” (henceforth 'backyard last week') and "About how often do you usually visit or pass through outdoor greenspaces for any reason?" (henceforth 'green space'). I tested the association between these measures using Spearman's rank correlation analysis in R v. 3.5.1 (R Core Team 2018) and selected the one that best represented the three. This is consistent with the approach taken in other studies using nature dose (e.g., Shanahan et al. 2016). Other predictor variables (Table 1) were checked for multicollinearity using Spearman's rank correlation analyses before running models (S2). 
Table 1 Description of variables used in analysis. The survey question numbers refer to the questionnaire survey provided in the supplementary material (S1)

\begin{tabular}{|c|c|c|c|}
\hline Variable & Description & Example statement & $\begin{array}{l}\text { Question } \\
\text { number }\end{array}$ \\
\hline Willingness & $\begin{array}{l}\text { Interest in participating indicated on a } \\
\text { five-point Likert scale. Respondents who } \\
\text { were currently participating in the activity } \\
\text { were assigned a score of five }\end{array}$ & - & $\begin{array}{l}14,15,18 \\
19,22,23\end{array}$ \\
\hline Motivations & $\begin{array}{l}\text { 18-item scale with five dimensions: } \\
\text { community, environment, social } \\
\text { interactions, ego defence and } \\
\text { enhancement, escape and exercise (from } \\
\text { Asah \& Blahna 2013). Respondents } \\
\text { indicated their level of agreement with } \\
\text { each statement (item) on a five-point } \\
\text { Likert scale. Responses were averaged } \\
\text { across items in each of the five } \\
\text { dimensions }\end{array}$ & $\begin{array}{l}\text { "To feel less guilty } \\
\text { about the problems we } \\
\text { cause to the } \\
\text { environment" } \\
\text { (dimension: ego } \\
\text { defence and } \\
\text { enhancement; see S1) }\end{array}$ & 26 \\
\hline $\begin{array}{l}\text { Nature } \\
\text { relatedness } \\
\quad(\mathrm{NR})\end{array}$ & $\begin{array}{l}\text { 21-item scale with three dimensions: self, } \\
\text { perspective and experience (Nisbet et al. } \\
\text { 2009). Respondents indicated their level } \\
\text { of agreement with each statement (item) } \\
\text { on a five-point Likert scale. Responses } \\
\text { were averaged across all } 21 \text { items for } \\
\text { combined NR between } 1 \text { and } 5\end{array}$ & $\begin{array}{l}\text { "I enjoy being } \\
\text { outdoors even in bad } \\
\text { weather" (dimension: } \\
\text { experience; see S1) }\end{array}$ & 28 \\
\hline $\begin{array}{l}\text { Nature } \\
\text { dosage }\end{array}$ & $\begin{array}{l}\text { Ordinal variable indicating the self- } \\
\text { reported frequency of usage of backyard } \\
\text { or deck for more than } 10 \text { minutes from } \\
\text { eight categories }\end{array}$ & - & 4 \\
\hline Age & $\begin{array}{l}\text { Age in years, selected from } 12 \text { ordinal } \\
\text { categories }\end{array}$ & - & 29 \\
\hline Gender & $\begin{array}{l}\text { Gender, selected from three categories: } \\
\text { female, male and gender diverse }\end{array}$ & - & 30 \\
\hline Education & $\begin{array}{l}\text { The highest formal educational } \\
\text { qualification achieved by the respondent, } \\
\text { grouped into nine categories treated as an } \\
\text { ordinal variable }\end{array}$ & - & 32 \\
\hline Income & $\begin{array}{l}\text { Total annual income before tax selected } \\
\text { from } 15 \text { categories defined based on the } \\
\text { income question provided in the New } \\
\text { Zealand census. For analysis purposes, } \\
\text { the categories were numbered from } \\
\text { lowest income to highest and treated as an } \\
\text { ordinal variable }\end{array}$ & - & 34 \\
\hline
\end{tabular}


I assessed differences in willingness among the three activities using a Kruskal-Wallis test and made pairwise comparisons using Wilcox tests.

Three cumulative link models (CLMs) were then run using the 'ordinal' package (Christensen 2018) in R to identify how the measured attributes relate to willingness to participate (i.e., one model for each of the three activity types). The 5-point willingness scale was the response variable and nature relatedness, nature dosage, age, sex, income, and education were predictors. Due to concerns that participation in any of the activities might influence the measure of nature dosage, these models were run with and without participants who indicated they were or had previously undertaken the activities. To understand how the association between nature relatedness and willingness to participate differs for the three activity types, I tested between the coefficients with a $z$-test using the method outlined by Clogg et al. (1995) which gives an unbiased estimate of the standard deviation of the sampling distribution (Paternoster et al. 1998).

Respondents who had not undertaken the behaviour but who expressed a high level of interest for a particular activity (responses greater than 3) were asked to describe what barriers they felt impeded participation in that activity. Responses were grouped into eight categories: time constraints, financial costs, lack of knowledge about how to undertake the activity or obtain required equipment, lack of suitable environment for activity, lack of motivation, safety of children or pets, aversion to handling dead animals and animal welfare. To compare the frequency of reporting of the different barrier types among the activities, I used mixed effects logistic regression. Eight different models were run (one for each barrier type) with the binary response 'barrier reported' (reported/not reported), activity type (biodiversity monitoring/pest monitoring/pest trapping) as a fixed factor and respondent ID as a random factor. A binomial distribution of errors was assumed.

Scores indicated by respondents for the different types of motivation were compared using a one-way ANOVA followed by a Tukey test of multiple comparisons in $\mathrm{R}$ (package 'stats' v. 3.6.1). To assess how respondents' motivations for participating in conservation related to their willingness to participate in the three activities, I ran a CLM for each combination of activity's willingness score and motivation type (i.e., 15 models in total). This was necessary as all of the motivation types were highly correlated with one another. 


\subsection{Results}

\subsubsection{Respondent demography}

The survey was completed by 299 people from around New Zealand. The majority of responses $(n=175,58.5 \%)$ came from the Wellington region but others came from the other major centres: Auckland $(n=5)$, Hamilton $(n=45)$, Christchurch $(n=3)$ and Dunedin $(n=19)$ and numerous smaller towns. Door knocking resulted in the recruitment of $65(21.7 \%)$ responses with the remaining responses coming via online surveys.

More respondents were female $(n=178,59.5 \%)$ than male $(n=118,39.5 \%)$ and three respondents were gender diverse (1.0\%). The median income bracket of respondents was $\$ 50,001-\$ 60,000$ per year $(\operatorname{mode}=\$ 70,001-\$ 100,000 ; n=55)$, the median age bracket was $41-45$ years (mode $=26-30$ years; $n=21$ ), and the median qualification was a bachelor's degree (mode $=$ post-graduate degree; $\mathrm{n}=138)(\mathrm{S} 3)$. The three questions asking about time spent outdoors were significantly correlated (Backyard 10 mins Greenspace, $\mathrm{r}=0.265, \mathrm{p}<0.001$; Backyard 10 mins $\sim$ Backyard last week, $\mathrm{r}=0.670, \mathrm{p}<$ 0.001; Greenspace $\sim$ Backyard last week, $r=0.182, \mathrm{p}<0.01$ ). As a result, I used only 'backyard 10 mins' to represent nature dosage to avoid multicollinearity in models, as it correlated most strongly with the two others. Only 12 respondents $(4.01 \%)$ reported not having a backyard or deck and most respondents spend at least 10 minutes in their backyard or on their deck on average more than two days a week $(n=192,64.0 \%)(\mathrm{S} 3)$. The most frequently reported activity undertaken in backyards was hanging out the washing $(n=247)$ followed by relaxing $(n=210)$, gardening (other than vegetable) $(n=$ 196), and home maintenance $(\mathrm{n}=178)$. Among respondents, nature relatedness ranged from 2.57 to 4.76 with a mean of 3.92 .

\subsubsection{Willingness to participate in backyard nature-based activities}

Of the 299 respondents, $52.5 \%$ indicated that they had at some time engaged in one of the three activities of interest. Backyard pest trapping was the most commonly reported of the three activities with $45.4 \%$ of respondents reporting undertaking it. The two monitoring activities were undertaken around half as frequently with $23.1 \%$ reporting undertaking biodiversity monitoring and $20.4 \%$ pest monitoring. The respondents' willingness to participate varied significantly by behaviour type $\left(\chi^{2}=6847.1, \mathrm{df}=10, \mathrm{p}<0.001\right)$. On average, willingness scores were $8.2 \%$ higher for pest trapping ( $4.25 \pm 0.068 \mathrm{SE})$ than pest monitoring $(3.93 \pm 0.073 \mathrm{SE} ; \mathrm{p}<0.001)$ and $4.2 \%$ higher for pest trapping than 
biodiversity monitoring $(4.08 \pm 0.071 \mathrm{SE} ; \mathrm{p}=0.044)$. Willingness scores for biodiversity monitoring were on average $3.8 \%$ higher than pest monitoring, however this difference was non-significant $(p=0.099)$. Although willingness scores for the different activities were significantly correlated (pest trapping $\sim$ pest monitoring $r=0.56, p<0.001$; pest trapping $\sim$ biodiversity monitoring $\mathrm{r}=0.45, \mathrm{p}<0.001$; pest monitoring $\sim$ biodiversity monitoring $\mathrm{r}=0.63, \mathrm{p}<0.001$ ), only $57 \%$ (171) of respondents reported high willingness scores (scores greater than three) for all of the activities, with 14\% reporting high scores for only a single activity type and $18 \%$ for two (Fig. 1)

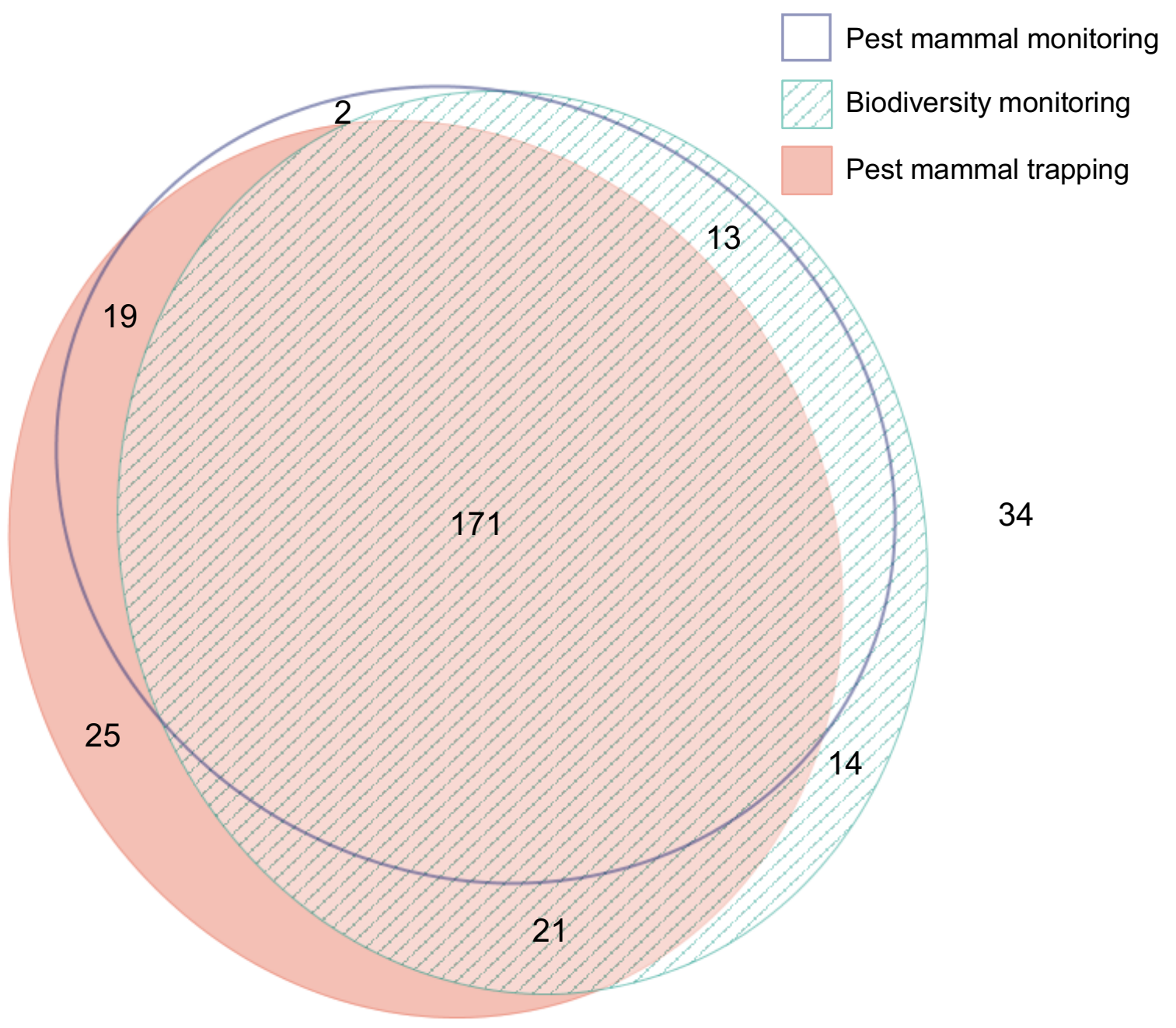

Figure 1 Venn diagram illustrating the number of respondents reporting willingness scores of four or five for various combinations of the three activity types $(n=299)$. Diagram created using EulerAPE v3 (Micallef \& Rodgers 2014) 
Two factors were significant predictors of willingness to participate in all three of the CLMs. Nature relatedness and nature dosage were found to be positively related to willingness to undertake all three activity types (Fig. 2, Table 2). Removing participants who had previously participated in the activities and might be spending more time in their backyards as a result had no effect on the significance or direction of the relationships for nature dosage. Additionally, education was found to be positively related to participation in biodiversity and pest monitoring. Gender, age and income were non-significant in all models (Table 2).

I found weak support that the relationship between nature relatedness and willingness varied in strength between the three activity types. The relationship with biodiversity monitoring was 1.9 times stronger than with pest trapping $(\mathrm{z}=1.518, \mathrm{p}=$ 0.065). Differences between the relationship with biodiversity monitoring and pest monitoring $(\mathrm{z}=0.942, \mathrm{p}=0.173)$, and pest monitoring and pest trapping $(\mathrm{z}=0.628, \mathrm{p}=$ $0.265)$ were non-significant.
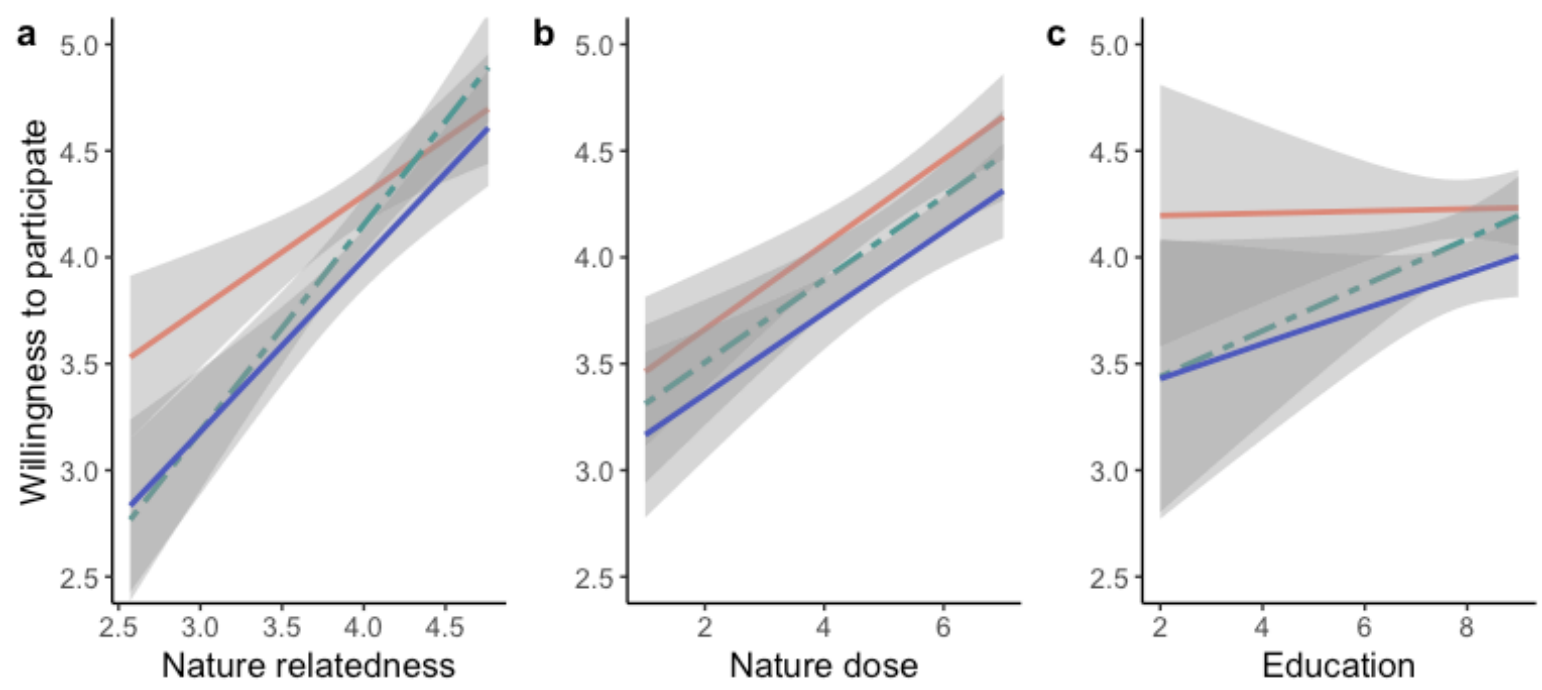

-Pest trapping --Biodiversity monitoring -Pest monitoring

Figure 2 Relationships between willingness to undertake each of the three behaviours and $\mathbf{a}$. nature relatedness, b. nature dosage, and c. education. Nature relatedness and dosage were significant predictors of willingness to participate for all activities while education was a significant predictor for only the monitoring activities. Areas shaded grey are $95 \%$ confidence intervals 
Table 2 Model estimates of the three CLMs. Willingness to undertake the behaviour is the response. Female was the reference category for gender. Variables and figures highlighted in bold are significant at $\mathrm{p}<0.05$

\begin{tabular}{rcccc} 
& Estimate & Std. Err. & z-value & p-value \\
\hline Biodiversity monitoring & & & & \\
Nature relatedness & $\mathbf{1 . 3 1 3}$ & $\mathbf{0 . 2 9 2}$ & $\mathbf{4 . 4 9 3}$ & $<\mathbf{0 . 0 0 1}$ \\
Gender: Gender diverse & 0.255 & 1.284 & 0.198 & 0.843 \\
Gender: Male & 0.067 & 0.283 & 0.237 & 0.813 \\
Age & 0.001 & 0.051 & 0.021 & 0.983 \\
Education & $\mathbf{0 . 2 4 4}$ & $\mathbf{0 . 0 9 5}$ & $\mathbf{2 . 5 5 1}$ & $\mathbf{0 . 0 1 1}$ \\
Income & 0.025 & 0.038 & 0.656 & 0.512 \\
Nature dosage & $\mathbf{0 . 3 0 0}$ & $\mathbf{0 . 0 9 1}$ & $\mathbf{3 . 3 1 0}$ & $<\mathbf{0 . 0 0 1}$ \\
\hline & & & & \\
Pest monitoring & & & & \\
Nature relatedness & $\mathbf{0 . 9 3 4}$ & $\mathbf{0 . 2 7 7}$ & $\mathbf{3 . 3 7 6}$ & $<\mathbf{0 . 0 0 1}$ \\
Gender: Gender diverse & -0.382 & 1.085 & -0.352 & 0.724 \\
Gender: Male & -0.019 & 0.270 & -0.071 & 0.944 \\
Age & 0.017 & 0.049 & 0.345 & 0.730 \\
Education & $\mathbf{0 . 2 2 8}$ & $\mathbf{0 . 0 9 1}$ & $\mathbf{2 . 5 1 6}$ & $\mathbf{0 . 0 1 2}$ \\
Income & 0.032 & 0.036 & 0.880 & 0.379 \\
Nature dosage & $\mathbf{0 . 2 7 6}$ & $\mathbf{0 . 0 8 7}$ & $\mathbf{3 . 1 8 9}$ & $\mathbf{0 . 0 0 1}$ \\
\hline & & & & \\
Nature relatedness & $\mathbf{0 . 6 7 8}$ & $\mathbf{0 . 2 9 9}$ & $\mathbf{2 . 2 6 5}$ & $\mathbf{0 . 0 2 4}$ \\
Gender: Gender diverse & -0.596 & 1.363 & -0.437 & 0.662 \\
Gender: Male & -0.029 & 0.298 & -0.097 & 0.923 \\
Age & 0.062 & 0.056 & 1.103 & 0.270 \\
Education & 0.043 & 0.105 & 0.414 & 0.679 \\
Income & 0.069 & 0.040 & 1.743 & 0.081 \\
Pest trapping & $\mathbf{0 . 4 0 6}$ & $\mathbf{0 . 0 9 3}$ & $\mathbf{4 . 3 5 1}$ & $<\mathbf{0 . 0 0 1}$ \\
\hline Nature dosage & $\mathbf{0 . 5 3}$ & &
\end{tabular}

\subsubsection{Barriers to participation}

Lack of knowledge and motivation were frequently reported barriers in all three activities, however, the frequency of reporting of the other barriers varied among the activity types (Fig. 3). Concern for the safety of children and pets was reported as a barrier more frequently for pest trapping than pest monitoring and not at all for biodiversity monitoring. Lack of time was reported more frequently as a barrier to monitoring activities than for trapping, and more frequently for biodiversity monitoring than pest monitoring. Lacking a suitable environment in which to carry out the activity was reported as a barrier more frequently for pest trapping than either monitoring activities. 
Three types of barrier were only reported for pest trapping: animal welfare, cost and having to deal with dead animals (Fig. 3).

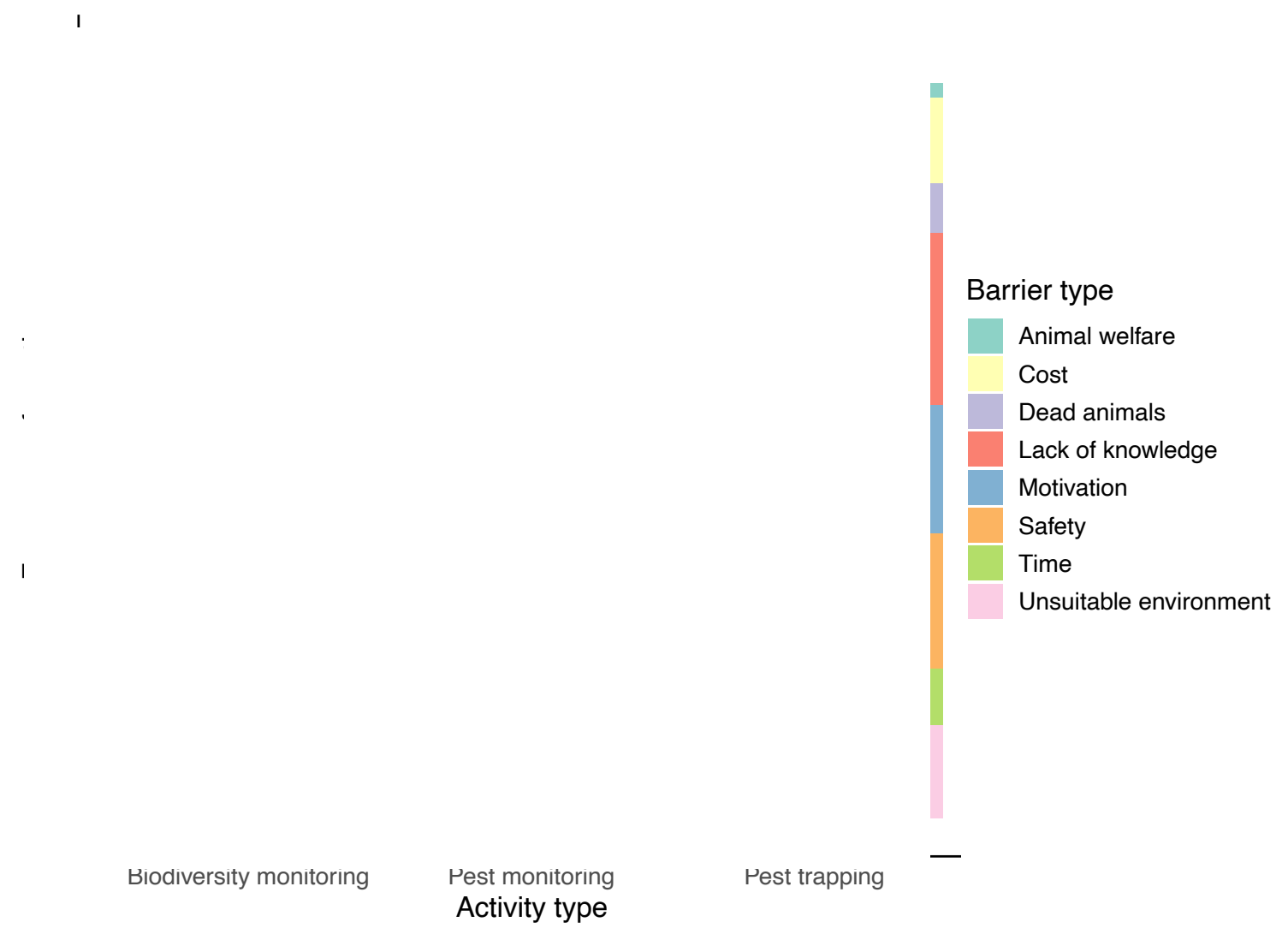

Figure 3 Frequency of mentions of different barrier types per number of responses from respondents who had never engaged in the activity but indicated a willingness greater than three. Activities that differ significantly in their frequency of reportage for a particular barrier type are labelled with non-identical letters

\subsubsection{Motivations}

Of the suggested reasons for participating, respondents indicated they were more likely to be motivated by environmental reasons than any other motivation type $\left(\mathrm{F}_{4,1484}=50.8, \mathrm{p}<\right.$ 0.001; Fig. 4). Participants also indicated they were more likely to consider social motivations than either the ego defence and enhancement or the escape and exercise motivations $\left(\mathrm{F}_{4,1484}=50.8, \mathrm{p}<0.05 ;\right.$ Fig. 4$)$. No other comparisons were significantly different. 


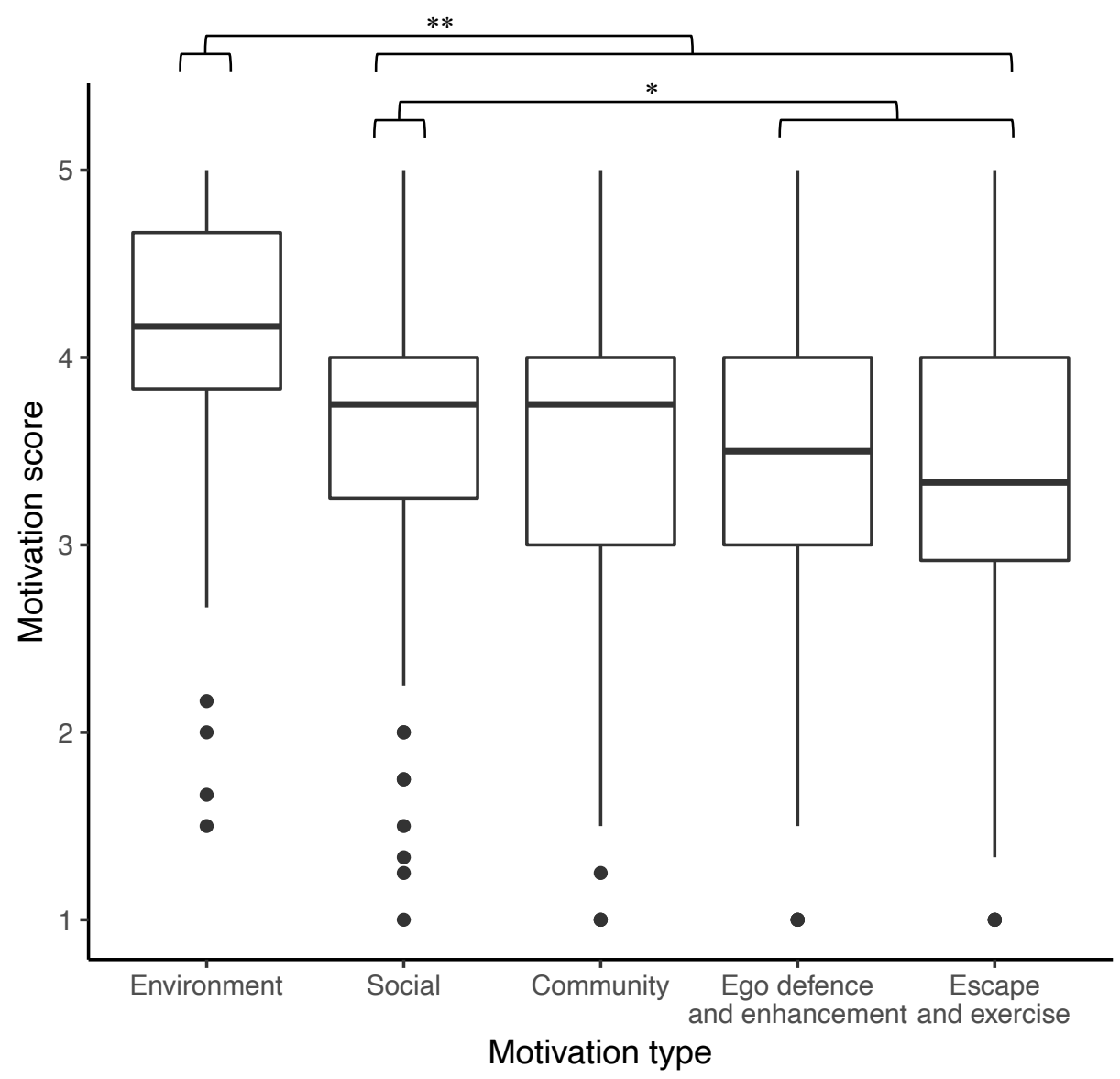

Figure 4 Results of ANOVA comparing the scores indicated by respondents for the different motivation types. Scores of 5 indicated participants were very likely to consider this when taking part. Box plot conventions are 'ggplot2' package defaults. Asterisks indicate statistically significant differences: $* \mathrm{p}<0.05, * * \mathrm{p}<0.001$

As motivation types were all significantly correlated with each other, relationships between motivation types and willingness scores for the activities were tested separately. Environment as a motivation was a significant positive predictor of willingness to undertake all three activities (Table 3). Its relationship with willingness was more than twice the strength for biodiversity monitoring than it was for pest mammal trapping. Ego defence and enhancement was also a significant positive predictor for all three activities, and community and social motivations were significant positive predictors for the two monitoring activities (Table 3). The escape and exercise motivation was non-significant in all of the models. 
Table 3 Relationships between willingness scores for the three activity types and the five motivation types. Due to all of the motivation types being significantly correlated each was run individually in the CLMs with each of three activity types. Variables and figures highlighted in bold are significant at $\mathrm{p}<0.05$

\begin{tabular}{rrrrr} 
& Estimate & Std. Err. & z value & p value \\
\hline Biodiversity monitoring & & & & \\
Community & $\mathbf{0 . 5 7 2}$ & $\mathbf{0 . 1 7 3}$ & $\mathbf{3 . 3 0 6}$ & $<\mathbf{0 . 0 0 1}$ \\
Environment & $\mathbf{1 . 2 3 7}$ & $\mathbf{0 . 2 3 6}$ & $\mathbf{5 . 2 3 8}$ & $<\mathbf{0 . 0 0 1}$ \\
Social & $\mathbf{0 . 4 9 0}$ & $\mathbf{0 . 1 8 5}$ & $\mathbf{2 . 6 4 9}$ & $\mathbf{0 . 0 0 8}$ \\
Ego defence and enhancement & $\mathbf{0 . 3 1 4}$ & $\mathbf{0 . 1 5 9}$ & $\mathbf{1 . 9 8 0}$ & $\mathbf{0 . 0 4 8}$ \\
Escape and exercise & 0.092 & 0.136 & 0.677 & 0.498 \\
\hline & & & & \\
Pest monitoring & & $\mathbf{0 . 1 6 3}$ & $\mathbf{2 . 8 3 2}$ & $\mathbf{0 . 0 0 5}$ \\
Community & $\mathbf{0 . 4 6 2}$ & $\mathbf{0 . 8 0}$ & $\mathbf{4 . 0 0 2}$ & $<\mathbf{0 . 0 0 1}$ \\
Social & $\mathbf{0 . 4 7 1}$ & $\mathbf{0 . 1 7 0}$ & $\mathbf{2 . 7 6 9}$ & $\mathbf{0 . 0 0 6}$ \\
Ego defence and enhancement & $\mathbf{0 . 3 8 4}$ & $\mathbf{0 . 1 5 3}$ & $\mathbf{2 . 5 0 9}$ & $\mathbf{0 . 0 1 2}$ \\
Escape and exercise & -0.034 & 0.130 & -0.264 & 0.792 \\
\hline Pest mammal trapping & & & & \\
Community & 0.283 & 0.168 & 1.681 & 0.093 \\
Environment & $\mathbf{0 . 6 1 6}$ & $\mathbf{0 . 2 2 2}$ & $\mathbf{2 . 7 6 9}$ & $\mathbf{0 . 0 0 6}$ \\
Social & 0.074 & 0.183 & 0.405 & 0.686 \\
Escape and exercise & -0.048 & 0.141 & -0.338 & 0.735 \\
\hline
\end{tabular}

\subsection{Discussion}

\subsubsection{Willingness to participate in backyard conservation activities}

In general, this study found that respondents were more willing to participate in the three activities if they scored highly in nature relatedness, spent more time outside and, for the two monitoring activities, had higher educational qualifications. Nature relatedness is a complex concept, incorporating people's identification, familiarity and comfort with nature as well as nature-related worldviews (Nisbet et al. 2009). Similar to other concepts of connection to nature (Tam 2013), it has previously been shown to correlate with membership to environmental organisations and proenvironmental behaviours (Nisbet et al. 2009; Whitburn et al. 2019). It was expected that nature dosage would be related to willingness to participate as carrying out the activities requires people to have the ability and inclination to be outside. Time spent in nature has previously been shown to relate to environmental attitudes (Wells \& Lekies 2006). A 12-year longitudinal study found that environmentally responsible behaviour in adulthood was related to time spent outdoors as 
a child (Evans et al. 2018). Age, gender and income were not important predictors in the models, in keeping with recent meta-analysis of the relationship between connection to nature (including nature relatedness) and proenvironmental behaviour which found no evidence that age and sex moderate the relationship (Whitburn et al. 2019).

Additionally, I found that a number of different motivations are related to willingness to engage in the different activities. The strongest of these, and the one present for all activity types was environmental concern, with participants indicating they are motivated by 'protecting the environment' or 'contributing to sustainability'. Interestingly, people were also motivated by the opportunity to spend time with friends or like-minded people, and contribute to and connect with their community, indicating the importance of these attributes to those who take part (Takase et al. 2019).

\subsubsection{Differences between the activity types}

While willingness score for all of the activities was predicted by participants' relationships and experience with nature, in other ways the activity types differed. Willingness scores were generally greater for biodiversity monitoring than for pest monitoring, and greater for pest mammal trapping than either of the monitoring activities. This same pattern was observed in the proportions of participants who indicated a high willingness (responses of four or five) for only one of the three activities: $8.4 \%$ for pest trapping, $4.7 \%$ for biodiversity monitoring and $0.7 \%$ for pest monitoring (Fig. 1). The higher willingness to engage in the trapping of small mammals in New Zealand possibly reflects the importance of ecological and social context for conservation (Russell 2014) and may not be indicative of this activity's appeal internationally. In New Zealand, pest mammals present one of the greatest threats to many of the country's endemic species (King 1990; Stoll, Maclean \& Holwell 2015). As a result, control of introduced mammals by trapping or poisoning is a well-established form of conservation management that is generally accepted by the public (Russell 2014).

People's willingness to carry out trapping may also reflect the fact that it was the only one of the activities that offers tangible benefits for native wildlife (by reducing densities of mammalian predators). Equally, the recent rise in predator-free community groups and the availability of easy-to-use traps has likely reduced barriers to trapping and increased its public acceptability (Predator Free Wellington 2018). Interestingly, the relationship between willingness to trap and nature relatedness was weaker than that with 
other activities. This difference may be driven by respondents with low nature relatedness scores being more willing to participate, rather than those with high scores being less willing. There are several plausible reasons why trapping may appeal to people who are less motivated by environmental goals including the perception of rodents as domestic, as well as environmental pests, or the present popularity of pest trapping in some cities which might drive a normative increase to participation (Clayton \& Myers 2009). Alternatively, it is also possible that the killing of animals (even pest species) may be at odds with the values of some people who score highly on nature relatedness. High nature relatedness scores have been found to be associated with strong affiliations with animals and vegetarianism (Nisbet et al. 2009). Unfortunately, there were too few responses reporting concerns about animal welfare and needing to handle dead animals as barriers to allow assessment of its effect on nature relatedness.

Level of highest educational qualification had a positive relationship with willingness score for the two monitoring activities but not for pest trapping (Table 2, Fig 2). This may be related to the different outcomes of the three activity types. A number of studies have established a link between educational attainment and nature engagement, including higher rates of participation in nature-related activities (Zuo et al. 2016), use of public gardens (Shanahan et al. 2017) and environmental concern (Clery \& Rhead 2013). The weaker relationship for pest trapping is likely due to the fact that willingness to undertake trapping is driven by factors other than environmental concern (e.g., removal of domestic pest, social norms).

\subsubsection{Barriers to participation in backyard conservation}

Identification of the barriers to participation can provide some insight into respondents' perceptions of these three activities. Two barriers frequently reported for all activities were lack of knowledge and lack of motivation. People lacking knowledge frequently reported not knowing how to obtain necessary equipment to do the activity (e.g., traps or tracking gear) as well as how to carry it out. Those classified as lacking motivation reported not seeing any reason to (especially not needing to trap rodents as they did not see them on their property) or not knowing who would have a use for the information. These comments illustrate the importance of clear communication about the purpose of pro-conservation actions and how the public can take part. Respondents also reported concerns about the time taken to participate in monitoring, particularly for biodiversity 
monitoring, however this was less of an issue for pest trapping. It is possible that popularity of trapping might be in part attributed to a perception that it requires less time than the other activities, however, its rates of reportage of some other barrier types were the highest of the three. Safety concerns for pets and children, concerns about the welfare of animals and a dislike for having to deal with animal carcasses were more frequent barriers for, and in some cases unique to, trapping. In addition, trapping was perceived by more people as expensive and having greater requirements of space or a particular type of backyard. Identification of barriers may provide opportunities to the designers and managers of participatory conservation projects to either modify them to make them more appealing or to resolve misconceptions regarding activities. No clear pattern was evident in the reportage of barriers that could help explain the differences in willingness among the activities.

\subsubsection{Motivating participation in backyard conservation}

As expected, willingness scores for all three activities were positively related to how likely respondents were to be motivated by environmental concern. Interestingly, the strength of these associations varied among the activity types with a similar pattern to that of willingness and nature relatedness (biodiversity monitoring $>$ pest monitoring $>$ pest trapping). This supports the notion that pro-environmental attitude has less influence on people's willingness to trap than for the other activities.

I expected that community and social motivations might be positively associated with pest trapping as, anecdotally, this activity seems to provide opportunities for the community to get to know one another. Instead, positive relationships existed for the monitoring activities but not for trapping. This indicates that although participants of pest trapping may enjoy social opportunities as a result of taking part, this is unlikely a factor motivating their initial participation.

\subsubsection{Implications for conservation and future research}

In general, people who are more related to nature and spend more time outdoors were more willing to participate in the three backyard conservation activities. This is unsurprising given that environmental concern was rated as the most important motivator of participation. However, participatory conservation activities, such as those used in this study, are as much opportunities for people to be affected by nature experiences as they 
are for people to affect positive change on the environment. Behaviours such as pest trapping that are satisfying for reasons other than their conservation or environmental benefits may be especially valuable to biodiversity conservation if they encourage people with low-conservation values to begin a path towards environmental stewardship (Clayton \& Myers 2009; Colléony et al. 2019). This may be especially the case when activities have a social component or increased exposure to nature associated with them (Clayton \& Myers 2009). The idea that experiences had while undertaking behaviours might be influential in changing future behaviour patterns, through altering nature relatedness could be important when encouraging participation (Soga \& Gaston 2016). Further research should examine what effects, if any, participation in different conservation activities has on participants' nature relatedness and motivation for taking part.

\subsubsection{Conclusions}

This study found that willingness to participate in backyard conservation activities was positively related to respondents' nature relatedness, nature dosage and, for the two monitoring activities, education. It was also related a number of motivation types, in particular environmental concern. Variation in the strength of these relationships among the three activities indicates that different characteristics of activities may influence how broadly they appeal to the public. In New Zealand, pest mammal trapping appears to hold broader appeal and be less related to environmental concern than biodiversity monitoring activities. These sorts of activities may be important for encouraging people with lowconservation values to begin a path towards environmental stewardship. 
110 - Chapter 5: Motivations for participatory conservation 


\section{Chapter 6}

\section{Conservation of lizards in cities}

\subsection{Introduction}

The rapid urbanisation of the world's population is bringing about dramatic ecological and social changes that have implications for species conservation, ecosystem function, and ultimately human welfare (Bolund \& Hunhammar 1999; Miller 2005; Mcdonald et al. 2008). One way to lessen these impacts is to encourage nature to thrive in cities through urban restoration (SER 2004) and reconciliation ecology (Rosenzweig 2003b). These actions require not only knowledge of the ecology of the species that live in these highly modified environments but also a nature-engaged urban populace. To support initiatives that promote biodiversity in cities, research must take a multidisciplinary approach that considers the socio-ecological nature of urban ecosystems (Farinha-Marques et al. 2011).

In this thesis, I have drawn together the ecological and social facets of urban lizard conservation. Its central aim was to investigate the conservation of endemic lizards in New Zealand cities by examining the current status of populations, how populations may be supported, and what role public participation might play in their conservation. 
In doing so, I addressed the following four key research questions:

- What lizards historically would have lived in the regions of New Zealand cities? (Chapter 2)

- What lizards are currently found in cities? (Chapters 2, 3 and 4)

- What factors in urban environments impact lizard populations? (Chapter 3)

- What can be done to support lizards in cities? (Chapters 2, 3 and 5)

The four data chapters answer these questions by presenting: a review of current knowledge of New Zealand's past, present and potential urban lizard fauna, robust baseline data of urban skink populations from a range of habitats in four cities, additional landscape-scale data of lizard occurrence from public-reported lizard sightings in Wellington, and questionnaire survey data examining public willingness to engage in backyard conservation activities. These chapters contribute towards the thesis's ultimate aim of providing knowledge that will inform urban management and restoration of lizards. In this final chapter, I summarise the findings of these studies and synthesise knowledge gained from them to make recommendations about how lizards should be managed in cities.

\subsection{Chapter overviews}

6.2.1. Chapter 2: Reviewing the past, present and potential lizard faunas of New Zealand cities

Knowledge about current and historical species distributions is essential for developing a plan for conservation and ecological restoration. In Chapter 2, I defined urban boundaries for six New Zealand cities and collated knowledge about current and historical (prehuman) lizard faunas within these areas. Little research had been published about lizards within these areas and the majority of records came from unpublished reports of salvage or biosecurity operations, as well as regional and national databases. Comparing the current and historical faunas, I found that, although each of the cities has at least one currently urban-dwelling species, the diversity of lizards in all of the cities has declined dramatically since human colonisation. Patterns of species loss in cities reflect those observed across New Zealand more generally; that is, the loss of large-bodied skinks and geckos, likely resulting from predation by introduced mammals, as well as the loss of regionally endemic species. This chapter also highlights opportunities for lizard 
conservation in cities including reintroductions into predator-free sanctuaries, community restoration of urban reserves, and backyard conservation initiatives such as lizard gardening and pest trapping.

\subsubsection{Chapter 3: Establishing population baselines of skinks in New Zealand} cities

To address the knowledge gaps identified in the previous chapter, in Chapter 3 I aimed to build knowledge about urban lizard populations by carrying out skink surveys in four New Zealand cities. Pitfall trapping was used to capture terrestrial skinks in a range of urban habitats, including reserves, informal greenspaces (such as cemeteries, parks, margins of transport infrastructure), and domestic gardens. Species diversity and characteristics of skink populations including density estimates and individual morphometrics were recorded and related to habitat characteristics and pest mammal abundances at study sites. Four species of endemic skink were captured during surveys in urban habitats, Oligosoma aeneum in Hamilton; O. polychroma, O. aeneum and $O$. ornatum in Wellington; O. polychroma in Nelson; and $O$. aff. polychroma Clade 5 in Dunedin. Site occupancy and numbers of captures were highly variable among species and cities, with a very high proportion of sites occupied by skinks in Nelson and Wellington compared with Hamilton and Dunedin. Modelling showed O. polychroma catch per unit effort was positively related to rat tracking rates when grass cover was low but showed a negative relationship when grass cover was high. Higher proportions of urban land cover within $500 \mathrm{~m}$ was negatively associated with $O$. polychroma body condition.

\subsubsection{Chapter 4: Using citizen science to understand human-wildlife} interactions in urban environments

Responding to the challenges of surveying non-vagile taxa in cities where land use and ownership is highly heterogeneous, in Chapter 4 I used a novel approach to gather data about lizard distributions. Using an online tool, I gathered citizen-contributed sightings of lizards from around Wellington, recording information about the context of the sighting as well as location. The distribution of these records was mapped and their occurrence analysed with respect to a range of environmental and socio-economic factors by comparing these with pseudoabsences. The public sightings website gathered more than 
100 records from around the Wellington region over one summer, suggesting this may be a cost-effective solution to building knowledge about lizards in residential gardens that are otherwise difficult to survey. While skink sightings were reported from all over the city, gecko sightings appeared in clusters. Compared with the random sample of street addresses, both skink and gecko sightings were more common closer to forest land cover, and skink sightings were more common in backyards that were north facing.

\subsubsection{Chapter 5: Understanding motivation and interest for participatory conservation}

In Chapter 5, I investigated relationships between sociodemographic characteristics and people's willingness to undertake three different backyard conservation activities (trapping of pest mammals, monitoring of pest mammals and monitoring of native animals) in New Zealand cities. I also examined relationships between different types of motivations and willingness. Willingness to engage in the pest trapping activity was greater than that of the other activities, and although willingness scores for all activities were related to respondents' nature relatedness and environmental motivation, these relationships were weakest for pest trapping. Degree of willingness was also positively related to nature dosage for all three activities and education for the two monitoring activities, as well as various motivation types. Differences in the relationships between respondent characteristics and willingness may be due to differences in the activities in terms of: the nature of their outcomes (tangible benefit to predator-vulnerable species through trapping compared with increased knowledge through monitoring), social perceptions of the wildlife they involve (positive for native wildlife $\mathrm{cf}$. negative for pest species) and their appeal to the public for reasons other than their conservation benefits (e.g., removal of pest species for hygiene or aesthetic reasons). Activities that benefit the environment while also offering additional benefits to those that take part may offer opportunities for encouraging people with low-environmental values to begin a path towards nature stewardship.

\subsection{Discussion and future research}

\subsubsection{Overview}

Endemic lizards are present in six of New Zealand's largest cities and likely many other urban centres around the country (Chapters 3 and 4). The species that survive in cities are 
those that can, at least to some extent, withstand the challenges of land cover change and mammalian predation (Woolley et al. 2019; Chapter 2). Some species appear to be almost ubiquitous in cities within their range, occurring in urban reserves and other urban green spaces (Chapter 3), and being encountered by the public in residential gardens (Chapter 4). Other species are rarely observed and may be present only in low numbers (Chapter $3)$.

This thesis has brought to light a number of knowledge gaps that require addressing to ensure this integral part of New Zealand's fauna remains present in cities in the future. These include which species occur in cities and in what habitats, which populations are vulnerable, and how these should be managed. In this section, I discuss how managers can build knowledge about urban lizards, what can be done to support existing populations and what future role human-nature engagement may have on their conservation, as well as opportunities for future research.

\subsubsection{How can we improve knowledge of urban lizard populations?}

In light of the dearth of information about lizards in cities identified in Chapter 2, there is a pressing need to build knowledge about what species are occurring in cities, where they are present and which populations are vulnerable.

A good place for managers to start building this knowledge is with broad-scale species occurrence (Table 1: Question 1). While this type of information might seem trivial, it appears that it is lacking for many New Zealand cities (Chapter 2), despite it being essential for protecting populations. In particular, it may help to protect lizards from habitat destruction and disturbance during urban development. Because all endemic lizards and their habitat are protected under the Wildlife (1953) and Resource Management (RMA, 1991) Acts, developers are required to mitigate the impacts of their activities on populations. However, due to the lack of knowledge about the locations of lizard populations, development in some jurisdictions takes place under the assumption that no populations are present. In addition to protecting populations that are at risk from development, knowledge of where lizard populations occur is important for informing where more targeted, resource-intensive surveys should take place in the future.

Using a wide variety of data sources, it may be possible to gather broad-scale distribution data with a relatively low investment of resources. For many cities, much of this information may come through surveys required under the RMA, such as those gathered in Chapter 2. This information could be supplemented with public-contributed 
records from iNaturalist or a purpose-built lizard citizen science project like the Lizard Locator (Chapter 4). While I trialled the Lizard Locator tool in backyards, such projects could be tailored to other urban contexts by targeting contract gardeners working in public green spaces or community groups in urban reserves. Despite some limitations, citizen science is an effective method for gathering large-scale data about species distributions in cities (Dickinson et al. 2010). The Lizard Locator citizen science tool recorded the presence of lizards at nearly 100 sites in Wellington over the course of one summer. While conducting expert lizard surveys in 100 backyards would have provided higher quality information and avoided limitations resulting from a lack of absence data, the time and financial cost of undertaking such surveys would likely have been prohibitive. Furthermore, the limited data provided by citizen science can be sufficient to contribute to conservation (Soroye et al. 2018; Norris et al. 2019). For example, although a key limitation of the Lizard Locator was its lack of species-level identification, because all New Zealand endemic lizards and their habitat are protected, knowledge of the presence of any lizard (especially in cities where the invasive skink, Lampropholis delicata is not present) is important for their protection. Drawing together data from these diverse sources may illustrate where prior surveys have been undertaken, which species are known in a city, and where populations are known to be present.

However, while opportunistic data may be able to identify broad-scale patterns of occurrence in urban habitats, in order to have confidence that species have not been overlooked, more intensive surveys are required. Due to the cryptic nature of many species, it is possible that without intensive surveys and sustained effort, those whose populations are sparse may not be detected (Hitchmough et al. 2016b). Observations of lizards recovering from undetectable to detectable levels following predator eradication suggest that some species are able to persist at very low densities for extended periods of time (Bellingham et al. 2010; Morgan-Richards et al. 2016). The recent discovery of $O$. ornatum at a reserve in Hamilton (Chapter 3) illustrates that undetected populations of lizards can occur in urban settings.

I therefore recommend that managers take a city-wide approach to lizard surveys that uses broad-scale data to identify locations for more resource-intensive surveys. These surveys should, at least in some habitats, be sustained for long periods and use a wide range of tools capable of detecting the full suite of potential lizards. Due to the cost of such surveys, potential sites for this work should be prioritised based on previous 
knowledge of species occurrence, the quality of the habitat they offer for lizards, or where efficiencies can be found with other biodiversity work occurring in a city.

Management of urban lizards relies not only upon knowledge of where populations exist however, but also their viability over time. While characteristics such as abundance and body condition (gathered in Chapter 3) may be able to provide an indication of population health (Hoare et al. 2007; Moore et al. 2007), in order to confidently prevent future loss of species from cities, an understanding of population trajectories is required. Predation by introduced mammals can cause slow declines in lizard populations (Hoare et al. 2007). It is possible that some populations in cities are declining and, as a result, some species may be at risk of extirpation. I therefore recommend that, in addition to surveys, long-term monitoring programmes should be established for representative lizard populations in a range of urban habitats (Table 1: Question 2). Such monitoring programmes could target species whose capture rates are found to be low during surveys (e.g., O. ornatum identified in Chapter 3). 


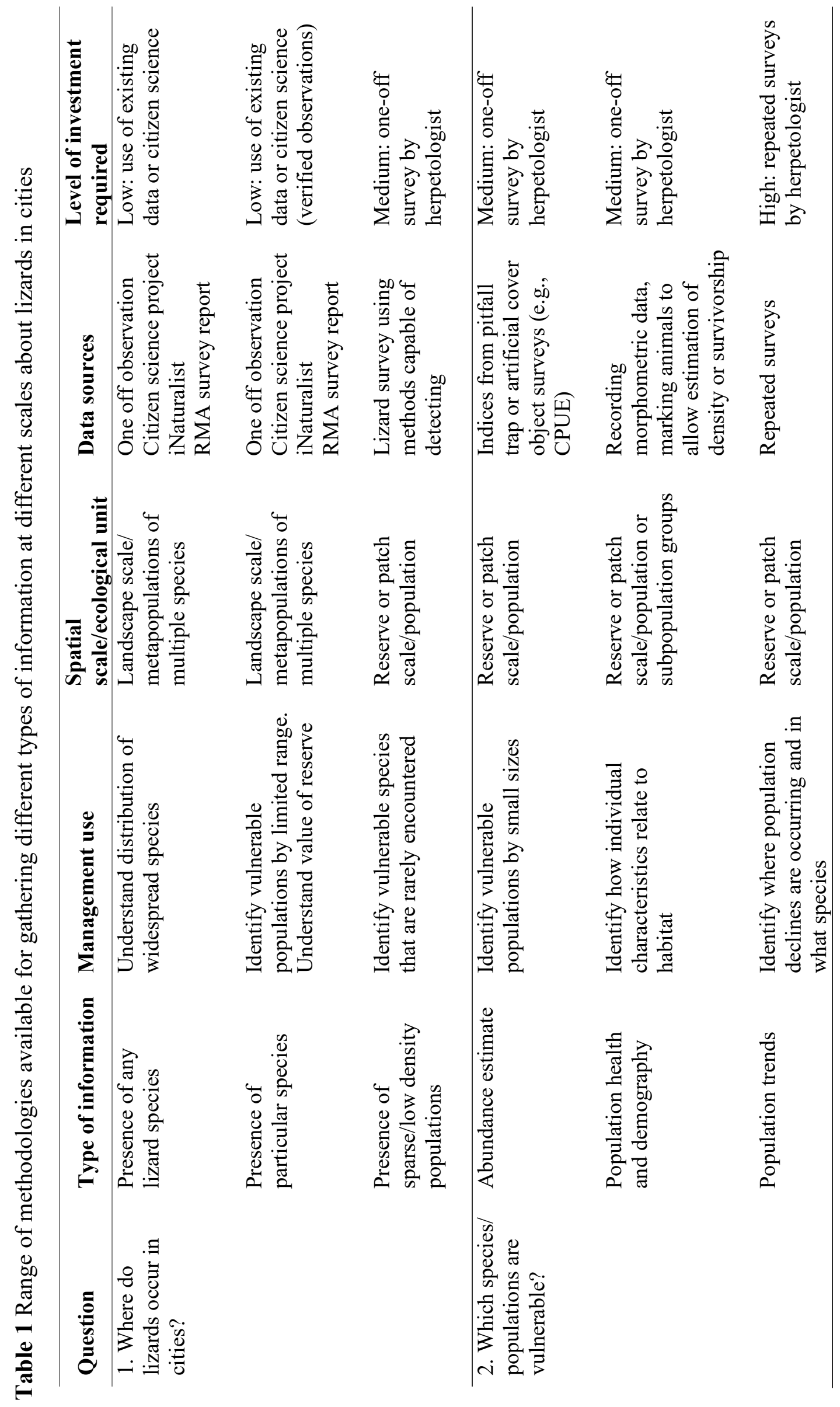

118 - Chapter 6: Conservation of lizards in cities 


\subsubsection{What can be done to support lizards in cities?}

Due to the current lack of knowledge about lizards in cities, few strategies for managing urban lizard populations have been tested to date. However, if knowledge of urban lizard populations grows to allow the identification of population trends, population management may become necessary to ensure their persistence. Potential tools that may be effective for management include predator control or elimination, and habitat enhancement. Cities may present advantages for undertaking these activities due to the potentially large workforce available in engaged members of the public (Chapter 5).

Like much of New Zealand's native fauna, many lizard species have been negatively impacted by introduced mammals (Diamond 1990; Towns \& Daugherty 1994). As a result, managing the recovery of at-risk lizard species in non-urban habitats has relied heavily upon predator eradication, especially on offshore islands (Towns 1991; Newman 1994). In cities, a number of promising options for mammal control exist, including: city-wide eradication such as that proposed by 'Predator-free' initiatives (e.g., Predator-free New Zealand, Predator-free Wellington; Russell et al. 2015), localised eradication such as ecosanctuaries (Nelson et al. 2016), and wide-scale suppression such as that commonly undertaken in urban reserves and, in some cities, backyards. However, while eradication of predators on islands and in sanctuaries have been demonstrated to allow the recovery of lizard populations (Towns 1991; Nelson et al. 2016), evidence for the efficacy of mammal suppression or of eradication of only a subset of lizard predators (such as that proposed by Predator-free initiatives) is lacking (though see Reardon et al. 2012). Further research is needed to understand what impacts these may have on populations.

Another approach that has been proposed to support urban lizards is habitat enhancement. Habitat enhancement involves the addition of natural or artificial components to the environment to provide conditions that increase individual survival and/or population viability (Shoemaker 2007). For lizards, enhancements may provide an improved thermal environment, food resources, or cover from predators. Built rock piles are a common enhancement used to provide habitat for lizards following mitigation translocation, with the idea that crevices between rocks may allow access to lizards but exclude larger predators (Towns 1996; Anderson et al. 2012; Lennon 2019). Planting of some native species has also been suggested to provide food resources and cover from predation (Auckland Council 2008; Department of Conservation 2018). However, the 
applied benefits of these strategies are yet to be demonstrated and further research is needed to test their efficacy (Lennon 2019).

In addition to the unknown utility of these management strategies, there is little known about other threats that may be more important in urban environments than other areas of New Zealand. In particular, how disturbance by vehicles, green space maintenance or domestic animals may influence behaviour or even selection of lizards, and what impact anthropogenic barriers to dispersal have for population fragmentation. Further research into challenges to urban wildlife and their solutions could significantly benefit the management of not only lizards, but also other terrestrial wildlife (e.g., large invertebrates such as wētā).

\subsubsection{Urban conservation and nature engagement}

Urban-dwelling humans are linked to the natural environment in cities, as any organism is linked to its ecosystem, depending upon services it provides and contributing to its condition through their behaviours. But cities are centres of human activity and are designed and managed primarily to accommodate their human inhabitants. For biodiversity to be effectively conserved in urban spaces, its management must simultaneously consider the values, needs and actions of the human population.

Participatory conservation activities such as citizen science monitoring and community predator control may be efficient solutions for achieving conservation goals in that they can potentially mobilise large numbers of volunteers (Dickinson et al. 2010). However, the effectiveness of such activities depends upon people's willingness to take part (Sakurai et al. 2015). In Chapter 5, it was found that willingness to participate varied between different activities, with pest mammal trapping being favoured over activities that monitored both native biodiversity and pest mammals. Reasons for this were unclear, but understanding what characteristics make some activities more or less likely to be undertaken could inform project design that maximises participation. One aspect of this to examine in future research could be people's values for different native and introduced species, their feelings about seeing or interacting with different species, and how these relate to socio-demography, nature relatedness, or nature literacy. This would also serve to inform our knowledge of what sort of fauna is desired by the residents of cities and may motivate their engagement with nature. 
Because exposure to nature has been demonstrated to foster connections with nature, it may be possible to guide people toward pro-conservation or pro-environmental behaviours by encouraging them to experience nature. A number of studies show how experience with nature can promote pathways to environmentalism (Wells \& Lekies 2006) and biodiversity conservation (Soga et al. 2016). In Chapter 5, while willingness to participate in all the activities was positively related to nature relatedness, the strength of these relationships varied among the activities. This suggests that certain types of naturebased activities may hold greater appeal to people with low nature relatedness and that these may act as 'gateway' activities that begin a journey towards greater nature engagement. Such activities may have low barriers to participation, or be appealing to participants for reasons other than, or in addition to, their conservation benefit (e.g., provide social interaction, development of skills). To assess whether participation in these activities is a plausible intervention, future research should look at what effect participating has on nature relatedness, nature literacy, wellbeing, and future willingness to participate in environmental activities.

As key agents of environmental change in cities, it is people and their behaviours that will ultimately decide how and what type of nature will exist in cities. Understanding people's engagement with nature and environmental behaviours will enable management of urban biodiversity to better consider social dimensions. In doing so, it may be possible to find outcomes that will benefit both the welfare of humans and the conservation of the other species with which we share our planet. 
122 - Chapter 6: Conservation of lizards in cities 


\section{References}

Ackley JW, Wu J, Angilletta MJ, Myint SW, Sullivan B. 2015. Rich lizards: How affluence and land cover influence the diversity and abundance of desert reptiles persisting in an urban landscape. Biological Conservation 182:87-92.

Alberti M, Marzluff JM, Shulenberger E, Bradley G, Ryan C, Zumbrunnen C. 2008. Integrating humans into ecology: Opportunities and challenges for studying urban ecosystems. Urban Ecology: An International Perspective on the Interaction Between Humans and Nature 53:143-158.

Allentoft ME, Heller R, Oskam CL, Lorenzen ED, Hale ML, Gilbert MTP, Jacomb C, Holdaway RN, Bunce M. 2014. Extinct New Zealand megafauna were not in decline before human colonization. Proceedings of the National Academy 111:4922-4927.

Anderson P, Bell T, Chapman S, Corbett K. 2012. New Zealand Lizards Conservation Toolkit. BioGecko Press, Wellington, New Zealand.

Aronson M, Sort F, Nilon C et al. 2014. A global analysis of the impacts of urbanization on bird and plant diversity reveals key anthropogenic drivers. Proceedings of the Royal Society B. 281: 20133330. 
Asah ST, Blahna DJ. 2012. Motivational functionalism and urban conservation stewardship: implications for volunteer involvement. Conservation Letters 5:470477.

Auckland Council. 2008. Lizards in your garden. Auckland, New Zealand. Available from https://www.aucklandcouncil.govt.nz/environment/plants-animals/plant-foryour-ecosystem/Documents/biodiversity-lizards-alive-brochure.pdf (accessed May $15,2020)$.

Auckland Council. 2012. Indigenous Biodiversity Strategy. Available from https://www.aucklandcouncil.govt.nz/environment/what-we-do-to-helpenvironment/Documents/indigeneous-biodiversity-strategy.pdf (accessed January $14,2020)$.

Balls CS. 2019. Understanding the distribution of introduced mammalian predators in urban environments using monitoring tools and community trapping. Unpublished MSc thesis, Victoria University of Wellington.

Barbet-Massin M, Jiguet F, Albert CH, Thuiller W. 2012. Selecting pseudo-absences for species distribution models: How, where and how many? Methods in Ecology and Evolution 3:327-338.

Barwick RE. 1959. The life history of the common New Zealand skink Leiolopisma zelandica (Gray, 1843). Transactions of the Royal Society of New Zealand 86:331-380.

Batson WG, O’Donnell CFJ, Nelson NJ, Monks JM. 2015. Placement period of artificial retreats affects the number and demographic composition but not the body condition of skinks. New Zealand Journal of Ecology 39:273-279.

Beatley T. 2011. Biophilic cities integrating nature into urban design and planning. Springer, Washington, DC.

Bell BD, Hare KM, Pledger SA. 2018. Lizards in the suburbs: a single-garden study of a small endemic New Zealand skink (Oligosoma aeneum). New Zealand Journal of Zoology 1-18. DOI: 10.1080/03014223.2018.1434212.

Bell K. 2010. Stress physiology and anti-predator behaviour in urban Northwestern Gartersnakes (Thamnophis ordinoides). Unpublished MSc thesis, University of Guelph.

Bell T. 2019. Wellington City Council lizard surveys: 2016-2018. Technical report prepared for Wellington City Council by EcoGecko Consultants Limited. 
Bellingham PJ, Towns DR, Cameron EK, Davis JJ, Wardle DA, Wilmshurst JM, Mulder CPH. 2010. New Zealand island restoration: Seabirds, predators, and the importance of history. New Zealand Journal of Ecology 34:115-136.

Beninde J, Veith M, Hochkirch A. 2015. Biodiversity in cities needs space: A metaanalysis of factors determining intra-urban biodiversity variation. Ecology Letters 18:581-592.

Bjerke T, Østdahl T. 2004. Animal-related attitudes and activities in an urban population. Anthrozoos 17:109-129.

Blaustein R. 2013. Urban Biodiversity Gains New Converts. BioScience 63:72-77.

Bogisch M, Cree A, Monks J. 2016. Short-term success of a translocation of Otago skinks (Oligosoma otagense) to Orokonui Ecosanctuary. New Zealand Journal of Zoology 43:211-220.

Bolund P, Hunhammar S. 1999. Ecosystem services in urban areas. Ecological Economics 29:293-301.

Botkin DB, Beveridge CE. 1997. Cities as environments. Urban Ecosystems 1:3-19.

Brashares JS, Arcese P, Sam MK, Coppolillo PB, Sinclair ARE, Balmford A. 2004. Bushmeat hunting, wildlife declines, and fish supply in West Africa. Science 306: $1180-3$

Brockie RE, Duncan C. 2012. Long term trends in Wellington City bird counts: 19692006. Notornis 59:1-6.

Brown ED, Williams BK. 2019. The potential for citizen science to produce reliable and useful information in ecology. Conservation Biology 33:561-569.

Brumby A, Hartley S, Salmon R. 2015. Evaluation of the Great Kererū Count 2014 and Recommendations for Future Citizen Science Projects. Unpublished report, Victoria University of Wellington.

Burns RJ, Bell BD, Haigh A, Bishop P, Easton L, Wren S, Germano J, Hitchmough RA, Rolfe JR, Makan T. 2018. Conservation status of New Zealand amphibians, 2017. New Zealand Threat Classification Series 25:7.

Cardwell H. 2016. Massive urban pest eradication effort launched. Available from https://www.rnz.co.nz/national/programmes/checkpoint/audio/2018703202/massi ve-urban-pest-eradication-effort-launched (accessed January 14, 2020).

Carpenter JK, Monks JM, Nelson N. 2016. The effect of two glyphosate formulations on a small, diurnal lizard (Oligosoma polychroma). Ecotoxicology 25:548-554.

Chapple DG. 2016. New Zealand lizards. New Zealand Lizards. Springer. Switzerland. 
Chapple DG, Hitchmough R. 2016. Biogeography of New Zealand lizards. Pages 109-

131 in D. G. Chapple, editor. New Zealand Lizards. Springer. Switzerland.

Chapple DG, Reardon JT, Peace JE. 2016. Origin, Spread and Biology of the Invasive

Plague Skink (Lampropholis delicata) in New Zealand. Pages 341-369 New

Zealand Lizards. Springer. Switzerland.

Chapple DG, Ritchie PA, Daugherty CH. 2009. Origin, diversification, and systematics of the New Zealand skink fauna (Reptilia: Scincidae). Molecular Phylogenetics and Evolution 52:470-487.

Charteris M. 2015. Field survey for lizards. Unpublished report. Waybacks Ltd.

Charteris M, Lettink M. 2015. Montgomery spur lizard management plan. Unpublished report. Waybacks Ltd.

Chejanovski ZA, Avilés-Rodríguez KJ, Lapiedra O, Preisser EL, Kolbe JJ. 2017. An experimental evaluation of foraging decisions in urban and natural forest populations of Anolis lizards. Urban Ecosystems 20:1011-1018.

Clark KH, Nicholas KA. 2013. Introducing urban food forestry: A multifunctional approach to increase food security and provide ecosystem services. Landscape Ecology 28:1649-1669.

Clarkson BD, Kirby CL. 2016. Ecological restoration in urban environments in New Zealand. Ecological Management \& Restoration 17:180-190.

Clarkson BD, Wehi PM, Brabyn LK. 2007. A spatial analysis of indigenous cover patterns and implications for ecological restoration in urban centres, New Zealand. Urban Ecosystems 10:441-457.

Clary EG, Snyder M, Ridge R. 1992. Volunteers' motivations: A functional strategy for the recruitment, placement, and retention of volunteers. Nonprofit Management and Leadership 2:333-350.

Clayton S, Myers G. 2009. Conservation Psychology Understanding and promoting human care for nature. Wiley-Blackwell, Oxford, UK.

Clery E, Rhead R. 2013. Education and attitudes towards the environment. Education for all global monitoring report. UNESCO.

Clewell A, Aronson J. 2013. The SER primer and climate change. Ecological Management and Restoration 14:182-186.

Clogg CC, Petkova E, Haritou A. 1995. Statistical Methods for Comparing Regression Coefficients Between Models. American Journal of Sociology 100:1261-1293. 
Cocklin C, Doorman P. 1994. Ecosystem protection and management in New Zealand: a private land perspective. Applied Geography 14:264-281.

Colléony A, White R, Shwartz A. 2019. The influence of spending time outside on experience of nature and environmental attitudes. Landscape and Urban Planning 187:96-104.

Cox DTC, Shanahan DF, Hudson HL, Plummer KE, Siriwardena GM, Fuller RA, Anderson K, Hancock S, Gaston KJ. 2017. Doses of Neighborhood Nature: The Benefits for Mental Health of Living with Nature. BioScience 7:173.

Cranz G, Boland M. 2003. The Ecological Park as an Emerging Type. Places 15:44-47.

Cree A, Hare KM. 2016. Reproduction and Life History of New Zealand Lizards. Pages 169-206 in D. G. Chapple, editor. New Zealand Lizards. Springer. Switzerland.

Czech B, Krausman PR, Devers PK. 2000. Economic Associations among Causes of Species Endangerment in the United States. BioScience 50:593-601.

Czech B, Krausman PR, Dobson A, Rodriguez JP, Roberts WM, Wilcove DS. 1997. Distribution and causation of species endangerment in the United States. Science 277:1116-1117.

Dandy N, Ballantyne S, Moseley D, Gill R, Peace A, Quine C. 2011. Preferences for wildlife management methods among the peri-urban public in Scotland. European Journal of Wildlife Research 57:1213-1221.

Daugherty C, Towns DR. 1991, April. The Cat's Breakfast. New Zealand Science Monthly:13-14.

Daugherty C, Towns DR, Atkinson IAE, Gibbs G. 1990. The significance of the biological resources of New Zealand islands for ecological restoration. Pages 9-21 Ecological restoration of New Zealand islands, Conservation Sciences Publication No. 2. Available from https://www.doc.govt.nz/documents/science-andtechnical/EcologicalRestorationNZIslands.pdf (accessed January 2020).

Davies R. 2004. Biodiversity Enhancement for Living Roofs. Unpublished report. Unitec Auckland.

Department of Conservation. 2017. BioWeb Herpetofauna Database. Department of Conservation, Wellington. Accessed: April 2017.

Department of Conservation. 2018. Attract lizards to your garden. Available from https://www.doc.govt.nz/get-involved/conservation-activities/attract-lizards-toyour-garden/ (accessed April 2019). 
Diamond JM., Veitch C. R. 1981. Extinctions and introductions in the New Zealand avifauna : Cause and effect? Science 211:499-501.

Diamond JM. 1990. New Zealand as an archipelago: an international perspective. Pages 3-8 in D. Towns, C. Daugherty, and I. Atkinson, editors. Ecological restoration of New Zealand islands, Conservation Sciences Publication No. 2. Department of Conservation, Wellington, NZ.

Dickinson JL, Zuckerberg B, Bonter DN. 2010. Citizen Science as an Ecological Research Tool: Challenges and Benefits. Annual Review of Ecology, Evolution, and Systematics 41:149-172.

Dixon LAM. 2017. Managing domestic gardens collectively to promote biodiversity: Opportunities and Constraints. Unpublished $\mathrm{PhD}$ thesis, University of Manchester.

Doherty TS, Glen AS, Nimmo DG, Ritchie EG, Dickman CR. 2016. Invasive predators and global biodiversity loss. Proceedings of the National Academy of Sciences 113:11261-11265.

Dow CL, DeWalle DR. 2000. Trends in evaporation and Bowen ratio on urbanizing watersheds in eastern United States. Water Resources Research 36:1835-1843.

Dunn RR, Gavin MC, Sanchez MC, Solomon JN. 2006. The pigeon paradox: Dependence of global conservation on urban nature. Conservation Biology 20:1814-1816.

Dupras J, Alam M. 2015. Urban Sprawl and Ecosystem Services: A Half Century Perspective in the Montreal Area (Quebec, Canada). Journal of Environmental Policy and Planning 17:180-200.

Eden SE, Tunstall S. 2006. Ecological versus social restoration? How urban river restoration challenges but also fails to challenge the science-policy nexus in the United Kingdom. Environment and Planning C: Government and Policy 24:661680.

Efford MG. 2019. secr: spatially explicit capture-recapture models. Available from https://cran.r-project.org/web/packages/secr/index.html (accessed April 24, 2020).

Efford MG, Fewster RM. 2013. Estimating population size by spatially explicit capture recapture:918-928.

Eifler DA, Eifler MA. 1999. The influence of prey distribution on the foraging strategy of the lizard Oligosoma grande (Reptilia: Scincidae). Behavioral Ecology and Sociobiology 45:397-402. 
Elmqvist T, Setälä H, Handel SN, van der Ploeg S, Aronson J, Blignaut JN, GómezBaggethun E, Nowak DJ, Kronenberg J, de Groot R. 2015. Benefits of restoring ecosystem services in urban areas. Current Opinion in Environmental Sustainability 14:101-108.

ESRI. 2017. ArcMap v.10.5.1. Redlands, CA.

Evans C, Abrams E, Reitsma R, Roux K, Salmonsen L, Marra PP. 2005. The Neighborhood Nestwatch program: Participant outcomes of a citizen-science ecological research project. Conservation Biology 19:589-594.

Evans GW, Otto S, Kaiser FG. 2018. Childhood Origins of Young Adult Environmental Behavior. Psychological Science 29:679-687.

Ewert A, Place G, Sibthorp J. 2005. Early-Life Outdoor Experiences and an Individual's Environmental Attitudes. Leisure Sciences 27:225-239.

Fahrig L. 2003. Effects of habitat fragmentation on biodiversity. Anual review of Ecology, Evolution and Systematics 34:487-515.

Farinha-Marques P, Lameiras JM, Fernandes C, Silva S, Guilherme F. 2011. Urban biodiversity: A review of current concepts and contributions to multidisciplinary approaches. Innovation 24:247-271.

Fea N, Linklater W, Hartley S. 2020. Responses of New Zealand forest birds to management of introduced mammals. Conservation Biology 00:1-15.

Feickert K. 2018. Lizard Survey Report: Southern Links. Unpublished report. 61p. FengA, Himsworth C. 2014. The secret life of the city rat: A review of the ecology of urban Norway and black rats (Rattus norvegicus and Rattus rattus). Urban Ecosystems 17:149-162.

Flux JEC. 2007. Seventeen years of predation by one suburban cat in New Zealand. New Zealand Journal of Zoology 34:289-296.

Francis RA. 2011. Wall ecology: A frontier for urban biodiversity and ecological engineering. Progress in Physical Geography 35:43-63.

Francis RA, Lorimer J. 2011. Urban reconciliation ecology: The potential of living roofs and walls. Journal of Environmental Management 92:1429-1437.

Franzen A, Meyer R. 2010. Environmental attitudes in cross-national perspective: A multilevel analysis of the ISSP 1993 and 2000. European Sociological Review 26:219-234. 
French SS, Webb AC, Hudson SB, Virgin EE. 2018. Town and Country Reptiles: A Review of Reptilian Responses to Urbanization. Integrative and Comparative Biology:1-19.

Freeman A.1997. Comparative ecology of two Oligosoma skinks in coastal Canterbury: A contrast with central Otago. New Zealand Journal of Ecology 21:153-160.

Fuller RA, Irvine KN, Devine-Wright P, Warren PH, Gaston KJ. 2007. Psychological benefits of greenspace increase with biodiversity. Biology letters 3:390-4.

Gaby MJ, Besson AA, Bezzina CN, Caldwell AJ, Cosgrove S, Cree A, Haresnape S, Hare KM. 2011. Thermal dependence of locomotor performance in two cool-temperate lizards. Journal of Comparative Physiology A: Neuroethology, Sensory, Neural, and Behavioral Physiology 197:869-875.

Germaine SS, Wakeling BF. 2001. Lizard species distributions and habitat ocupation along an urban gradient in Tucson, Arizona, USA. Biological Conservation 97:229-237.

Germano JM, Field KJ, Griffiths RA, Clulow S, Foster J, Harding G, Swaisgood RR. 2015. Mitigation-driven translocations: Are we moving wildlife in the right direction? Frontiers in Ecology and the Environment 13:100-105.

Gibbs JP, Shriver WG. 2002. Estimating the effects of road mortality on turtle populations. Conservation Biology 16:1647-1652.

Gillies C, Clout M. 2003. The prey of domestic cats (Felis catus) in two suburbs of Auckland City, New Zealand. Journal of Zoology 259:309-315.

Gillies C, Williams D. 2013. Using tracking tunnels to monitor rodents and mustelids. DOC tracking tunnel guide v. 2.5.2. Hamilton, New Zealand.

Gobster PH. 2001. Visions of nature: Conflict and compatibility in urban park restoration. Landscape and Urban Planning 56:35-51.

Gobster PH. 2010. Introduction: Urban ecological restoration. Nature and Culture 5:227230.

Goddard MA, Dougill AJ, Benton TG. 2010. Scaling up from gardens: biodiversity conservation in urban environments. Trends in Ecology and Evolution 25:90-98.

Goddard MA, Dougill AJ, Benton TG. 2013. Why garden for wildlife? Social and ecological drivers, motivations and barriers for biodiversity management in residential landscapes. Ecological Economics 86:258-273. 
González-García A, Sal AG. 2008. Private Urban Greenspaces or "Patios" as a Key Element in the Urban Ecology of Tropical Central America. Human Ecology 36:291-300.

Grayson KL, Mitchell NJ, Monks JM, Keall SN, Wilson JN, Nelson NJ. 2014. Sex ratio bias and extinction risk in an isolated population of tuatara (Sphenodon punctatus). PLoS ONE 9:1-10.

Grimm NB, Faeth SH, Golubiewski NE, Redman CL, Wu J, Bai X, Briggs JM. 2008. Global change and the ecology of cities. Science 319:756-760.

Hamilton RJ, Potuku T, Montambault JR. 2011. Community-based conservation results in the recovery of reef fish spawning aggregations in the Coral Triangle. Biological Conservation 144:1850-1858.

Hare KM. 2012a. Herpetofauna: pitfall trapping. Inventory and monitoring toolbox: herpetofauna. Department of Conservation, New Zealand.

Hare KM. 2012b. Herpetofauna : funnel trapping. Inventory and monitoring toolbox: herpetofauna. Department of Conservation, New Zealand.

Hare KM. 2012c. Herpetofauna: systematic searches. DOCDM-725787 Herpetofauna: systematic searches. Department of Conservation, New Zealand.

Hartig T, Mitchell R, de Vries S, Frumkin H. 2014. Nature and Health. Annu. Rev. Public Health 35:207-28.

He C, Liu Z, Tian J, Ma Q. 2014. Urban expansion dynamics and natural habitat loss in China: A multiscale landscape perspective. Global Change Biology 20:28862902.

Hitchmough R, Barr B, Lettink M, Monks J, Reardon J, Tocher M, Winkel D van, Rolfe J. 2016a. Conservation status of New Zealand reptiles, 2015. New Zealand Threat Classification Series 17:14.

Hitchmough RA, Adams LK, Reardon JT, Monks JM. 2016b. Current challenges and future directions in lizard conservation in New Zealand. Journal of the Royal Society of New Zealand 46:29-39.

Hoare JM, Adams LK, Bull LS, Towns DR. 2007. Attempting to Manage Complex Predator-Prey Interactions Fails to Avert Imminent Extinction of a Threatened New Zealand Skink Population. Journal of Wildlife Management 71:1576-1584. Hobbs SJ, White PCL. 2015. Achieving positive social outcomes through participatory urban wildlife conservation projects. Wildlife Research 42:607-617. 
Hope D, Gries C, Zhu W, Fagan WF, Redman CL, Grimm NB, Nelson AL, Martin C, Kinzig A. 2003. Socioeconomics drive urban plant diversity. Proceedings of the National Academy of Sciences 100:8788-8792.

Hough RL. 2014. Biodiversity and human health: Evidence for causality? Biodiversity and Conservation 23:267-288.

Hurlbert AH, Liang Z. 2012. Spatiotemporal variation in avian migration phenology: Citizen science reveals effects of climate change. PLoS ONE 7.

Ignatieva M, Meurk C, Roon M Van, Simcock R, Stewart GH. 2008. How to put nature into our neighbourhoods. Landcare Reserch Series No. 5. Lincoln, New Zealand.

Ignatieva M, Stewart GH, Meurk C. 2011. Planning and design of ecological networks in urban areas. Landscape and Ecological Engineering 7:17-25.

Ingram M. 2008. Urban Ecological Restoration. Ecological Restoration 26:175-177.

Innes J, Lee WG, Burns B, Campbell-Hunt C, Watts C, Phipps H, Stephens T. 2012. Role of predator-proof fences in restoring New Zealand's biodiversity: A response to Scofield et al. (2011). New Zealand Journal of Ecology 36:232-238.

Ishitani M, Kotze DJ, Niemelä J. 2003. Changes in carabid beetle assemblages across an urban-rural gradient in Japan. Ecography 26:481-489.

IUCN/SSC. 2013. Guidelines for reintroductions and other conservation translocations, Version 1. Gland, Switzerland: IUCN Species Survival Commission,

Ives CD et al. 2016. Cities are hotspots for threatened species. Global Ecology and Biogeography 25:117-126.

Ives CD, Abson DJ, von Wehrden H, Dorninger C, Klaniecki K, Fischer J. 2018. Reconnecting with nature for sustainability. Sustainability Science 13:1389-1397.

Jamieson SL. 2010. Sand dune restoration in New Zealand: Methods, motives, and monitoring. Unpublished MSc thesis, Victoria University of Wellington.

Jones C, Norbury G, Bell T. 2013. Impacts of introduced European hedgehogs on endemic skinks and weta in tussock grassland. Wildlife Research 40:36-44.

Kaplan S. 2000. Human nature and environmentally responsible behavior. Journal of Social Issues 56:491-508.

Kark S, Iwaniuk A, Schalimtzek A, Banker E. 2007. Living in the city: Can anyone become an "urban exploiter"? Journal of Biogeography 34:638-651.

Keniger LE, Gaston KJ, Irvine KN, Fuller RA. 2013. What are the benefits of interacting with nature? International Journal of Environmental Research and Public Health 10:913-935. 
King CM, editor. 1990. The Handbook of New Zealand Mammals. Oxford University Press, Auckland.

Knox CD, Cree A, Seddon PJ. 2012. Direct and indirect effects of grazing by introduced mammals on a native, arboreal gecko (Naultinus gemmeus). Journal of Herpetology 46:145-152.

Koenig J, Shine R, Shea G. 2001. The ecology of an Australian reptile icon: How do blue tongue lizards (Tiliqua scincoides) survive in suburbia? Wildlife Research 28:215-227.

Kowarik I. 2011. Novel urban ecosystems, biodiversity, and conservation. Environmental Pollution 159:1974-1983.

Krasny ME, Tidball KG. 2012. Civic ecology: A pathway for Earth stewardship in cities. Frontiers in Ecology and the Environment 10:267-273.

Krawiec J, Krauss SL, Davis RA, Spencer. 2015. Weak genetic structuring suggests historically high genetic connectivity among recently fragmented urban populations of the scincid lizard, Ctenotus fallens. Australian Journal of Zoology 63:279-286.

Lande R. 1998. Anthropogenic, ecological and genetic factors in extinction and conservation. Researches on Population Ecology 40:259-269.

Lennon O. 2019. Mitigation translocation for conservation of New Zealand skinks. Unpublished $\mathrm{PhD}$ thesis, Victoria University of Wellington.

Lettink M. 2006. Biosecurity New Zealand (Ministry of Agriculture and Forestry): Rapid assessment of possible establishment of rainbow skinks (Lampropholis delicata) at two sites in Christchurch, New Zealand. Unpublished report. Biosecurity New Zealand, Ministry of Agriculture and Forestry, Wellington, New Zealand.

Lettink M. 2012. Herpetofauna: artificial retreats. Herpetofauna toolbox, Department of Conservation, New Zealand.

Lettink M. 2015. Relocation and monitoring of Canterbury geckos (Woodworthia cf. brunnea) salvaged from the Crater Rim Bluffs, Port Hills, to Riccarton Bush, Christchurch. Unpublished report. Fauna Finders, Christchurch, New Zealand.

Lettink M, Patrick B. 2016a. Moth and lizard recovery at Deans Head, Sumner-Redcliffs Road Corridor, Christchurch. Unpublished report. Wildlands, New Zealand.

Lettink M. 2016b. Lizard salvage and relocation from Wakefield Avenue, Sumner. Unpublished report. 
Lettink M. 2018. Lizard survey of Knights Basin Wetland Christchurch. Unpublished report. Fauna Finders, Christchurch, New Zealand.

Lettink M, O’Donnell CFJ, Hoare JM. 2011. Accuracy and precision of skink counts from artificial retreats. New Zealand Journal of Ecology 35:236-246.

Lettink M, Seddon P. 2007. Influence of microhabitat factors on capture rates of lizards in a coastal New Zealand environment. Journal of Herpetology 41:187-196.

Liggins L, Chapple DG, Ritchie PA, Daugherty CH. 2007. Phylogeography of the New Zealand common skink, Oligosoma nigriplantare polychroma. New Zealand Journal of Zoology 34:267.

Linklater W, Chapman H, Gregor A, Calder-Flynn R, Gouws J, Quigan O, Rustandi A, Brian-Molitaviti J, Ying Y. 2018. Initiating a conflict with wildlife-the reintroduction and feeding of kākā, Wellington City, New Zealand. Pacific Conservation Biology 24:360-370.

LINZ. 2015. LCDB v4.1 - Land Cover Database version 4.1, Mainland New Zealand. Available from: https://lris.scinfo.org.nz/layer/48423-lcdb-v41-land-coverdatabase-version-41-mainland-new-zealand/ (last accessed: February 2020).

LINZ. 2017. New Zealand Street Address (Electoral). Available from: https://data.linz.govt. nz/layer/ 50779-nz-street-address-electoral-deprecated/ (accessed: November 2016).

Lo AY, Jim CY. 2010. Willingness of residents to pay and motives for conservation of urban green spaces in the compact city of Hong Kong. Urban Forestry and Urban Greening 9:113-120.

Luck GW, Davidson P, Boxall D, Smallbone L. 2011. Relations between urban bird and plant communities and human well-being and connection to nature. Conservation Biology 25:816-826.

Luiselli L, Agelici FM, Akani GC. 2001. Food habits of Python sebae in suburban and natural habitats. African Journal of Ecology 39:116-118.

Magle SB, Hunt VM, Vernon M, Crooks KR. 2012. Urban wildlife research: Past, present, and future. Biological Conservation 155:23-32. Elsevier Ltd.

Martínez ML, López-Barrera F. 2008. Special issue: Restoring and designing ecosystems for a crowded planet. Ecoscience 15:1-5.

Marzluff J. 2001a. Worldwide urbanization and its effects on birds. Pages 19-47 in J. Marzluff, R. Bowman, and R. Donnelly, editors. Avian ecology in an urbanizing world. Kluwer, Norwell, Massachusetts. 
Marzluff J. 2001b. Restoration of fragmented landscapes for the conservation of birds : A general framework and specific recommendations for urbanizing landscapes. Restoration Ecology 9:280-292.

Mathieu R, Freeman C, Aryal J. 2007. Mapping private gardens in urban areas using object-oriented techniques and very high-resolution satellite imagery. Landscape and Urban Planning 81:179-192.

McClure C. 2010. Survey of the Lizard Fauna of Janet Stewart and Styx Mill Conservation Reserves, Christchurch. Unpublished report, Lincoln University, New Zealand.

Mcdonald RI, Kareiva P, Forman RTT. 2008. The implications of current and future urbanization for global protected areas and biodiversity conservation. Biological Conservation 141:1695-1703.

McDonnell M, Pickett S, Groffman P, Bohlen P, Pouyat R, Zipperer W, Parmelee R, Carreiro M, Medley K. 1997. Ecosystem processes along an urban-to-rural gradient. Urban Ecosystems 1:21-36.

McDonnell MJ, Hahs AK. 2013. The future of urban biodiversity research: Moving beyond the "low-hanging fruit." Urban Ecosystems 16:397-409.

McKinley DC et al. 2017. Citizen science can improve conservation science, natural resource management, and environmental protection. Biological Conservation 208:15-28.

McKinney ML. 2002. Urbanization, Biodiversity and Conservation. BioScience 52:883890.

McKinney ML. 2006. Urbanization as a major cause of biotic homogenization. Biological Conservation 127:247-260.

McKinney ML. 2008. Effects of urbanisation on species richness: A review of plants and animals. Urban Ecosystems 11:161-176.

Melgren P. 2012. Observations from a goldstripe gecko, Woodworthia chrysosireticus, population in suburban New Plymouth. Biogecko:34-37.

Melzer S, Bell T. 2014. Lizard survey of Wellington City Council- Administered Parks \& Reserves: Final Report. Unpublished EcoGecko Consultants Ltd report prepared for the Wellington Council, June 2014. Wellington, New Zealand.

Melzer S, Bell T, Patterson GB. 2017. Hidden conservation vulnerability within a cryptic species complex: Taxonomic revision of the spotted skink (Oligosoma lineoocellatum; Reptilia: Scincidae) from New Zealand. Zootaxa 4300:355-379. 
MetService. 2018. Climate summary. Available from https://about.metservice.com/ourcompany/learning-centre/climate-summary/ (accessed: Feb 2018)

Meurk CD, Blaschke PM, Simcock RC 2013. Ecosystem services in New Zealand cities. In Dymond JR ed. Ecosystem services in New Zealand - conditions and trends. Manaaki Whenua Press, Lincoln, New Zealand.

Micallef L, Rodgers P. 2014. euler APE: Drawing area-proportional 3-Venn diagrams using ellipses. PLoS ONE 9.

Miller JR. 2005. Biodiversity conservation and the extinction of experience. Trends in Ecology and Evolution 20:430-434.

Miller JR, Hobbs RJ. 2002. Conservation where people live and work. Conservation Biology 16:330-337.

Miskelly CM, Powlesland RG. 2013. Conservation translocations of New Zealand birds, 1863-2012. Notornis 60:3-28.

Moore JA, Hoare JM, Daugherty CH, Nelson NJ. 2007. Waiting reveals waning weight: Monitoring over 54 years shows a decline in body condition of a long-lived reptile (tuatara, Sphenodon punctatus). Biological Conservation 135:181-188.

Moreno-Rueda G, Pizarro M. 2007. The relative influence of climate, environmental heterogeneity, and human population on the distribution of vertebrate species richness in south-eastern Spain. Acta Oecologica 32:50-58.

Morgan-Richards M, Hinlo AR, Smuts-Kennedy C, Innes J, Ji W, Barry M, Brunton D, Hitchmough RA. 2016. Identification of a rare gecko from North Island New Zealand, and genetic assessment of its probable origin: A novel mainland conservation priority? Journal of Herpetology 50:77.

Morgan SA, Hansen CM, Ross JG, Hickling GJ, Ogilvie SC, Paterson AM. 2009. Urban cat (Felis catus) movement and predation activity associated with a wetland reserve in New Zealand. Wildlife Research 36:574-580.

Nelson-Tunley M, Blayney A. 2016. Habitat assessment and salvage field report: Hamilton Western Rail Trail. Unpublished report prepared for Opus International Consultants, New Zealand.

Nelson N, Romijn R, Dumont T, Reardon JT, Monks J, Hitchmough RA, Empson R, Briskie J. 2016. Lizard conservation in mainland sanctuaries. Pages 321-339 in D. G. Chapple, editor. New Zealand Lizards. Springer. Switzerland.

Newman DG. 1994. Effects of a mouse, Mus musculus, eradication programme and habitat change on lizard populations of Mana Island, New Zealand, with special 
reference to McGregor's skink, Cyclodina macgregori. New Zealand Journal of Zoology 21:443-456.

Nichols KRN. 2014. Habitat features of urban forest fragments supporting native lizards in the presence of introduced mammals Kelsey Rhonda Naina Nichols. Unpublished MSc thesis, Massey University Albany, New Zealand.

Nielsen S V., Bauer AM, Jackman TR, Hitchmough RA, Daugherty CH. 2011. New Zealand geckos (Diplodactylidae): Cryptic diversity in a post-Gondwanan lineage with trans-Tasman affinities. Molecular Phylogenetics and Evolution 59:1-22.

Niemelä J, Kotze DJ, Venn S, Penev L, Stoyanov I, Spence J, Hartley D, Montes de Oca E. 2002. Carabid beetle assemblages (Coleoptera, Carabidae) across urban-rural gradients: An international comparison. Landscape Ecology 17:387-401.

Nisbet EK, Zelenski JM, Murphy SA. 2009. The Nature Relatedness Scale. Environment and Behavior 27:1-26.

Noël S, Lapointe FJ. 2010. Urban conservation genetics: Study of a terrestrial salamander in the city. Biological Conservation 143:2823-2831.

Norbury G. 2001. Conserving dryland lizards by reducing predator-mediated apparent competition and direct competition with introduced rabbits. Journal of Applied Ecology 38:1350-1361.

Norbury G. 2017. The case for 'bottom-up' pest management. New Zealand Journal of Ecology 41:271-277.

Norbury G, Byrom A, Pech R, Smith J, Clarke D, Anderson D, Forrester G. 2013. Invasive mammals and habitat modification interact to generate unforeseen outcomes for indigenous fauna. Ecological Applications 23:1707-1721.

Norbury G, Munckhof M Van Den, Neitzel S, Hutcheon A, Reardon J, Ludwig K. 2014. Impacts of invasive house mice on post-release survival of translocated lizards. New Zealand Journal of Ecology 38:322-327.

Norris D, Peres CA, Michalski F, Gibbs JP. 2019. Prospects for freshwater turtle population recovery are catalyzed by pan-Amazonian community-based management. Biological Conservation 233:51-60.

O’Donnell CFJ, Borkin KM, Christie JE, Lloyd B, Parsons S, Hitchmough RA. 2018. Conservation status of New Zealand bats, 2017. New Zealand Threat Classification Series 21:4. Department of Conservation, New Zealand. ODPM. 2005. Creating Sustainable Communities: Greening the Gateway Implementation Plan. Unpublished report, ODPM, London, UK. 
Oke TR. 1973. City size and the urban heat island. Atmospheric Environment 7:769-779. Oliver-Smith N. 2015. Biodiversity outcomes of an urban revegetation programme in Wellington, New Zealand: The role of patch size, isolation, age and the urban matrix. Unpublished MSc thesis, Victoria University of Wellington.

Parry L, Barlow J, Pereira H. 2014. Wildlife Harvest and Consumption in Amazonia's Urbanized Wilderness. Conservation Letters 7:565-574.

Paternoster R, Brame R, Mazerolle P, Piquero A. 1998. Using the correct statistical test for the equality of regression coefficients. Criminology 36:859-866.

Patterson GB. 1992. The ecology of a New Zealand grassland lizard guild. Journal of the Royal Society of New Zealand 22:91-106.

Paul MJ, Meyer JL. 2001. Streams in the urban landscape. Annual Review of Ecology and Systematics 32:333-365.

Peters MA. 2016. An inventory of citizen science initiatives, resources and learning opportunities in New Zealand. NZ Landcare Trust, Hamilton, New Zealand.

Peters MA, Hamilton D, Eames C. 2015. Action on the ground: A review of community environmental groups' restoration objectives, activities and partnerships in New Zealand. New Zealand Journal of Ecology 39:179-189.

Pickett STA, Cadenasso ML, Grove JM, Nilon CH, Pouyat R V., Zipperer WC, Costanza R. 2001. Urban ecological systems: Linking terrestrial ecological, physical, and socioeconomic components of metropolitan areas. Annual Review of Ecology and Systematics 32:127-157.

Porter E, Forschner B, Blair R. 2001. Woody vegetation and canopy fragmentation along a forest-to-urban gradient. Urban Ecosystems 5:131-151.

Porter R. 1987. An ecological comparison of two Cyclodina skinks (Reptilia: Lacertilia) in Auckland, New Zealand. New Zealand Journal of Zoology 14:493-507.

Pouyat R V., McDonnell MJ. 1991. Heavy metal accumulations in forest soils along an urban- rural gradient in Southeastern New York, USA. Water, Air, and Soil Pollution 57-58:797-807.

Prebble J. 2015. Polhill management plan. Unpublished report, Victoria University of Wellington, New Zealand.

Predator Free New Zealand Trust. 2018. Backyard trapping. Available from https://predatorfreenz.org/get-involved/backyard-trapping/ (accessed February 26, 2019). 
Predator Free Wellington. 2018. Get involved. Available from https://www.pfw.org.nz/ (accessed February 26, 2019).

Prosser C, Hudson S, Thompson MB. 2006. Effects of urbanization on behavior, performance, and morphology of the garden skink, Lampropholis guichenoti. Journal of Herpetology 40:151-159.

R Core Team. 2018. R: A language and environment for statistical computing. R Foundation for Statistical Computing, Vienna, Austria.

Reardon JT, Whitmore N, Holmes KM, Judd LM, Hutcheon AD, Norbury G, Mackenzie DI. 2012. Predator control allows critically endangered lizards to recover on mainland New Zealand. New Zealand Journal of Ecology 36:141-150.

Robertson HA et al. 2017. Conservation status of New Zealand birds, 2016. New Zealand Threat Classification Series 19:27.

Romijn RL. 2013. Can skinks recover in the presence of mice? Unpublished honours thesis, Victoria University of Wellington.

Romijn RL, Hartley S. 2016. Trends in lizard translocations in New Zealand between 1988 and 2013. New Zealand Journal of Zoology 43:191-210.

Romijn RL, Nelson NJ, Monks JM. 2014. Forest geckos (Mokopirirakau "Southern North Island") display diurno-nocturnal activity and are not reliant on retreats. New Zealand Journal of Zoology 41:103-113.

Rosenzweig ML. 2001. Loss of speciation rate will impoverish future diversity. Proceedings of the National Academy of Sciences 98:5404-5410.

Rosenzweig ML. 2003a. Win-win Ecology, How the Earth's species can survive in the midst of human enterprise. Oxford, UK.

Rosenzweig ML. 2003b. Reconciliation ecology and the future of species diversity. Oryx 37:194-205.

Rudd H, Vala J, Schaefer V. 2002. Urban Space Connectivity 10:368-375.

Rupprecht CDD, Byrne JA, Ueda H, Lo AY. 2015a. "It's real, not fake like a park": Residents' perception and use of informal urban green-space in Brisbane, Australia and Sapporo, Japan. Landscape and Urban Planning 143:205-218. Rupprecht CDDD, Byrne JA, Garden JG, Hero JM. 2015b. Informal urban green space: A trilingual systematic review of its role for biodiversity and trends in the literature. Urban Forestry and Urban Greening 14:883-908. 
Ruscoe WA et al. 2011. Unexpected consequences of control: Competitive vs. predator release in a four-species assemblage of invasive mammals. Ecology Letters 14:1035-1042.

Russell JC. 2014. A comparison of attitudes towards introduced wildlife in New Zealand in 1994 and 2012. Journal of the Royal Society of New Zealand 44:136-151.

Russell JC, Innes JG, Brown PH, Byrom AE. 2015. Predator-free New Zealand: Conservation country. BioScience 65:520-525.

Sakurai R, Kobori H, Nakamura M, Kikuchi T. 2015. Factors influencing public participation in conservation activities in urban areas: A case study in Yokohama, Japan. Biological Conservation 184:424-430.

Saunders A, Norton DA. 2001. Ecological restoration at mainland islands in New Zealand. Biological Conservation 99:109-119.

Savidge JA. 2012. Food Habits of Boiga irregularis, an Introduced Predator on Guam. Journal of Herpetology 22:275-282.

Schrader B. 2016. The Big Smoke: New Zealand Cities, 1840-1920. Bridget Williams Books, Wellington, NZ.

Scott DM, Berg MJ, Tolhurst BA, Chauvenet ALM, Smith GC, Neaves K, Lochhead J, Baker PJ. 2014. Changes in the distribution of red foxes (Vulpes vulpes) in urban areas in Great Britain: Findings and limitations of a media-driven nationwide survey. PLoS ONE 9.

SER. 2004. The SER international primer on ecological restoration. Society for Ecological Restoration. Tucson, Arizona. Available from: https://www.ser.org/page/ SERDocuments (accessed: June 2016).

Shanahan DF, Bush R, Gaston KJ, Lin BB, Dean J, Barber E, Fuller RA. 2016. Health benefits from nature experiences depend on dose. Scientific Reports 6:28551.

Shanahan DF, Cox DTCC, Fuller RA, Hancock S, Lin BB, Anderson K, Bush R, Gaston KJ. 2017. Variation in experiences of nature across gradients of tree cover in compact and sprawling cities. Landscape and Urban Planning 157:231-238.

Shanahan DF, Lin BB, Gaston KJ, Bush R, Fuller RA. 2014. Socio-economic inequalities in access to nature on public and private lands: A case study from Brisbane, Australia. Landscape and Urban Planning 130:14-23.

Shanahan DF, Miller C, Possingham HP, Fuller RA. 2011. The influence of patch area and connectivity on avian communities in urban revegetation. Biological Conservation 144:722-729. 
Shea K, Chesson P. 2002. Community ecology theory as a framework for biological invasions. Trends in Ecology \& Evolution 17:170-176.

Shine R, Fitzgerald M. 1996. Large snakes in a mosaic rural landscape: The ecology of carpet pythons Morelia spilota (Serpentes: pythonidae) in coastal eastern Australia. Biological Conservation 76:113-122.

Shine R, Koenig J. 2001. Snakes in the garden: An analysis of reptiles "rescued" by community-based wildlife carers. Biological Conservation 102:271-283.

Shoemaker KT. 2007. Habitat manipulation as a viable strategy for the conservation of the massasauga rattlesnake in New York State. Unpublished MSc thesis, State University of New York, USA.

Soga M, Gaston KJ. 2016. Extinction of experience: The loss of human-nature interactions. Frontiers in Ecology and the Environment 14:94-101.

Soga M, Gaston KJ, Yamaura Y, Kurisu K, Hanaki K. 2016. Both direct and vicarious experiences of nature affect children's willingness to conserve biodiversity. International Journal of Environmental Research and Public Health 13:529-541.

Soroye P, Ahmed N, Kerr JT. 2018. Opportunistic citizen science data transform understanding of species distributions, phenology, and diversity gradients for global change research. Global Change Biology 24:5281-5291.

Soulsbury CD, White PCL. 2015. Human-wildlife interactions in urban areas: A review of conflicts, benefits and opportunities. Wildlife Research 42:541-553.

St. John FAV, Edwards-Jones G, Jones JPG. 2010. Conservation and human behaviour: Lessons from social psychology. Wildlife Research 37:658-667.

Standish RJ, Hobbs RJ, Miller JR. 2013. Improving city life: Options for ecological restoration in urban landscapes and how these might influence interactions between people and nature. Landscape Ecology 28:1213-1221.

Statistics New Zealand. 2013. 2013 Census data. Available from: http://archive.stats.govt.nz/_Census/2013-census/data-tables.aspx (accessed: June 2018).

Stokland JN, Halvorsen R, Stoea B. 2011. Species distribution modelling-Effect of design and sample size of pseudo-absence observations. Ecological Modelling 222:18001809.

Sushinsky JR, Rhodes JR, Shanahan DF, Possingham HP, Fuller RA. 2017. Maintaining experiences of nature as a city grows. Ecology and Society 22. 
Swenson JJ, Franklin J. 2000. The effects of future urban development on habitat fragmentation in the Santa Monica Mountains. Landscape Ecology 15:713-730.

Takase Y, Hadi AA, Furuya K. 2019. The relationship between volunteer motivations and variation in frequency of participation in conservation activities. Environmental Management 63:32-45.

Tam KP. 2013. Concepts and measures related to connection to nature: Similarities and differences. Journal of Environmental Psychology 34:64-78.

Thalia East K, East MR, Daugherty CH. 1995. Ecological restoration and habitat relationships of reptiles on Stephens Island, New Zealand. New Zealand Journal of Zoology 22:249-261.

Thomas R. 2016. Wellington's predator free hero Kelvin Hastie - the smiling assassin. Available from https://www.stuff.co.nz/environment/84726335/wellingtonspredator-free-hero-kelvin-hastie--the-smiling-assasin (accessed October 12, 2019).

Tingley R, Hitchmough RA, Chapple DG. 2013. Life-history traits and extrinsic threats determine extinction risk in New Zealand lizards. Biological Conservation 165:62-68.

Todd B, Willson J, Gibbons J. 2010. The global status of reptiles and causes of their decline. Pages 47-46 in D. Sparling, C. Bishop, and S. Krest, editors. In Ecotoxicology of Amphibians and Reptiles. CRC Press, Pensacola, FL, USA.

Toomey AH, Domroese MC. 2019. Can citizen science lead to positive conservation attitudes and behaviors? Society for Human Ecology 20:50-62.

Towns DR. 1991. Response of lizard assemblages in the Mercury Islands, New Zealand, to removal of an introduced rodent: the kiore (Rattus exulans). Journal of the Royal Society of New Zealand 21:119-136.

Towns DR. 1996. Changes in habitat use by lizards on a New Zealand island following removal of introduced Pacific Rat (Rattus exulans). Pacific Conservation Biology 2:286-92.

Towns DR, Broome KG. 2003. From small Maria to massive Campbell: forty years of rat eradications from New Zealand islands. New Zealand Journal of Zoology 30:377398.

Towns DR, Daugherty CH. 1994. Patterns of range contractions and extinctions in the New Zealand herpetofauna following human colonisation. New Zealand Journal of Zoology 21:325-339. 
Towns DR, Daugherty CH, Cree A. 2001. Raising the prospects for a forgotten fauna: A review of 10 years of conservation effort for New Zealand reptiles. Biological Conservation 99:3-16.

Towns DR, Ferreira SM. 2001. Conservation of New Zealand lizards (Lacertilia: Scincidae) by translocation of small populations. Biological Conservation 98:211222.

Towns DR, Hitchmough RA, Perrott J. 2016a. Conservation of New Zealand lizards: A fauna not forgotten but undervalued? Page 27 in D. G. Chapple, editor. New Zealand Lizards. Springer. Switzerland.

Towns DR, Miller KA, Nelson NJ, Chapple DG. 2016b. Can translocations to islands reduce extinction risk for reptiles? Case studies from New Zealand. Biological Conservation 204:120-127.

Turner WR, Nakamura T, Dinetti M. 2004. Global Urbanization and the Separation of Humans from Nature. BioScience 54:585.

United Nations. 2014. World Urbanization Prospects: The 2014 Revision, Highlights (ST/ESA/SER.A/352). United Nations Department of Economic and Social Affairs, Population Division.

United Nations. 2019. World Urbanization Prospects. Demographic Research. United Nations, Department of Economic and Social Affairs. New York, USA.

Valiela I, Martinetto P. 2007. Changes in bird abundance in eastern North America: Urban sprawl and global footprint? BioScience 57:360-370.

van den Berg AE, Terry H, Henk S. 2007. Preference for nature in urbanized societies: Stress, restoration, and the pursuit of sustainability. Journal of Social Issues 63:79-96.

van Heezik Y. 2010. Pussyfooting around the issue of cat predation in urban areas. Oryx 44:153.

van Heezik Y, Freeman C, Porter S, Dickinson KJMM. 2013. Garden size, householder knowledge, and socio-economic status influence plant and bird diversity at the scale of individual gardens. Ecosystems 16:1442-1454.

van Heezik Y, Ludwig K. 2012. Proximity to source populations and untidy gardens predict occurrence of a small lizard in an urban area. Landscape and Urban Planning 104:253-259. 
van Heezik Y, Seddon PJ. 2018. Animal reintroductions in peopled landscapes: moving towards urban-based species restorations in New Zealand. Pacific Conservation Biology https://doi.org/10.1071/PC18026.

van Heezik Y, Smyth A, Adams A, Gordon J. 2010. Do domestic cats impose an unsustainable harvest on urban bird populations? Biological Conservation 143:121-130.

van Heezik Y, Smyth A, Mathieu R. 2008. Diversity of native and exotic birds across an urban gradient in a New Zealand city. Landscape and Urban Planning 87:223232.

van Strien AJ, van Swaay CAM, Termaat T. 2013. Opportunistic citizen science data of animal species produce reliable estimates of distribution trends if analysed with occupancy models. Journal of Applied Ecology 50:1450-1458.

van Winkel D, Baling M, Hitchmough R. 2018. Reptiles and Amphibians of New Zealand. Auckland University Press, Auckland, New Zealand.

Vitousek P. 1994. Beyond Global Warming: Ecology and Global Change. Ecology 75:1861-1876.

Walker S, Wilson DJ, Norbury G, Monks A, Tanentzap AJ. 2014. Effects of secondary shrublands on bird, lizard and invertebrate faunas in a dryland landscape. New Zealand Journal of Ecology 38:242-256.

Wallis GP, Trewick SA. 2009. New Zealand phylogeography: Evolution on a small continent. Molecular Ecology 18:3548-3580.

Walter T, Zink R, Laaha G, Zaller JG, Heigl F. 2018. Fox sightings in a city are related to certain land use classes and sociodemographics: Results from a citizen science project. BMC Ecology 18:1-11.

Weir S, Yu S, Knox A, Talent L, Monks J, Salice C. 2016. Acute toxicity and risk to lizards of rodenticides and herbicides commonly used in New Zealand. New Zealand Journal of Ecology 40:342-350.

Wellington City Council. 2015. Our Natural Capital. Wellington's biodiversity strategy and action plan 2015. Available from: https://wellington.govt.nz/ /media/yourcouncil /plans-policies-and-bylaws/plans-and-policies/a-toz/biodiversity/files/2015/our-natural-capital-entire.pdf?la=en (accessed: August 2017) 
Wells NM, Lekies KS. 2006. Nature and the life course: Pathways from childhood nature experiences to adult environmentalism. Children, youth and environments 16:125.

Whitburn J, Linklater W, Abrahamse W. 2019. Meta-analysis of human connection to nature and proenvironmental behavior. Conservation Biology 0:1-14.

Wilmshurst JM, Anderson AJ, Higham TFG, Worthy TH. 2008. Dating the late prehistoric dispersal of Polynesians to New Zealand using the commensal Pacific rat. Proceedings of the National Academy of Sciences 105:7676.

Wilson DJ, Mulvey RL, Clarke DA, Reardon JT. 2017. Assessing and comparing population densities and indices of skinks under three predator management regimes. New Zealand Journal of Ecology 41:84-97.

Wine S, Gagne SA, Meentemeyer RK. 2015. Understanding human-coyote encounters in urban ecosystems using citizen science data: What do socioeconomics tell us? Environmental management:159-170.

Woinarski JCZ, Murphy BP, Palmer R, Legge SM, Dickman CR, Doherty TS, Edwards G, Nankivell A, Read JL, Stokeld D. 2018. How many reptiles are killed by cats in Australia? Wildlife Research 45:247-266.

Wolf LJ, Zu Ermgassen S, Balmford A, White M, Weinstein N. 2017. Is variety the spice of life? An experimental investigation into the effects of species richness on selfreported mental well-being. PLoS ONE 12:1-17.

Wolfe AK, Bateman PW, Fleming PA. 2018. Does urbanization influence the diet of a large snake? Current Zoology 64:311-318.

Woolley CK, Hartley S. 2019. Activity of free-roaming domestic cats in an urban reserve and public perception of pet-related threats to wildlife in New Zealand. Urban Ecosystems 22:1123-1137.

Woolley CK, Hartley S, Hitchmough RA, Innes JG, van Heezik Y, Wilson DJ, Nelson NJ. 2019. Reviewing the past, present and potential lizard faunas of New Zealand cities. Landscape and Urban Planning 192.

Worthy TH, Holdaway RN. 2002. The lost world of the moa: Prehistoric life in New Zealand. Indiana University Press, Bloomington, Indiana.

Zavaleta ES, Hobbs RJ, Mooney HA. 2001. Viewing invasive species removal in a whole-ecosystem context. Trends in Ecology and Evolution 16:454-459. 
Zuo A, Wheeler SA, Edwards J. 2016. Understanding and encouraging greater nature engagement in Australia: results from a national survey. Journal of Environmental Planning and Management 59:1107-1125. 


\section{Appendix}

\section{Supplementary materials}

\section{Chapter 2 supplementary materials}

S1 Generalisation of land cover classes. * excluded from analysis

\begin{tabular}{cl}
\hline Reclassified land cover classes & Land cover classes (LCDB v. 4.1) \\
\hline Exotic forest & Deciduous hardwoods \\
& Exotic forest \\
& Forest- harvested \\
\hline Exotic grassland & High producing exotic grassland \\
& Low producing exotic grassland \\
\hline Exotic scrub & Gorse and/or broom \\
& Mixed exotic shrubland \\
\hline Gravel & Gravel or rock \\
& Sand or gravel \\
\hline Horticulture & Orchard, vineyard or other perennial crop \\
& Short-rotation crop \\
\hline Indigenous forest & Indigenous forest \\
\hline Indigenous scrub & Broadleaved indigenous hardwoods \\
& Manuka and/or kanuka \\
& Matagouri or grey scrub \\
& Flaxland \\
\hline Urban & Built-up area (settlement) \\
& Surface mine or dump \\
& Transport infrastructure \\
& Urban parkland/open space \\
& Estuarine open water \\
& Lake or pond \\
& River \\
\hline Water* & Herbaceous freshwater vegetation \\
& Herbaceous saline vegetation \\
& Mangrove \\
\hline
\end{tabular}


S2 Long list of urban lizard candidates based on biogeographic categories coincident with six New Zealand cities (from Chapple \& Hitchmough 2016). Bolded species are those excluded; superscripts indicate reason for exclusion: ${ }^{1}$ West coast endemic, ${ }^{2}$ Too far from known range, ${ }^{3}$ South Island endemic, ${ }^{4}$ Montane specialist, ${ }^{5}$ Unlikely to overlap with $M$. granulatus, ${ }^{6}$ Probably montane, ${ }^{7}$ Unlikely to overlap with $O$. lineoocellatum

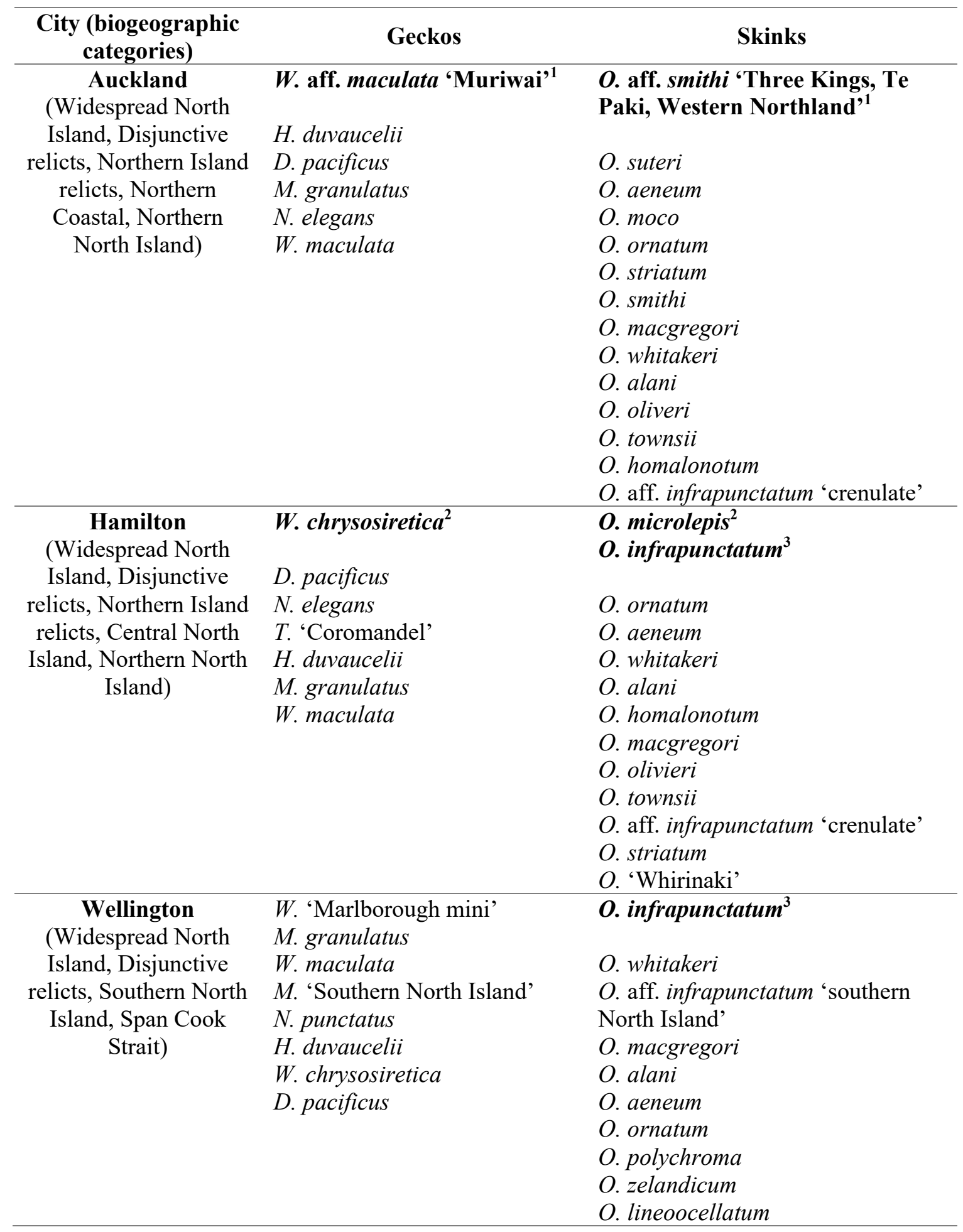




\section{S2 continued}

\begin{tabular}{|c|c|c|}
\hline $\begin{array}{c}\text { City (biogeographic } \\
\text { categories) }\end{array}$ & Geckos & Skinks \\
\hline $\begin{array}{l}\text { Nelson (Widespread } \\
\text { South Island, } \\
\text { Marlborough/ } \\
\text { Canterbury, Nelson/ } \\
\text { Marlborough } \\
\text { endemic, Span Cook } \\
\text { Strait) }\end{array}$ & $\begin{array}{l}\text { M. } \text { kahutarae }^{4} \\
\text { M. 'Cupola'5 } \\
\text { N. manukanus' } \\
\text { N. rudis' } \\
\text { W. 'Kaikouras'2 } \\
\text { W. 'Mount Arthur' } \\
\text { N. gemmeus' } \\
\text { W. 'Southern Alps'2 } \\
\text { T. stephensi } \\
\text { N. stellatus } \\
W . \text { maculata } \\
\text { M. granulatus } \\
W . \text { 'Marlborough mini' }\end{array}$ & $\begin{array}{l}\text { O. aff. lineoocellatum 'South } \\
\text { Marlborough'2 } \\
\text { O. } \text { waimatense }^{2} \\
\text { O. maccanni }{ }^{2} \\
\text { O. longipes } \\
\text { O. aff. polychroma clade } 2^{2} \\
\text { O. aff. polychroma clade } 3^{2} \\
\text { O. lineoocellatum } \\
\text { O. polychroma } \\
\text { O. infrapunctatum } \\
\text { O. zelandicum }\end{array}$ \\
\hline $\begin{array}{c}\text { Christchurch } \\
\text { (Widespread South } \\
\text { Island, Marlborough/ } \\
\text { Canterbury, } \\
\text { Canterbury endemic) }\end{array}$ & $\begin{array}{l}\text { W. pygmy } \\
\text { W. 'Southern Alps' } \\
\text { M. granulatus } \\
\text { N. gemmeus } \\
\text { W. cf. brunnea }\end{array}$ & $\begin{array}{l}\text { O. aff. polychroma clade } 4^{6} \\
\text { O. aff. lineoocellatum 'Mackenzie } \\
\text { Basin'7 } \\
\text { O. aff. longipes 'southern' } \\
\text { O. aff. longipes 'Rangitata' }{ }^{4} \\
\text { O. waimatense }{ }^{4} \\
\text { O. maccanni } \\
\text { O. aff. polychroma clade } 5 \\
\text { O. lineoocellatum }\end{array}$ \\
\hline $\begin{array}{c}\text { Dunedin } \\
\text { (Widespread South } \\
\text { Island, Otago } \\
\text { endemic, Otago/ } \\
\text { Southland) }\end{array}$ & $\begin{array}{l}\text { M. 'Roys Peak'4 } \\
W . \text { 'Southern mini' } \\
W . \text { 'Central Otago', } \\
W . \text { 'Cromwell'2 } \\
\text { M. cryptozoicus }{ }^{4} \\
\text { W. 'Southern Alps', } \\
\text { W. 'Otago/Southland large' } \\
\text { N. gemmeus } \\
\text { M. 'Southern forest' }\end{array}$ & $\begin{array}{l}\text { O. aff. chloronoton 'West Otago' } \\
\text { O. grande } \\
\text { O. aff. inconspicuum 'North Otago' } \\
\text { O. otagense }{ }^{4} \\
\text { O. aff. polychroma clade } 5 \\
\text { O. chloronoton } \\
\text { O. inconspicuum } \\
\text { O. maccanni }\end{array}$ \\
\hline
\end{tabular}




\section{S3 The following users contributed lizard sightings to iNaturalist NZ which was used in Chapter 2}

pierre_t, onetwenty, herpguy, jon_sullivan, steveattwood, grahame, cabbagetree, thomasjwalsh, janegosden, neil_fitzgerald, mohawkalex, ian_g, tbay, mark2-nz, anna-nz, nikbaines, meurkc, dubh, rowanbuxton, kerry2, tony_wills, stephen_thorpe, epitree, jasonbutt, mcnamaral, john barkla, melissa hutchison, joepb, toucan22, dingo, heni, suemcgaw, samwise, alice shanks, linda johnson, phillipcochrane, number8dave, scottybmoore, jesse_bythell, parkecology, gailtv, shiloh, felixcollins, nzwide, myxonz, nicholasmaynenz, ecotype, leonperrie, zealandia, elmoz343, waikarischool, zealandia2, anton, savvy, chrismorse, steve_kerr, kiwilightweight, nilsr, zealandia1, mcarthurn, kiwifi, erinmagliozzi, timlogan, gcoleman, neil mitchell, takahe, kueda, stpats5, yforbes, mike68lusk, arnim, ninamum, robynpepperell, anmar2015, abigael, lisa_bennett, pjd1, hannahsteel, batfish71, paremata3, sea-kangaroo, laverymike, jeni, nakileigh, school, tuateawa, fish2, kristiholland, givernykate, villecath, hamishmcw, majo00, birdcall, tony_steer, beaumasters, jswizzle, xtine 73, barred_looper, brixkisseleff, rogierwesterhoff, jack4, takeahike, jacqui-nz, c_t_troup, moynihac, shane_orchard, bill-nz, janet_ledingham, absoluteandy, britanniacubs, stjosephsnelson, fernridge, stevepawson, danilo_hegg, jonathan_frericks, orsome4some, wainui, cloudy781, tarshpixie, paloma, rogerbrowne, aunty, bobatkinson, katherinew, simonnicholas, tim_hopley, kimberleycollins, saras, kiwitastic, gemma_g_maslin, wmblom, gregb, greenschist, edinatw, kiokiorm7, shuds, biodragon, cooperj, ecoman, lek, glenn2, totaraparkschool, rebekah6, flyingkiwigirl, oakuranp, sandboa, debontmarc, estuarytrust, javfer05, camkay, nana_j, shaun-lee, tangatawhenua, belstudholme, nsturgess, hendersoncreek, arthur, charlesfryett, peter_kelly, caroline9, tam_topes, zaschf, crumpton, temanihera, clinton, horterka, bamberlynn, mimiklein, houi, rhendra, matt61, annettefasher, sarikiri, victrapping, matthew108, adnayt, john_early, al45, andymckay, jefffryett, mmiller1, dhwalsh, gumtree, joakimliman, jozefpolec, tamzin, ericcleveland, lotte, tayloab, rosey2, emma cassidy, tittera2016, onslow2016, kakago, adzebill, kennetchey, hbutler, amos, fairyeagle, mariana-nz, colin_miskelly, godolphin, hawkdoc, yokosonz, averil1, judehooson, vitexlucens, edwilson, valc, nessmander, rosiebug, eastharbourkaitiaki, ainslie2, cara-lisa, wbsimey, stephen_c, conradsmith, kiwihunter, slartybart, lottie2, traceybates6, candler, oscarkokako, $\operatorname{dog} 359$, loritruck, mandyb1, mikey crikey, heather121, siobhanleachman, naturewatchwidow, jo d, corina3, chrisnoble nz, tina troup, karoriwill, gr8kidz159, kaitiaki-o-te-taiao, johnb-nz, citizenjane, caqalai, francesca18, dougalt, bob64, littlefantail, johnflower, graylockett, benweatherley, jacog, minguscasey, offtrackecology, kiwifergus, christy25, alphaecho, kate_curtis, goodonya, mns, tikoukagill, d_kluza, miscellaneous obs, springstonschoolnature, nate-nz, thorelley, bridgespotter, room4and5arakuraschool, davidwhyte, pgtips 91 , pagreer, reinderw, aotearoasteve, yvettemai, ahorsfall, allisonwelch, isabella_plummer, ebrownson, sean_tromans, lizid, callum_i, bill9013, johnsteel, ben01, vsuresh, nick112, joelknightnz, gillztaylor, mipmop, marleyii, nfl68, pierrickbl, johnstones, loreleiboyd99, nymjin, chloechallis, floracck, kermadec, dana60, bradhubley, seaview, pgarcia-diaz, yanidubin, kyleb, roaldbomans, manu, ayamccabre, elise, reenieb, dirk6, johntucker, robert4m, david351, peregrin, obblue, room14, nadiacooper1975, zoology, maritha, jacobl, himirpatel, sianmoana, aniste, fiona1980, jdenyer, timharker, ccrummack, emma-and-tom, janicelord, emma30, george_hobson, paul_prior, kererunz, susanne-kasimir, gwyn_ashcroft, peter_sweetapple, mikefake, kahukahu, miro, cullen7, marshy, emmarowell_214, fayerbam, iandickie, sallybain, alicebonne29, zoewatson, xamhokainuku, c-darrah, trudymira, dwilson, happyfern, pittosporum, hazel9, kag, hazelvalerie, tobyshanley, karend, spindrift11, kevin38, graham9a, duncanmc42, makomako, nzsnowman, pamtempleton, cal, nijaga, phil46, lloyd_esler, deanmckay, ethanprattley, bellfrogs1, desmondbovey, anthonymccaughan, noahfenwick, calumethan, altomio, jeantompkins, christopherstephens, rubecula, albeer23, ja8, ashleycomeau, alyssab, crispychipp, jack-, sibylle, zagothedrago, luke_sutton, kevin_frank, raewyn_wilson, tetraodon1, robert_briggs, paddy3, ambersimmonds, willparsons, matthew284, brennamarie, seabourne, nathmckenzie, jorgeponce 92 , nicsmithnz, josling, baxter_laurence, flecksy, delta_cephei, fredward86, annahenderson, kererukade, badger_88, caspertheghost, tomnz, fcohe, caroline110, corinne38, maddie39, bcal003, williamdomenge9, claremahoney, devin45, kmagee, scubyw, dhahara, johnnie fraser, johnvandenhoeven, axons, stk091655, neenapage, wouterkoch, flora_w, murray2, eviewal, smlfri, nick_goldwater, jonaht, urbanwildlifetrust, linda_g, christophercaine, pourewa, paulaschenberger, wild_wind, grinninberit, p_doyle, pfolsenstaff, ellap, rogerfrost, kane_fleury, questagame, robbd, nhudson, ilsec, johanneshillerich, possumsend, grantcollie, andybellnz, jopearce, dave_holland, frasercrescent, marquesa, liznz, ogpx, ryvesie, dataknut, jennysaito, michael-white, todd_boland, mrutherford, rstuart, brony, tretherington, ellerykr, flamingtofunz, btree, samcarruthers, kelvinperrie, eternities23, jsimons, rosiewww, sulavanderplank, kidpakeha, derekcraig, samueltuitahi, mathiasm, rosawoodsii, ytchien, jw890, jam308, schneehagen, dvanwinkel, peterrussell, martinsnz, simon-waugh, sarahmilicich, shanmonkey31, jamiemcaulay, zooschool, juan_arteaga, flinsect, pelser, hisemra, berthine, hammy, oliverruan, stonyer, christinejacobson, tammyprice, markb, uppy, leonb, karinahadden, klalor1234, iansfinds, grey, gracetwinn, jetnz, blm687, stevie13, henklouw, familynaturecargill, flossiepip, matkf, jgjulander, hudsonianjoe, janedixon, vmoser, lilyrose24, sdjbrown, sonjabrown, nzdncjw, lawrencetroup, ronanboon, superhuels, gregs, lilithfisher, rikiparata, pdbellbutler, ianstephenson, calebspencer, makura, mikebennett1, britt fb, sfitzgerald86, witchegurl, ben393, jcripps 25 , hass, brendandoogan, lewisu, madkat, flyingdouglas, andrew530, ilikebirds2, bronhooper, samh, mathieu_pelissie, stevereekie1, marc-nz, pghfrost, silversea_starsong, llenyd, terrymuns, martingatens, jackaljemmiah, chinz, amypie71, hurunui, tombell, kchscheid, katherine230, heymilly, zilyman, drwhall, josutherland, joshwedlake, beebanks, bugman-nz, ari-mac, jovirens, ruthbee, felixxscott, sarah_richardson, cmwb, philking, ekojeo, erinaceus, katesteeds, edmundss, chandarana, christinastet, alixmckenzie, scott487, james760, juditgee, tripleaxel, itzalive, reggied, radinis, aucklandgnome, whau_river20, fergus, chamandarino, darmozrac, jamesmifan, denise-nz, levonne1, arkinthepark, douglasriverside, humanahuman, mstanford, matt_howse, elisooker, mattcampbellaus, loudrage, khayhurst, bjorn, j_ashcroft, dan686, moira_parker, tomno, aeterno, corokid, nataliequeally, dianevallienne, rubymoore, childskp, crashlegac, eain_si, sophiemia95, madelyngunn, dylanparker, davidmunro, eringal, syreeta, eovran, natalie337, georgepollard, hovmoller, theoworld, mykichuk, lorraine59, shantimorgan, koraunuischool, kate39, hamishfairbairn, magaemilce, williamboulton, adamalexander, reubendharland, ecotrina, westendtekuraomorere, tanqueray, aurora $\mathrm{j}$, garethmuller, janetjohn, benackerley, bumblebee11, bambixo, chauncy, ottomm, csearle, tutukiwi, erincpow, kristelvh, nic_charlton, mel_tupe, farmpug, marsci_nelson, leocalderknight, samw, shelley_mcmurtrie, strewick, melissa29, raine1158, janeharkin, dougalm, ml254, zhengchen, liamwright, davidsummers, cat-davis, lstella, jokertheskink, meg29, kaylahawkins, lofty5, mmckiwi, barrett10, waiata, chrise, kate_z, smillie, lukewaiheke, mark506, shona_sam, ohitshamish, luke19007, ddinnis, rheanne2, browny, dononhigh, maxdurkin, cashdaughters, grahamc57, boogsiepie, hollandd9, reneetermaat, richardlyonsnz, nick668, jeninwildnature, mette10, chrismac, kaf_nz, tepapa, peter820, tonicliffin, ryruther, dapsaunders, courtney_92, iamsahari, lemansfield, keitetahatai, curtis94, ruvaze, brent_tandy, rachael93, amarzee, stunielsen, mattruglys, euanbrook, tom-kirschey-nabu, greva977, taylor349, jacobkaiwai, markaspin, charliev, anaandrew, samdean, frankbennett, jdobson, jamespaterson, eoyston, nharker, hokonui, sydney75, oharamclennan, cara79, cbabirat, savannahleiguana, lroderick16, kiwibear153, sarahwright2, andrew950, kotoreke, es_stir, aalbertrebergen, kellyeaton, ryan_nz, fionadavies23, sidc, katiew, rattrappa97531, nationfamily, marknixonacc, tlim, dcoling, ediesmum, katederidder, ginakahikatea, chrismoody, emeraldspotter, emottnature, kvg, tienglander, evilrenee, naturemaniac111, graceallison, edaemus, anna-mac, oaag1993, feickertk, jacobjh, nzct, nahgwulf, malts, tynammcculloch, emma_curtin, kotare-geraldine, kimjones, peaknuckles, leahstewart20, tortiebell, intyrely_eco, darragh132, the_cat_bunny_lady, rakieora, jessijm, jaznmorris, jeanro, timberdoodles, mattt394, supergirl17, ecologirl, hwhc, paddy18, warwickb, halldevoeco, gloh, ashleyfaith, joannabullock, davejevans, adamdonovan, rich_fuller, lance_robison, witherst, simon001, dwilly, matdiamond, marilynva, susanhall333, pfhccoordinator, myconaughtgoose, michellewnz, aratema, helena_newman, dede_lachaume, ananamx, gemback17, nelly_noodle, denisasher, a-j, colleen180, lucypip, trishstretton, caro1464, gerry_kessels, fionapfk, ellalasenby, carlabedford, snikoid, arisdon, beetle25, virginiamoreno, aucklandmuseum, rkg208, rowan hindmarsh walls, timquinnell, oebarker, pahampton, jessicadohmenvereijssen, laurawitty, reino1, hominoidcreamhorn, karenriddell, ecyy, ranger2020, isabelt12, susanev, marcusgill, emmamclean1, artemisnz, emilylane, jenny-sunflower, yvanpapa, sarah1874, nellieboyle, jamie_murphy, gregwatkinscolwell, wonderers, loretta30, jd40, scanning, aleewon, remi_bigonneau, stuarthouston, kelly_and_zen, fthomson, yipho, melzi, jakeca91 


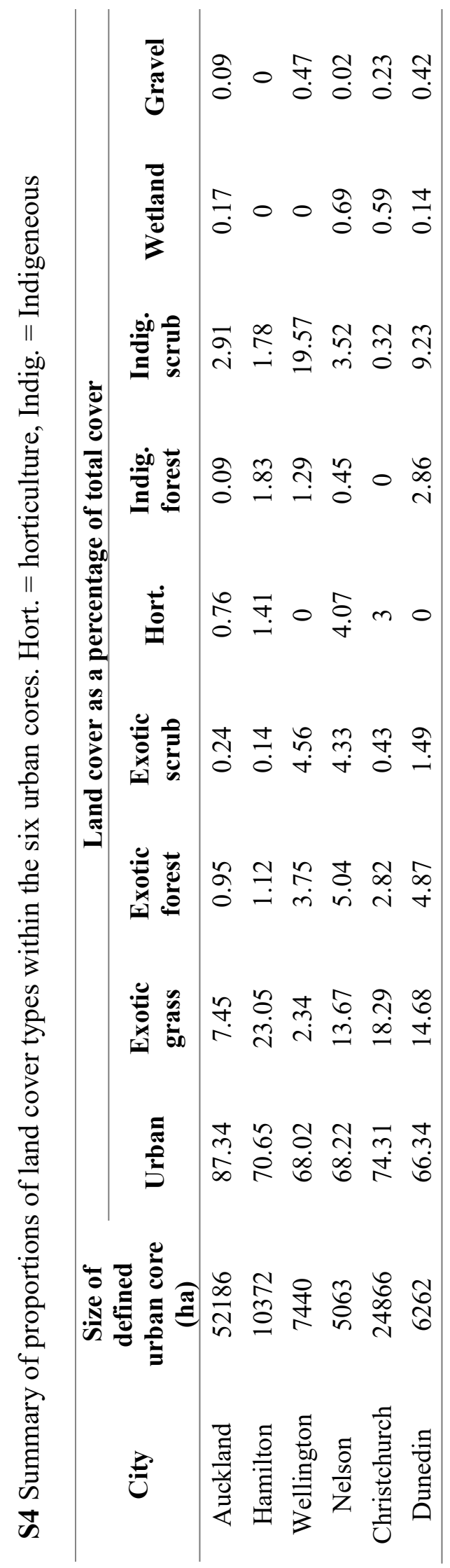


S5 Published studies of lizards in New Zealand cities. Asterisks denote additional articles reporting studies in other cities that were not returned by the search terms

\begin{tabular}{|c|c|c|c|c|}
\hline Location & Years & Species & Aims & Citation \\
\hline $\begin{array}{l}\text { Wellington, } \\
\text { suburban } \\
\text { cemetery }\end{array}$ & 1954-1955 & $\begin{array}{l}\text { O. polychroma } \\
\text { and/or O. } \\
\text { zelandicum (as } \\
\text { Leiolopisma } \\
\text { zealandica) }\end{array}$ & $\begin{array}{l}\text { Morphology; } \\
\text { reproductive cycle; } \\
\text { behaviour (copulation, } \\
\text { activity, home-range); } \\
\text { diet; growth; capture } \\
\text { rate; sloughing }\end{array}$ & $\begin{array}{l}\text { (Barwick } \\
\text { 1959) }\end{array}$ \\
\hline $\begin{array}{l}\text { Auckland, } \\
\text { public parks }\end{array}$ & $1980-1981$ & $\begin{array}{l}\text { O. aeneum and } O . \\
\text { ornatum (as } \\
\text { Cyclodina aenea } \\
\text { and Cyclodina } \\
\text { ornata } \\
\text { respectively) }\end{array}$ & $\begin{array}{l}\text { Morphology; population } \\
\text { demographics; } \\
\text { locomotion; diet }\end{array}$ & $\begin{array}{l}\text { (Porter } \\
1987 \text { ) }\end{array}$ \\
\hline $\begin{array}{l}\text { New } \\
\text { Plymouth, } \\
\text { suburban } \\
\text { garden }\end{array}$ & 1979-1981 & W. chrysosiretica & $\begin{array}{l}\text { Behavioural observations } \\
\text { (activity, conspecific } \\
\text { interactions, foraging, } \\
\text { basking) and broad } \\
\text { demographic numbers }\end{array}$ & $\begin{array}{l}\text { (Melgren } \\
2012)^{*}\end{array}$ \\
\hline $\begin{array}{l}\text { Dunedin, } \\
\text { suburban } \\
\text { gardens }\end{array}$ & $2007-2008$ & $\begin{array}{l}\text { O. polychroma } \\
\text { clade } 5\end{array}$ & $\begin{array}{l}\text { Occurrence patterns } \\
\text { across an urban } \\
\text { landscape }\end{array}$ & $\begin{array}{l}\text { (van } \\
\text { Heezik \& } \\
\text { Ludwig } \\
\text { 2012) }\end{array}$ \\
\hline $\begin{array}{l}\text { Wellington, } \\
\text { bush reserve }\end{array}$ & $2011-2012$ & $\begin{array}{l}M \text {. 'southern } \\
\text { North Island' }\end{array}$ & $\begin{array}{l}\text { Habitat use; movement } \\
\text { patterns; morphometrics; } \\
\text { reproductive status }\end{array}$ & $\begin{array}{l}\text { (Romijn et } \\
\text { al. 2014) }\end{array}$ \\
\hline $\begin{array}{l}\text { Lower Hutt, } \\
\text { suburban } \\
\text { garden }\end{array}$ & $1971-1973$ & O. aeneum & $\begin{array}{l}\text { Morphology; population } \\
\text { demographics }\end{array}$ & $\begin{array}{l}\text { (Bell et al. } \\
2018)^{*}\end{array}$ \\
\hline
\end{tabular}


S6 Unpublished reports from city councils, regional DOC offices and ecological consultants

\begin{tabular}{|c|c|c|c|c|}
\hline Location & Year & Species detected & Purpose and outcomes & Citation \\
\hline Auckland & 2014 & $\begin{array}{l}\text { O. aeneum, } O \text {. } \\
\text { ornatum, } M \text {. } \\
\text { granulatus }\end{array}$ & $\begin{array}{l}\text { Master's thesis examining habitat } \\
\text { characteristics of urban forest } \\
\text { fragments that support native } \\
\text { lizards. Five sites used within urban } \\
\text { core: Eskdale, Kauri Glen, Kauri } \\
\text { Park, Lady Phoenix and Torbay } \\
\text { Heights. Skinks captured at all sites } \\
\text { and } M \text {. granulatus at Eskdale. }\end{array}$ & $\begin{array}{l}\text { (Nichols } \\
2014)\end{array}$ \\
\hline Hamilton & 2018 & O. aeneum, L. delicata & $\begin{array}{l}\text { Survey for roading project. } 51 \mathrm{O} \text {. } \\
\text { aeneum and } 62 \text { L. delicata were } \\
\text { captured at the Southern Links } \\
\text { Highway site on the southern fringe } \\
\text { of the city. }\end{array}$ & $\begin{array}{l}\text { (Feickert } \\
2018)\end{array}$ \\
\hline Hamilton & 2016 & O. aeneum & $\begin{array}{l}\text { Habitat assessment and salvage field } \\
\text { report at Hamilton Western Rail } \\
\text { Trail. Fifteen skinks were taken into } \\
\text { captivity prior to the work }\end{array}$ & $\begin{array}{l}\text { (Nelson- } \\
\text { Tunley \& } \\
\text { Blayney } \\
\text { 2016) }\end{array}$ \\
\hline Wellington & 2015 & O. polychroma & $\begin{array}{l}\text { Master's thesis examining the } \\
\text { effects of urban revegetation } \\
\text { characteristics on biodiversity } \\
\text { outcomes. Thirty-eight } O \text {. } \\
\text { polychroma captured at six urban } \\
\text { reserves }\end{array}$ & $\begin{array}{l}\text { (Oliver- } \\
\text { Smith } \\
2015)\end{array}$ \\
\hline Wellington & $\begin{array}{l}2013- \\
2014\end{array}$ & $\begin{array}{l}\text { W. maculata, } M \text {. aff. } \\
\text { granulatus 'southern } \\
\text { North Island', } \\
\text { Woodworthia } \\
\text { 'Marlborough mini', } \\
\text { N. punctatus, } O \text {. } \\
\text { polychroma, } O \text {. } \\
\text { aeneum, O. ornatum }\end{array}$ & $\begin{array}{l}\text { Biodiversity survey of council- } \\
\text { administered parks and reserves }\end{array}$ & $\begin{array}{l}\text { (Melzer } \\
\& \text { Bell } \\
\text { 2014) }\end{array}$ \\
\hline Wellington & 2010 & O. polychroma & $\begin{array}{l}\text { Master's thesis investigating effects } \\
\text { of dune restoration on invertebrate } \\
\text { and lizard populations. Eighty-five } \\
O \text {. polychroma observed across six } \\
\text { study sites (only one of which meets } \\
\text { this study's definition of urban) }\end{array}$ & $\begin{array}{l}\text { (Jamieson } \\
2010)\end{array}$ \\
\hline $\begin{array}{l}\text { Christchurch, } \\
\text { Bexley }\end{array}$ & 2018 & $\begin{array}{l}O \text {. aff. polychroma } \\
\text { clade } 5\end{array}$ & $\begin{array}{l}\text { Survey for ecological values of a } \\
\text { site proposed for development of } \\
\text { storm water basins. Fifty-one } \\
\text { different skinks caught }\end{array}$ & $\begin{array}{l}\text { (Lettink } \\
2018)\end{array}$ \\
\hline $\begin{array}{l}\text { Christchurch, } \\
\text { Deans Head, } \\
\text { Sumner }\end{array}$ & 2016 & $\begin{array}{l}O \text {. aff. polychroma } \\
\text { clade } 5\end{array}$ & $\begin{array}{l}\text { Remediation works following } \\
\text { earthquakes. Three skinks were } \\
\text { encountered and } 2 \text { removed }\end{array}$ & $\begin{array}{l}\text { (Lettink } \\
\text { 2016a) }\end{array}$ \\
\hline $\begin{array}{l}\text { Christchurch, } \\
\text { Sumner }\end{array}$ & 2016 & $\begin{array}{l}\text { O. aff. polychroma } \\
\text { clade } 5\end{array}$ & $\begin{array}{l}\text { Salvage and relocation prior to } \\
\text { vegetation clearance and bund } \\
\text { construction. } 11 \text { skinks detected }\end{array}$ & $\begin{array}{l}\text { (Lettink } \\
\text { 2016b) }\end{array}$ \\
\hline Christchurch & 2015 & $W$. cf. brunnea & $\begin{array}{l}\text { Mitigation for geotechnical work as } \\
\text { part of roading project. } 209 \mathrm{~W} \text {. cf. }\end{array}$ & $\begin{array}{l}\text { (Lettink } \\
\text { 2015) }\end{array}$ \\
\hline
\end{tabular}




\begin{tabular}{|c|c|c|c|c|}
\hline & & & $\begin{array}{l}\text { brunnea relocated from Crater Rim } \\
\text { Bluffs, Port Hills to Riccarton Bush. } \\
19 \text { were subsequently radio tracked }\end{array}$ & \\
\hline $\begin{array}{l}\text { Christchurch, } \\
\text { Montgomery } \\
\text { Spur (near } \\
\text { Hillsborough }\end{array}$ & 2015 & $\begin{array}{l}\text { W. cf. brunnea, } O \text {. aff. } \\
\text { polychroma clade } 5\end{array}$ & $\begin{array}{l}\text { Survey for resource consent to } \\
\text { develop work site. } 40-100 \text { geckos } \\
\text { estimated. Plan for mitigation } \\
\text { developed. }\end{array}$ & $\begin{array}{l}\text { (Charteris } \\
\text { \& Lettink } \\
\text { 2015) }\end{array}$ \\
\hline $\begin{array}{l}\text { Christchurch, } \\
\text { Bowenvale } \\
\text { Park }\end{array}$ & 2015 & $\begin{array}{l}W . \text { cf. brunnea, } O \text {. aff. } \\
\text { polychroma clade } 5\end{array}$ & $\begin{array}{l}\text { Impact assessment for rockfall } \\
\text { hazard removal. } 20-50 \text { geckos } \\
\text { estimated }\end{array}$ & $\begin{array}{l}\text { (Charteris } \\
2015)\end{array}$ \\
\hline $\begin{array}{l}\text { Christchurch, } \\
\text { Styx Mill } \\
\text { Reserve }\end{array}$ & 2010 & $\begin{array}{l}\text { O. polychroma, } O \text {. } \\
\text { maccanni }\end{array}$ & $\begin{array}{l}\text { Biodiversity surveys conducted at } \\
\text { Styx Mill and Janet Stewart } \\
\text { Reserves identified presence of two } \\
\text { species (numbers not given) }\end{array}$ & $\begin{array}{l}\text { (McClure } \\
2010)\end{array}$ \\
\hline Christchurch & 2006 & $\begin{array}{l}O \text {. aff. polychroma } \\
\text { clade } 5\end{array}$ & $\begin{array}{l}\text { Biosecurity survey for } L . \text { delicata at } \\
2 \text { commercial freight companies. No } \\
\text { L. delicata detected but } 53 \text { records } \\
\text { of } O \text {. polychroma }\end{array}$ & $\begin{array}{l}\text { (Lettink } \\
\text { 2006) }\end{array}$ \\
\hline
\end{tabular}

S7 Results of binomial generalised linear model. Response variable was current status in urban habitat (present in core or extirpated). Where factors are binary the contrast occurs first in parenthesis. Degrees of freedom $=36$

\begin{tabular}{rrrrr}
\hline Factor & Estimate & Std. Error & z value & p value \\
\hline Size (mm) & -0.055 & 0.031 & -1.77 & 0.076 \\
Activity (nocturnal or diurnal) & 0.105 & 0.975 & 0.11 & 0.914 \\
$\begin{array}{r}\text { Reproductive output (max. number } \\
\text { of young per female per year) }\end{array}$ & 0.053 & 0.358 & 0.15 & 0.883 \\
Family (skink or gecko) & 0.185 & 1.631 & 0.11 & 0.910 \\
Habitat specialisation & 0.110 & 0.091 & 1.21 & 0.225 \\
\hline
\end{tabular}


S8 Summary list of extirpated and extant (within last 20 years) urban lizards. Maximum snout to vent length (SVL) and reproductive output (max. number of young per female per annum) from Tingley et al. (2013). Conservation statuses from Hitchmough et al. 2015. Dashes indicate where information was not available

\begin{tabular}{|c|c|c|c|c|c|c|}
\hline & $\begin{array}{l}\text { Presence } \\
\text { in cities }\end{array}$ & Species name & $\begin{array}{l}\text { Conservation } \\
\text { status }\end{array}$ & $\begin{array}{l}\text { Single } \\
\text { city }\end{array}$ & $\begin{array}{l}\text { Max } \\
\text { SVL } \\
(\mathbf{m m})\end{array}$ & $\begin{array}{c}\text { Reproductive } \\
\text { output }\end{array}$ \\
\hline \multirow[t]{24}{*}{ Skinks } & Extant & O. aeneum & Not threatened & $\mathrm{n}$ & 62 & 6 \\
\hline & Extant & $O$. aff. & At risk: & $\mathrm{n}$ & 77 & 8 \\
\hline & & $\begin{array}{l}\text { polychroma } \\
\text { Clade } 5\end{array}$ & Declining & & & \\
\hline & Extant & O. kokowai & At risk: Relict & $\mathrm{n}$ & - & - \\
\hline & Extant & O. lineoocellatum & At risk: Relict & $\mathrm{y}$ & 111 & 4 \\
\hline & Extant & O. maccanni & Not threatened & $\mathrm{n}$ & 73 & 6 \\
\hline & Extant & O. moco & At risk: Relict & $\mathrm{y}$ & 73 & 3 \\
\hline & Extant & O. ornatum & $\begin{array}{l}\text { At risk: } \\
\text { Declining }\end{array}$ & $\mathrm{n}$ & 80 & 6 \\
\hline & Extant & O. polychroma & Not threatened & $\mathrm{n}$ & 77 & 8 \\
\hline & Extant & O. zelandicum & $\begin{array}{l}\text { At risk: } \\
\text { Declining }\end{array}$ & $\mathrm{n}$ & 73 & 7 \\
\hline & Extirpated & $\begin{array}{l}O . \text { aff. } \\
\text { infrapunctatum } \\
\text { "crenulate" }\end{array}$ & At risk: Relict & $\mathrm{n}$ & - & - \\
\hline & Extirpated & $\begin{array}{l}\text { O. aff. } \\
\text { infrapunctatum } \\
\text { "southern North } \\
\text { Island" }\end{array}$ & $\begin{array}{l}\text { Threatened: } \\
\text { Nat. } \\
\text { vulnerable }\end{array}$ & $\mathrm{y}$ & 106 & - \\
\hline & Extirpated & O. alani & $\begin{array}{l}\text { At risk: } \\
\text { Recovering }\end{array}$ & $\mathrm{n}$ & 142 & 5 \\
\hline & Extirpated & O. chloronoton & $\begin{array}{l}\text { At risk: } \\
\text { Declining }\end{array}$ & $\mathrm{y}$ & 125 & 4 \\
\hline & Extirpated & O. homalonotum & $\begin{array}{l}\text { Threatened: } \\
\text { Nat. } \\
\text { vulnerable }\end{array}$ & $\mathrm{n}$ & 143 & 8 \\
\hline & Extirpated & O. inconspicuum & $\begin{array}{l}\text { At risk: } \\
\text { Declining }\end{array}$ & $\mathrm{y}$ & 75 & 6 \\
\hline & Extirpated & $\begin{array}{l}\text { O. } \\
\text { infrapunctatum }\end{array}$ & $\begin{array}{l}\text { At risk: } \\
\text { Declining }\end{array}$ & $\mathrm{y}$ & 115 & 4 \\
\hline & Extirpated & O. macgregori & $\begin{array}{l}\text { At risk: } \\
\text { Recovering }\end{array}$ & $\mathrm{n}$ & 114 & 2 \\
\hline & Extirpated & O. oliveri & At risk: Relict & $\mathrm{n}$ & 114 & 4 \\
\hline & Extirpated & O. smithi & $\begin{array}{l}\text { At risk: Nat. } \\
\text { uncommon }\end{array}$ & $\mathrm{y}$ & 80 & 6 \\
\hline & Extirpated & O. striatum & $\begin{array}{l}\text { At risk: } \\
\text { Declining }\end{array}$ & $\mathrm{n}$ & 76 & 8 \\
\hline & Extirpated & O. suteri & At risk: Relict & $\mathrm{y}$ & 108 & 6 \\
\hline & Extirpated & O. townsi & $\begin{array}{l}\text { At risk: } \\
\text { Recovering }\end{array}$ & $\mathrm{y}$ & 87 & - \\
\hline & Extirpated & O. "Whirinaki" & $\begin{array}{l}\text { Threatened: } \\
\text { Nat. critical }\end{array}$ & $\mathrm{y}$ & 75 & - \\
\hline
\end{tabular}


Extirpated O. whitakeri

Threatened:

n

101

3

endangered

\begin{tabular}{|c|c|c|c|c|c|c|}
\hline \multirow[t]{16}{*}{ Geckos } & Extant & D. pacificus & At risk: Relict & $\mathrm{n}$ & 80 & 2 \\
\hline & Extant & M. granulatus & $\begin{array}{l}\text { At risk: } \\
\text { Declining }\end{array}$ & $\mathrm{n}$ & 95 & 2 \\
\hline & Extant & $\begin{array}{l}\text { M. "southern } \\
\text { North Island" }\end{array}$ & $\begin{array}{l}\text { At risk: } \\
\text { Declining }\end{array}$ & $\mathrm{y}$ & 90 & 2 \\
\hline & Extant & N. elegens & $\begin{array}{l}\text { At risk: } \\
\text { Declining }\end{array}$ & $\mathrm{n}$ & 70 & 2 \\
\hline & Extant & N. punctatus & $\begin{array}{l}\text { At risk: } \\
\text { Declining }\end{array}$ & $\mathrm{y}$ & 95 & 2 \\
\hline & Extant & W. cf. brunnea & $\begin{array}{l}\text { At risk: } \\
\text { Declining }\end{array}$ & $\mathrm{y}$ & 80 & 2 \\
\hline & Extant & W. maculata & Not threatened & $\mathrm{n}$ & 82 & 2 \\
\hline & Extirpated & H. duvaucelii & At risk: Relict & $\mathrm{n}$ & 161 & 2 \\
\hline & Extirpated & $\begin{array}{l}M . \text { "southern } \\
\text { forest" }\end{array}$ & $\begin{array}{l}\text { Threatened: } \\
\text { Nat. } \\
\text { endangered }\end{array}$ & $\mathrm{y}$ & 90 & 2 \\
\hline & Extirpated & N. gemmeus & $\begin{array}{l}\text { At risk: } \\
\text { Declining }\end{array}$ & $\mathrm{n}$ & 80 & 2 \\
\hline & Extirpated & N. stellatus & $\begin{array}{l}\text { Threatened: } \\
\text { Nat. } \\
\text { vulnerable }\end{array}$ & $\mathrm{y}$ & 80 & 2 \\
\hline & Extirpated & T. "Coromandel" & $\begin{array}{l}\text { Threatened: } \\
\text { Nat. } \\
\text { vulnerable }\end{array}$ & $\mathrm{y}$ & 80 & 2 \\
\hline & Extirpated & T. stephensi & $\begin{array}{l}\text { Threatened: } \\
\text { Nat. } \\
\text { vulnerable }\end{array}$ & $\mathrm{y}$ & 80 & 2 \\
\hline & Extirpated & W. chrysosiretica & At risk: Relict & $\mathrm{y}$ & 80 & 2 \\
\hline & Extirpated & $\begin{array}{l}W . \text { "Marlborough } \\
\text { mini”" }\end{array}$ & Not threatened & $\mathrm{n}$ & 65 & 2 \\
\hline & Extirpated & $\begin{array}{l}W . \\
\text { "Otago/Southland } \\
\text { large" }\end{array}$ & $\begin{array}{l}\text { At risk: } \\
\text { Declining }\end{array}$ & $\mathrm{y}$ & - & - \\
\hline
\end{tabular}




\section{Chapter 3 Supplementary materials}

S1 Trapping effort for all sites. Sites in each city were surveyed in at least three sessions during the course of the study

\begin{tabular}{|c|c|c|c|c|c|c|c|}
\hline \multirow[b]{2}{*}{ Site } & \multicolumn{4}{|c|}{ Number of days } & \multirow[b]{2}{*}{$\begin{array}{l}\text { Total \# } \\
\text { of days }\end{array}$} & \multirow[b]{2}{*}{$\begin{array}{l}\# \text { of } \\
\text { traps }\end{array}$} & \multirow{2}{*}{$\begin{array}{l}\text { \# of } \\
\text { trap- } \\
\text { days }\end{array}$} \\
\hline & $\begin{array}{l}\text { Nov } \\
2017\end{array}$ & $\begin{array}{c}\text { Feb } \\
2018\end{array}$ & $\begin{array}{l}\text { Nov } \\
2018\end{array}$ & $\begin{array}{c}\text { Feb } \\
2019\end{array}$ & & & \\
\hline \multicolumn{8}{|l|}{ Dunedin } \\
\hline Unity Park & 8 & 7 & - & 10 & 25 & 25 & 625 \\
\hline St Clair backyard & 8 & 7 & - & 10 & 25 & 10 & 250 \\
\hline Ellis Park & 8 & 7 & - & 10 & 25 & 25 & 625 \\
\hline Frasers Gully & 8 & 7 & - & 10 & 25 & 25 & 625 \\
\hline $\begin{array}{r}\text { Andersons Bay } \\
\text { backyard }\end{array}$ & 8 & 7 & - & 10 & 25 & 10 & 250 \\
\hline Jubilee Park & 8 & 7 & - & 10 & 25 & 25 & 625 \\
\hline Kettle Park & 8 & 7 & - & 10 & 25 & 25 & 625 \\
\hline Arai Te Uru Marae & 8 & 7 & - & 10 & 25 & 10 & 250 \\
\hline Ocean Grove & 8 & 7 & - & 10 & 25 & 25 & 625 \\
\hline Roberts Park & 8 & 7 & - & 10 & 25 & 25 & 625 \\
\hline Ross Creek & 8 & 7 & - & 10 & 25 & 25 & 625 \\
\hline \multicolumn{8}{|l|}{ Hamilton } \\
\hline Dinsdale backyard \#1 & 10 & 8 & 8 & - & 26 & 6 & 156 \\
\hline Hammond Park & 10 & 8 & 8 & - & 26 & 25 & 650 \\
\hline Jubilee Bush & 10 & 8 & 8 & - & 26 & 25 & 650 \\
\hline Lake Domain & 10 & 8 & 8 & - & 26 & 25 & 650 \\
\hline Minogue Park & 10 & 8 & 8 & - & 26 & 25 & 650 \\
\hline Hamilton East & 10 & 8 & 8 & - & 26 & 6 & 156 \\
\hline Onukutara Gully & 10 & 8 & 8 & - & 26 & 25 & 650 \\
\hline Waiwhakareke Park & 10 & 8 & 8 & - & 26 & 25 & 650 \\
\hline Dinsdale backyard \#2 & 10 & 8 & 8 & - & 26 & 6 & 156 \\
\hline Beerescourt backyard & 10 & 8 & 8 & - & 26 & 6 & 156 \\
\hline Hamilton Gardens & 10 & 8 & 8 & - & 26 & 25 & 650 \\
\hline Innes Common & 10 & 8 & 8 & - & 26 & 25 & 650 \\
\hline \multicolumn{8}{|l|}{ Nelson } \\
\hline Toi Toi backyard \#1 & - & 0 & 0 & 9 & 9 & 6 & 54 \\
\hline Toi Toi backyard \#2 & - & 0 & 0 & 9 & 9 & 6 & 54 \\
\hline Moana backyard & - & 0 & 7 & 9 & 16 & 6 & 96 \\
\hline Centre of NZ & - & 7 & 7 & 9 & 23 & 25 & 575 \\
\hline Stoke Backyard & - & 7 & 7 & 9 & 23 & 6 & 138 \\
\hline Grampians Reserve & - & 7 & 7 & 9 & 23 & 25 & 575 \\
\hline Piper's Park & - & 7 & 7 & 9 & 23 & 25 & 575 \\
\hline Piper's Reserve & - & 7 & 7 & 9 & 23 & 25 & 575 \\
\hline Tahuna Foreshore & - & 7 & 0 & 9 & 16 & 25 & 400 \\
\hline Waimarama Gardens & - & 7 & 7 & 9 & 23 & 25 & 575 \\
\hline Wakapuaka Cemetery & - & 7 & 7 & 9 & 23 & 25 & 575 \\
\hline Whakatu Drive & - & 7 & 7 & 9 & 23 & 25 & 575 \\
\hline
\end{tabular}




\begin{tabular}{rccccccc}
\hline Wellington & & & & & & & \\
Te Ahumairangi & 9 & 9 & 7 & 8 & 33 & 25 & 825 \\
Cobham Drive & 9 & 9 & 7 & 8 & 33 & 25 & 825 \\
Karori backyard & 9 & 9 & 7 & 8 & 33 & 6 & 198 \\
Karori Cemetery & 9 & 9 & 7 & 8 & 33 & 25 & 825 \\
Otari/Wilton's Bush & 9 & 9 & 7 & 8 & 33 & 25 & 825 \\
Scorching Bay & 7 & 9 & 7 & 8 & 31 & 25 & 775 \\
Wadestown backyard & 8 & 9 & 7 & 8 & 32 & 6 & 192 \\
Wright's Hill & 8 & 9 & 7 & 8 & 32 & 25 & 800 \\
Massey Memorial & 7 & 9 & 7 & 8 & 31 & 25 & 775 \\
Miramar backyard & 7 & 9 & 7 & 8 & 31 & 6 & 186 \\
Mt Victoria & 8 & 9 & 7 & 8 & 32 & 25 & 800 \\
Mt Victoria backyard & 7 & 9 & 7 & 8 & 31 & 6 & 186 \\
\hline Totals & $\mathbf{3 0 5}$ & $\mathbf{3 4 4}$ & $\mathbf{2 4 3}$ & $\mathbf{3 1 4}$ & $\mathbf{1 2 0 6}$ & $\mathbf{9 0 2}$ & $\mathbf{2 3 5 5 3}$ \\
\hline
\end{tabular}


S2 Summary of AIC results of all candidate SECR models. Behavioural responses are: $b$ $=\mathrm{a}$ permanent behavioural response to capture, $b k=\mathrm{a}$ permanent trap-specific behavioural response, $B=$ a transient behavioural response, and $B k=$ a transient trapspecific response. Separate models were run for each trapping session so that populations could be assumed to be closed. Number of parameters vary among sessions due to variation in the numbers of sites being used

\begin{tabular}{|c|c|c|c|c|c|}
\hline g0 model & Parameters & $\log ($ Likelihood) & AICc & $\triangle \mathrm{AICc}$ & AICcwt \\
\hline \multicolumn{6}{|l|}{ February 2018} \\
\hline$\sim \mathrm{b}+\mathrm{t}$ & 23 & -659.0 & 1372.9 & 0.00 & 0.877 \\
\hline$\sim \mathrm{Bk}+\mathrm{t}$ & 23 & -661.3 & 1377.5 & 4.59 & 0.088 \\
\hline$\sim \mathrm{bk}+\mathrm{t}$ & 23 & -662.8 & 1380.4 & 7.46 & 0.021 \\
\hline$\sim \mathrm{B}+\mathrm{t}$ & 23 & -663.8 & 1382.6 & 9.62 & 0.007 \\
\hline$\sim t$ & 22 & -665.3 & 1382.7 & 9.79 & 0.007 \\
\hline$\sim \mathrm{Bk}$ & 15 & -677.9 & 1389.5 & 16.55 & 0.000 \\
\hline$\sim \mathrm{bk}$ & 15 & -679.1 & 1391.8 & 18.89 & 0.000 \\
\hline$\sim \mathrm{b}$ & 15 & -680.1 & 1393.8 & 20.89 & 0.000 \\
\hline$\sim 1$ & 14 & -681.4 & 1394.0 & 21.04 & 0.000 \\
\hline$\sim \mathrm{B}$ & 15 & -680.5 & 1394.6 & 21.63 & 0.000 \\
\hline \multicolumn{6}{|l|}{ November 2018} \\
\hline$\sim \mathrm{b}$ & 13 & -324.3 & 681.4 & 0.00 & 0.728 \\
\hline$\sim \mathrm{t}$ & 18 & -317.7 & 685.4 & 4.06 & 0.096 \\
\hline$\sim \mathrm{Bk}+\mathrm{t}$ & 19 & -316.1 & 686.1 & 4.75 & 0.068 \\
\hline$\sim \mathrm{bk}+\mathrm{t}$ & 19 & -316.3 & 686.5 & 5.09 & 0.057 \\
\hline$\sim \mathrm{b}+\mathrm{t}$ & 19 & -317.0 & 687.9 & 6.51 & 0.028 \\
\hline$\sim \mathrm{B}+\mathrm{t}$ & 19 & -317.2 & 688.3 & 6.90 & 0.023 \\
\hline$\sim 1$ & 12 & -331.1 & 691.8 & 10.40 & 0.000 \\
\hline$\sim \mathrm{Bk}$ & 13 & -329.8 & 692.4 & 11.00 & 0.000 \\
\hline$\sim \mathrm{bk}$ & 13 & -330.2 & 693.2 & 11.84 & 0.000 \\
\hline$\sim \mathrm{B}$ & 13 & -330.9 & 694.6 & 13.23 & 0.000 \\
\hline \multicolumn{6}{|l|}{ February 2019} \\
\hline$\sim \mathrm{B}+\mathrm{t}$ & 24 & -912.3 & 1879.9 & 0.00 & 0.752 \\
\hline$\sim t$ & 23 & -915.6 & 1883.9 & 4.03 & 0.100 \\
\hline$\sim \mathrm{bk}+\mathrm{t}$ & 24 & -914.5 & 1884.2 & 4.29 & 0.088 \\
\hline$\sim \mathrm{Bk}+\mathrm{t}$ & 24 & -915.5 & 1886.2 & 6.29 & 0.032 \\
\hline$\sim \mathrm{b}+\mathrm{t}$ & 24 & -915.6 & 1886.5 & 6.62 & 0.028 \\
\hline$\sim \mathrm{B}$ & 16 & -948.5 & 1932.1 & 52.21 & 0.000 \\
\hline$\sim 1$ & 15 & -950.4 & 1933.5 & 53.58 & 0.000 \\
\hline$\sim b$ & 16 & -950.6 & 1936.3 & 56.41 & 0.000 \\
\hline$\sim \mathrm{bk}$ & 16 & -950.6 & 1936.3 & 56.43 & 0.000 \\
\hline$\sim \mathrm{Bk}$ & 16 & -951.3 & 1937.8 & 57.88 & 0.000 \\
\hline
\end{tabular}


S3 Spearman rank correlation analyses for factors in linear mixed effects models.

Correlations that were significant at $\mathrm{p}<0.05$ are underlined. Correlations greater than |0.3| were omitted from models

\begin{tabular}{|c|c|c|c|c|c|c|c|c|}
\hline $\begin{array}{c}\text { Body } \\
\text { condition }\end{array}$ & 0.10 & & & & & & & \\
\hline $\begin{array}{c}\text { Canopy } \\
\text { cover }\end{array}$ & -0.07 & 0.05 & & & & & & \\
\hline $\begin{array}{l}\text { Grass } \\
\text { cover }\end{array}$ & -0.01 & $\underline{0.29}$ & 0.06 & & & & & \\
\hline $\begin{array}{l}\text { Rat } \\
\text { tracking } \\
\text { index }\end{array}$ & 0.05 & -0.02 & -0.14 & -0.22 & & & & \\
\hline $\begin{array}{l}\text { Mouse } \\
\text { tracking } \\
\text { index }\end{array}$ & 0.01 & -0.06 & 0.09 & $\underline{-0.75}$ & $\underline{0.34}$ & & & \\
\hline $\begin{array}{l}\text { Hedgehog } \\
\text { tracking } \\
\text { index }\end{array}$ & -0.09 & -0.07 & $\underline{0.26}$ & $\underline{-0.3}$ & -0.18 & -0.06 & & \\
\hline $\begin{array}{c}\text { Substrate } \\
\text { temp }\end{array}$ & 0.11 & $\underline{-0.27}$ & $\underline{-0.23}$ & -0.06 & -0.03 & $\underline{-0.47}$ & $\underline{0.29}$ & \\
\hline \multirow{2}{*}{$\begin{array}{c}\% \text { urban } \\
\text { land } \\
\text { cover }\end{array}$} & 0.06 & -0.26 & 0.21 & 0.06 & -0.08 & -0.01 & -0.1 & 0.2 \\
\hline & CPUE & $\begin{array}{c}\text { Body } \\
\text { condition }\end{array}$ & $\begin{array}{c}\text { Canopy } \\
\text { cover }\end{array}$ & $\begin{array}{l}\text { Grass } \\
\text { cover }\end{array}$ & $\begin{array}{l}\text { Rat } \\
\text { index }\end{array}$ & $\begin{array}{l}\text { Mouse } \\
\text { index }\end{array}$ & $\begin{array}{l}\text { Hedgehog } \\
\text { index }\end{array}$ & $\begin{array}{l}\text { Substrate } \\
\text { temp }\end{array}$ \\
\hline
\end{tabular}




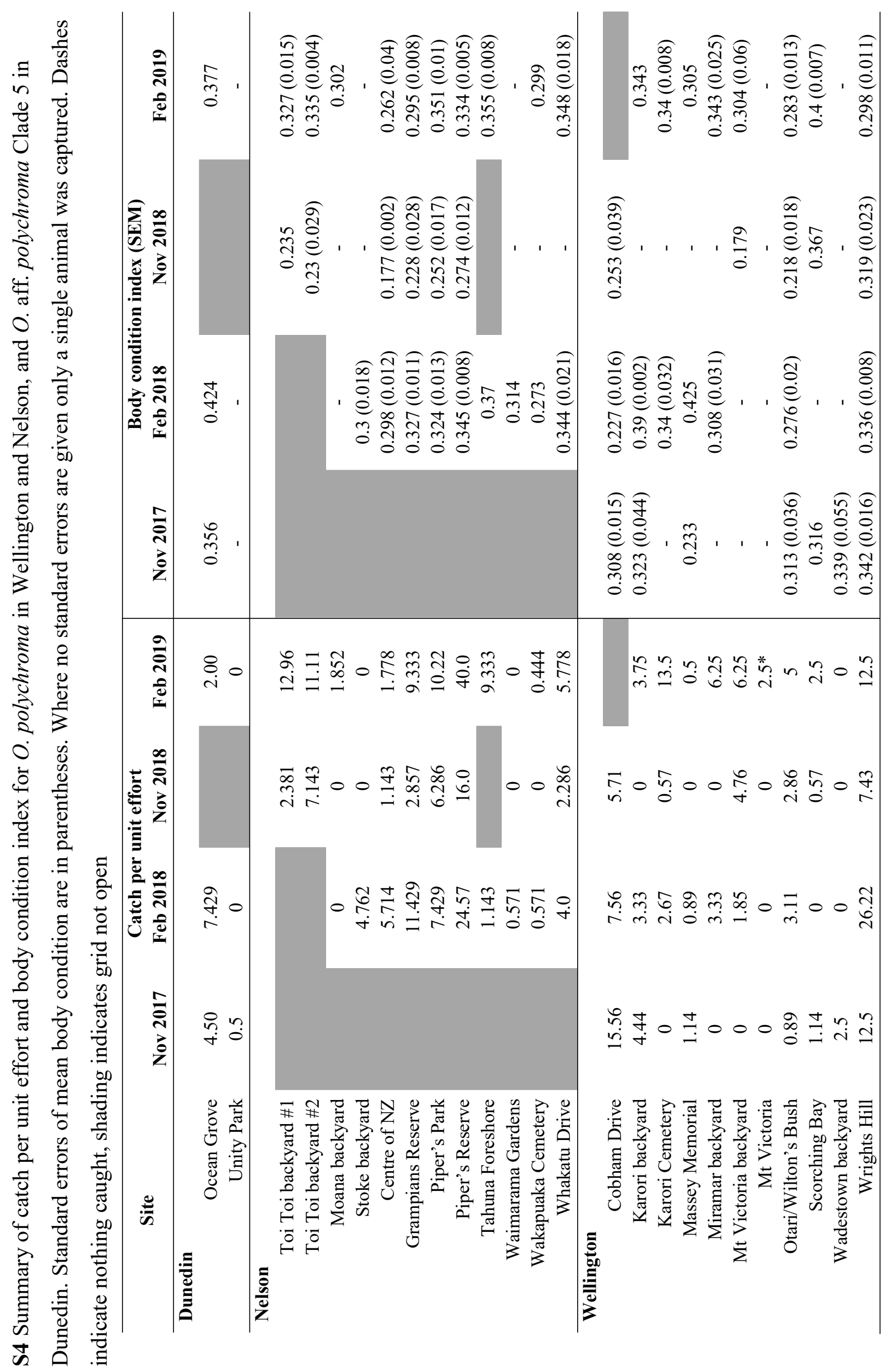




\section{Chapter 4 Supplementary materials}

S1 Reclassification of land cover classes (LCDB v4.1; LINZ 2015)

\begin{tabular}{ll}
\hline Reclassified land cover classes & Land cover classes (LCDB v. 4.1) \\
\hline Forest land cover & Deciduous hardwoods \\
& Exotic forest \\
& Forest- harvested \\
& Indigenous forest \\
\hline Grass/scrub land cover & High producing exotic grassland \\
& Low producing exotic grassland \\
& Gorse and/or broom \\
& Mixed exotic shrubland \\
& Broadleaved indigenous hardwoods \\
& Manuka and/or kanuka \\
& Matagouri or grey scrub \\
& Flaxland \\
\hline
\end{tabular}

S2 Spearman's correlation coefficients for predictor variables in the logistic regression.

Asterisks indicate statistical significance: $*<0.05, * *<0.01$

\begin{tabular}{rccccc}
\hline & $\begin{array}{l}\text { Distance to } \\
\text { grass/scrub } \\
\text { land cover }\end{array}$ & $\begin{array}{l}\text { Distance to } \\
\text { forest land } \\
\text { cover }\end{array}$ & $\begin{array}{l}\text { North- } \\
\text { facing } \\
\text { aspect }\end{array}$ & Income & Transport \\
\hline $\begin{array}{r}\text { Distance to forest land cover } \\
\text { North-facing aspect }\end{array}$ & 0.1 & & & & \\
Income & $0.24 *$ & 0.06 & & & \\
Transport & 0.08 & 0.00 & $\mathbf{- 0 . 2 4 *}$ & & \\
Education & $\mathbf{0 . 2 6 *}$ & -0.11 & -0.06 & -0.02 & $\mathbf{0 . 3 2 * *}$ \\
\hline
\end{tabular}




\section{Chapter 5 Supplementary materials}

S1 Questionnaire survey form

\section{Your backyard and nearby green spaces}

\section{What is your address?}

Remember, your responses are confidential and anonymous. Your address will only be used to map your approximate location, and will be deleted from our system once this is done. The information will not be passed on to anyone.

Street number and name (if you prefer, provide the nearest street corner or indicate your address to the nearest ten houses, e.g. 90- 100 Kereru Drive)

Suburb

Postcode

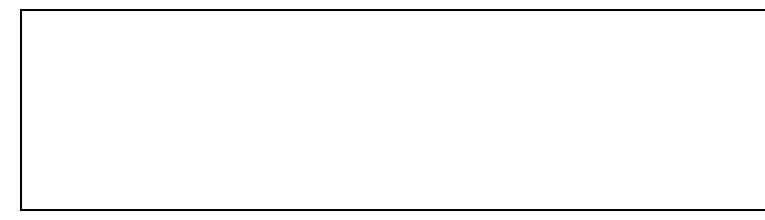

2. How long have you lived at this address? (please write in number)

Years

Months

3. Do you (tick any that apply):

$\square$ Own the home you live in (with or without a mortgage)

$\square$ Rent the home you live in

$\square$ Live with parents or family

Board with others

Other 
4. About how often do you usually spend more than $\mathbf{1 0}$ minutes in your own yard or on your deck? (please tick one)

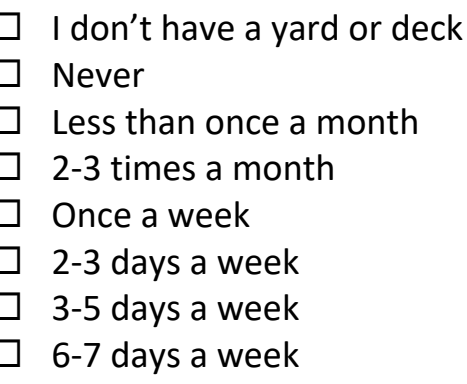

5. Thinking about the last week, about how much time in total did you spend in your own yard or on your deck?
$\square$ No time
$\square$ 1-30 minutes
31 minutes to 1 hour
$\square$ 1-3 hours
$\square$ 3-5 hours
$\square$ 5-7 hours
$\square$ 7-9 hours
$\square 9+$ hours

6. In the last week did you spend more or less time outdoors than you usually do?

$\square$ About the same

$\square$ Less time

$\square$ More time

7. What activities have you undertaken in your own backyard during the last year? (tick as many as apply)
$\square$ Relaxing
$\square$ Vegetable gardening
$\square$ Other gardening
$\square$ Sports or exercise
$\square$ Home maintenance
$\square$ Mowing the lawn
$\square$ Hanging out washing
$\square$ Enjoying nature
Spending time with people
Spending time with pets
$\square$ Other 
8. About how often do you usually visit or pass through outdoor greenspaces for any reason?

This includes, for example, beaches, bushland, playgrounds or picnic areas, dog off-leash areas, golf courses, beaches, national parks.

$\square$ Never

Once a year

Once every three months

$\square$ Once a month

2-3 times a month

Once a week

2-3 days a week

$\square$ 3-5 days a week

$\square$ 6-7 days a week

9. Did you happen to visit or pass through any outdoor greenspace in the last week? Please also think about places you may have passed through when traveling to or from places on foot or exercising.

$\square$ No

$\square$ Yes 


\section{Conservation activities}

10. Are you a member of an environmental or conservation organisation, or another organisation that undertakes some conservation activities?

$\square$ No

$\square$ Yes

11. Are you a member of a predator-free community group?

No

$\square$ Yes

12. Have you actively participated in conservation in the last $\mathbf{1 2}$ months? Active participation includes conservation efforts such as (but not limited to): tree planting projects, weed control, helping to build tracks and/or predator control (either in your own backyard or in public spaces).

$\square$ No

$\square$ Yes

13. Have you ever done any of the following when concerned about the environment or conservation issues that could affect you or your local community?

Please select all that apply.

Talked to family or friends

$\square$ Shared a post on social media

$\square$ Attended a public meeting

$\square$ Donated money to and/or joined an environmental group

$\square$ Found out more about an issue

Joined a community group campaigning for the issue

$\square$ Signed a petition

$\square$ Voted for a candidate in an election, in part because he or she shared your views on an issue

$\square$ Wrote a letter to the local newspaper

$\square$ Wrote a letter or spoke to your local Councillor or Member of Parliament (MP)

$\square$ No, I have not done any of these 
14. Are you presently undertaking any form of pest mammal control (trapping, poisoning) on your property?

$\square$ No

(Please continue to question 15 and 16)

$\square$ Yes

(Please move on to question 17)

15. If you selected No for the previous question, please indicate your level of interest in undertaking predator control on your property:

Not interested

Interested

1

2

3

4

16. If you selected either 4 or 5 for question 15, what barriers exist that prevent you from undertaking predator control? (If you selected 1, 2 or 3 continue to question 18)

17. If you answered yes to question 14 , briefly describe your efforts. 
18. Are you presently, or have you ever, recorded information about numbers of native birds or lizards on your property?

$\square$ No

$\square$ Yes (Please continue to question 19 and 20)

(Please move on to question 21)

19. If you selected No for the previous question, please indicate your level of interest in recording information about the numbers of native birds or lizards on your property:

20. If you selected either 4 or 5 for question 19, what barriers exist that prevent you from recording such information? (If you selected 1, 2 or 3 continue to question 22)

21. If you answered yes to question 18 , briefly describe your efforts. 
22. Are you presently, or have you ever, recorded information about numbers of pest mammals on your property?

$\square$ No

(Please continue to question 23 and 24)

$\square$ Yes

(Please move on to question 25)

23. If you selected No for the previous question, please indicate your level of interest in recording information about the numbers of pest mammals on your property:

24. If you selected either 4 or $\mathbf{5}$ for question 23 , what barriers exist that prevent you from recording such information? (If you selected 1, 2 or 3 continue to question 26)

25. If you answered yes to question 22 , briefly describe your efforts. 
26. Please indicate how likely are you to be motivated by the following when making a decision about whether to engage in a conservation behaviour

27. Please write any other factors (not listed above) that would motivate you to engage.

\begin{tabular}{|c|c|c|c|c|c|}
\hline & $\begin{array}{c}\text { Very } \\
\text { unlikely }\end{array}$ & Unlikely & $\begin{array}{l}\text { Not } \\
\text { sure }\end{array}$ & Likely & $\begin{array}{l}\text { Very } \\
\text { likely }\end{array}$ \\
\hline To be with like-minded people & $\square$ & $\square$ & $\square$ & $\square$ & $\square$ \\
\hline $\begin{array}{l}\text { To feel less guilty about the problems } \\
\text { we cause to the environment }\end{array}$ & $\square$ & $\square$ & $\square$ & $\square$ & $\square$ \\
\hline $\begin{array}{l}\text { To help restore some aspect of the } \\
\text { environment }\end{array}$ & $\square$ & $\square$ & $\square$ & $\square$ & $\square$ \\
\hline $\begin{array}{l}\text { To see people and talk with them } \\
\text { about volunteering and other things }\end{array}$ & $\square$ & $\square$ & $\square$ & $\square$ & $\square$ \\
\hline $\begin{array}{l}\text { To enhance parks and recreational } \\
\text { areas }\end{array}$ & $\square$ & $\square$ & $\square$ & $\square$ & $\square$ \\
\hline To enjoy the experience & $\square$ & $\square$ & $\square$ & $\square$ & $\square$ \\
\hline To show my community that I care & $\square$ & $\square$ & $\square$ & $\square$ & $\square$ \\
\hline To get exercise & $\square$ & $\square$ & $\square$ & $\square$ & $\square$ \\
\hline To get out of the house & $\square$ & $\square$ & $\square$ & $\square$ & $\square$ \\
\hline $\begin{array}{l}\text { To give something back to my } \\
\text { community }\end{array}$ & $\square$ & $\square$ & $\square$ & $\square$ & $\square$ \\
\hline To show that I can make a difference & $\square$ & $\square$ & $\square$ & $\square$ & $\square$ \\
\hline To be with friends & $\square$ & $\square$ & $\square$ & $\square$ & $\square$ \\
\hline To feel connected with my community & $\square$ & $\square$ & $\square$ & $\square$ & $\square$ \\
\hline To help protect the environment & $\square$ & $\square$ & $\square$ & $\square$ & $\square$ \\
\hline $\begin{array}{l}\text { To get away from the busy demands } \\
\text { of everyday life }\end{array}$ & $\square$ & $\square$ & $\square$ & $\square$ & $\square$ \\
\hline $\begin{array}{l}\text { To feel connected to my surrounding } \\
\text { landscape }\end{array}$ & $\square$ & $\square$ & $\square$ & $\square$ & $\square$ \\
\hline To give back to the environment & $\square$ & $\square$ & $\square$ & $\square$ & $\square$ \\
\hline $\begin{array}{l}\text { To contribute to environmental } \\
\text { sustainability }\end{array}$ & $\square$ & $\square$ & $\square$ & $\square$ & $\square$ \\
\hline
\end{tabular}




\section{Your relationship with nature}

28. Please rate the extent to which you agree with each statement. Please tick the box that indicates how you really feel, rather than how you think "most people" feel.

\begin{tabular}{|c|c|c|c|c|c|}
\hline & \multicolumn{5}{|c|}{ Neither } \\
\hline & $\begin{array}{l}\text { Disagree } \\
\text { strongly }\end{array}$ & $\begin{array}{l}\text { Disagree } \\
\text { a little }\end{array}$ & $\begin{array}{c}\text { Agree nor } \\
\text { Disagree }\end{array}$ & $\begin{array}{l}\text { Agree } \\
\text { a little }\end{array}$ & $\begin{array}{l}\text { Agree } \\
\text { strongly }\end{array}$ \\
\hline $\begin{array}{l}\text { I enjoy being outdoors, even in } \\
\text { unpleasant weather. }\end{array}$ & $\square$ & $\square$ & $\square$ & $\square$ & $\square$ \\
\hline $\begin{array}{l}\text { Some species are just meant to die } \\
\text { out or become extinct. }\end{array}$ & $\square$ & $\square$ & $\square$ & $\square$ & $\square$ \\
\hline $\begin{array}{l}\text { Humans have the right to use natural } \\
\text { resources any way we want. }\end{array}$ & $\square$ & $\square$ & $\square$ & $\square$ & $\square$ \\
\hline $\begin{array}{l}\text { My ideal vacation spot would be a } \\
\text { remote wilderness area. }\end{array}$ & $\square$ & $\square$ & $\square$ & $\square$ & $\square$ \\
\hline $\begin{array}{l}\text { I always think about how my actions } \\
\text { affect the environment. }\end{array}$ & $\square$ & $\square$ & $\square$ & $\square$ & $\square$ \\
\hline $\begin{array}{l}\text { I enjoy digging in the earth and } \\
\text { getting dirt on my hands. }\end{array}$ & $\square$ & $\square$ & $\square$ & $\square$ & $\square$ \\
\hline $\begin{array}{l}\text { My connection to nature and the } \\
\text { environment is a part of my } \\
\text { spirituality. }\end{array}$ & $\square$ & $\square$ & $\square$ & $\square$ & $\square$ \\
\hline $\begin{array}{l}\text { I am very aware of environmental } \\
\text { issues. }\end{array}$ & $\square$ & $\square$ & $\square$ & $\square$ & $\square$ \\
\hline $\begin{array}{l}\text { I take notice of wildlife wherever I } \\
\text { am. }\end{array}$ & $\square$ & $\square$ & $\square$ & $\square$ & $\square$ \\
\hline I don't often go out in nature. & $\square$ & $\square$ & $\square$ & $\square$ & $\square$ \\
\hline $\begin{array}{l}\text { Nothing I do will change problems in } \\
\text { other places on the planet. }\end{array}$ & $\square$ & $\square$ & $\square$ & $\square$ & $\square$ \\
\hline $\begin{array}{l}\text { I am not separate from nature, but a } \\
\text { part of nature. }\end{array}$ & $\square$ & $\square$ & $\square$ & $\square$ & $\square$ \\
\hline $\begin{array}{l}\text { The thought of being deep in the } \\
\text { bush, away from civilisation, is } \\
\text { frightening. }\end{array}$ & $\square$ & $\square$ & $\square$ & $\square$ & $\square$ \\
\hline $\begin{array}{l}\text { My feelings about nature do not } \\
\text { affect how I live my life. }\end{array}$ & $\square$ & $\square$ & $\square$ & $\square$ & $\square$ \\
\hline $\begin{array}{l}\text { Animals, birds and plants should } \\
\text { have fewer rights than humans. }\end{array}$ & $\square$ & $\square$ & $\square$ & $\square$ & $\square$ \\
\hline $\begin{array}{l}\text { Even in the middle of the city, I } \\
\text { notice nature around me. }\end{array}$ & $\square$ & $\square$ & $\square$ & $\square$ & $\square$ \\
\hline $\begin{array}{l}\text { My relationship to nature is an } \\
\text { important part of who I am. }\end{array}$ & $\square$ & $\square$ & $\square$ & $\square$ & $\square$ \\
\hline $\begin{array}{l}\text { Conservation is unnecessary because } \\
\text { nature is strong enough to recover } \\
\text { from any human impact. }\end{array}$ & $\square$ & $\square$ & $\square$ & $\square$ & $\square$ \\
\hline $\begin{array}{l}\text { The state of non-human species is an } \\
\text { indicator of the future for humans. }\end{array}$ & $\square$ & $\square$ & $\square$ & $\square$ & $\square$ \\
\hline $\begin{array}{l}\text { I think a lot about the suffering of } \\
\text { animals. }\end{array}$ & $\square$ & $\square$ & $\square$ & $\square$ & $\square$ \\
\hline $\begin{array}{l}\text { I feel very connected to all living } \\
\text { things and the earth. }\end{array}$ & $\square$ & $\square$ & $\square$ & $\square$ & $\square$ \\
\hline
\end{tabular}




\section{A little bit about you}

29. What is your age range?
$\square$ 18-20 years
$\square \quad 21-25$ years
$\square$ 26-30 years
$\square$ 31-35 years
$\square$ 36-40 years
$\square$ 41-45 years
$\square$ 46-50 years
$\square$ 51-55 years
$\square$ 56-60 years
$\square$ 61-65 years
$\square$ 66-70 years
$\square 70+$ years

30. What is your gender?

$\square$ Female

$\square$ Male

$\square$ Gender diverse/other

31. Do you speak a language other than English at home?

$\square$ No

$\square$ Yes

If yes, what other language do you speak most often?

32. What is the level of the highest qualification or schooling year you have completed? (please tick one)

$\square$ Year 9 or below $\square$ Trade certificate

$\square$ Year 10 or equivalent $\square$ Bachelor degree

$\square$ Year 11 or equivalent

Graduate diploma

$\square$ Year 12 or equivalent

$\square$ Post-graduate degree

$\square$ Year 13 or equivalent

$\square$ Other (please specify)

33. Are you currently attending, studying or enrolled at a school or other educational institution?

$\square$ No

$\square$ Yes, part-time

$\square$ Yes, full-time 
34. Before tax, what is the total of all wages/salaries, government benefits, pensions, allowances and other income you usually receive? (please tick one)

$$
\begin{aligned}
& \square \$ 150,001 \text { or more per year }(\$ 2,886 \text { or more a week) } \\
& \square \$ 100,001-\$ 150,000 \text { per year }(\$ 1,924-\$ 2,885 \text { a week) } \\
& \square \$ 70,001-\$ 100,000 \text { per year }(\$ 1,347-\$ 1,923 \text { a week) } \\
& \square \$ 60,001-\$ 70,000 \text { per year }(\$ 1,155-\$ 1,346 \text { a week) } \\
& \square \$ 50,001-\$ 60,000 \text { per year }(\$ 962-\$ 1,154 \text { a week) } \\
& \square \$ 40,001-\$ 50,000 \text { per year }(\$ 770-\$ 961 \text { a week) } \\
& \square \$ 35,001-\$ 40,000 \text { per year }(\$ 674-\$ 769 \text { a week) } \\
& \square \$ 30,001-\$ 35,000 \text { per year }(\$ 578-\$ 673 \text { a week) } \\
& \square \$ 25,001-\$ 30,000 \text { per year }(\$ 481-\$ 577 \text { a week) } \\
& \square \$ 20,001-\$ 25,000 \text { per year }(\$ 386-\$ 480 \text { a week) } \\
& \square \$ 15,001-\$ 20,000 \text { per year }(\$ 289-\$ 385 \text { a week) } \\
& \square \$ 10,001-\$ 15,000 \text { per year }(\$ 193-\$ 288 \text { a week) } \\
& \square \$ 5,001-\$ 10,000 \text { per year }(\$ 97-\$ 192 \text { a week) } \\
& \square \$ 1-\$ 5,000 \text { per year (\$1 - } \$ 96 \text { a week) } \\
& \square \text { Nil or negative income }
\end{aligned}
$$

35. Which of the following best represents your employment status?
$\square$ Unemployed
Employed, part-time
$\square$ Employed, full-time 
S2 Significant correlations between predictor variables used in regressions

\begin{tabular}{lcc}
\hline Correlation & $\mathrm{r}$ & $\mathrm{p}$ \\
\hline Nature relatedness x environmental motivation & 0.57 & $<0.001$ \\
Nature relatedness x dosage & 0.28 & $<0.001$ \\
Age x motivation & -0.22 & $<0.001$ \\
Age x income & 0.23 & $<0.001$ \\
Age x dosage & 0.33 & $<0.001$
\end{tabular}


S3 Samples sizes and percentages of different groups $(n=299)$. Continued over page

\begin{tabular}{|c|c|c|}
\hline Factor and levels & $\mathbf{n}$ & $\%$ \\
\hline \multicolumn{3}{|l|}{ Age (years) } \\
\hline $18-20$ & 2 & 0.67 \\
\hline $21-25$ & 29 & 9.7 \\
\hline $26-30$ & 41 & 13.71 \\
\hline $31-35$ & 37 & 12.37 \\
\hline $36-40$ & 23 & 7.69 \\
\hline $41-45$ & 21 & 7.02 \\
\hline $46-50$ & 38 & 12.71 \\
\hline $51-55$ & 28 & 9.36 \\
\hline $56-60$ & 22 & 7.36 \\
\hline $61-65$ & 23 & 7.69 \\
\hline $66-70$ & 17 & 5.69 \\
\hline $70+$ & 18 & 6.02 \\
\hline \multicolumn{3}{|l|}{ Total annual income (before tax) } \\
\hline Nil or negative income & 5 & 1.67 \\
\hline$\$ 1-\$ 5,000$ & 7 & 2.34 \\
\hline$\$ 5,001-\$ 10,000$ & 7 & 2.34 \\
\hline$\$ 10,001-\$ 15,000$ & 14 & 4.68 \\
\hline$\$ 15,001-\$ 20,000$ & 13 & 4.35 \\
\hline$\$ 20,001-\$ 25,000$ & 13 & 4.35 \\
\hline$\$ 25,001-\$ 30,000$ & 18 & 6.02 \\
\hline$\$ 30,001-\$ 35,000$ & 15 & 5.02 \\
\hline$\$ 35,001-\$ 40,000$ & 5 & 1.67 \\
\hline$\$ 40,001-\$ 50,000$ & 23 & 7.69 \\
\hline$\$ 50,001-\$ 60,000$ & 32 & 10.7 \\
\hline$\$ 60,001-\$ 70,000$ & 26 & 8.7 \\
\hline$\$ 70,001-\$ 100,000$ & 55 & 18.39 \\
\hline$\$ 100,001-\$ 150,000$ & 33 & 11.04 \\
\hline$\$ 150,001$ or more & 18 & 6.02 \\
\hline
\end{tabular}




\begin{tabular}{|c|c|c|c|}
\hline \multicolumn{4}{|l|}{ Gender } \\
\hline & Female & 118 & 39.46 \\
\hline & Male & 178 & 59.53 \\
\hline & Gender diverse & 3 & 1.00 \\
\hline \multicolumn{4}{|c|}{ Frequency of backyard/deck use longer than 10 mins } \\
\hline & Never & 7 & 2.34 \\
\hline & I don't have a backyard or deck & 12 & 4.01 \\
\hline & Less than once a month & 15 & 5.02 \\
\hline & 2-3 times a month & 29 & 9.7 \\
\hline & Once a week & 44 & 14.72 \\
\hline & 2-3 days a week & 62 & 20.74 \\
\hline & 3-5 days a week & 64 & 21.4 \\
\hline & 6-7 days a week & 66 & 22.07 \\
\hline \multicolumn{4}{|c|}{ Highest qualification } \\
\hline & Year 10 & 1 & 0.33 \\
\hline & Year 11 & 1 & 0.33 \\
\hline & Year 12 & 4 & 1.34 \\
\hline & Year 13 & 16 & 5.35 \\
\hline & Trade certificate & 12 & 4.01 \\
\hline & Graduate diploma & 42 & 14.05 \\
\hline & Bachelor degree & 73 & 24.41 \\
\hline & Post-graduate degree & 138 & 46.15 \\
\hline & Other & 11 & 3.68 \\
\hline \multicolumn{4}{|c|}{ Backyard activities } \\
\hline & Relaxing & 210 & 70.23 \\
\hline & Vegetable gardening & 177 & 59.2 \\
\hline & Other gardening & 196 & 65.55 \\
\hline & Relaxing & 210 & 70.23 \\
\hline & Home maintenance & 178 & 59.53 \\
\hline & Hanging out washing & 247 & 82.61 \\
\hline & Sports or exercise & 52 & 17.39 \\
\hline & Mowing the lawn & 121 & 40.47 \\
\hline & Spending time with people & 169 & 56.52 \\
\hline & Spending time with pets & 118 & 39.46 \\
\hline & Enjoying nature & 178 & 59.53 \\
\hline & Other & 33 & 11.04 \\
\hline
\end{tabular}

